Universidade de São Paulo

Instituto de Geociências

\title{
Características físicas e químicas e modelo eruptivo para os riolitos tipo Santa Maria (Província Magmática Paraná) na região de Gramado Xavier, RS
}

\author{
Letícia Freitas Guimarães \\ Orientador: Prof. Dr. Valdecir de Assis Janasi
}

Dissertação de Mestrado

Programa de Pós-Graduação em Mineralogia e Petrologia

São Paulo

2014 
Ficha catalográfica preparada pelo Serviço de Biblioteca e Documentação do Instituto de Geociências da Universidade de São Paulo

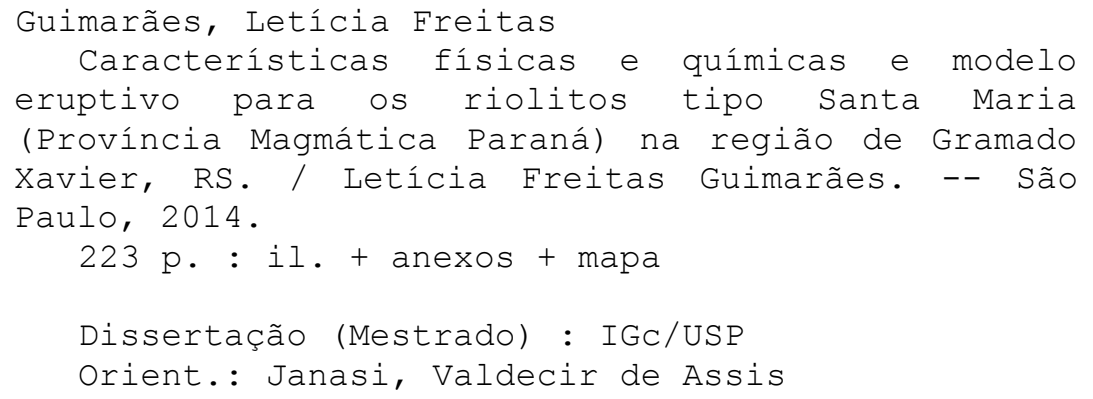

1. Rochas vulcânicas 2. Geoquímica 3. Província Magmática Paraná I. Título 
"Geologia? Pois o Visconde andava a estudar geologia? Verdade, sim. O Visconde descobrira entre os livros de Dona Benta um tratado dessa ciência e pusera-se a estudá-la - a ciência que conta a história da terra, não da terra-mundo, mas da terra-terra, da terra-chão. E de tanto estudar, ficou com um permanente sorriso de superioridade nos lábios - sorriso de dó da ignorância dos outros.

Naquela noite, logo que todos se reuniram, Pedrinho plantou o geólogo na cátedra. - Nivele as extremidades e comece, Senhor Visconde. O sábio assim fez; depois de apoiar os pés na geologia, erguendo-os ao nível da cartolinha, cuspiu o pigarro e começou: - A Geologia é a história da Terra. Tudo que aconteceu desde o nascimento deste nosso Planeta se acha escrito nas rochas que o formam. A terra é uma rocha, uma bola de pedra.

Como nasceu? Temos de adivinhar, porque nenhum de nós assistiu a isso. Uns imaginam que foi dum jeito. Outros imaginam que foi de outro jeito. Vou contar como nós, sábios, imaginamos o nascimento da terra."

Trechos do livro "O poço do Visconde" - de Monteiro Lobato 


\section{AGRADECIMENTOS}

Escrever os agradecimentos definitivamente não é uma parte fácil. São muitas pessoas presentes de alguma forma ao longo deste caminho.

"Quem caminha sozinho pode até chegar mais rápido. Mas aquele que vai acompanhado, com certeza vai mais longe". E eu fui muito bem acompanhada!

Os primeiros agradecimentos à minha família. Meus pais, Gilberto e Maria Helena, que são meu maior exemplo. De vida, de profissionalismo, de ética, de respeito, de tudo. Ensinaram-me a ser quem sou e a buscar aquilo que quero e que sempre estiveram ao meu lado. Aos meus irmãos, Matheus, Marcelo, Simone e também à Lu, à Julia e Lua. Se eu tivesse tido a oportunidade de escolher uma família, com certeza não teria feito melhor.

Ao Lucas, meu maior companheiro, amigo, amor, confidente e claro, incentivador. A pessoa que mais me apoiou em tudo. Sem ele, poderia ter desistido no meio do caminho.

Ao Valdecir, meu querido orientador. Um exemplo de ética e profissionalismo, uma pessoa em quem me espelho na minha vida profissional. Um orientador que tem qualidades que prezo e que são raras. Obrigada por todo incentivo, ajudas e ensinamentos. À Liza, sempre tão fervorosa, com quem sempre tive discussões muito frutíferas. Uma amiga e colega de trabalho, obrigada por toda ajuda.

À Irene por todo auxílio no campo e no laboratório, que ela confiou à mim em muitos momentos. Obrigada por toda ajuda e ensinamentos. Ao Evandro (Chinês) que também sempre se mostrou disposto nos nossos curtos e raros encontros e e-mails. Ao Bolovo pela ajuda e bom humor no campo.

Aos funcionários do IGC, sem os quais com certeza esta escola não funcionaria. Em especial à Sandra, pela paciência, educação e extrema boa vontade, ao pessoal do laboratório de química (em especial o Vinícius e o Paulinho) e do CPGeo (em especial à Gisele), Zé Paulo (LTA), ao Marcos (microssonda), Samuca, Angélica (ótica), às funcionárias da biblioteca (em especial a Sandra e a Erika), ao Tadeu, ao Léo, Magali e Kate (seção de pós), a Valéria, Zeca, ao pessoal da gráfica (que sempre quebraram meus galhos em cima da hora!), e os motoristas. $\mathrm{E}$ àqueles que não são da Geo ou da USP: Liz (LCT-Poli), pela incrível ajuda no MEV e Larry e Andy pelas análises na Universidade de Alberta. 
À todos os professores, mas, alguns em especial: Bisteka (professora, mas amiga antes de tudo), Lucelene, Gaston, Sílvio e Excelso (com quem trabalhei nas monitorias de petrologia ígnea), Rogério e Ivo (com quem trabalhei na monitoria de geologia geral), Renato e à Fátima da UFRGS.

Aos fundamentais amigos. São tantos!! Às metralhas (Alice, Barbariza, Mari, Chava, Pará, Manu, Kátia, Carol, Dani, as Joanas, Kaka, Débora, Juca, Pig, Alissim, Grazi, Lusandra e claro, à Lua, amiga e conselheira maior), à Clô, Sô (Edlayne), Sofia, Eva e Lesado (ótimos colegas de sala), Borba, Bixa, Kabong, Rachel, Pedro, Tábata, Cotoco, Fofona, Mikuin, Harry, aos amigos de fora Amós, Jepeto e Fera, Gasta, Marcelo. Foram festas, conversas, campos, disciplinas, artigos compartilhados e sempre, claro, aquela ajudinha pra levar tudo de maneira mais alegre.

Ao pessoal que me recebeu na breve viagem à Itália: Cristina, Daniele Giordano, Russell, Claudia Principe e Sonia. Espero ainda ter a oportunidade de trabalhar com vocês.

Aos alunos das monitorias (turmas 53, 54 e 55), que nos ajudam a aprender mais, e aos do laboratório de anisotropias magnéticas, que me ajudaram a manter o bom humor mesmo nos momentos de trabalho, trabalho e mais trabalho.

Às minhas famílias paulistanas: tio Celso, tia Rita, Má e agora a fofíssima Nina, às meninas da república (Rô, Déia e Isa) e à família do Lucas que sempre me acolhe.

Por fim, ao importantíssimo auxílio financeiro da CAPES (primeiros 6 meses), da FAPESP (projeto 2012/01973-0 - financiador deste projeto de mestrado - e projeto 2012/06082-6 - financiador do projeto temático "A Província Magmática Paraná-Etendeka no Brasil: relações temporais e petrológicas entre o magmatismo toleítico e alcalino e suas implicações geodinâmicas"), da Reitoria da USP pela ajuda de custo no Goldschmidt 2013 e claro, à toda ajuda também do Valdecir, afinal, 3 congressos em 2 anos não é nada, nada mal! 


\section{RESUMO}

Os riolitos Santa Maria correspondem a uma seqüência efusiva de rochas vítreas a hipocristalinas aflorantes na porção sul da Província Magmática Paraná, sul do Brasil. Mapeamentos de detalhe na região de Barros Cassal Gramado Xavier mostraram que eles correspondem à sequência superior do magmatismo de baixo Ti, que é caracterizado por uma sucessão de basaltos pahoehoe - basaltos rubbly - dacitos - andesitos e dacitos - riolitos.

Do ponto de vista químico, os riolitos são homogêneos, com 71-73\% de $\mathrm{SiO}_{2}$, 0,65-0,70\% de $\mathrm{TiO}_{2}$ e enriquecidos em $\mathrm{K}_{2} \mathrm{O}$ (4-5\%) e outros elementos incompatíveis (210-300 ppm Rb; 680-930 ppm Ba; 350 ppm de $\mathrm{Zr}$ e $\Sigma$ REE 300 ppm) em comparação com as unidades dacíticas precedentes. Do ponto de vista isotópico, correspondem à unidade mais evoluída, com razões ${ }^{87} \mathrm{Sr} /{ }^{86} \mathrm{Sr}_{(134)}=$ 0,7230 a 0,7255 , razões ${ }^{143} \mathrm{Nd} /{ }^{144} \mathrm{Nd}_{(134)}=0,51204$ a 0,51205 e correspondentes valores mais negativos para $\varepsilon \mathrm{Nd}_{(134)}=-8,2$ e $-8,4$. Petrograficamente, são rochas porfiríticas com microfenocristais de plagioclásio, pigeonita e Ti-magnetita. Os cristais de plagioclásio, principal fase mineral, apresentam feições de reabsorção e zonamento composicional inverso, além de razões ${ }^{87} \mathrm{Sr} / 86 \operatorname{Sr}_{(134)}$ sistematicamente mais elevados que as obtidas para rocha total $(0,7267$ a 0,7280), sendo classificados como antecristais, cuja cristalização se deu, possivelmente, nas bordas do conduto. Modelamentos AFC mostram que os riolitos Santa Maria podem ter sido gerados por 30-40\% de cristalização de magmas parentais com composição equivalente à composição de um andesito basáltico da Sequencia Barros Cassal e de 8-15\% de assimilação de composições graníticas equivalentes à composição de granitos neoproterozóicos regionais (Granitóides Garopaba).

Os magmas geradores dos riolitos Santa Maria caracterizam-se por elevadas temperaturas (média de $\left.970^{\circ} \mathrm{C}\right)$, baixos teores de água $(0,7$ a $1,1 \%$ para a fase inicial de cristalização e $0,2 \%$ para a fase final), e viscosidades da ordem de $10^{5}$ a $10^{6}$ Pa.s. Estas características permitiram uma forma de ocorrência não explosiva, que resultou em estruturas particulares de fluxos lobados e derrames de lava, corroboradas pelos resultados obtidos através de estudos de anisotropia de susceptibilidade magnética. 


\begin{abstract}
The Santa Maria rhyolites correspond to a sequence of effusive glassy to hipocrystalline rocks that outcrop in the southern portion of Paraná Magmatic Province, southern Brazil. Detailed field work in the Barros Cassal - Gramado Xavier region allows recognize that they correspond to the uppermost sequence of the low-Ti magmatism, which is characterized by a succession of pahoehoe basalt-rubbly basalt-dacite-dacite and andesite-rhyolite.

The rhyolites are chemically homogeneous, with 71-73 wt $\% \mathrm{SiO}_{2}, 0.65-0.70$ $\mathrm{wt} \% \mathrm{TiO}_{2}$ and are enriched in $\mathrm{K}_{2} \mathrm{O}(4-5 \mathrm{wt} \%)$ and other incompatible elements (210-300 ppm Rb; 680-930 ppm Ba; $\sim 350$ ppm Zr and $\Sigma$ REE $\sim 300$ ppm) when compared to the previous dacite units. Isotopically, it is the most evolved unit of all succession with the highest initial ${ }^{87} \mathrm{Sr}^{86}{ }^{8 S_{(134)}}(0.7230$ to 0.7256$)$ and ${ }^{143} \mathrm{Nd} /{ }^{144} \mathrm{Nd}_{(134)}=0,51204$ to 0,51205 , corresponding to negative $\mathrm{ENd}_{(134)}(-8,2$ to $8,4)$. The rhyolites are porphyritic with microphenocrysts of plagioclase, pigeonite and Ti-magnetite. The plagioclase microphenocrysts show resorption features and inverse compositional zoning, with ${ }^{87} \mathrm{Sr}^{86} \mathrm{Sr}_{(134)}$ higher than those obtained for whole rock, indicating that they may correspond to antecrysts which crystallized near the walls of the conduit, and were affected by crustal contamination. AFC models indicate that the Santa Maria rhyolites may be generated by $30-40 \%$ of crystallization of basaltic andesite parental magmas with $8-15 \%$ of assimilation of granitic crust similar to regional Neoproterozoic granites (Garopaba Granitoid).
\end{abstract}

The rhyolite magmas are characterized by high temperatures $\left(970^{\circ} \mathrm{C}\right)$, low water contents ( 0.7 to $1.1 \%$ for the initial phase and $0.2 \%$ for the final stage) and viscosities around $10^{5}$ to $10^{6} \mathrm{~Pa}$.s. These characteristics allowed an effusive extrusion, which resulted in peculiar structures as lava-domes, as corroborated by the results of anisotropy of magnetic susceptibility. 


\section{SUMÁRIO}

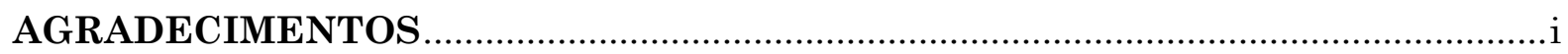

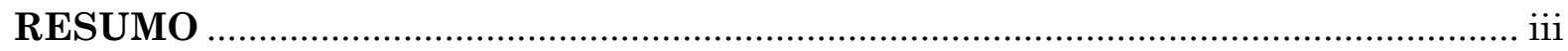

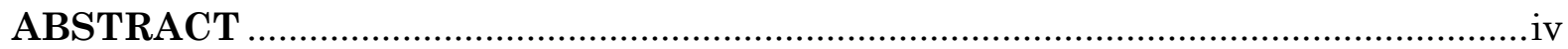

SUMÁRIO

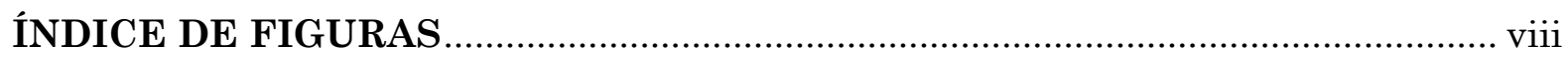

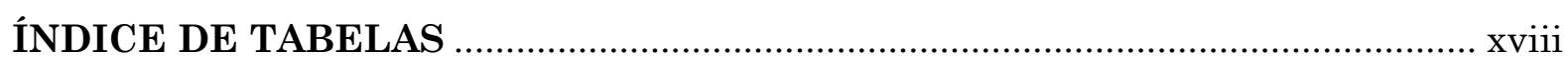

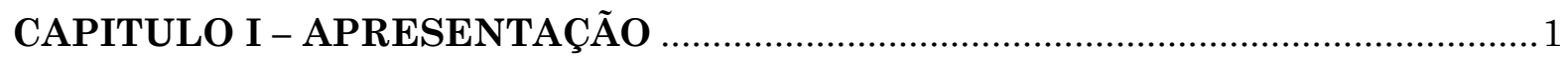

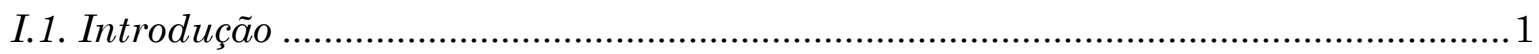

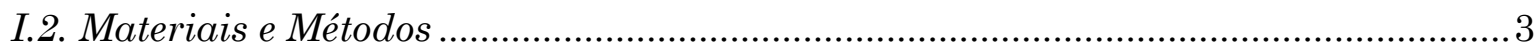

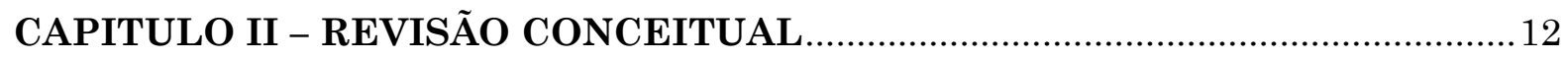

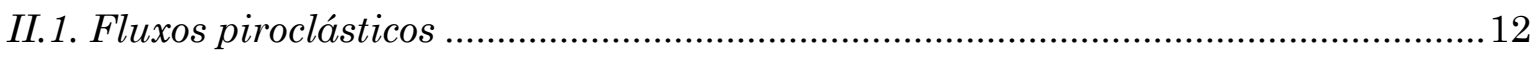

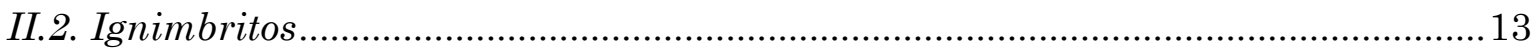

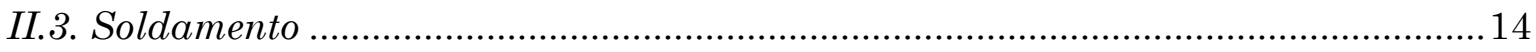

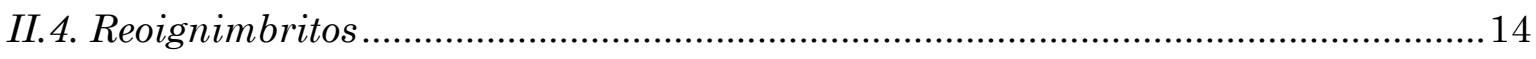

II.5. Derrames de lavas .......................................................................................... 14

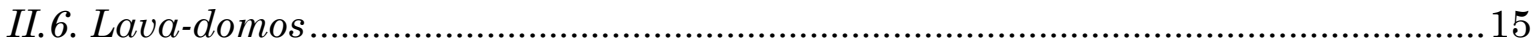

II.7. Reoignimbritos versus lava-domos......................................................................16

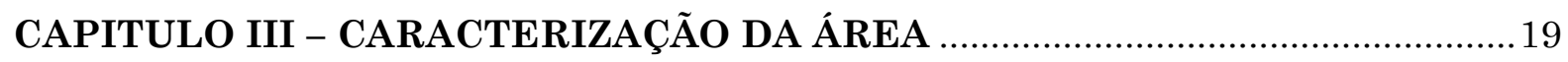

III.1. Localização e acessos ............................................................................................... 19

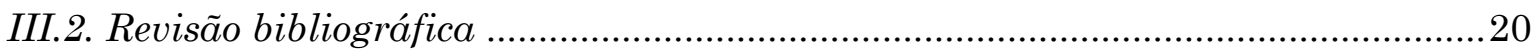

III.2.1. BREVE HISTÓRICO DOS ESTUDOS GEOCRONOLÓGICOS ....................26

III.2.2. GENNESE, PROCESSOS EVOLUTIVOS E ESTILO ERUPTIVO DAS

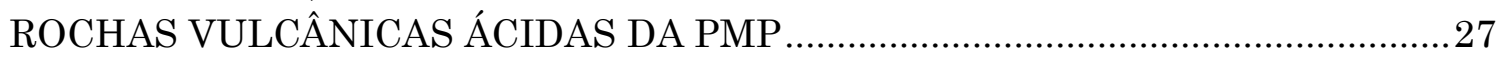

III.2.3. AS ROCHAS VULCÂNICAS ÁCIDAS NA REGIÃO SUL DA PMP...............29 CAPITULO IV - ASPECTOS GEOLÓGICOS E ESTRUTURAIS DOS RIOLITOS SANTA MARIA. 
IV.1. Caracterização estrutural a partir de levantamentos de campo

IV.1.1. BANDAMENTO DE FLUXO E ESTRUTURAS ASSOCIADAS VS

ESTRUTURA MACIÇA.

IV.1.2. INTERCALAÇÃO ENTRE A FÁCIES CRISTALINA E A FÁCIES OBSIDIANA .36

IV.1.4. DISJUNÇÕES 39

IV.1.5. VESÍCULAS .40

IV.1.6. ESTRUTURAS DE INTERAÇÃO COM SEDIMENTOS 41

IV.1.7. ENCLAVES .42

IV.2. Caracterização estrutural a partir da Anisotropia de Susceptibilidade Magnética $(A S M)$ .43

IV.2.1. REVISÃO CONCEITUAL .43

IV.2.2. ANISOTROPIAS MAGNÉTICAS DOS RIOLITOS TIPO SANTA MARIA ..52

CAPITULO V - PETROGRAFIA E QUÍMICA MINERAL .67

V.1. VIDRO .69

V.2. PLAGIOCLÁSIO. .71

V. 3. PIROXÊENIO. 76

V. 4. MINERAIS OPACOS .78

CAPITULO VI - GEOQUÍMICA E ISOTOPIA .80

VI.1. Geoquímica de rocha total .80

VI.1.1. CLASSIFICAÇÃO E AFINIDADES GEOQUÍMICAS. .80

VI.1.2. VARIAÇÕES DE ELEMENTOS MAIORES E TRAÇOS \& COMPARAÇÃO COM OUTRAS UNIDADES DE ROCHAS ÁCIDAS..... 82

VI.2. Geoquímica de elementos traço em plagioclásio (por LA-ICPMS). .87

VI.3. Geoquímica isotópica .90

VI.3.1. SISTEMAS Rb/Sr e Sm/Nd EM ROCHA TOTAL. .90

VI.3.2. SISTEMA Rb/Sr e RAZÕES ${ }^{87} \mathrm{Sr} /{ }^{86} \mathrm{Sr}$ EM MICROFENOCRISTAIS DE PLAGIOCLÁSIO - UMA COMPARAÇÃO COM ROCHA TOTAL .92

CAPITULO VII - PETROGÊNESE.

VII.1. Estimativa da composição da fusão em equilíbrio a partir de teores de elementos traço em plagioclásio .96 


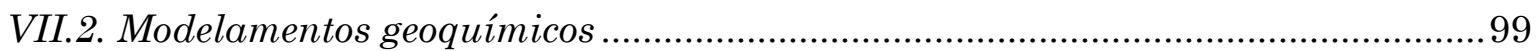

VII.2.1. CRISTALIZAÇÃO FRACIONADA .......................................................... 100

CAPITULO VIII - PARÂMETROS INTENSIVOS E SUA RELAÇÃO COM A FORMA DE OCORRÊNCIA ...................................................................................111

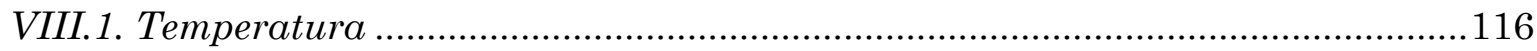

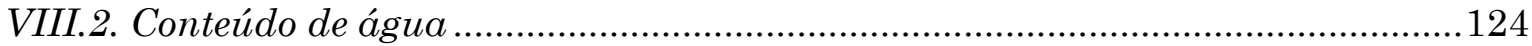

VIII.2.1. SOLUBILIDADE E DIFUSIBILIDADE................................................. 126

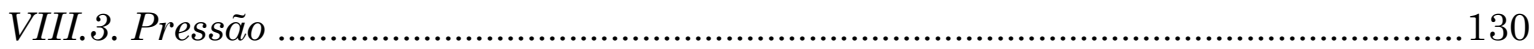

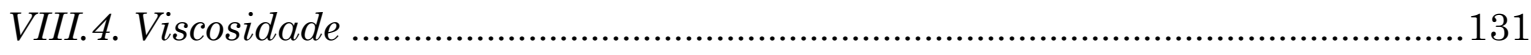

VIII.4.1. CONSIDERAÇÕES E RESSALVAS ..................................................... 133

CAPITULO IX - DISCUSSÕES E CONSIDERAÇÕES FINAIS ….........................138

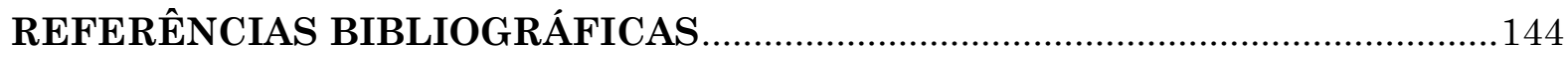

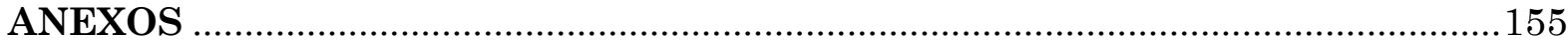




\section{ÍNDICE DE FIGURAS}

Figura 01: Perfuratriz STHILL com broca de $20 \mathrm{~cm}$ e 1", com extremidade diamantada. B e C) Processo de perfuração dos cilindros, com destaque em amarelo para bomba de água+óleo para refrigeração da máquina e diminuição do atrito durante a perfuração.

\section{5}

Figura 02: A) Cilindros de amostragem ainda in situ - notar que é feita uma marcação com a broca previamente à perfuração para que, em caso de quebra do cilindro, ele possa ser corretamente orientado. B) Instrumentação utilizada para orientação dos cilindos: bússola tipo Brunton adaptada, com haste para encaixe no afloramento, transferidor para medida de mergulho e bússola solar acoplada. 6

Figura 03: Detalhe da serra utilizada para corte dos cilindros. ................................ 6

Figura 04: Equipamento Kappabridge 4S da Agico, utilizado para a medição das propriedades magnéticas das amostras. 7

Figura 05: Esquema de fluxo piroclástico formado a partir do colapso de coluna piroclástica gerada em erupção explosiva. Adaptado de Carey \& Bursik (2000). 13

Figura 06: Representação idealizada de depósito de fluxo prioclástico (ignimbrito). A camada 2 pode apresentar uma variedade de estruturas de gradação, desde ausente até variações em zonas enriquecidas em fragmentos líticos e púmices. As partículas pretas representam os fragmentos líticos, as brancas representam púmices e os pontos representam fragmentos na fração cinza.

Figura 07: A) Modelo tridimensional de crescimento de domo endógeno (Richardson, 1978; adaptado por Polo, 2014). $\quad$ B) Modelo de lavas coulées formando domo exógeno (Branney et al. 2008; adaptado por Polo, 2014). ...................................... 16

Figura 08: Localização da área de estudo, na porção central do estado do Rio Grande do Sul e principais vias de acesso.

Figura 09: Mapa de distribuição das rochas vulcânicas da Bacia do Paraná, com ênfase nos diferentes tipos de rochas vulcânicas ácidas (extraído de Luchetti et al. 2005), com a localização aproximada da área de estudos (quadrado amarelo).

Figura 10: Classificação das rochas tipo Palmas (triângulos) e tipo Chapecó (círculos). Extraído de Nardy et al., 2008.

Figura 11: Diagramas de Harker para elementos maiores e menores das rochas vulcânicas ácidas tipo Palmas (triângulos) e Chapecó (círculos). Extraído de Nardy et al. (2008).

.24

Figura 12: Polígonos representativos das áreas mínimas de distribuição dos distintos fluxos piroclásticos resultantes de eventos eruptivos de grande magnitude na região de Etendeka. Extraído de Bryan et al. (2010). .28

Figura 13: Mapa geológico da área de estudos, abrangendo os municípios de Barros Cassal e Gramado Xavier. Extraído de Polo \& Janasi (2014). 
Figura 14: Afloramento GX-123. Rocha de coloração avermelhada e estrutura caracterizada por bandamento ígneo onde observa-se alternância entre bandas de coloração esbranquiçada e bandas de coloração avermelhada. Nota-se que o bandamento magmático apresenta-se dobrado.

Figura 15: Rocha cristalina (à esquerda) e rocha vítrea (à direita) caracterizadas por bandamento afetado por dobramentos de fluxo magmático. .35

Figura 16: Afloramento RS-74. A porção inferior do afloramento constitui-se de rocha de rocha cristalina de coloração avermelhada, marcada por bandamento magmático com fraturamento associado. A porção superior constitui-se de rocha vítrea (obsidiana) com padrão de disjunção vertical sobreposto a fraturamento paralelo ao bandamento. A porção intermediária caracteriza-se pela alternância entre bandas centimétricas a decimétricas das duas variedades. 36

Figura 17: Afloramento GX-140. Destaque para estrutura lobada, com borda de resfriamento vítrea, vesiculada, e núcleo intensamente alterado, também vesiculado e preservando feições de fluxo magmático. 37

Figura 18: Esquema representativo do relevo do entorno do afloramento GX-140 (cuja localização encontra-se destacada em amarelo), evidenciando alinhamento de morros sugestivos de estruturas dômicas reliquiares. As setas vermelhas indicam possíveis direções de fluxo magmático. A coloração mais avermelhada indica a unidade riolítica Santa Maria. Imagem: Google Earth. (Polo, 2014). 38

Figura 19: Afloramento RS-80. Estrutura elipsoidal semelhante a um domo - Unidade Santa Maria 38

Figura 20: Afloramento RS-74. Padrão de disjunção associada a resfriamento (predominante na porção superior do afloramento, onde ocorre rocha vítrea obsidiana) com espaçamento decimétrico. No detalhe, observa-se disjunção com geometria tabular (linhas amarelas) e disjunção de geometria prismática, similar às disjunções colunares típicas de basaltos (linhas vermelhas)

Figura 21: Amostra GX-124. Rocha avermelhada, caracterizada por matriz intensamente desvitrificada, com vesículas milimétricas com geometria arredondada a ovalada. As vesículas podem ocorrer parcial ou completamente preenchidas por quartzo .40

Figura 22: Rocha apresentando matriz parcialmente desvitrificada, com vesículas milimétricas estiradas (destacadas em amarelo). As vesículas podem ocorrer parcial ou completamente preenchidas por quartzo.

Figura 23: Brechas peperíticas - porções esbranquiçadas correspondem a fragmentos angulosos de rocha vulcânica; porções avermelhadas correspondem a arenito cozido e vesiculado. Nota-se que os fragmentos de rocha vulcânica não sofreram retrabalhamento, sendo possível notar "encaixe" entre os fragmentos adjacentes. A presença de arenitos cozidos e vesiculados preenchendo as fraturas indicam que o sedimento ainda encontrava-se inconsolidado e úmido quando foi recoberto pela lava 
Figura 24: Auto-brecha concêntrica em fluxo lobado composto. Extreaído de Polo \& Janasi (2014). 42

Figura 25: Enclaves centimétricos de geometria arredondada (foto à esqueda) e subarredondada (foto à direita). As setas indicam as bordas de reação. 42

Figura 26: Exemplo de padrão de ASM em estruturas dômicas - obtido para o modelo H4 (de Závada et al., 2009). Este modelo corresponde ao material com maior razão massa/água $(2,6)$, maior fração volumétrica de partículas $(48 \%)$ e maiores viscosidades - para maiores detalhes, ver referência. Os limites dos lobos exógenos individuais são demarcados pelas linhas pretas contínuas. A) Representações dos planos de foliação magmáticao; B) Representações das direções e mergulho das lineações magnéticas em seção vertical. As variações dos ângulos de mergulho são representadas de acordo com o padrão de coloração apresentado ao lado. Extraído de Závada et al., 2009. 48

Figura 27: Exemplo de padrão de ASM em estruturas dômicas obtido para o modelo H4 (de Závada et al., 2009). Este modelo corresponde ao material com maior razão massa/água $(2,6)$, maior fração volumétrica de partículas (48\%) e maiores viscosidades - para maiores detalhes, ver referência. Os limites dos lobos exógenos individuais são demarcados pelas linhas pretas contínuas. A) Representações dos planos de foliação magnética sobrepostos em plano horizontal. As variações dos mergulhos são representadas pelas variações de coloração (padrão representado junto à figura); B) Representações das direções e mergulho das lineações magnéticas em seção horizontal. As variações dos ângulos de mergulho são representadas de acordo com o padrão de coloração apresentado acima da figura. Extraído de Závada et al., 2009. 49

Figura 28: Representação em 3D (junção dos padrões obtidos para corte vertical e horizontal) do diagrama de contorno dos domos exógenos formando estrutura dômica combinado com o parâmetro de forma ( $\mathrm{T}$ - figura $\mathrm{A}$ ) e grau de anisotropia ( $\mathrm{P}$ - figura $\mathrm{B})$. As variações destes parâmetros são representadas pelas variações de cor, que estão definidas ao lado das figuras. Extraído de Závada et al., 2009. 49

Figura 29: Representação do efeito de "pinçagem" dos cristais nas paredes de um dique, como proposto por Knight \& Walker (1988). A seta vermelha indica a direção do fluxo e a azul, o ângulo de imbricação. Extraído de Cañón-Taipa (2004) 50

Figura 30: Curvas de histereses obtidas para algumas amostras representativas dos riolitos tipo Santa Maria. M corresponde à magnetização (unidade: $\mu \mathrm{A} . \mathrm{m}^{2}$ ) e H corresponde ao campo magnético aplicado.

Figura 31: Gráfico Mrs/Ms vs Hcr/Hc - as linhas tracejadas correspondem aos limites propostos por Day et al. (1977). $\mathbf{H}_{\text {cr }}$ corresponde à força coersiva de remanência; $\mathbf{H}_{\mathrm{c}}$ corresponde à força coersiva; $\mathbf{M}_{\mathrm{rs}}$ corresponde à magnetização de saturação remanente; $\mathbf{M}_{\mathrm{s}}$ corresponde à magnetização de saturação. .54

Figura 32: Curvas termomagnéticas dos riolitos Santa Maria, mostrando as variações da susceptibilidade magnética (K) em função da temperatura (T). As linhas 
cheias representam curvas de aumento de temperatura $\left(-150^{\circ} \mathrm{C}\right.$ a $0^{\circ} \mathrm{C}$ e $50^{\circ} \mathrm{C}$ a $700^{\circ} \mathrm{C}$ ), enquanto que as curvas tracejadas representam o experimento de redução da temperatura $\left(700^{\circ} \mathrm{C}\right.$ a $\left.50^{\circ} \mathrm{C}\right)$. .55

Figura 33: Curvas de desmagnetização inicial das amostras representativas dos riolitos tipo Santa Maria. Legendas indicadas junto aos gráficos. ..........................56

Figura 34: Curvas de aquisição da pARM (magnetização remanete anisterética parcial) para as amostras representativas dos riolitos tipo Santa Maria. Legendas indicadas junto aos gráficos. 57

Figura 35: Curvas de aquisição de IRM para as amostras representativas dos riolitos tipo Santa Maria. Legendas indicadas junto aos gráficos. .58

Figura 36: Curvas de aquisição de AF-SIRM para as amostras representativas dos riolitos tipo Santa Maria. Legendas indicadas junto aos gráficos. 59

Figura 37: Diagrama de correlação entre a susceptibilidade total da amostra (K) e o grau de anisotropia $(\mathrm{P})$.

Figura 38: Diagrama de correlação entre os parâmetros de forma (T) e grau de anisotropia (P) para os riolitos Santa Maria.

Figura 39: Tramas magnéticas com pólos da foliação (eixo $K_{\min }$ - círculos rosados) verticais a sub-verticais, lineações (eixo $K_{\text {máx }}$ - quadrados azuis) horizontais e foliações (plano definido pelos eixos $\mathrm{K}_{\text {máx }}-\mathrm{K}_{\text {int }}$ - quadrados azuis e círculos verdes, respectivamente) com mergulhos de até $20^{\circ}$, com direções dispersas.

Figura 40: Tramas magnéticas com pólos de foliação (eixo Kmin - círculos rosados) com caimentos em torno de $60^{\circ}$, foliações (planos definidos pelos eixos $K_{\text {máx }}-K_{\text {int }}-$ quadrados azuis e círculos verdes, respectivamente) com mergulhos entre $25^{\circ} \mathrm{e}$ $30^{\circ}$ e lineações (eixo $\mathrm{K}_{\text {máx }}$ - quadrados azuis) horizontais.

Figura 41: Tramas magnéticas com pólo da foliação (eixo Kmin - círculos rosados) com caimentos de $50-60^{\circ}$, lineações aproximadamente $\mathrm{E}-\mathrm{W}$ com caimentos de $19^{\circ}$. $24^{\circ}$ (eixo $\mathrm{K}_{\text {máx }}$ - quadrados azuis) e foliações (planos definidos pelos eixos $\mathrm{K}_{\text {máx }}$ $\mathrm{K}_{\text {int }}$ - quadrados azuis e círculos verdes, respectivamente) com mergulhos entre $30^{\circ}$ e $40^{\circ}$ .64

Figura 42: Tramas magnéticas com pólo da foliação (eixo $\mathrm{K}_{\min }$ - círculos rosados) com caimentos de $29-45^{\circ}$, lineações aproximadamente NW-SE e NE-SW com caimentos de $19^{\circ}-43^{\circ}$ (eixo $\mathrm{K}_{\text {máx }}$ - quadrados azuis) e foliações (planos definidos pelos eixos $\mathrm{K}_{\text {máx }}-\mathrm{K}_{\text {int }}$ - quadrados azuis e círculos verdes, respectivamente) com maiores mergulhos, entre $45^{\circ}$ e $61^{\circ}$.

Figura 43: Diagrama em roseta mostrando a frequência para as diferentes direções das lineações magnéticas dos riolitos Santa Maria (direção média $\left.=231.4^{\circ}\right) \ldots \ldots . .65$

Figura 44: Fotomicrografia da amostra GX-125. Riolito com matriz vítrea, e pequenas porções afetadas por desvitrificação (coloração acastanhada). Notar orientação dos cristais de piroxênio e plagioclásio devido fluxo magmático. Escala: Lado maior apresenta $5,20 \mathrm{~mm}$

Figura 45: Fotomicrografia da amostra GX-124 - Polarizadores paralelos à esquerda e cruzados à direita. Riolito com matriz intensamente desvitrificada, onde é 
possível notar o padrão radial de intercrescimento entre quartzo e feldspato potássico (esferulitos). Observa-se aglomerado de microfenocristais de plagioclásio e vesícula arredondada preenchida por calcedônia. Escala: Lado maior apresenta $3,25 \mathrm{~mm}$. .68

Figura 46: Fotomicrografia da amostra GX-127. Riolito com matriz vítrea, com porções afetadas por desvitrificação (coloração acastanhada). Notar vesículas estiradas e preenchidas por calcedônia e cristais de piroxênio orientados segundo o estiramento das vesículas, evidenciando direção do fluxo magmático. Escala: Lado maior apresenta $3,25 \mathrm{~mm}$. .68

Figura 47: Fotomicrografia da amostra GX-140. Riolito com matriz vítrea, com pequenas porções desvitrificadas (esferulitos de coloração acastanhada). Notar vesículas estiradas e cristais de piroxênio e plagioclásio orientados segundo o estiramento das vesículas, evidenciando direção do fluxo magmático. Escala: Lado maior apresenta $3,25 \mathrm{~mm}$. .68

Figura 48: Diagrama classificatório para as análises de vidro obtidas por microssonda (Le Bas et. al., 1986). 69

Figura 49: Diagramas tipo Harker (elementos maiores vs $\mathrm{SiO} 2$ para as análises de vidro (matriz). A simbologia utilizada é indicada junto aos diagramas. ................70

Figura 50: Fotomicrografia da amostra RS-73. Riolito apresentando matriz intensamente desvitrificada (coloração acastanhada) e microfenocristal de plagioclásio euédrico, com zoneamento oscilatório concêntrico. Escala: lado maior da foto $3,25 \mathrm{~mm}$.

Figura 51: Fotomicrografia da amostra TF-02E (RS-74A). Riolito apresentando matriz vítrea e cristais de plagioclásio euédricos, sob a forma de micrólitos dispersos na matriz e microfenocristais de geometria tabular (canto direito da foto). Escala: lado maior da foto $2,60 \mathrm{~mm}$. .72

Figura 52: Fotomicrografia da amostra TF-02F (RS-74B). Riolito apresentando matriz desvitrificada, localmente caracterizada por textura granofírica e em padrão radial (esferulitos - seta amarela) e microfenocristal de plagioclásio apresentando lei da albita, anédrico, afetado por reações de reabsorção (gerando feições tipo "esponja"). Escala: lado maior da foto $2,60 \mathrm{~mm}$.................................... 72

Figura 53: Diagramas ternários An-Ab-Or para classificação dos plagioclásios da SVSM. a) Amostra GX-35; b) Amostra GX-108; c) Amostra GX-23. A simbologia utilizada é indicada acima. .73

Figura 54: Diagrama de variação dos teores de An vs Or para os plagioclásios da amostra GX-23 (fácies bandada (cristalina) da SVSM). A nomenclatura e a descrição dos pontos analisados encontra-se ao lado do diagrama. Para identificar as variações núcleo-borda deve-se acompanhar as setas nas cores correspondentes .74

Figura 55: Diagramas de variação dos teores de An vs Or para os plagioclásios da amostra GX-35 (fácies obsidiana da SVSM). A nomenclatura e a descrição dos 
pontos analisados encontra-se ao lado do diagrama. Para identificar as variações núcleo-borda deve-se acompanhar as setas nas cores correspondentes. .75

Figura 56: Diagrama de variação dos teores de An vs Or para os plagioclásios da amostra GX-108 (fácies obsidiana da SVSM). A nomenclatura e a descrição dos pontos analisados encontra-se ao lado do diagrama. Para identificar as variações núcleo-borda deve-se acompanhar as setas nas cores correspondentes. .75

Figura 57: Fotomicrografia da amostra GX-140. Riolito apresentando matriz parcialmente desvitrificada (apresentando coloração acastanhada) com destaque para microcristais orientados de piroxênio (setas amarelas) com inclusões de opacos. Escala: lado maior da foto 2,60 $\mathrm{mm}$. .76

Figura 58: Fotomicrografia da amostra RS-73C. Riolito apresentando matriz desvitrificada (coloração acastanhada) com destaque para microfenocristal de piroxênio. Escala: lado maior da foto $2,60 \mathrm{~mm}$. 77

Figura 59: Fotomicrografia da amostra TF-02D. Riolito apresentando matriz vítrea. Notar vesícula arredondada preenchida por calcedônia e cristal subédrico de mineral opaco com borda de piroxênio. Escala: lado maior da foto $1,30 \mathrm{~mm}$..........77

Figura 60: Diagramas ternários Wo-En-Fs para classificação dos piroxênios da SVSM. a) Amostra GX-35; b) Amostra GX-108; c) Amostra GX-23. A legenda da simbologia utilizada apresenta-se acima, junto aos diagramas. .78

Figura 61: Diagrama ternário para a composição dos óxidos de Fe e Ti da unidade Santa Maria. Triângulos azuis: amostra GX-23; quadrados vermelhos: amostra GX-35; círculos verdes: amostra GX-108. .79

Figura 62: Diagrama TAS para classificação geoquímica das rochas da unidade Santa Maria (Le Bas et al., 1986). Os círculos vermelhos correspondem às rochas de matriz cristalina enquanto que os triângulos verdes correspondem às rochas de matriz vítrea.

80

Figura 63: Diagrama classificatório R1-R2 para as rochas da unidade Santa Maria (De La Roche et al., 1980). Os círculos vermelhos correspondem às rochas de matriz cristalina enquanto que os triângulos verdes correspondem às rochas de matriz vítrea 81

Figura 64: Diagrama classificatório AFM para as rochas da unidade Santa Maria. Os círculos vermelhos correspondem às rochas de matriz cristalina enquanto que os triângulos verdes correspondem às rochas de matriz vítrea. 82

Figura 65: Diagrama classificatório com base na saturação em alumina para as rochas da unidade Santa Maria. Os círculos vermelhos correspondem às rochas de matriz cristalina enquanto que os triângulos verdes correspondem às rochas de matriz vítrea. .82

Figura 66: Diagrama \#mg vs $\mathrm{SiO} 2$ comparativo entre os riolitos Santa Maria (os círculos vermelhos correspondem às rochas de matriz cristalina enquanto que os triângulos verdes correspondem às rochas de matriz vítrea) e as rochas da unidadeBarros Cassal (quadrados pretos) e Caxias do Sul (losangos pretos). ......82 
Figura 67: Diagramas tipo Harker para variação dos teores de elementos maiores usando $\mathrm{SiO}_{2}$ como índice de diferenciação. Para a unidade Santa Maria os círculos vermelhos correspondem às rochas de matriz cristalina e os triângulos verdes correspondem às rochas de matriz vítrea; losangos pretos: unidade Caxias do Sul - Polo \& Janasi (2014); quadrados pretos: unidade Barros Cassal - Polo \& Janasi (2013). 84

Figura 68: Diagramas de variação nos teores de elementos traços, utilizando-se $\mathrm{SiO}_{2}$ como índice de diferenciação, para os riolitos Santa Maria (círculos vermelhos correspondem às rochas de matriz cristalina e o triângulos verdes correspondem às rochas de matriz vítrea) e as rochas das unidades Caxias do Sul (losangos pretros) e Barros Cassal (quadrados pretos). .86

Figura 69: Diagrama com os teores de elementos traço (ETR) para as amostras da unidade Santa Maria. Valores normalizados pelo condrito de Boynton (1984)....86

Figura 70: Diagramas spider para elementos traço (A.1; B.1 e C.1) e elementos terras raras (ETR - A.2; B.2 e C.2) das amostras GX-23, GX-35 e GX-108, representativas dos riolitos Santa Maria. A simbologia utilizada encontra-se junto de cada amostra.

Figura 71: Diagramas ${ }^{87} \mathrm{Sr} /{ }^{86} \mathrm{Sr}$ iniciais versus $\mathrm{SiO}_{2}$ (A) e $\mathrm{Rb} / \mathrm{Sr}$ (B) dos dados apresentados nesse trabalho para os riolitos Santa Maria comparados aos dados de Polo (2014) para as rochas das unidades Caxias do Sul e Barros Cassal. A simbologia utilizada encontra-se junto aos diagramas. .91

Figura 72: Diagrama ENd inicial versus $\mathrm{SiO}_{2}$ dos dados apresentados nesse trabalho para os riolitos Santa Maria comparados aos dados de Polo (2014) para as rochas das unidades Caxias do Sul e Barros Cassal. .92

Figura 73: Diagrama evolutivo para o sistema $\mathrm{Sm} / \mathrm{Nd}$. A linha preta contínua (DM) corresponde à linha de evolução do manto empobrecido (depleted mantle) de DePaolo (1981). As linhas coloridas (simbologia junto ao diagrama) correspondem à evolução para as amostras do riolito Santa Maria. .92

Figura 74: Gráficos comparativos entre as razões de ${ }^{87} \mathrm{Sr} / 86 \mathrm{Sr}$ iniciais e seus respectivos erros para os cristais de plagioclásio e a razão obtida para análise em rocha total (linhas vermelhas). A) Análises correspondentes à amostra GX-35; B) Análises correspondentes à amostra GX-108.

Figura 75: Representação dos líquidos em equilibrio calculados para as amostras GX23, GX-35 e GX-108 com base nas análises de elementos traço em plagioclásio via LA-ICPMS. As linhas coloridas representam os diferentes cristais das amostras, sendo que os símbolos representam diferentes zonas composicionais. Os valores obtidos são comparados com os resultados de rocha total representados pelas linhas cinzas e simbolizados por estrelas.

Figura 76: Dados isotópicos dos riolitos Santa Maria (losangos vermelhos) e das unidades subjacentes Barros Cassal (triângulos verdes) e Caxias do Sul (triângulos roxos) plotados em diagrama ${ }^{143} \mathrm{Nd} / 144 \mathrm{Nd}$ inicial versus ${ }^{87} \mathrm{Sr} /{ }^{86} \mathrm{Sr}$ inicial (calculados para $130 \mathrm{Ma}$ ) extraído de Garland et al. (1995), mostrando os campos 
ocupados por rochas vulcânicas de outras regiões da PMP e por rochas do embasamento cristalino. 100

Figura 77: Modelo de cristalização fracionada de geração de magmas riolíticos (Santa Maria) a partir de magmas intermediários (basaltos, andesitos e dacitos Barros Cassal) inseridos em diagrama binário Ba versus Zr. Losangos vermelhos: riolitos Santa Maria; quadrados verdes: rochas da unidade Barros Cassal. As linhas de evolução da cristalização fracionada apresentam diferentes cores para cada magma parental e cada quadrado representa um aumento de $10 \%$ na taxa de cristalização (com início em 0\% no ponto da amostra). 103

Figura 78: Modelo de cristalização fracionada de geração de magmas riolíticos (Santa Maria) a partir de magmas intermediários (basaltos, andesitos e dacitos Barros Cassal) inseridos em diagramas binários. Losangos vermelhos: riolitos Santa Maria; quadrados verdes: rochas da unidade Barros Cassal. As linhas de evolução da cristalização fracionada apresentam diferentes cores para cada magma parental e cada quadrado representa um aumento de $10 \%$ na taxa de cristalização (com início em $0 \%$ no ponto da amostra). 104

Figura 79: Dados isotópicos dos riolitos Santa Maria (losangos vermelhos) e das unidades subjacentes Barros Cassal (quadrados verdes) e Caxias do Sul (triângulos roxos) plotados em diagrama ${ }^{143} \mathrm{Nd} /{ }^{144} \mathrm{Nd}$ inicial versus ${ }^{87} \mathrm{Sr} /{ }^{86} \mathrm{Sr}$ inicial (calculados para $130 \mathrm{Ma}$ ) extraído de Garland et al. (1995), que contem valores das rochas vulcânicas de outras regiões da PMP, do embasamento Brasiliano e das unidades neoproterozóicas do Escudo Catarinense - Granitóides Garopaba, Granitos Paulo Lopes, Granitos Mariscal e Granitóides Quatro Ilhas. ...............106

Figura 80: Modelos de cristalização fracionada com assimilação crustal (AFC) para a geração de magma riolítico (Santa Maria - losangos vermelhos) a partir de magmas intermediários (andesitos e dacitos Barros Cassal - quadrados verdes). O círculo azul representa a amostra do Granitóide Garopaba usada como contaminante. As linhas cinzas representam a trajetória AFC - cada quadrado equivale a um acréscimo de $10 \%$ da taxa de cristalização, com início em $0 \%$ na composição básica. Foram consideradas diferentes razões assimilação/cristalização (" $r$ "), a depender do magma parental, para que se obtivesse as retas de melhores ajustes. 107

Figura 81: Diagrama representativo da comparação entre o líquido obtido $\left(\mathrm{C}_{\mathrm{L}}\right)$ a partir um modelamento de AFC (considerando-se cristalização de magmas com composições equivalentes às composições médias dos basaltos, andesitos e dacitos da unidade Barros Cassal e assimilação de uma composição equivalente à composição média dos Granitódes Garopaba) e a composição média dos riolitos Santa Maria ( $\left.\mathrm{C}_{\mathrm{SM}}\right)$. Cada símbolo representa um valor de "F", enquanto as cores representam diferentes composições de magma parental a sofrer cristalização fracionada. 108

Figura 82: Modelos de cristalização fracionada com assimilação crustal (AFC) para a geração de magma riolítico (Santa Maria - losangos vermelhos) a partir de 
magmas intermediários (andesitos e dacitos Barros Cassal - quadrados verdes). Os círculos azuis correspondem às amostras dos Granitóides Garopaba - as setas indicam a amostra selecionada como contaminante (por apresentar o melhor ajuste da reta). Foram consideradas diferentes razões assimilação/cristalização ("r"), a depender do magma parental, para que se obtivesse as retas de melhores ajustes - os valores de " $r$ " são indicados junto às curvas de evolução do processo AFC.

Figura 83: Diagrama reológico representativo de uma composição granítica e uma composição basáltica (segundo Fernandez, 1984). A viscosidade (representada no eixo à esquerda) apresenta correlação positiva com a tensão cisalhante (eixo à direita) e a cristalinidade (eixo horizontal), sendo definidos três campos de comportamento reológico distintos. O campo III caracteriza-se pela perda da mobilidade do magma.

112

Figura 84: A) Determinação experimental da solubilidade de água em fusões basálticas e riolíticas a temperaturas típicas. A solubilidade da água é maior em magmas riolíticos do que em magmas basálticos a pressões acima de 0,5 Kbar. Extraído de Carroll \& Holloway (1994) in Wallace \& Anderson Jr (2000). B) Efeito da água dissolvida na viscosidade de fusão granítica (riolítica). Notar que a baixas concentrações de água as curvas de $700^{\circ} \mathrm{C}$ e $800^{\circ} \mathrm{C}$ são para magmas super-resfriados, uma vez que as temperaturas são inferiores à temperatura de solidus para um líquido granítico desidratado $\left(\sim 900^{\circ} \mathrm{C}\right)$. Calculado a partir de Hess \& Dingwell (1996), extraído de Wallace \& Anderson Jr (2000). C) Densidade de fusões com composições variando desde komatíticas até riolíticas em função do conteúdo de água dissolvida. As temperaturas consideradas são as típicas para as respectivas composições. Densidades calculadas para pressão de 1 bar $\left(10^{-4} \mathrm{GPa}\right)$. Extraído de Spera (2000).

115

Figura 85: Estimativas de temperatura de saturação em plagioclásio para diferentes conteúdos de água dissolvida nos magmas, calculadas segundo o modelo de Putirka (2008). Os intervalos obtidos a cada teor de água correspondem à variação composicional dos riolitos (considerando-se as amostras GX-23, GX-35 e GX-108). O intervalo em amarelo destaca um intervalo de temperatura estimada para os magmas através das metodologias de saturação em apatita e dos termômetros de equilíbrio plagioclásio-liquido 126

Figura 86: Diagrama de solubilidade em função da pressão para o intervalo composicional representado pelas amostras GX-23, GX-35 e GX-108. O campo verde corresponde aos teores obtidos pelo geohigrômetro inédito de Lange e o campo amarelo corresponde aos teores de água obtidos pelo geohigrômetro de Putirka (2008) de acordo com o equilíbrio plagioclásio-líquido. 128

Figura 87: Viscosidades obtidas em função da variação da temperatura para os magmas riolíticos Santa Maria a partir do modelo de Giordano et al. (2008), considerando-se os diferentes teores de água obtidos a partir do geohigrômetro de Lange (cf. recalibração ainda a ser publicada). A linha vertical indica a 
temperatura média $\left(970^{\circ} \mathrm{C}\right)$ considerada para estes magmas e a seta vermelha representa uma ascensão isotérmica, considerada a partir dos teores de água obtidos através dos fenocristais (média de $0.9 \%$ - ponto A), cristalizados em profundidade, e o teor obtido a partir da composição dos micrólitos ( $0,2 \%$ - ponto B), cristalizado em próximo ou já em superfície.

Figura 88: Modelo simplificado para a evolução e erupção dos riolitos Santa Maria. 


\section{ÍNDICE DE TABELAS}

Tabela 01: Parâmetros de histerese das amostras representativas dos riolitos tipo Santa Maria. $H_{\text {cr }}$ corresponde à força coerciva de remanência; $H_{c}$ corresponde à força coerciva; $\mathrm{M}_{\mathrm{rs}}$ corresponde à magnetização de saturação remanente; $\mathrm{M}_{\mathrm{s}}$ corresponde à magnetização de saturação...............................................................54

Tabela 02: Dados obtidos através das análises de ASM para cada amostra obtida e suas respectivas coordenadas geográficas. 60

Tabela 03: Coordenadas UTM dos sítios de amostragem, dados estruturais obtidos em campo ( ${ }^{1}$ correspondentes à fraturas e disjunções associadas à resfriamento) e dados estruturais magnéticos (foliação e lineação). 62

Tabela 04: Estimativa de ordem de cristalização com base na variação dos teores de An dos principais microfenocristais de plagioclásio das amostras GX-23, GX-35 e GX-108. As zonas são indicadas por letras: "n" - núcleo; "z" - zona intermediária; "b" - borda; "-" indica zona não analisada e "**" indica cristal com zonamento oscilatório onde foram feitas 2 análises de maneira aleatória. .76

Tabela 05: Razões $(\mathrm{La} / \mathrm{Sm}) \mathrm{N},(\mathrm{La} / \mathrm{Yb}) \mathrm{N}$ e $(\mathrm{Eu} / \mathrm{Eu})^{*}$ e teores totais de elementos terras raras (ETR) obtidos via análises LA-ICPMS para os microfenocristais de

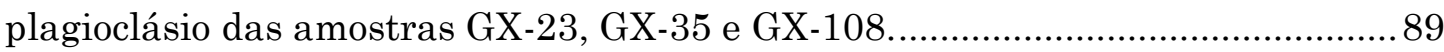

Tabela 06: Resultados das análises isotópicas para os sistemas $\mathrm{Rb} / \mathrm{Sr}$ e $\mathrm{Sm} / \mathrm{Nd}$ em rocha total para os riolitos Santa Maria e as unidades subjacentes Barros Cassal e Caxias do Sul (dados de Polo, 2014). 90

Tabela 07: Resultados das análises $87 \mathrm{Sr} / 86 \mathrm{Sr}$ obtidas em cristais de plagioclásio via LA-ICPMS.

Tabela 08: Composição obtida para fusão em equilibrio calculado de acordo com Bédard (2006). Os cálculos são feitos utilizando-se os teores obtidos para elementos traço no plagioclásio via LA-ICPMS e com base nos coeficientes de partição (Kd) dos elementos. .98

Tabela 09: Coeficientes de partição para os elementos selecionados das fases minerais cristalizadas e o coeficiente global (D) resultante. ${ }^{1}$ - Calculados a partir de Bédard (2006); ${ }^{2}$ - Extraídos de Bellieni et al. (1986b); ${ }^{3}$ - Extraídos de Renner et al. (2011). 102

Tabela 10: Fatores controladores dos processos vulcânicos. Modificado de Sigurdsson et al. (2000)

Tabela 11: Temperaturas obtidas a partir da saturação em apatita (Harrison \& Watson, 1984) para os riolitos Santa Maria.

Tabela 12: Resultados obtidos pelo termômetro/higrômetro plagioclásio-líquido de Putirka (2008).

Tabela 13: Resultados obtidos pelo termômetro/barômetro clinopiroxênio-líquido de Putirka (2008). 
Tabela 14: Resultados obtidos para o geohigrômetro inédito (ainda não publicado) de Lange. Destacado em azul, núcleo com menor teor de anortita preservado e em a marelo, análise correspondente à micrólito.................................................... 125 


\section{CAPITULO I - APRESENTAÇÃO}

\section{I.1. Introdução}

O estudo do vulcanismo ácido da Província Magmática Paraná-Etendeka tem despertado bastante interesse, seja sob seus aspectos petrológicos (Garland et al., 1995; Nardy et al., 2008; Janasi et al., 2007), estratigráficos (Janasi et al., 2011), vulcanológicos (Luchetti, 2010) ou de aplicação industrial (Montanheiro et al., 2011). O progresso desses estudos tem mostrado que, embora volumetricamente subordinadas em relação ao magmatismo basáltico associado, as rochas vulcânicas ácidas da PMPE têm diversas características singulares que as colocam em destaque no contexto científico atual. $\mathrm{O}$ volume preservado ( $15.000 \mathrm{~km}^{3}$; Nardy et al., 2008) é o maior entre todas as grandes províncias basálticas continentais do planeta; a diversidade composicional é expressiva; o posicionamento estratigráfico é variado, e marcador de mudanças fundamentais na evolução da província (Peate, 1997; Janasi et al., 2011). Um aspecto de particular interesse é a forma de ocorrência desse vulcanismo, cujas características físicas são reconhecidamente distintas das manifestações vulcânicas ácidas mais típicas; em particular, as elevadas temperaturas, estimadas em torno de $1000^{\circ} \mathrm{C}$ por diversos autores, podem se refletir em comportamento vulcanológico singular, com poucos análogos conhecidos (e.g. Branney et al., 2008), e ainda pouco compreendido.

A evolução do conhecimento sobre o vulcanismo ácido da PMPE nos últimos anos resultou em uma base de dados geológicos e geoquímicos bastante expressiva, que dá suporte a estudos de maior detalhe, necessários para a compreensão dos processos vulcanológicos associados. Estudos de detalhe desenvolvidos por Polo (2014) na área de maior expressão deste vulcanismo, no Platô do Rio Grande do Sul, mostram uma história geológica bem definida, com a sucessão de três episódios principais de vulcanismo ácido, cada qual marcado por características composicionais e estruturais peculiares. A sucessão mais 
jovem, designada Santa Maria, é também a mais diferenciada, com composição riolítica, e se manifesta na forma de extensos corpos tabulares aparentemente contínuos, cuja origem é controversa. De fato, enquanto estudos de detalhe revelam estruturas e texturas compatíveis com extrusão na forma de lava ou lava-domos (Polo et al., 2011), existem propostas na literatura internacional recente que os consideram expressivos corpos de natureza piroclástica, que constituiriam algumas das mais extensas manifestações vulcânicas do planeta (Bryan et al., 2010).

Dentro deste contexto, o presente trabalho de mestrado procurou contribuir para a definição de modelos de gênese e colocação dos magmas ácidos da Província com base em estudos voltados tanto para os aspectos físicos e vulcanológicos quanto para os aspectos geoquímicos.

Os estudos estruturais e dos aspectos físicos se embasam em feições bem descritas dentro da área de estudos como lava-domos, estruturas lobadas ou mesmo corpos tabulares com foliação magmática e dobras de fluxo. Estas feições foram estudadas também sob o ponto de vista da técnica de anisotropia de susceptibilidade magnética, eficiente metodologia para a determinação da trama estrutural (petrofábrica) das rochas, em especial daquelas de caráter textural isotrópico em escala macroscópica, como é o caso das ocorrências vulcânicas. A utilização desta técnica permitiu reconhecer feições compatíveis com ocorrências efusivas, um importante passo na identificação da forma de ocorrência de lavas ácidas em grandes províncias magmáticas.

Os estudos geoquímicos incluem desde química mineral através de microssonda eletrônica e LA-ICPMS, química de rocha total por FRX e ICP-MS e geoquímica isotópica tanto em cristais de plagioclásio como em rocha total.

Por fim, as estimativas dos parâmetros intensivos como temperatura, pressão, teor de água e viscosidade contempladas no último capítulo buscam entender os parâmetros controladores da forma de ocorrência destas rochas. 
Esta caracterização, embasada pela caracterização química destas rochas, fornece argumentos que justificam uma forma de ocorrência efusiva para estes depósitos.

\section{I.2. Materiais e Métodos}

\section{I.2.1. ATIVIDADES PREVIAMENTE DESENVOLVIDAS}

O presente trabalho de mestrado embasa-se em estudos já realizados pela aluna durante seu trabalho de graduação intitulado "Caracterização geológica-estrutural e geoquímica dos riolitos da Província Magmática Paraná na região de Soledade (RS)", os quais envolvem petrografia, análise por microscopia eletrônica de varredura (MEV) e análises de química mineral e de rocha total.

As análises petrográficas foram realizadas nos laboratórios de microscopia óptica do Instituto de Geociências (IGc - USP), com a utilização de aparelhos Olympus BX-50, visando o reconhecimento da mineralogia principal e das relações texturais das amostras de riolitos e a seleção das melhores amostras para as etapas seguintes.

As análises de microscopia eletrônica de varredura (MEV) compreenderam 03 amostras, das quais duas apresentam matriz vítrea e uma apresenta matriz cristalina. As análises foram realizadas no Laboratório de Caracterização Tecnológica (LCT) do Instituto de Engenharia de Minas e Petróleo, da Escola Politécnica da USP e visaram o reconhecimento de mineralogia acessória não distinguível em microscópio óptico, além do detalhamento de relações texturais entre as paragêneses minerais e, principalmente, o direcionamento das análises químicas minerais. 
As análises de química mineral envolveram as amostras analisadas através de MEV e foram realizadas no Laboratório de Microssonda Eletrônica do IGc - USP. Tais análises foram feitas para vidro (primeira fase a ser analisada a fim de se evitar a perda de componentes voláteis), piroxênio, óxidos de Fe e Ti e plagioclásio. No caso dos plagioclásios as análises envolveram a caracterização de zonamentos composicionais e identificação das variações nos teores de anortita.

As análises químicas de rocha foram realizadas via FRX no Laboratório de Fluorescência de Raios X do IGc - USP com utilização de pastilhas prensadas para análises de elementos menores, e pastilhas fundidas para análises de elementos maiores.

\section{I.2.2. TRABALHO DE CAMPO}

As atividades de campo foram realizadas no período de 24 a 30 de março de 2013, com o levantamento de perfis de detalhe da estratigrafia da área e a coleta de amostras para estudos de anisotropia de susceptibilidade magnética (ASM).

A coleta de amostras cilíndricas em um total de 28 sítios foi feita utilizando-se uma perfuratriz portátil STHIL que utiliza uma broca cilíndrica oca de $1^{\prime \prime}$ de diâmetro e $20 \mathrm{~cm}$ de comprimento, com a extremidade diamantada. Acoplada à máquina encontra-se uma bomba manual responsável pela injeção de uma mistura de água e óleo solúvel biodegradável responsável pelo resfriamento da máquina e pela diminuição do atrito entre a broca e a rocha, facilitando assim a perfuração (Figura 01). Ressalta-se a importância da certificação de que a rocha a ser amostrada encontra-se in situ e com baixo grau de alteração. 

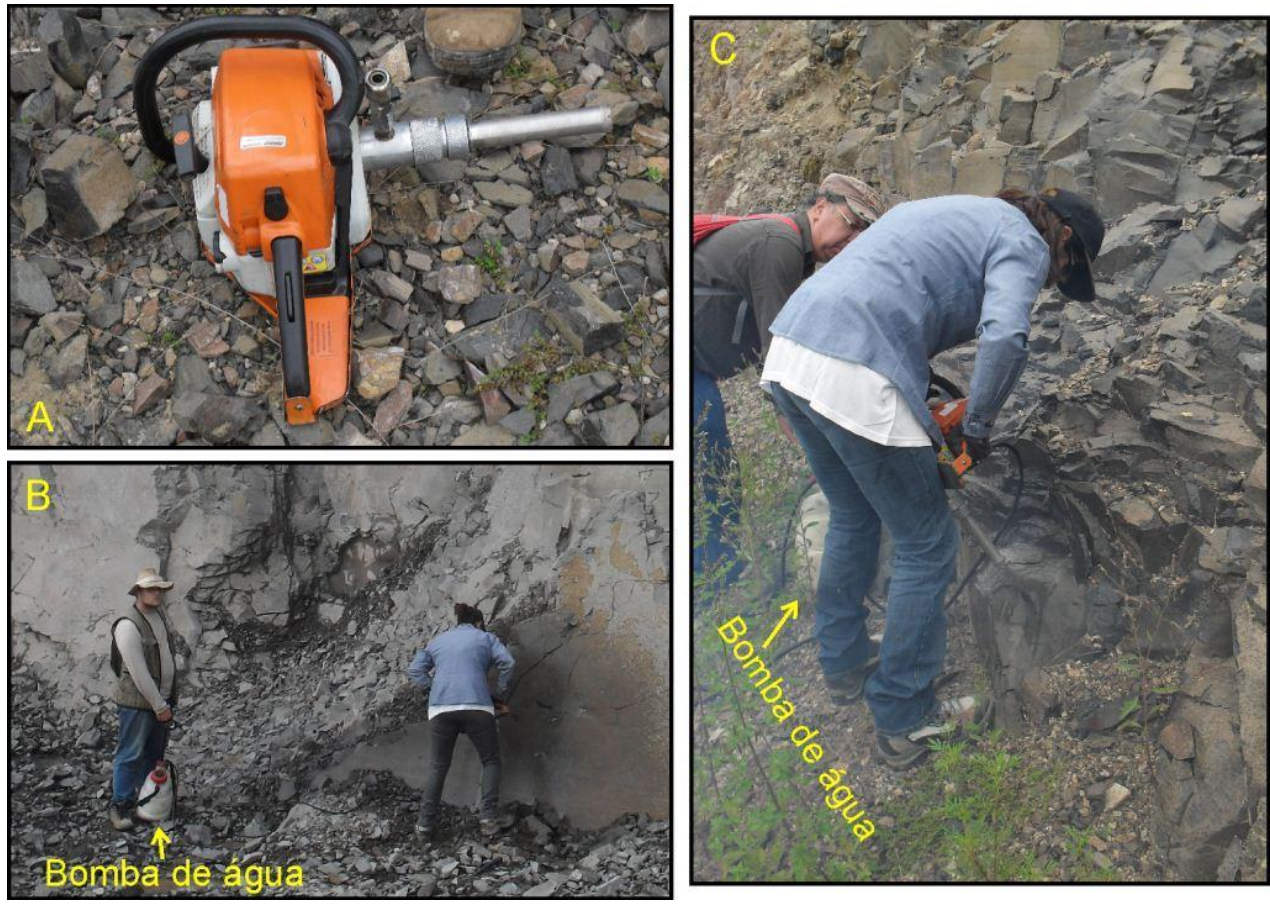

Figura 01: Perfuratriz STHILL com broca de $20 \mathrm{~cm}$ e 1", com extremidade diamantada. B e C) Processo de perfuração dos cilindros, com destaque em amarelo para bomba de água+óleo para refrigeração da máquina e diminuição do atrito durante a perfuração.

Após a perfuração dos cilindros, faz-se a orientação dos mesmos utilizando-se uma bússola tipo Brunton adaptada, à qual se encontra acoplada uma haste cilíndrica (que se encaixa no afloramento perfurado), uma bússola solar para correções necessárias caso a rocha seja fortemente magnética e um transferidor para a medição da inclinação do furo (Figura 02). Terminada a orientação do cilindro, este é retirado do afloramento e é feita a marcação da orientação por toda a amostra. 

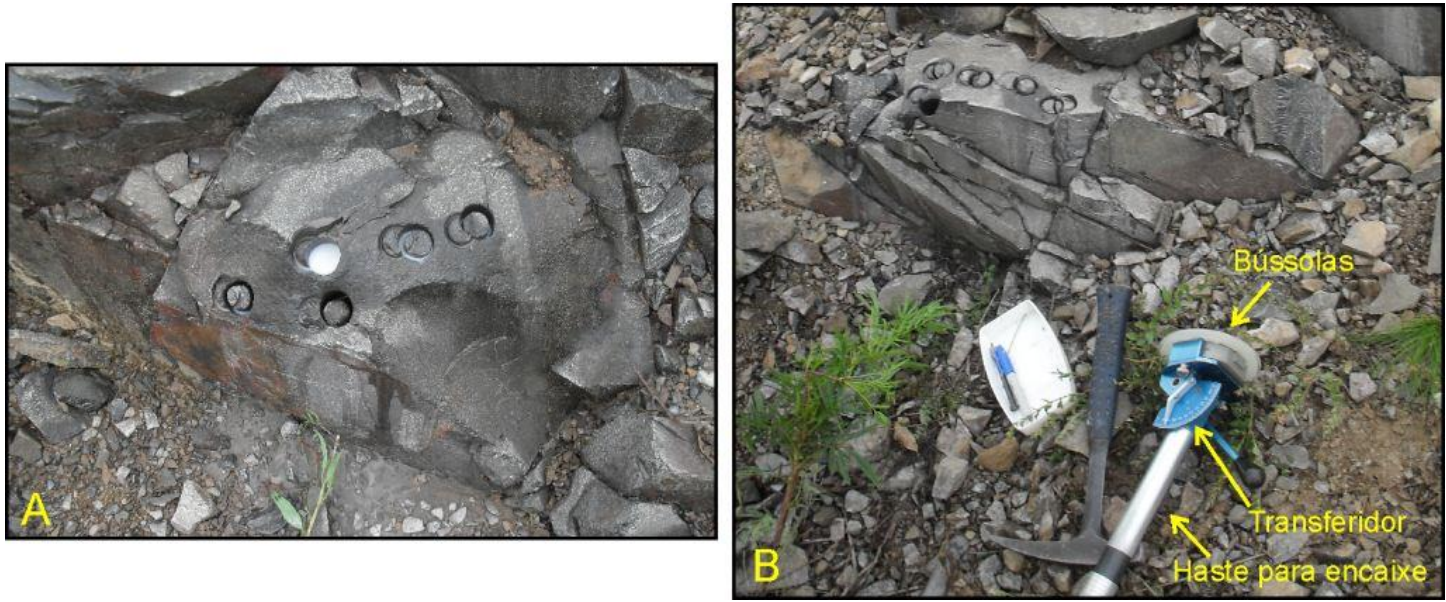

Figura 02: A) Cilindros de amostragem ainda in situ - notar que é feita uma marcação com a broca previamente à perfuração para que, em caso de quebra do cilindro, ele possa ser corretamente orientado. B) Instrumentação utilizada para orientação dos cilindos: bússola tipo Brunton adaptada, com haste para encaixe no afloramento, transferidor para medida de mergulho e bússola solar acoplada.

\section{I.2.3. ANÁLISE DE ANISOTROPIAS MAGNÉTICAS}

\section{I.2.3.1. Preparação das amostras}

No Laboratório de Tratamento de Amostras (LTA-IGc USP) as amostras foram fatiadas em serra específica (Figura 03) de modo a não apresentarem comprimento superior a $22 \mathrm{~mm}$, totalizando 729 espécimes. Todos os espécimes foram marcados indicando sua orientação e as posições de topo e base e posteriormente foram embalados em papel filme para evitar que haja contaminação dos equipamentos.

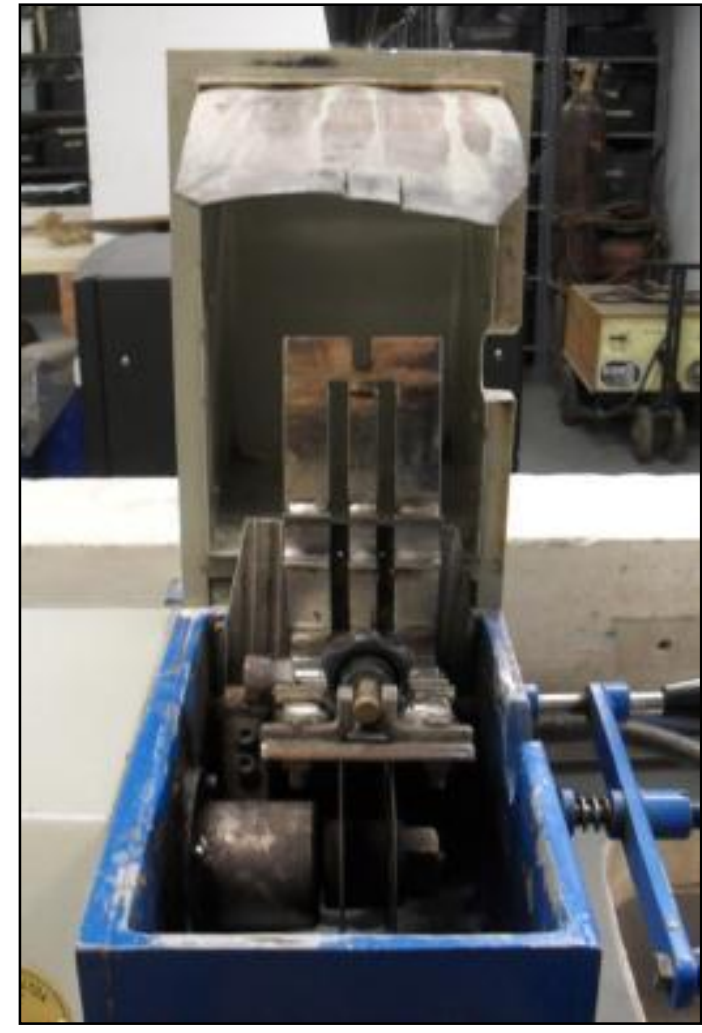

Figura 03: Detalhe da serra utilizada para corte dos cilindros. 
Para a realização de alguns experimentos, como é o caso da obtenção das curvas de histerese e do termomagnetismo, faz-se necessário moer as amostras. Nestes casos, iniciou-se o processo através da quebra das amostras em prensa, com os devidos cuidados para se evitar a contaminação (amostras revestidas por papelão para que não entrassem em contato com o equipamento), para posteriormente serem reduzidas à fração mais fina através do moinho de ágata.

Todas as análises para a caracterização das propriedades magnéticas das amostras foram realizadas no Laboratório de Anisotropias Magnéticas do IGc (LAM IGc USP).

\section{I.2.3.2. Anisotropia de Susceptibilidade Magnética (ASM)}

As medidas de susceptibilidade magnética e a obtenção da anisotropia de

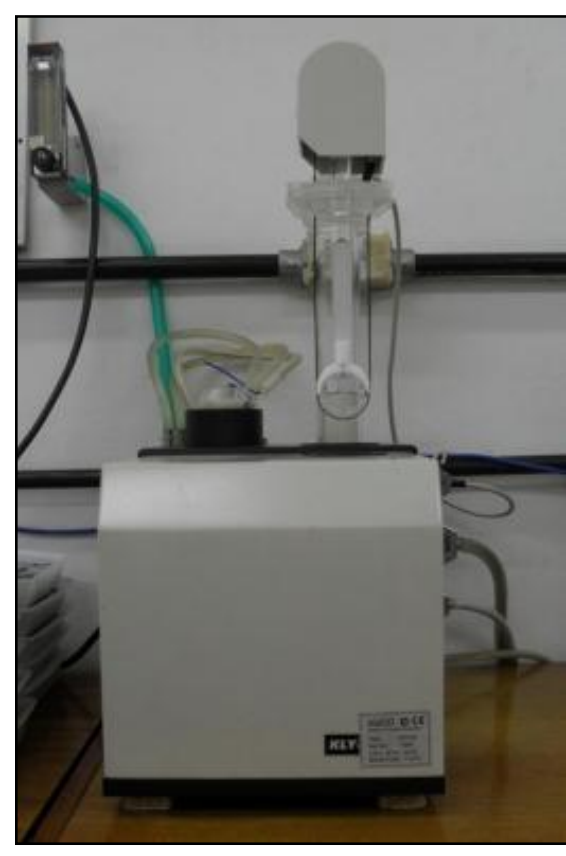

Figura 04: Equipamento Kappabridge $4 \mathrm{~S}$ da Agico, utilizado para a medição das propriedades magnéticas das amostras. susceptibilidade magnética das amostras foram realizadas no equipamento Kappabridge (KLY4S AGICO; Figura 04), sendo os dados tratados posteriormente no software ANISOFT 4, considerando-se a estatística de Jelinek (1977). A obtenção das propriedades magnéticas das amostras envolve medidas em três posições distintas do cilindro, além de uma última referente à susceptibilidade total, para o cálculo do tensor de ASM. Tais análises permitem determinar a trama magnética da rocha, definida por todos os minerais que a compõem. Os resultados obtidos para os estudos de ASM são expressos em termos de declinação, 
inclinação e magnitude dos eixos do elipsoide de anisotropia de susceptibilidade magnética (ver definições no item IV.2.1), os quais são corrigidos para a orientação natural da amostra, obtida em campo.

\section{I.2.3.3. Magnetismo de Rocha}

Os estudos de magnetismo de rocha abrangem diferentes experimentos. Inicialmente, com o objetivo de se verificar a contribuição das diferentes fases minerais (dia-, para- e ferromagnéticas) na susceptibilidade magnética da rocha, procedeu-se com a obtenção das curvas de histerese, através da análise de pó das amostras no magnetômetro VSM (vibrating sample magnetometer).

Posteriormente seguiu-se com os experimentos para determinação da magnetização remanente (MRN), da coercividade dos cristais (pARM), magnetização remanente isotermal (IRM) e magnetização de saturação (SIRM). Em um espécime representativo de cada sítio amostrado iniciou-se a medição da MRN, seguida da desmagnetização em campos magnéticos alternados (AF), até $200 \mathrm{mT}$, no desmagnetizador Molspin. A cada indução, mediu-se a magnetização remanente através do magnetômetro tipo spinner JR5A (AGICO).

O espectro de coercividade é obtido através da execução da magnetização anisterética parcial (pARM), a qual consiste na aplicação de um campo alternado (AF) em intervalos de $10 \mathrm{mT}$ até que se atinja o pico de $200 \mathrm{mT}$, com a sobreposição de um campo contínuo (DC - steady field) de 0,01 mT, medindose a cada intervalo a magnetização remanente da amostra. Os cristais que apresentarem $\mathrm{H}_{\mathrm{CR}}$ (força coercivas remanente) dentro do intervalo de campo aplicado irão adquirir magnetização (ARM), enquanto os demais cristais

permanecerão desmagnetizados. Deste modo, a curva obtida através deste estudo representa o espectro de coercividade dos cristais da amostra. 
Para a obtenção da curva de magnetização remanente isotermal (IRM) as amostras são submetidas a um campo magnético (iniciando-se em $10 \mathrm{mT}$ ) com incrementos sucessivos, através de um magnetômetro tipo "pulse", até que se atinja um valor máximo e constante de magnetização das amostras (magnetização de saturação). Depois de atingida tal saturação, as amostras são novamente desmagnetizadas em AF, progressivamente.

Finalmente, para determinação da susceptibilidade magnética da amostra, em função da temperatura, são realizados os experimentos de termomagnetismo, que visam à determinação da mineralogia magnética em função da temperatura de Curie, característica de cada mineral (ver item IV.2.1.1). As curvas termomagnéticas foram obtidas através da execução, no Kappabridge $4 \mathrm{~S}$ ao qual foi acoplado equipamento específico (furnance), em atmosfera de argônio e a baixa $\left(-200^{\circ} \mathrm{C}\right.$ a $\left.0^{\circ} \mathrm{C}\right)$ e alta $\left(50^{\circ} \mathrm{C}\right.$ a $\left.700^{\circ} \mathrm{C}\right)$ temperaturas das amostras selecionadas e previamente moídas.

\section{I.2.4. ANÁLISE QUÍMICA DE ELEMENTROS TRAÇO E ISOTOPIA DE Sr EM PLAGIOCLÁSIO POR LA-ICPMS}

As análises por LA-ICPMS para detecção de elementos traço em cristais de plagioclásio foram realizadas no Laboratório de Química do Instituto de Geociências da Universidade de São Paulo (IGc-USP) utilizando-se um espectrômetro quadruplo do tipo MS-ELAN 6100 DRC (Perkin Elmer) sendo conduzidas sobre lâminas delgadas, polidas e devidamente limpas, com $80 \mu \mathrm{m}$ de espessura. Foram selecionados cristais previamente analisados através de microscopia eletrônica de varredura (MEV) e microssonda eletrônica, de acordo com suas variações composicionais e com tamanho suficiente para suportar a aplicação do feixe de laser - ao todo foram analisados 9 cristais em 3 amostras: GX-23, GX-35 e GX-108. Foram aplicados feixes de laser sob a forma de spots (circulares) com diâmetros de $30 \mu \mathrm{m}$ ou $40 \mu \mathrm{m}$ ou, no caso dos zonamentos mais 
diminutos, rasters lineares, com largura de $25 \mu \mathrm{m}$. As concentrações foram calculadas com base nos padrões externos BHVO (basalto, Jochum et al., 2006) e NIST 612 e os dados foram trabalhados no software Glitter (Macquarie University).

As análises por LA-ICPMS para obtenção de razões isotópicas $87 \mathrm{Sr} / 86 \mathrm{Sr}$ foram realizadas na Universidade de Alberta (Canadá) utilizando-se um espectrômetro $\mathrm{Nu}$ Plasma ${ }^{\mathrm{TM}}$ MC-ICPMS acoplado ao sistema de laser ablation New Wave UP213, sendo conduzidas sobre as mesmas lâminas e seus respectivos cristais previamente analisados para elementos traço. Devido ao pequeno tamanho dos cristais e das dimensões dos zonamentos e, uma vez que quanto maior o feixe melhor é o sinal, optou-se pela utilização de spots de 80 $\mu \mathrm{m}$ de diâmetro, o que resultou na análise do mineral como um todo, sem distinção das variações composicionais entre as zonas. O padrão utilizado corresponde a uma labradorita da Mina Ponderosa de Oregon (EUA).

\section{I.2.5. ANÁLISE QUÍMICA DE ELEMENTROS TRAÇO POR ICP-MS E ISOTOPIA Rb/Sr e Sm/Nd POR TIMS EM ROCHA TOTAL}

De modo a complementar as análises de elementos maiores e menores para rocha total por FRX previamente desenvolvidas, foram também efetuadas análises de elementos traço, presentes em baixas concentrações, incluindo-se os elementos terras-raras (ETRs), por ICP-MS. Os procedimentos, realizados no Laboratório de Química do Núcleo Geoanalítica, IGc-USP, seguiram o protocolo descrito em Navarro (2004), e envolveram a dissolução de $40 \mathrm{mg}$ de amostra (pós previamente utilizados para obtenção das análises por FRX) em ataque ácido $\left(\mathrm{HF}+\mathrm{HNO}_{3}\right)$ durante 5 dias a $200^{\circ} \mathrm{C}$.

As análises isotópicas $\mathrm{Rb} / \mathrm{Sr}$ e $\mathrm{Sm} / \mathrm{Nd}$ foram obtidas no Centro de Pesquisas Geocronológicas (CPGeo) do IGc-USP. Os mesmos pós utilizados 
para as análises de elementos maiores, menores e traços foram utilizados para estas análises, que envolveu as seguintes etapas: 1) dissolução em HF em bombas tipo Parr; 2) separação elementar em colunas primárias de trocas catiônicas; 3) adição de $\mathrm{HCl}$ 2,62N para coleta de Sr eluído e de $\mathrm{HCl}$ 6,2N para coleta dos demais elementos; 4) os resíduos contendo os demais elementos são levados a colunas de resina onde o $\mathrm{Nd}$ é eluído e coletado com a adição de $\mathrm{HCl}$ 0,26N. Posteriormente a estes procedimentos, os resíduos contendo Sr e Nd são aquecidos e secos e levados para as análises nos espectrômetros de massa que, através de uma fonte de íons ioniza as amostras em altas temperaturas e separa os íons através da aplicação de um campo magnético. As análises isotópicas ${ }^{87} \mathrm{Sr} /{ }^{86} \mathrm{Sr}$ e ${ }^{147} \mathrm{Sm} / 144 \mathrm{Nd}$ foram realizadas via termal ionization mass spectrometry (TIMS) em um espectrômetro VG354 equipado com um detector Faraday. Os padrões utilizados foram o NBS-987 para o Sr, com valores obtidos de 0,710251 $\pm 0,000038$, e o JNDi para o Nd, com valores obtidos de 0,512102 \pm 0,000007 .

As razões ${ }^{87} \mathrm{Sr} /{ }^{86} \mathrm{Sr}$ foram normalizadas para ${ }^{87} \mathrm{Sr} / 86 \mathrm{Sr}=0,1194$ e as razões ${ }^{143} \mathrm{Nd} / 144 \mathrm{Nd}$ foram normalizadas pelo modelo de manto empobrecido de De Paolo $\left(1981 ;{ }^{143} \mathrm{Nd} / 144 \mathrm{Nd}=0,7219\right)$. 


\section{CAPITULO II - REVISÃO CONCEITUAL}

Neste item serão apresentados alguns conceitos utilizados no presente trabalho acerca da geração e caracterização das possíveis manifestações do vulcanismo ácido.

Os processos vulcânicos podem se manifestar através de explosões ou efusão de lavas, sendo que o estilo eruptivo (ou seja, o modo de extrusão do magma) depende principalmente de dois fatores: da concentração de voláteis dissolvidos e da reologia deste magma. A reologia, por sua vez, é função da composição química e da concentração de voláteis, da temperatura e da cristalinidade do magma.

\section{II.1. Fluxos piroclásticos}

Fluxos piroclásticos são correntes densas e quentes, originadas através do colapso de plumas vulcânicas resultantes de erupções explosivas (Best, 2002; Figura 05). Compõem-se de elevadas concentrações de material piroclástico, onde o transporte se dá predominantemente por tração, sendo a gravidade e a topografia fatores controladores (Carey \& Bursik, 2000). Esses fluxos são constituídos predominantemente por material piroclástico juvenil, i.e. fragmentos vesiculados de magma (púmices e escórias), cristais e fragmentos vítreos (glass-shards), podendo também conter fragmentos líticos (rocha densa) derivados do substrato deposicional, das paredes do conduto vulcânico ou porções cristalizadas do próprio magma.

Segundo Carey \& Bursik (2000), os fluxos piroclásticos podem atingir velocidades da ordem de $200-300 \mathrm{~m} / \mathrm{s}$, sendo que o material transportado concentra-se na porção basal do fluxo. Os depósitos gerados caracterizam-se como muito pobremente selecionados e ocorrem confinados em vales, evidenciando o controle gravitacional. 


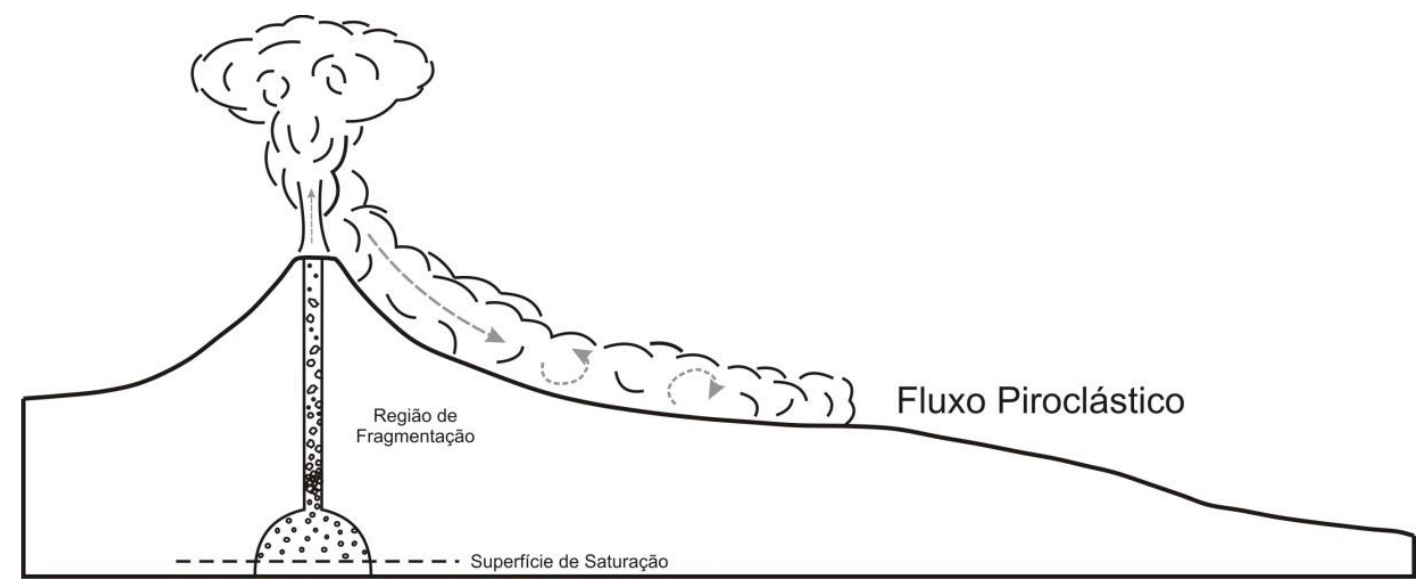

Figura 05: Esquema de fluxo piroclástico formado a partir do colapso de coluna piroclástica gerada em erupção explosiva. Adaptado de Carey \& Bursik (2000).

\section{II.2. Ignimbritos}

Segundo Freundt et al. (2000), ignimbritos são depósitos (soldados ou não) formados a partir de fluxos piroclásticos ricos em púmice. Caracterizam-se como depósitos muito mal selecionados, com acamamento horizontal, espessos (quando ocorrem preenchendo vales) ou muito finos (quando cobrem áreas muito extensas), capazes de recobrir áreas que variam de algumas centenas de $\mathrm{m}^{2}$ a milhares de $\mathrm{km}^{2}$, com um volume que pode variar desde centenas de $\mathrm{m}^{3}$ a poucos milhares de $\mathrm{km}^{3}$.

A estruturação de um ignimbrito é apresentada na Figura 06, extraída de Freundt et al. (2000).

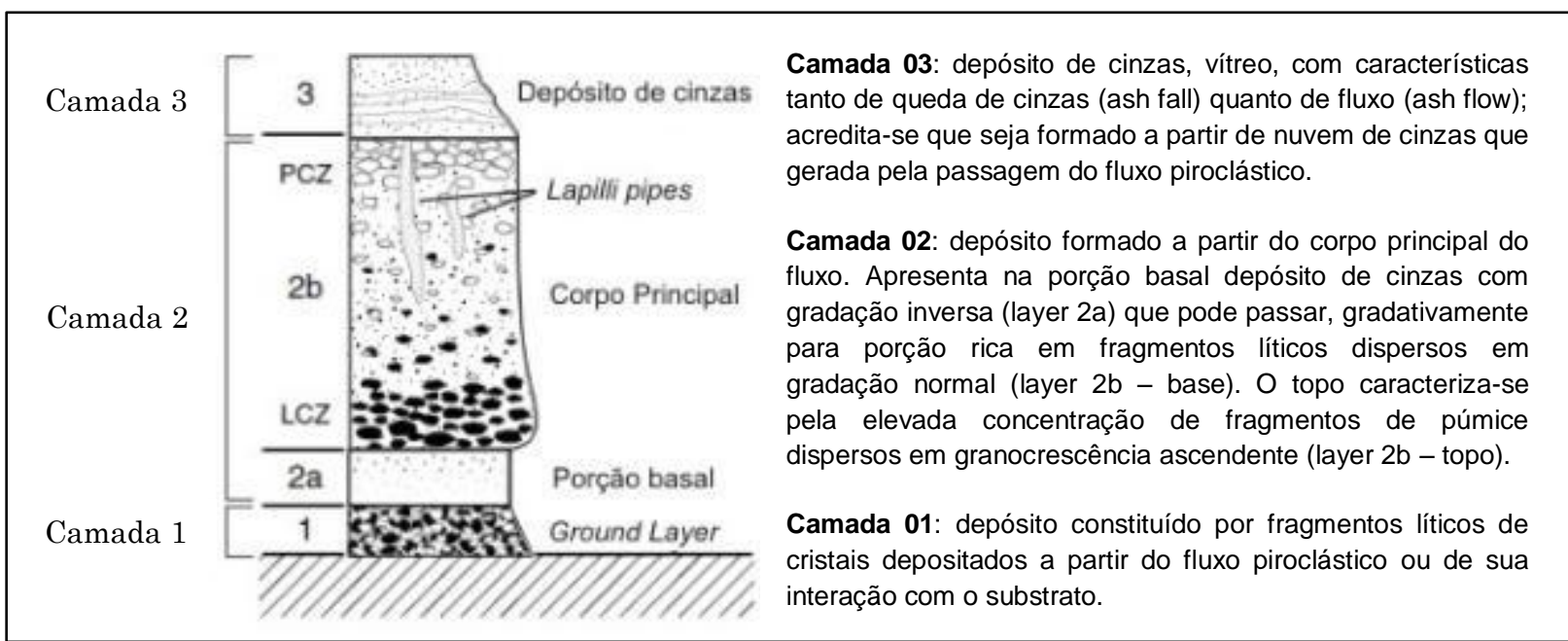

Figura 06: Representação idealizada de depósito de fluxo prioclástico (ignimbrito). A camada 2 pode apresentar uma variedade de estruturas de gradação, desde ausente até variações em zonas enriquecidas em fragmentos líticos e púmices. As partículas pretas representam os fragmentos líticos, as brancas representam púmices e os pontos representam fragmentos na fração cinza. 


\section{II.3. Soldamento}

Segundo Freundt et al., (2000), soldamento corresponde à "coesão, deformação e eventual coalescência dos piroclastos (vesiculados e vítreos) submetidos a elevadas temperaturas e sobrecargas".

O soldamento pode ser reconhecido, principalmente, através do achatamento e perda da porosidade dos piroclastos juvenis. Quanto maior a temperatura do fluxo no momento da deposição e menor a viscosidade do clasto a ser deformado, mais intenso será o soldamento e menor será a sobrecarga necessária.

O grau de soldamento é definido com base na densidade, isto é, na relação entre os eixos horizontal e vertical de fragmento juvenil ou mesmo de vesículas, podendo variar de 1:1 até 100:1, em casos de ignimbritos intensamente soldados (Freundt et al., 2000).

\section{II.4. Reoignimbritos}

Em alguns casos, os fluxos piroclásticos podem apresentar temperaturas suficientemente elevadas, a ponto de viabilizar a manutenção dos ignimbritos em estado plástico. Desta maneira, durante os processos de soldamento, os depósitos apresentarão uma fluidez secundária, que permite a formação de depósitos cuja reologia se assemelha à de lavas. Tais depósitos são denominados reoignimbritos ou depósitos "lava-like" (Best, 2002).

\section{II.5. Derrames de lavas}

Os derrames de lavas constituem a mais comum expressão do vulcanismo efusivo, podendo apresentar um amplo espectro composicional, sendo que as composições silicáticas são as mais típicas (com magmas a temperaturas da ordem de $800^{\circ} \mathrm{C}$ a $1200^{\circ} \mathrm{C}$ ). Distinguem-se de lava-domos por apresentarem uma maior mobilidade e consequente espalhamento ao longo do terreno, podendo estender-se por quilômetros e apresentar espessuras que podem atingir centenas de metros. 
Como consequência do desequilíbrio físico-químico causado pela ascensão do magma, a cristalização é um processo contemporâneo à efusão, resultando no aumento da viscosidade do fluxo conforme o avanço da lava.

Durante seu deslocamento em superfície, os fluxos de lava tendem a gerar, devido à formação de uma crosta de resfriamento, um tubo ou canal por onde o fluxo será canalizado. Os fluxos de lava são constantemente alimentados por novos derrames e, no caso de lavas com alta mobilidade, associadas a uma maior taxa de efusão e o escoamento em superfícies inclinadas, que permitem a canalização da lava, a crosta de resfriamento pode se fragmentar e gerar fluxos individualizados com estruturas brechadas (na base e no topo), como é o caso das lavas tipo aa ou lavas blocadas. Por outro lado, lavas de menor mobilidade, com menor taxa de efusão e escoamento em superfície aplainada, que apresentam um espalhamento lento, são capazes de manter sua crosta de resfriamento, gerando estruturas cordadas, como é o caso das lavas tipo pahoehoe.

\section{II.6. Lava-domos}

Segundo Fink \& Anderson (2000), as estruturas tipo lava-domo constituem feições topográficas positivas geradas a partir do acúmulo de magma viscoso que se resfria imediatamente após sua extrusão. Tais magmas apresentam, mais frequentemente, composições ricas em sílica, e sua elevada viscosidade garante uma baixa velocidade de dispersão. Com a baixa mobilidade associada às altas taxas de efusão (que, em casos extremos, atingem até $100 \mathrm{~m}^{3} / \mathrm{s}$ ), os domos podem apresentar diâmetros que variam de alguns metros até quilômetros, chegando a alcançar até $1 \mathrm{~km}$ de altura, com morfologia variada (circular, elipsoidal ou até mesmo tabular).

Os lava-domos podem ser classificados de acordo com seu modo de ocorrência e evolução. Quando um magma de alta viscosidade escoa de maneira lenta, formando uma carapaça vítrea devido ao resfriamento das porções externas e impedindo o extravasamento de novos fluxos de lava, o domo é então caracterizado como domo endógeno (Figura 07a). Nestes casos, devido à pressão exercida pelo acúmulo de lava, a carapaça se expande e se fragmenta, formando auto-brechas. A ocorrência de 
estrutura vesiculada também é comum nestes casos, devido à impossibilidade de escape dos voláteis através das porções externas já resfriadas (Best, 2002).

Magmas menos viscosos capazes de extrudir e fluir desprendendo-se formam estruturas lobadas denominadas coullés. O sucessivo empilhamento destas lavas dá origem ao chamado domo exógeno (Figura 07b). Por outro lado, quando o material fundido não extravasa e se acumula sob a superfície, o domo é denominado criptodomo (Best, 2002).
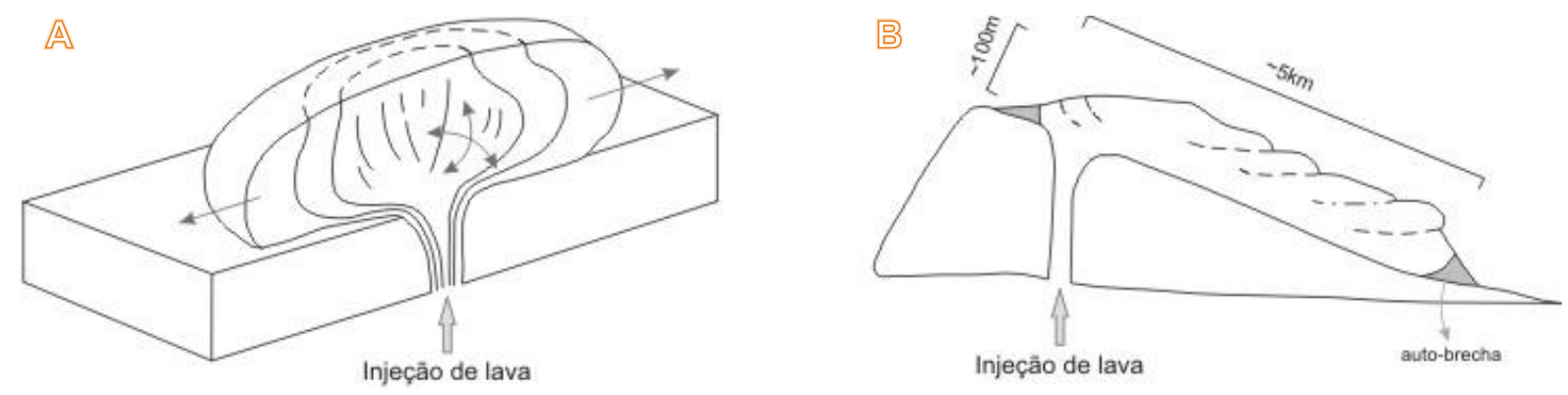

Figura 7: A) Modelo tridimensional de crescimento de domo endógeno (Richardson, 1978; adaptado por Polo, 2014). $\quad$ B) Modelo de lavas coulées formando domo exógeno (Branney et al. 2008; adaptado por Polo, 2014).

\section{II.7. Reoignimbritos versus lava-domos}

A ocorrência de extensos corpos vulcânicos de composição ácida causa discussões controversas a respeito de sua origem, sendo de difícil consenso entre os pesquisadores.

Segundo Manley (1995), é consenso para alguns autores, ao longo da história da vulcanologia, que magmas de composições ácidas, viscosos e enriquecidos em voláteis, devem constituir erupções explosivas, e a ausência de texturas vulcanoclásticas nos depósitos resultantes pode ser devida a soldamento a altas temperaturas, de modo que estes depósitos representariam reoignimbritos. Entretanto, muitos autores (e.g. Manley, 1995; Henry \& Wolff, 1992) reconhecem que tanto lavas como reoignimbritos podem apresentar diversas texturas e estruturas semelhantes, o que dificulta a classificação do depósito quanto à sua gênese. Deste modo, Henry \& Wolff (1992) 
propuseram critérios para distinção entre depósitos de reoignimbritos e extensos derrames de lavas (em condições ideais), apresentados a seguir:

a) base: como já exposto anteriormente, os derrames de lava apresentam resfriamento de sua superfície e, como consequência do fluxo constante, esta superfície tende a se fragmentar. Desta forma, os depósitos se caracterizarão por apresentar, no topo e na base, brechas constituídas por fragmentos de texturas variadas e mal selecionados. Por outro lado, nos depósitos piroclásticos, a deformação dos clastos juvenis tende a ocorrer após a deposição (Henry \& Wolff, 1992), de modo que o resfriamento da porção basal do depósito permite que ocorra a preservação das características piroclásticas.

b) margens: depósitos piroclásticos tendem a apresentar um afinamento nas porções distais dos depósitos, a menos que encontrem uma barreira topográfica onde poderão se acumular (Cas \& Wright, 1987 apud Henry \& Wolff, 1992). Em contraposição, os derrames de lava tendem a manter uma significativa espessura, com uma frente de fluxo íngreme e abrupta.

c) topografia pré-existente: os depósitos piroclásticos apresentam velocidades de centenas de $\mathrm{m} / \mathrm{s}$, permitindo-lhes superar barreiras topográficas. Já os derrames de lavas, lentos e viscosos, não são capazes de transpor barreiras topográficas, a menos que estas se apresentem menores que a espessura do fluxo.

d) fonte: este critério não pode ser tomado como inequívoco, uma vez que raramente é possível reconhecer a fonte precisa dos depósitos. Porém, de maneira geral, depósitos piroclásticos são associados a caldeiras e lavas são associadas a fissuras. Uma possível explicação para a escassa observação da fonte (ou edifício vulcânico) no caso dos derrames de lavas é que o próprio fluxo de lava poderá encobrir as fraturas alimentadoras.

Segundo Luchetti (2010), alguns autores (e.g. Henry \& Wolff, 1992; Bonnichsen \& Kauffman, 1987) consideram a presença de shards, púmices e fragmentos líticos (especialmente xenólitos provenientes do substrato deposicional) como característicos de depósitos piroclásticos. Porém, Henry \& Wolff (1992) apontam que depósitos de 
lavas também podem apresentar tais fragmentos, principalmente nas porções brechadas do topo e da base do depósito, em contrapartida à distribuição preferencialmente basal no caso dos ignimbritos.

Bonnichsen \& Kauffman (1987; apud Luchetti, 2010) apresentam outras características que seriam diagnósticas de fluxos de lavas, como: (a) ausência de cinzas provenientes de quedas (ash-fall) na base dos derrames; (b) contato irregular entre a zona basal vítrea e a zona central desvitrificada, sendo que a zona basal vítrea preserva evidências de fluxo, como por exemplo, dobras; (c) ausência de zoneamento composicional; (d) presença de grandes cavidades de gás (vesículas); (e) abundância de fenocristais euédricos, comumente orientados segundo o fluxo magmático.

Em contrapartida, Henry \& Wolff (1992) destacam que a morfologia dos fenocristais (euédricos no caso de lavas, e fraturados e/ou quebrados no caso de ignimbritos) pode ser uma evidência pouco confiável, uma vez que reoignimbritos são gerados a partir de vulcanismo caracterizado por elevadas temperaturas e baixo teor de voláteis, o que impede a ocorrência de erupções explosivas violentas, responsáveis pelo fraturamento dos cristais. Os mesmos autores mostram ainda que feições de rápido resfriamento (como terminações tipo "rabo-de-andorinha") só são possíveis a partir do resfriamento de lavas, constituindo assim boas evidências destes depósitos. 


\section{CAPITULO III - CARACTERIZAÇÃO DA ÁREA}

\section{III.1. Localização e acessos}

A área de estudos compreende a região dos municípios de Gramado Xavier e Barros Cassal, na porção centro-norte do estado do Rio Grande do Sul, distando, respectivamente, 204 e $256 \mathrm{~km}$ da capital Porto Alegre (Figura 08). O acesso, a partir da capital, pode ser feito através das rodovias BR-290 e BR386 , as quais se ligam à rodovia BR/RS-153/471. As cartas topográficas que cobrem a área correspondem as folhas SH.22-V-C-III-2 (folha Barros Cassal MI-2950/2) e SH.22-V-C-III-4 (folha Gramado Xavier - MI2950/4).

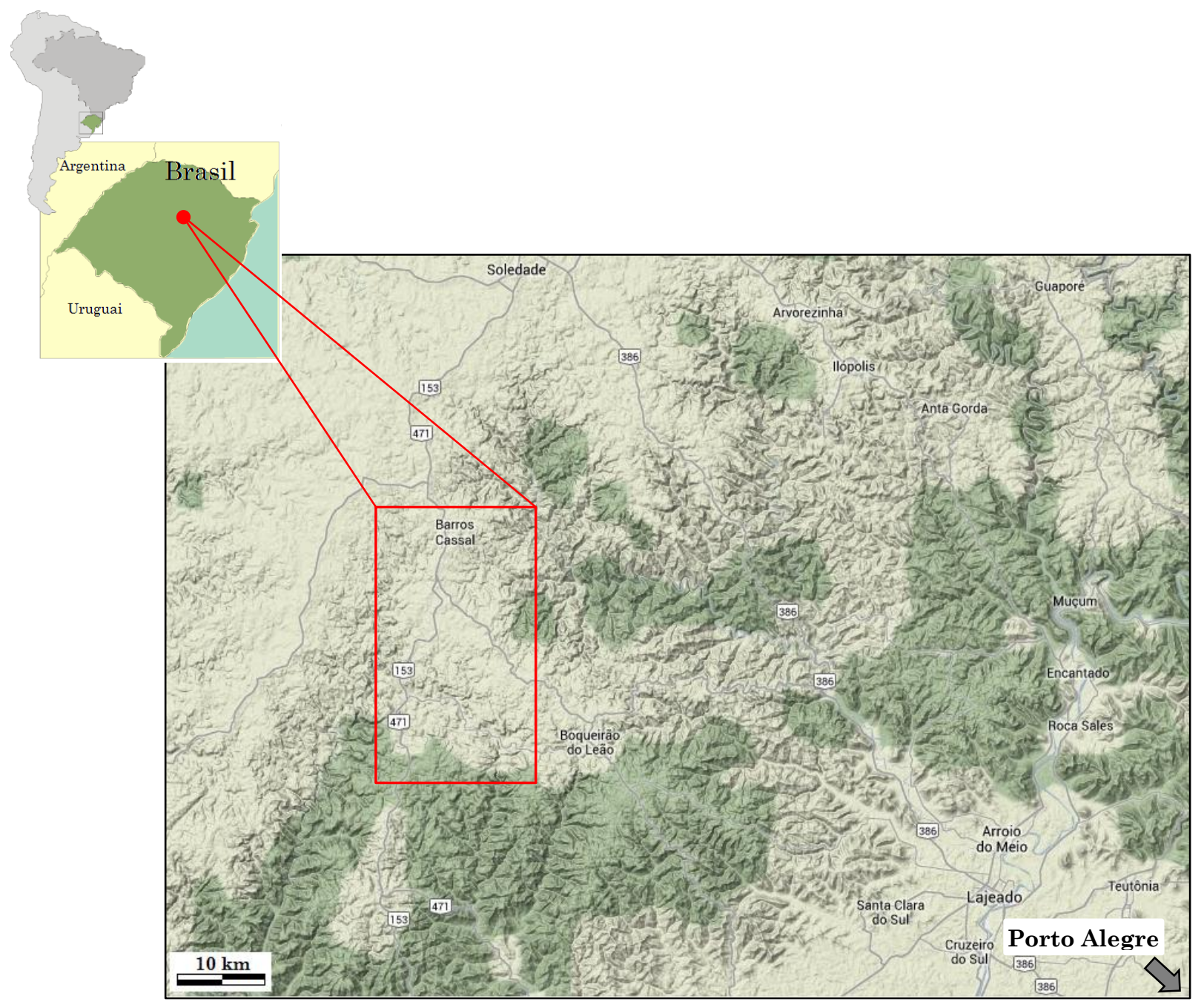

Figura 08: Localização da área de estudo, na porção central do estado do Rio Grande do Sul e principais vias de acesso. 


\section{III.2. Revisão bibliográfica}

O intenso vulcanismo associado aos processos de abertura do Oceano Atlântico Sul teve como um de seus principais produtos a geração da segunda maior província vulcânica continental do mundo, a Província Magmática Paraná (PMP), que compreende cerca de $600.000 \mathrm{~km}^{3}$ de rochas vulcânicas e sub-vulcânicas. Tal província estende-se pelos estados do centro-oeste e sul do Brasil - onde corresponde à Formação Serra Geral - e pelos países vizinhos como Paraguai, Uruguai e Argentina, atingindo espessuras que ultrapassam os $1500 \mathrm{~m}$ em sua porção central. Cerca de 90\% do volume total das rochas corresponde a basaltos toleíticos, $7 \%$ correspondem a rochas vulcânicas de composição intermediária e apenas $3 \%$ a rochas de composição ácida. Segundo Nardy (1996), os derrames basálticos caracterizam-se por espessuras variáveis entre 10 e $90 \mathrm{~m}$, formando sequências que podem atingir $1000 \mathrm{~m}$, enquanto as ocorrências de rochas vulcânicas ácidas apresentam espessuras de 20 a 80 m, formando sequências de até $400 \mathrm{~m}$.

Do ponto de vista estratigráfico as rochas vulcânicas da PMP encontramse, de maneira geral, sobrepostas diretamente sobre os arenitos da Formação Botucatu (Grupo São Bento), sendo recobertas por sedimentos cretáceos do Grupo Bauru. Do ponto de vista estratigráfico as rochas vulcânicas da PMP encontram-se, de maneira geral, sobrepostas diretamente sobre os arenitos da Formação Botucatu (Grupo São Bento), sendo recobertas por sedimentos cretáceos do Grupo Bauru. Além do significativo volume de rochas vulcânicas ocorre também grande volume de rochas sub-vulcânicas representadas por enxames de diques e sills, dentre os quais se destaca o Arco de Ponta Grossa, que se distribui de maneira subparalela aos lineamentos tectônicos Rio Piquiri (a norte) e Rio Uruguai (a sul), os quais apresentam direção NW-SE e dividem geograficamente a PMP em porção norte, porção central e porção sul.

Os critérios composicionais que classificam as rochas da PMP com base em seus teores de $\mathrm{TiO}_{2}$ foram definidos inicialmente por Bellieni et al. (1984a) e 
Mantovani et al. (1985) sendo que, sob este ponto de vista, as rochas basálticas de alto $\mathbf{T i}\left(\mathbf{T i O}_{2}>\mathbf{2 \%}\right)$ e ácidas associadas dominam as porções norte e central da província, apresentando composição relativamente enriquecida em elementos incompatíveis como $\mathrm{Ba}, \mathrm{La}, \mathrm{Ce}, \mathrm{Zr}$ e $\mathrm{Sr}$ e empobrecida em $\mathrm{Rb}$, Th e $\mathrm{U}$ em relação aos basaltos baixo $\mathbf{T i}\left(\mathbf{T i O}_{2}<\mathbf{2 \%}\right)$ e rochas ácidas associadas, dominantes da porção sul da província.

Petrograficamente, os basaltos podem ocorrer como lavas afaníticas a faneríticas finas, com coloração cinza a negra, e aspecto maciço ou vesiculado (Nardy 1996). Apresentam textura hialofítica a hipocristalina (Nardy 1996), sendo mineralogicamente compostos por plagioclásio, pigeonita, augita, Timagnetita e ilmenita (Bellieni et al. 1986). Segundo Belleini et al. (1986), os fenocristais podem representar até $10 \%$ do volume da rocha, sendo constituídos por plagioclásio (An 83-50), augita (Wo42-45), pigeonita (Wo12-7), Ti-magnetita e esporádicas olivinas.

As rochas vulcânicas intermediárias a ácidas ocorrem como corpos tabulares de grande extensão lateral, sendo verticalmente possível reconhecer texturas e estruturas que permitem a subdivisão destas rochas em: (a) domínio basal, marcado pela presença de diaclases horizontais e brechas epiclásticas; (b) domínio intermediário, caracterizado pela presença de vesículas e amigdalas, uma zona maciça com diaclases verticais e uma zona com bandamento ígneo; (c) domínio superior, onde se notam estruturas de fluxo, como bandamento ígneo, que pode apresentar dobras de fluxo, feições de resfriamento rápido e brechas autoclásticas (Nardy et al. 2008)

A classificação destas rochas, assim como a dos basaltos, tem sido feita com critérios geoquímicos. Foram reconhecidos dois grupos principais (Bellieni et al. 1984, 1986; Piccirillo et al. 1987), o Tipo Palmas (predominante na parte sul da PMP), com teores de $\mathrm{SiO}_{2}$ entre $64 \%$ e $72 \%$ e concentrações de $\mathrm{TiO}_{2}$ entre $\mathbf{0 , 5 7 \%}$ e $\mathbf{1 , 2 3 \%}$, e o Tipo Chapecó (predominante na parte norte da PMP), com teores de $\mathrm{SiO}_{2}$ de $64 \%$ a $68 \%$ e $0,95 \%$ a $1,59 \%$ de $\mathrm{TiO}_{2}$. Para um 
mesmo conteúdo de $\mathrm{SiO}_{2}$, as rochas tipo Chapecó apresentam maiores teores de álcalis, além de serem enriquecidas em $\mathrm{P}_{2} \mathrm{O}_{5}, \mathrm{Al}_{2} \mathrm{O}_{3}$ e $\mathrm{Fe}_{2} \mathrm{O}_{3}$ e empobrecidas em $\mathrm{CaO}$ e $\mathrm{MgO}$ em relação às rochas tipo Palmas. A Figura 09 mostra a distribuição geográfica das rochas vulcânicas ácidas da PMP, enquanto que os diagramas classificatórios para as rochas dos tipos Palmas e Chapecó são apresentados nas Figuras 10 e 11 (extraídas de Nardy et al. 2008). 


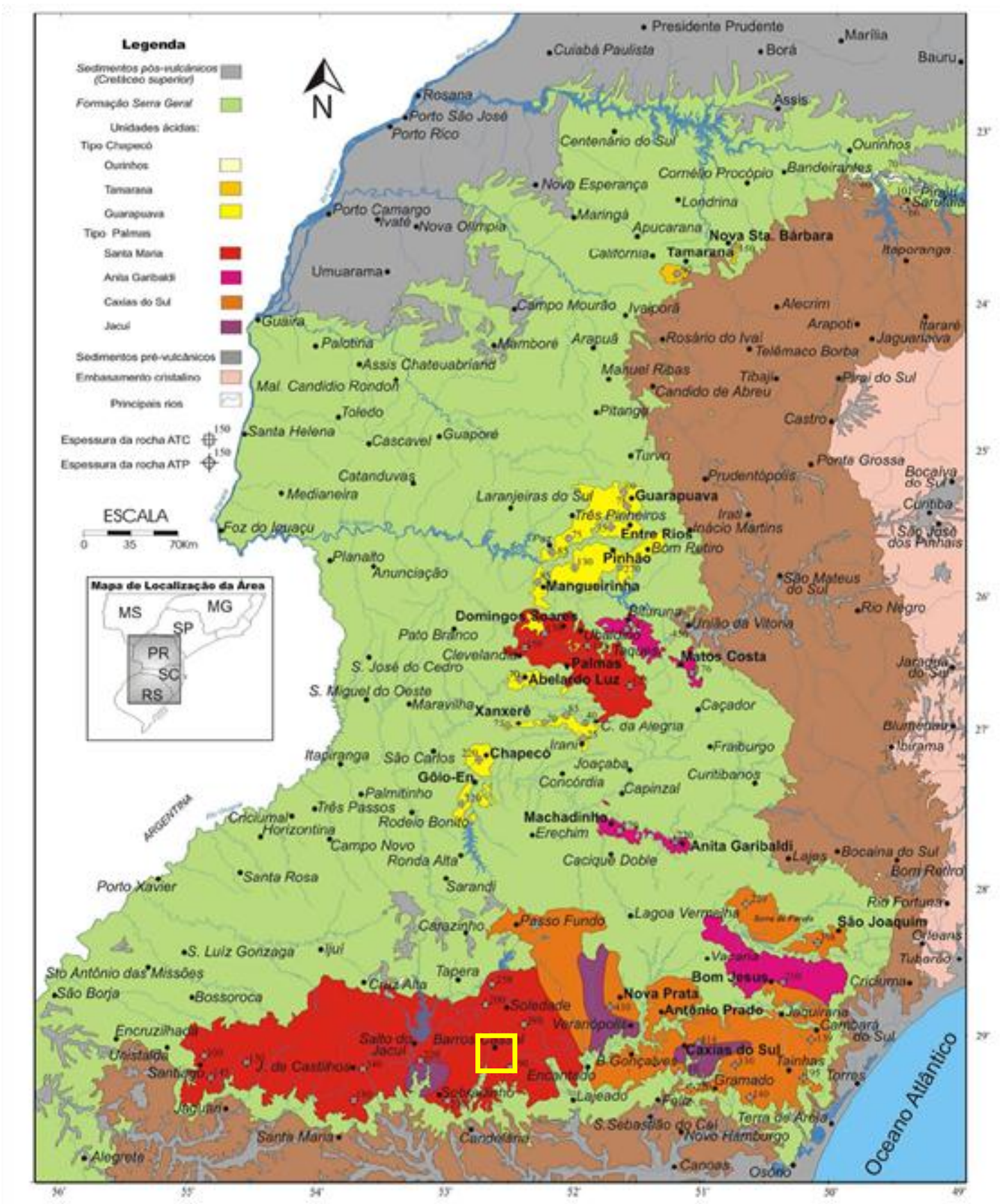

Figura 9: Mapa de distribuição das rochas vulcânicas da Bacia do Paraná, com ênfase nos diferentes tipos de rochas vulcânicas ácidas (extraído de Luchetti et al. 2005), com a localização aproximada da área de estudos (quadrado amarelo). 


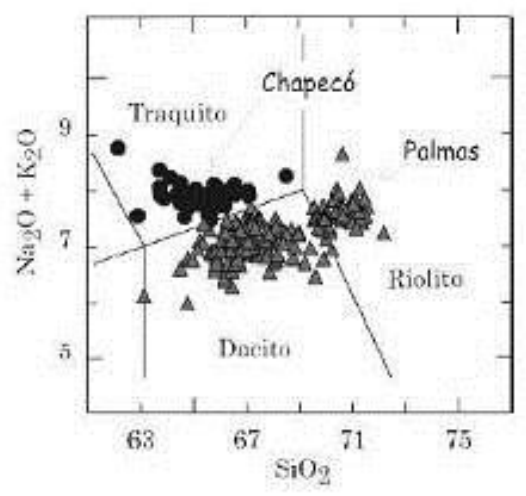

Figura 10: Classificação das rochas tipo Palmas (triângulos) e tipo Chapecó (círculos). Extraído de Nardy et al., 2008.
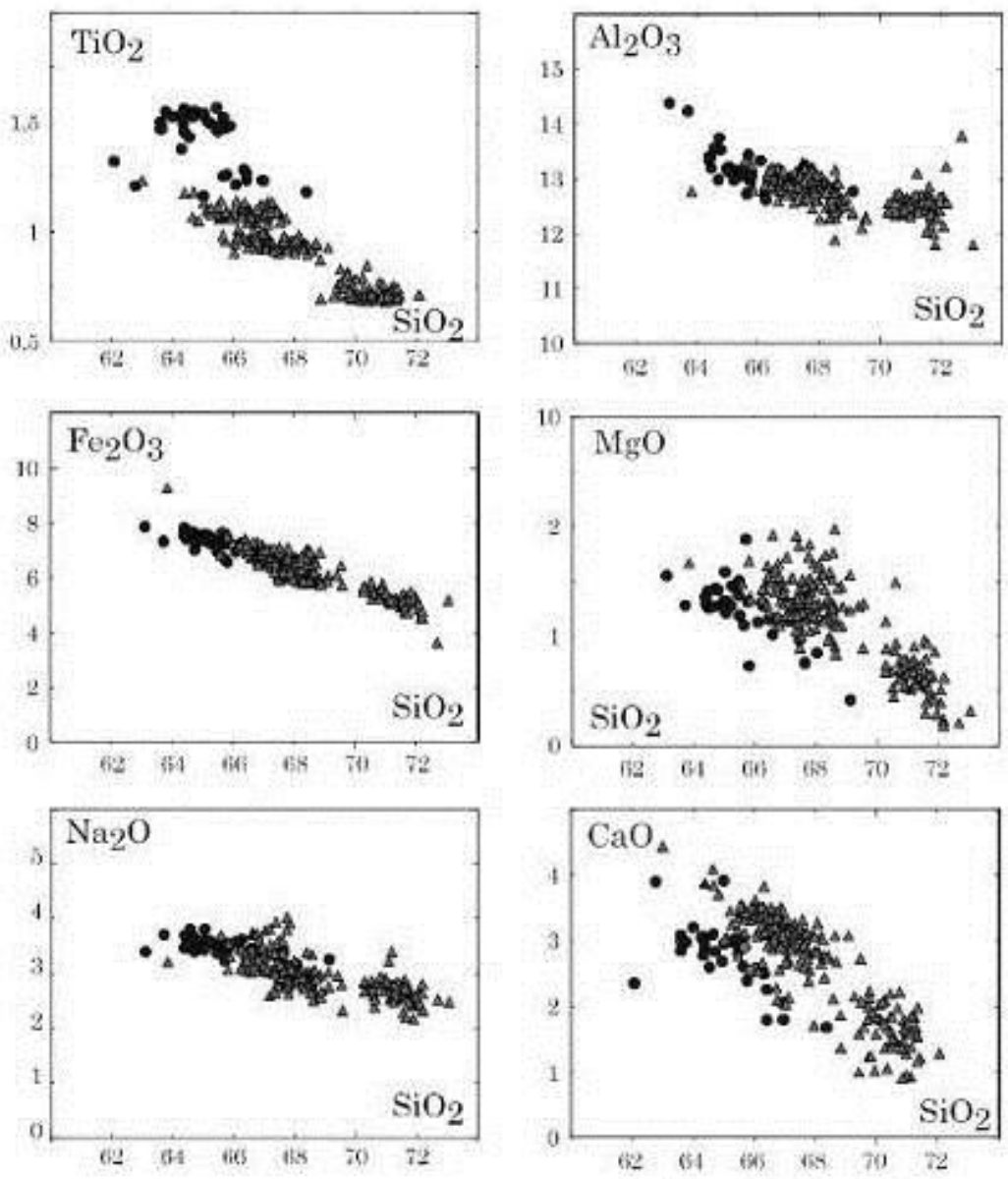

Figura 11: Diagramas de Harker para elementos maiores e menores das rochas vulcânicas ácidas tipo Palmas (triângulos) e Chapecó
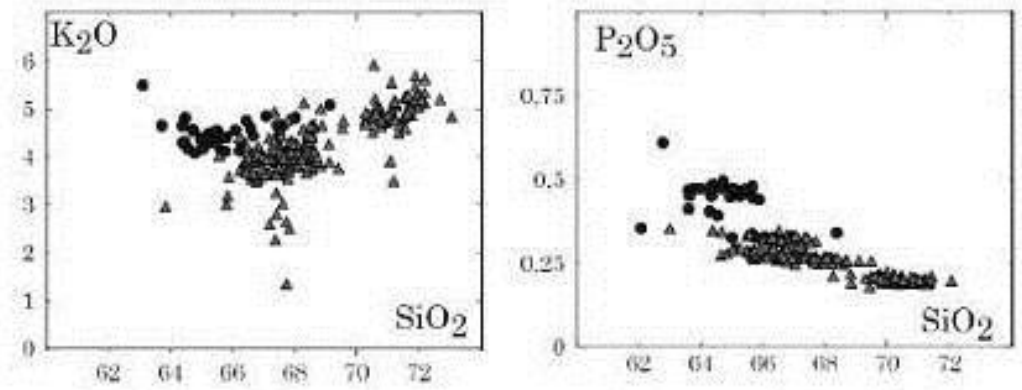
(círculos). Extraído de Nardy et al. (2008). 
As rochas do tipo Chapecó foram subdivididas por Garland et al. (1995) nos subtipos Ourinhos $\left(\mathrm{SiO}_{2} 65 \%\right.$ - 69\%) e Guarapuava $\left(\mathrm{SiO}_{2} 64,3 \%\right.$ - 66,3\%), sendo as rochas do primeiro subtipo empobrecidas em $\mathrm{Fe}_{2} \mathrm{O}_{3}, \mathrm{CaO}, \mathrm{TiO}_{2}, \mathrm{P}_{2} \mathrm{O}_{5}$ e $\mathrm{Zr}$, e enriquecidas em $\mathrm{Rb}$, $\mathrm{Pb}$ e Th em relação às do segundo subtipo. Tais subtipos correspondem à base da sequência basaltos alto Ti, e localmente podem se dispor diretamente sobre os arenitos da Formação Botucatu (Janasi et al. 2007; Piccirillo et al. 1987).

Nardy et al. (2008) definiram um novo subtipo, denominado Tamarana, o qual apresenta composição intermediária entre os subtipos Ourinhos e Guarapuava, e também ocorre na base da sequência de alto Ti.

As rochas do tipo Chapecó apresentam textura porfirítica, com matriz cristalina e, quando frescas, uma coloração cinza esverdeada. A matriz constitui-se de quartzo, feldspato alcalino ( Or $_{68-52}$ ), plagioclásio, piroxênio, Ti-magnetita e ilmenita (Bellieni et al. 1986). Imersos na matriz ocorrem fenocristais de até $5 \mathrm{~mm}$ (que podem chegar a $15 \%$ do volume total da rocha) de plagioclásio $\left(\mathrm{An}_{43-40}\right)$, augita $\left(\mathrm{Wo}_{32-37}\right)$, Ti-magnetita e apatita (Janasi et al. 2007b; Bellieni et al. 1986).

As rochas do tipo Palmas correspondem a $80 \%$ do volume das rochas ácidas (perfazendo 2,5\% do magmatismo da PMP) e ocorrem predominantemente nas porções meridionais da província, sob a forma de um extenso platô com direção E-W, estratigraficamente acima ou intercaladas aos basaltos de baixo Ti.. Apresentam ainda esparsas ocorrências na porção central da província, onde são sobrepostas pelas rochas do tipo Chapecó. De maneira geral, com base nas variações geoquímicas apresentadas, tais rochas são subdivididas em dois grupos (Nardy et al. 2008):

a) Riolitos: rochas com teores de $\mathrm{SiO}_{2}$ de $69,5 \%$ a 70,3\% e $\mathrm{TiO}_{2}<0,9 \%$, separadas nos subtipos Santa Maria e Clevelândia;

b) Dacitos: rochas com teores de $\mathrm{SiO}_{2}$ entre $63,8 \%$ e $69,5 \%$ e $\mathrm{TiO}_{2}>0,9 \%$, agrupadas nos subtipos Caxias do Sul, Anita Garibaldi e Jacuí.

Petrograficamente, as rochas tipo Palmas apresentam coloração acinzentada quando frescas e cinza amarelada quando alteradas. Tipicamente são afíricas e hipohialinas, com matriz granofírica resultante de processos de devitrificação, onde ocorre intercrescimento de quartzo com feldspato alcalino. Quando holohialinas, as rochas apresentam coloração escura (negra) e fraturas conchoidais. São bastante susceptíveis ao 
intemperismo (passam a apresentar coloração acastanhada), e podem conter vesículas e amigdalas de até $10 \mathrm{~mm}$. Fenocristais de plagioclásio $\left(\mathrm{An}_{59-51}\right)$, augita $\left(\mathrm{Wo}_{37-32}\right)$, pigeonita $\left(\mathrm{Wo}_{9,0}\right)$, ortopiroxênio $\left(\mathrm{Wo}_{3,8-3,5} ; \mathrm{En}_{62-59}\right)$ e Ti-magnetita podem estar presentes, constituindo até 3-5\% do volume da rocha e com tamanho que raramente excede 0,2 mm (Nardy et al. 2008; Bellieni et al. 1986).

\section{III.2.1. BREVE HISTÓRICO DOS ESTUDOS GEOCRONOLÓGICOS}

Mantovani et al. (1985b) obtiveram para rochas vulcânicas da Província Magmática Paraná idades K-Ar em plagioclásio entre 123,8 e 129,9 Ma e obtiveram uma isócrona Rb-Sr de 133-134 \pm 6 Ma. Rocha Campos et al. (1988) apresentaram uma compilação dos dados existentes até a época e sugeriram, com base em datações K-Ar, que a atividade magmática abrangeu o período de $138 \mathrm{Ma}$ a $115 \mathrm{Ma}$.

Já nos anos 1990, com o desenvolvimento da tecnologia de datação ${ }^{40} \mathrm{Ar} /{ }^{39} \mathrm{Ar}$, esta metodologia foi largamente empregada nas rochas da PMP. Renne et al. (1992) e Hawkesworth et al. (1992) propuseram uma atividade vulcânica num curto período de 1 Ma, com idades da ordem de $133 \pm 1$ Ma. Em contrapartida, outros autores (Turner et al., 1994; Stewart et al., 1996) sugeriram um período maior para o vulcanismo, de aproximadamente $10 \mathrm{Ma}$, com idades entre 138 e $127 \mathrm{Ma}$, com base em datações ${ }^{40} \mathrm{Ar} /{ }^{39} \mathrm{Ar}$ pelo método de fusão total .

Os trabalhos recentes de Thiede \& Vasconcelos (2008) reanalisaram três amostras datadas previamente pela metodologia ${ }^{40} \mathrm{Ar} /{ }^{39} \mathrm{Ar}$ por fusão total e constataram que as idades obtidas por Turner et al. (1994) e Stewart et al, (1996) forneciam resultados imprecisos. Deste modo, apenas idades ${ }^{40} \mathrm{Ar} /{ }^{39} \mathrm{Ar}$ obtidas pelo método "stepped heating" são atualmente consideradas confiáveis, e estas se resumem a pouco mais de uma dezena de determinações para as ocorrências efusivas em território brasileiro, um número muito pequeno dada a extensão da província. Mais recentemente, foram obtidos, pela primeira vez, 
dados geocronológicos U-Pb em zircão e badeleíta, uma técnica robusta e que permite obter precisão adequada para identificar variações temporais na província, especialmente pelo método TIMS. Janasi et al. (2011), com base nas datações U-Pb TIMS em zircão e baddeleíta dos dacitos tipo Chapecó, indicam que o magmatismo destas rochas iniciou-se a 134,3 \pm 0,8 Ma, sugerindo ainda um período de $\sim 3$ Ma para a colocação dos magmas ácidos alto-Ti. Pinto et al. (2011) obtiveram em datações U-Pb em zircão por SHRIMP, que geralmente não alcança a mesma precisão, e obtiveram idades de $135 \pm 2,3$ e $137,3 \pm 1,8$ Ma para dacitos tipo Chapecó.

\section{III.2.2. GÊNESE, PROCESSOS EVOLUTIVOS E ESTILO ERUPTIVO DAS ROCHAS VULCÂNICAS ÁCIDAS DA PMP}

A origem e evolução dos magmas ácidos que constituem a PMP - seus magmas parentais, os processos geradores e de colocação - ainda é tema muito controverso na literatura. As características petrográficas, químicas e isotópicas dos vários tipos de magma são em muitos casos admitidas como consequência de diferentes processos evolutivos (e.g. Bellieni et al. 1986; Garland et al. 1995).

A respeito das rochas vulcânicas ácidas do tipo Palmas, alguns autores (e.g. Mantovani et al. 1985; Peate, 1997) consideram a origem associada a processos de cristalização fracionada dos basaltos de baixo Ti em sistema aberto, apontando para provável influência de contaminação crustal devido à assimilação de fusões parciais geradas na crosta média/superior. Outros autores (e.g. Cordani et al. 1980; Hawkesworth et al. 1988; Harris et al. 1990; Bellieni et al., 1986), com base em dados isotópicos $\left({ }^{87} \mathrm{Sr} /{ }^{86} \mathrm{Sr}\right.$ e $\left.\delta^{18} \mathrm{O}\right)$, sugerem que a gênese das rochas ácidas da PMPE pode estar relacionada a processos de anatexia crustal, como consequência do afinamento litosférico e quebra continental. Já as rochas vulcânicas do tipo Chapecó são em geral consideradas de origem distinta, por refusão de "underplates" básicos na crosta inferior, 
tendo em vista sua correlação geoquímica e isotópica com os basaltos de alto Ti (Bellieni et al., 1986; Garland et al., 1995).

Em contraposição aos abundantes trabalhos de geoquímica, isotópica e geocronologia, são raros os trabalhos que tentam compreender o caráter eruptivo das rochas ácidas através de estudos vulcanológicos.

Os estudos mais difundidos consideram uma origem explosiva para as rochas vulcânicas ácidas da PMPE, sendo a ausência de feições piroclásticas salvo aquelas raras apresentadas por Milner et al. (1992) em depósitos localizados em Etendeka, NW da Namíbia - justificada pelas elevadas taxas de soldamento, consequência das altas temperaturas estimadas.

Seguindo nesta linha, os trabalhos de Milner e Ewart (1989; apud Milner et al. 1992) apresentam a hipótese de que a cratera Messum, localizada em Etendeka, seria o centro eruptivo responsável pela explosão originadora de tais depósitos, e Bryan et al. (2010) definem diferentes fluxos piroclásticos que seriam resultantes de eventos eruptivos de grande magnitude, delimitando áreas de distribuição de tais depósitos a partir de correlações feitas entre as rochas aflorantes em Etendeka e na Bacia do Paraná (Figura 12).
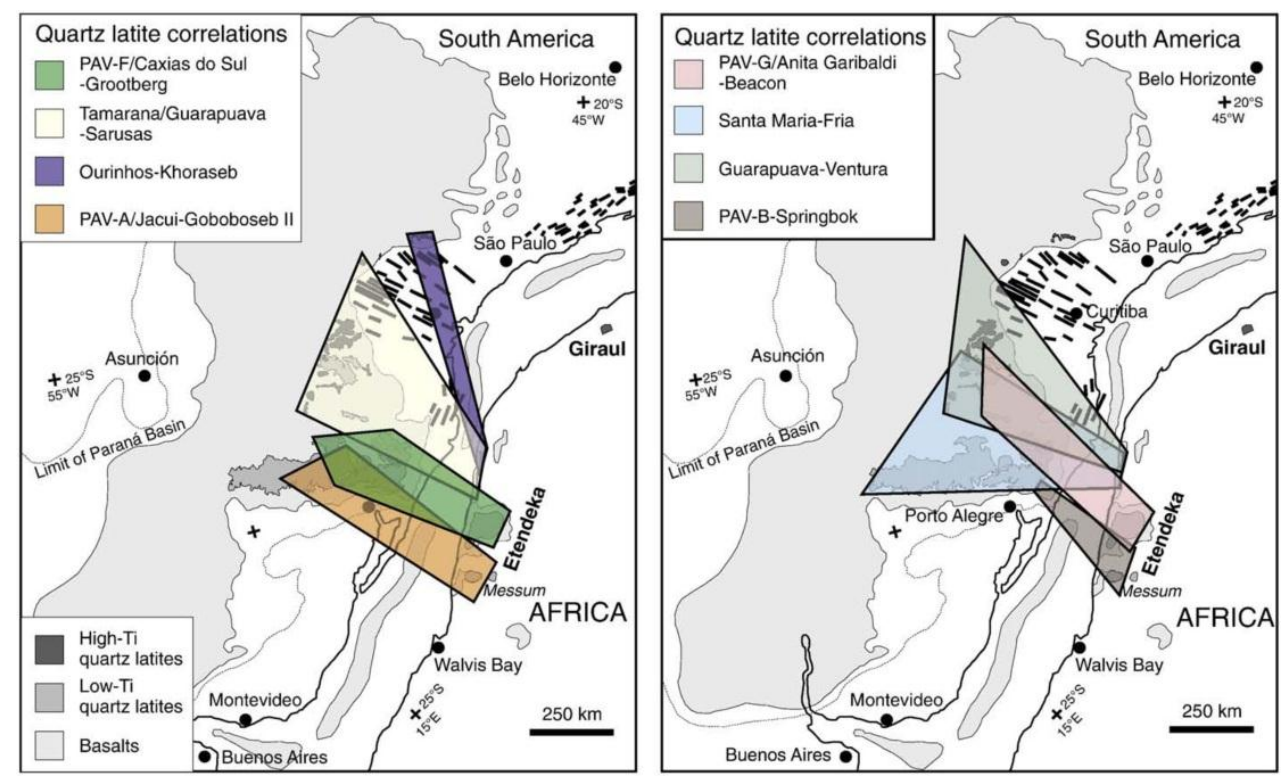

Figura 12: Polígonos representativos das áreas mínimas de distribuição dos distintos fluxos piroclásticos resultantes de eventos eruptivos de grande magnitude na região de Etendeka. Extraído de Bryan et al. (2010). 
Em contrapartida, estudos recentes realizados nas ocorrências localizadas em território brasileiro (e.g. Janasi et al., 2007; Luchetti, 2010; Guimarães, 2011; Nardy et al., 2011; Lima et al., 2012) têm evidenciado que as rochas ácidas da PMP apresentam características atípicas para rochas semelhantes, como por exemplo temperaturas da ordem de $1000^{\circ} \mathrm{C}-$ valores elevados considerando-se magmas riolíticos, o que poderia justificar uma erupção não explosiva. Lima et al. (2012) sugerem que o vulcanismo ácido pode ter extravasado a partir de fontes eruptivas localizadas na porção brasileira da província e descrevem feições indicativas de diques alimentadores, com foliação magmática vertical a sub-vertical, com dobras de fluxo, que passam progressivamente para uma foliação sub-horizontal. Outros autores (e.g. Polo, 2010; Guimarães, 2011 e Polo \& Janasi, 2014) descrevem feições indicativas de lava-domos e fluxos lobados associados, estruturas condizentes com uma ocorrência vulcânica de elevadas temperaturas.

\section{III.2.3. AS ROCHAS VULCÂNICAS ÁCIDAS NA REGIÃO SUL DA PMP}

Estudos recentes têm revisado a estratigrafia da PMP, definindo em mapeamentos de detalhe as diferentes unidades básicas e ácidas que compõem as sequências vulcânicas da região. Waichel et al. (2011) definem na porção sul da PMP, na Sinclinal de Torres, uma sequência que envolve: a) derrames basálticos pahoehoe recobrindo os arenitos da Fm. Botucatu; b) derrames basálticos compostos por fluxos simples, de arquitetura tabular; c) derrames ácidos compostos por fluxos lobados, com arquitetura de lava-domos; d) derrames basálticos tipo 'a'ā e rubbly com arquitetura tabular a lobada, escoriácea; e) derrames ácidos de arquitetura tabular. Os autores destacam ainda que a ausência de paleossolos entre os derrames seria indicativa do curto período de colocação destas lavas. 
Polo \& Janasi (2014) apresentam o primeiro mapa de detalhe para o vulcanismo ácido no platô do Rio Grande do Sul (Figura 13), na região dos municípios de Soledade, Barros Cassal e Gramado Xavier, definindo a estratigrafia em três sequências vulcânicas intermediárias a ácidas denominadas, da base para o topo, Caxias do Sul, Barros Cassal e Santa Maria, as quais se sobrepõem a sequências de basaltos do tipo Gramado, e entre as quais se intercalam depósitos sedimentares. A ocorrência de tais depósitos sedimentares caracteriza um importante marcador estratigráfico, indicativo da existência de um intervalo temporal entre a colocação dos magmas.

\section{III.2.3.1. Unidades pré-Santa Maria na área de estudos}

A unidade Caxias do Sul, representada por dacitos com teores de $\mathrm{SiO}_{2}$ entre $68 \%$ e $69,6 \%$, e $\mathrm{TiO}_{2}$ em torno de $0,90 \%$, compõe-se de diversos fluxos magmáticos que têm espessura de até 140 metros no domínio sul da área de estudos. Polo (2010) com base nas características físicas apresentadas, divide esta unidade em 3 fácies: a) Fácies Cinza: rocha de coloração acinzentada, afanítica a fanerítica muito fina, pouco vesiculada, maciça ou com bandamento ígneo e intensa disjunção de resfriamento; b) Fácies Obsidiana: rocha holohialina (obsidiana), maciça, de coloração escura; c) Fácies Vesiculada: rocha de coloração avermelhada, afanítica, intensamente vesiculada - vesículas milimétricas a centimétricas, arredondadas ou estiradas, associadas a estruturas de fluxo magmático, comumente preenchidas por calcedônia e calcita. Estruturalmente, esta unidade caracteriza-se por apresentar frequentes estruturas de fluxo magmático, como bandamento ígneo e dobras de fluxo, além da ocorrência de lobos e complexos de lava-domos - estruturas dômicas circulares, com dimensões da ordem de 8 metros de altura e 30 metros de largura, com disjunções verticais na porção central e esféricas nas porções externas (Polo, 2010; Polo \& Janasi, 2014). 


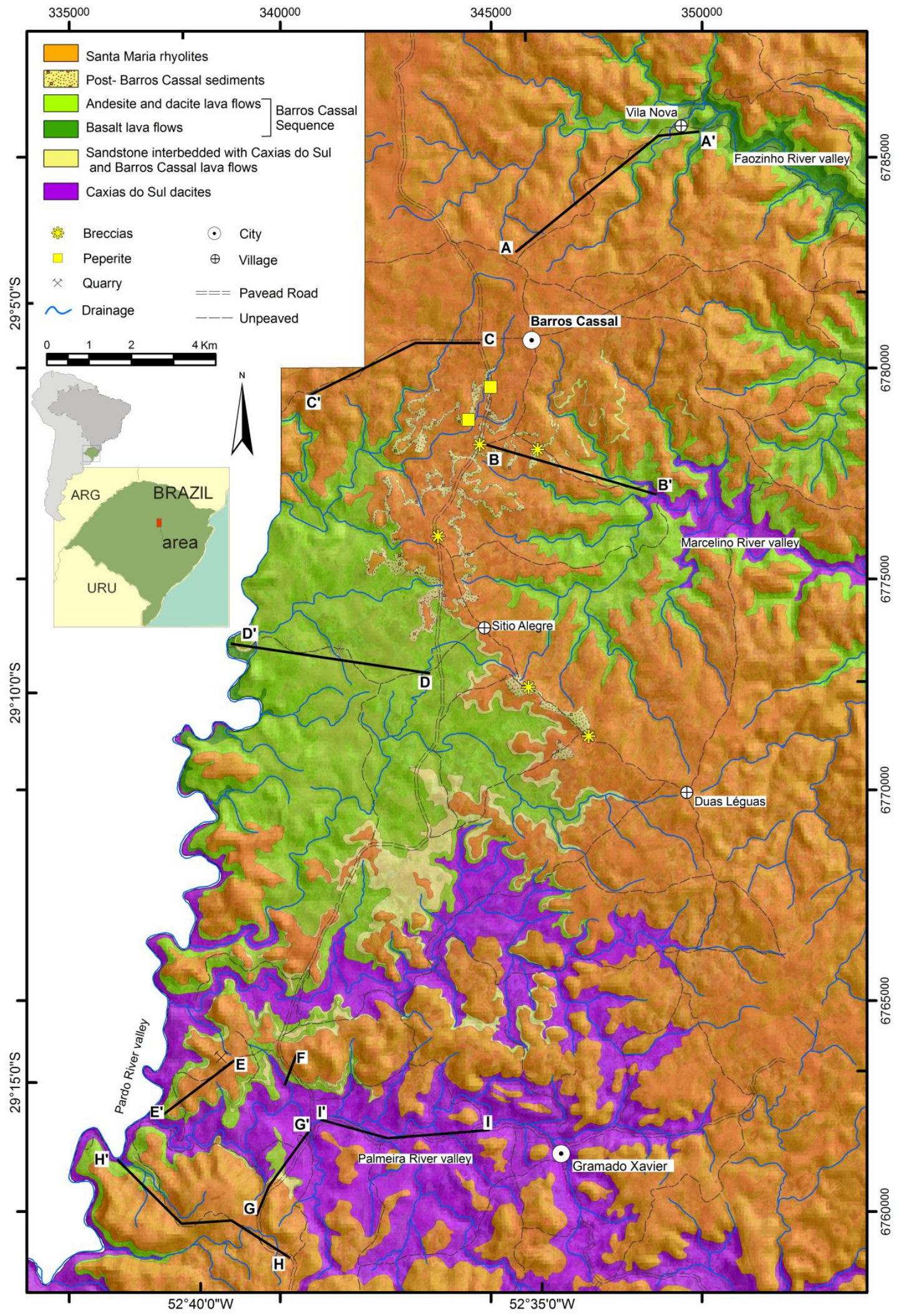

Figura 13: Mapa geológico da área de estudos, abrangendo os municípios de Barros Cassal e Gramado Xavier. Extraído de Polo \& Janasi (2014). 
A sequência vulcânica Barros Cassal, segundo Polo \& Janasi (2014), compreende basaltos que ocorrem como fluxos maciços ("sheet lavas") ou lobados e vesiculados com carapaça vítrea no topo (caracterizando fluxos pahoehoe), que são recobertos por andesitos que afloram como uma rocha vítrea de coloração preta a esverdeada (quando alterada), formando derrames de lavas de até $3 \mathrm{~m}$ de espessura, e por dacitos que afloram como fluxos de lava de até $5 \mathrm{~m}$ de espessura, apresentando-se comumente como rocha vítrea (obsidiana). Depósitos sedimentares e estruturas de interação entre estes depósitos e os derrames de lava (como diques clásticos) são comuns entre as diferentes unidades desta sequência, assim como estruturas magmáticas como dobras de fluxo.

\section{III.2.3.2. Unidade Santa Maria}

A unidade Santa Maria, alvo de estudos deste projeto de pesquisa, corresponde a um espesso pacote riolítico, da ordem de 200 metros de espessura, que se estende por uma vasta área recobrindo as demais unidades.

Assim como a unidade Caxias do Sul, a unidade Santa Maria apresenta variações faciológicas que podem ocorrer em um mesmo derrame ou compondo, individualmente, diferentes corpos ígneos:

a) A fácies bandada caracteriza-se por uma rocha de coloração avermelhada, afanítica a fanerítica fina, comumente apresentando esferulitos de até $1 \mathrm{~mm}$ e bandamento ígneo com fraturamento horizontal associado. Localmente este fraturamento horizontal dá lugar a um intenso fraturamento vertical, gerado pelo resfriamento do corpo ígneo.

b) A fácies maciça é representada por uma rocha de coloração acinzentada, maciça, afanítica a fanerítica fina, com esferulitos milimétricos de coloração esbranquiçada e disjunções de resfriamento - fraturamentos 
verticais. Tanto a fácies bandada quanto a fácies maciça foram classificadas como cristalinas.

c) A fácies obsidiana caracteriza-se por rocha vítrea, de coloração escura (preta), maciça ou localmente bandada, que pode ser marcada, nestes casos, por dobramentos em escala centimétrica. Nesta fácies ocorrem também fraturas de resfriamento.

Estruturas de interação com sedimentos inconsolidados, como peperitos, e brechas (auto-brechas e brechas de fluxo magmático) são comuns na porção basal desta sequência. Ocorrem também feições dômicas e lobulares, além de dobras de fluxo magmático, que serão melhor detalhadas nos itens subsequentes. 


\section{CAPITULO IV - ASPECTOS GEOLÓGICOS E ESTRUTURAIS DOS RIOLITOS SANTA MARIA}

\section{IV.1. Caracterização estrutural a partir de levantamentos de campo}

O termo estrutura refere-se ao arranjo dos componentes de uma rocha, independentemente de sua composição, em escala tanto macro, quanto microscópica. No caso das rochas ígneas, em especial no caso das rochas vulcânicas, as estruturas são um retrato das condições que caracterizam o modo de erupção e colocação das lavas, tornando-se um importante indicador da dinâmica desses magmas. Neste item estão descritas as principais estruturas observadas na unidade Santa Maria.

\section{IV.1.1. BANDAMENTO DE FLUXO E ESTRUTURAS ASSOCIADAS VS ESTRUTURA MACIÇA}

As rochas da unidade Santa Maria podem apresentar tanto estrutura maciça, quanto estrutura bandada, sendo estas características condicionadas principalmente pela localização no corpo vulcânico.

Estruturas bandadas são mais frequentes nas bordas dos corpos vulcânicos, principalmente na sua base, onde o calor do magma é preservado devido à espessura do derrame e o resfriamento se dá de maneira mais lenta em relação ao topo.

O bandamento caracteriza-se pela alternância de bandas milimétricas de coloração clara (acinzentada) e escura (preta ou avermelhada quando alterada) - Figura 14, destacando-se pela orientação de microcristais quando a rocha se apresenta mais cristalina. $O$ fraturamento pode estar associado ao bandamento, apresentando-se ora mais ora menos espaçado (o espaçamento tende a ficar mais espaçado em direção ao centro do corpo vulcânico). Foi observado que este tipo de fraturamento tende a acompanhar a morfologia do 
corpo vulcânico e do bandamento, podendo apresentar variações de atitude mesmo em escala de afloramento, indicando que a formação destas estruturas pode ser resultado de cisalhamento durante a movimentação de um magma relativamente viscoso.

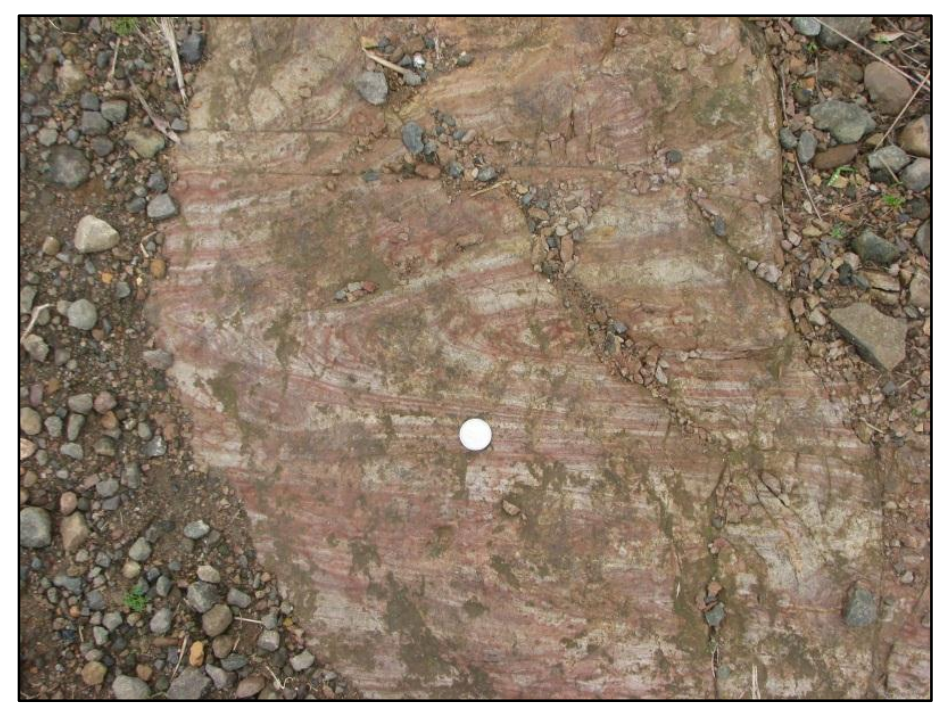

Figura 14: Afloramento GX-123. Rocha de coloração avermelhada e estrutura caracterizada por bandamento ígneo onde observa-se alternância entre bandas de coloração esbranquiçada e bandas de coloração avermelhada. Nota-se que o bandamento magmático apresenta-se dobrado.

Outra estrutura associada ao bandamento são as dobras de fluxo magmático (Figura 15), que podem apresentar-se tanto abertas, com suaves ondu-
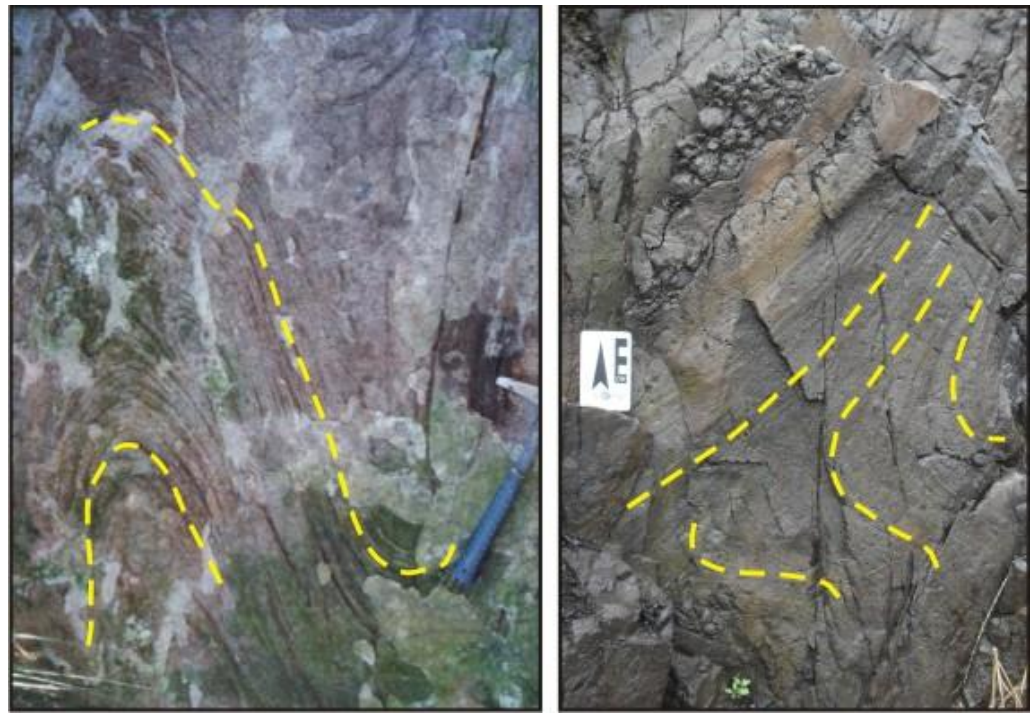

Figura 15: Rocha cristalina (à esquerda) e rocha vítrea (à direita) caracterizadas por bandamento afetado por dobramentos de fluxo magmático. lações; como fechadas, nestes casos com pequenas magnitudes (escala centimétrica). A deformação que afeta o bandamento evidencia a movimentação de um magma de viscosidade relativamente baixa (quando comparada à viscosidade típica de um magma riolítico). Por 
outro lado, estruturas maciças são mais comuns nos núcleos dos corpos vulcânicos, principalmente quando estes se apresentam espessos.

\section{IV.1.2. INTERCALAÇÃO ENTRE A FÁCIES CRISTALINA E A FÁCIES OBSIDIANA}

Localmente observou-se a intercalação das fácies cristalinas e da fácies obsidiana em escala de afloramento. A intercalação consiste em uma faixa com menos de 1 metro de espessura onde ocorre alternância entre bandas centimétricas a decimétricas de rocha cristalina (de coloração acinzentada) e de rocha vítrea (obsidiana de coloração preta), Figura 16.
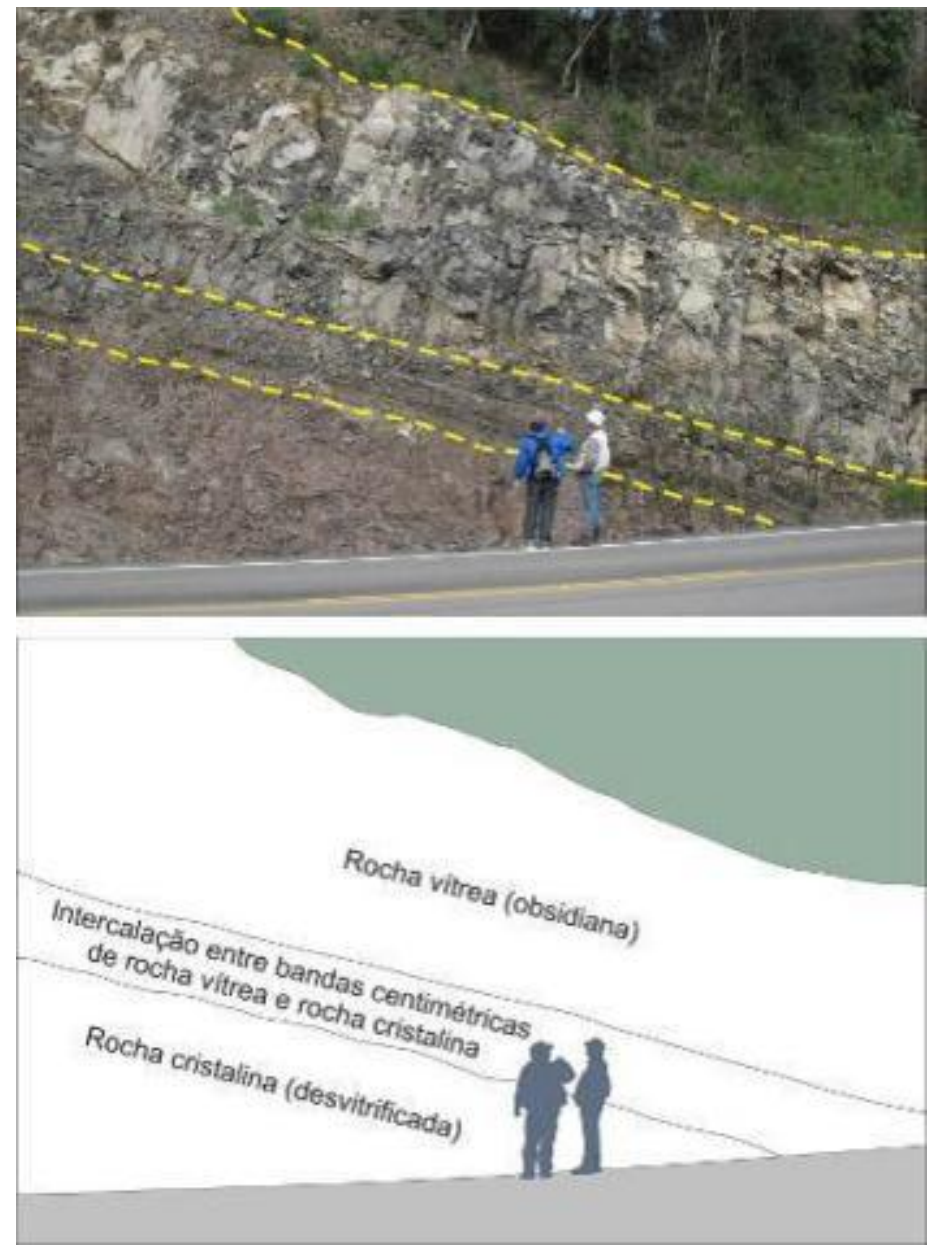

Figura 16: Afloramento RS-74. A porção inferior do afloramento constitui-se de rocha de rocha cristalina de coloração avermelhada, marcada por bandamento magmático com fraturamento associado. A porção superior constitui-se de rocha vítrea (obsidiana) com padrão de disjunção vertical sobreposto a fraturamento paralelo ao bandamento. A porção intermediária caracteriza-se pela alternância entre bandas centimétricas a decimétricas das duas variedades. 


\section{IV.1.3. ESTRUTURAS LOBADAS}

As estruturas lobadas têm geometria concêntrica, elipsoidal, em escala métrica, podendo atingir $5 \mathrm{~m}$ de altura, cuja morfologia é indicativa de fluxo de lava confinado devido ao resfriamento das porções externas.

De maneira geral, estas estruturas apresentam borda de resfriamento vítrea (obsidiana), maciça e vesiculada, com uma porção interna intensamente alterada para um material argiloso de coloração variada (avermelhada, esverdeada), porém ainda preservando feições indicativas de fluxo magmático (foliação associada ao fluxo, como descrito no item II.1.1) - Figura 17. A preservação de tais estruturas e ausência de uma zona maciça deve-se provavelmente às pequenas dimensões do corpo vulcânico.

A presença de vesículas estiradas, em forma de gota (Figuras 46 e 47), tanto na porção externa quanto na porção interna da estrutura, são importantes feições indicativas da movimentação da lava em superfície.

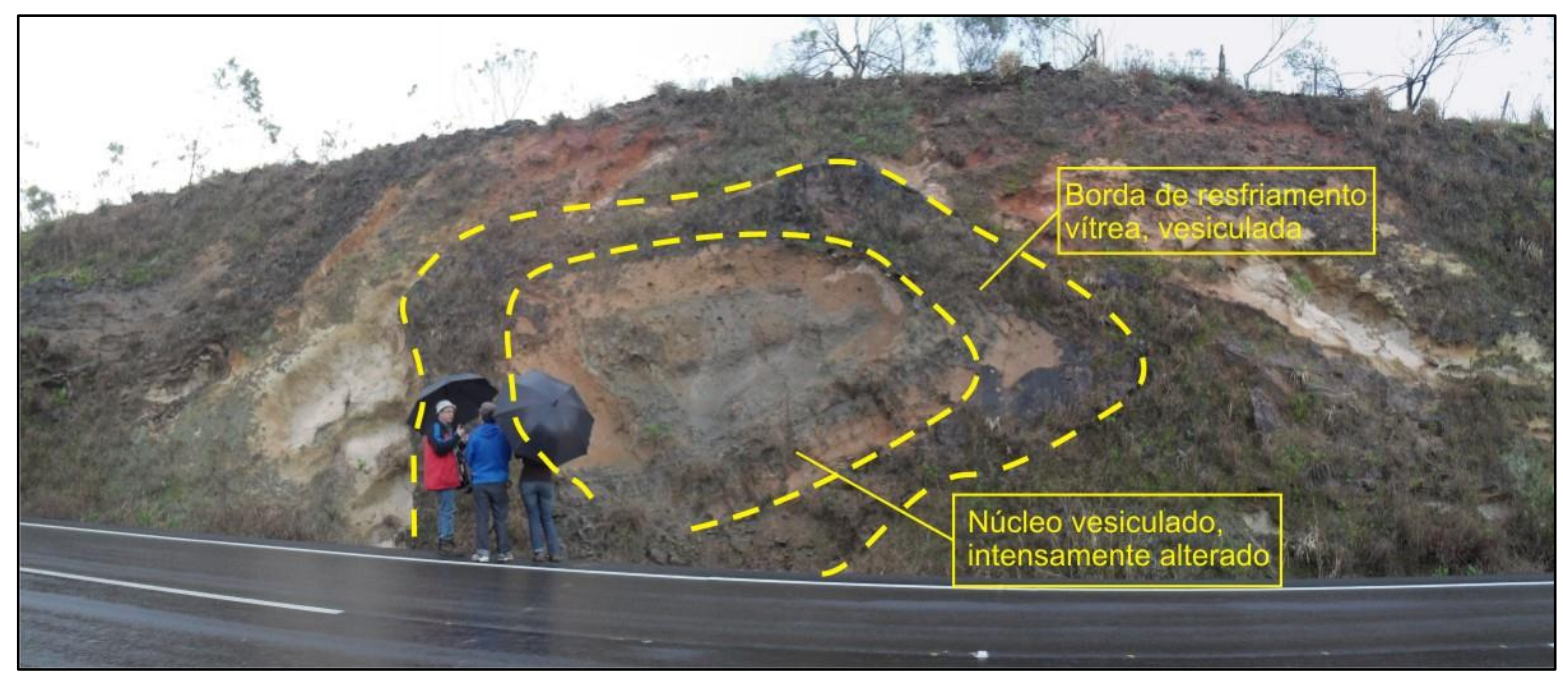

Figura 17: Afloramento GX-140. Destaque para estrutura lobada, com borda de resfriamento vítrea, vesiculada, e núcleo intensamente alterado, também vesiculado e preservando feições de fluxo magmático. 


\section{As estruturas lobadas observadas encontram-se geograficamente} adjacentes a lineamentos de pequenos morros de geometria circular, possivelmente reliquiares de estruturas dômicas (Figuras 18 e 19).

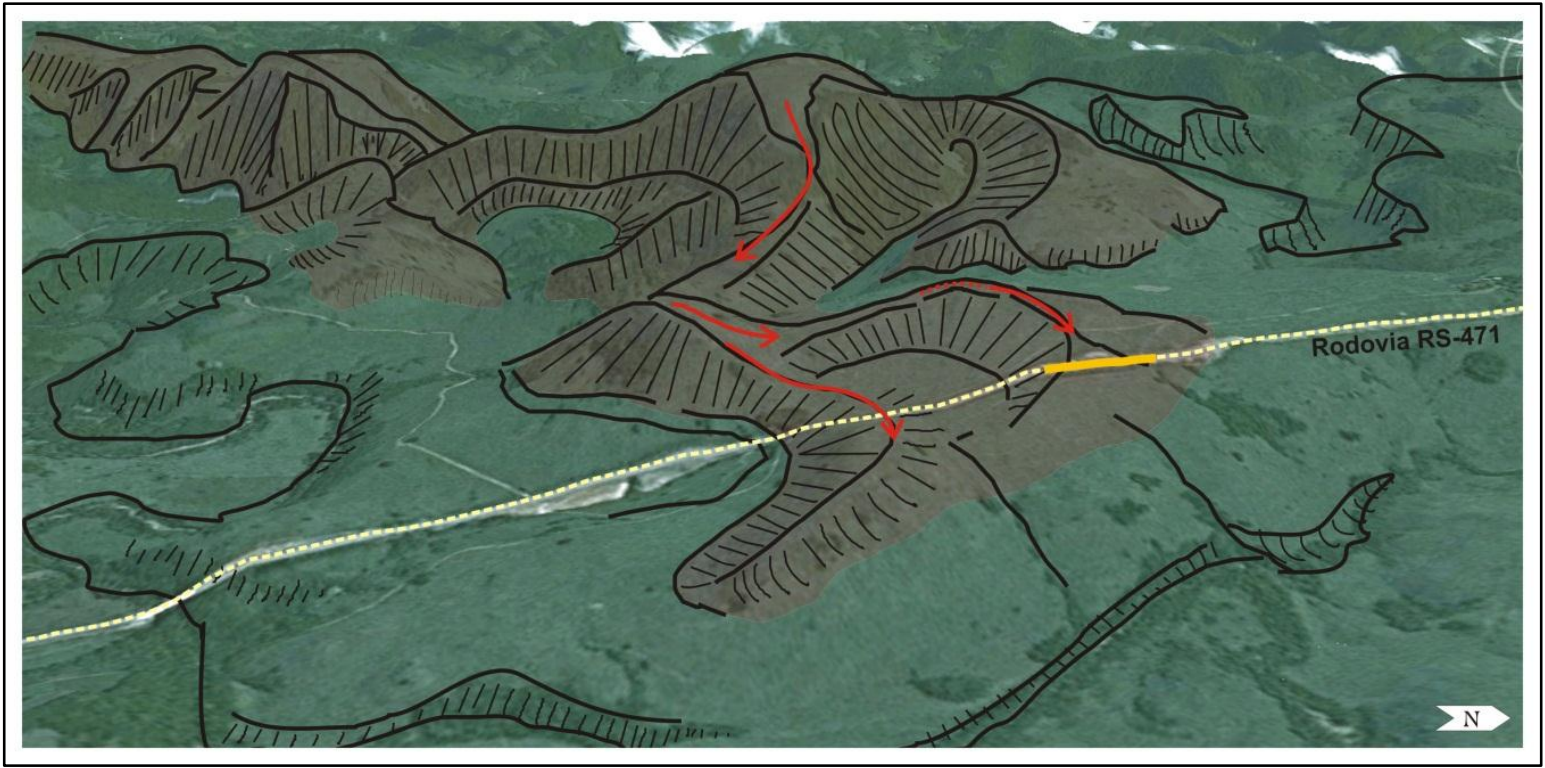

Figura 18: Esquema representativo do relevo do entorno do afloramento GX-140 (cuja localização encontra-se destacada em amarelo), evidenciando alinhamento de morros sugestivos de estruturas dômicas reliquiares. As setas vermelhas indicam possíveis direções de fluxo magmático. A coloração mais avermelhada indica a unidade riolítica Santa Maria. Imagem: Google Earth. (Polo, 2014).

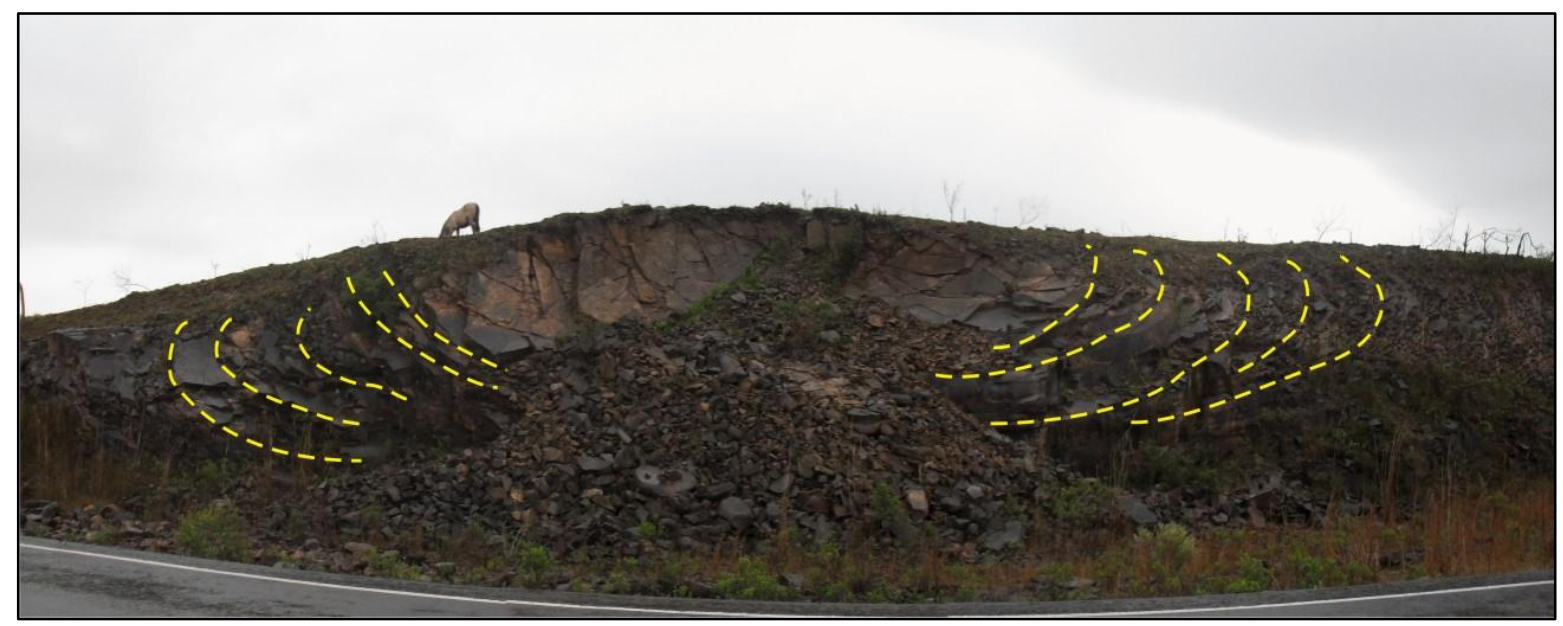

Figura 19: Afloramento RS-80. Estrutura elipsoidal semelhante a um domo - Unidade Santa Maria. 


\section{IV.1.4. DISJUNÇÕES}

As disjunções correspondem a fraturas de alto ângulo, cuja gênese associa-se à contração do corpo vulcânico devido o resfriamento do magma, e de maneira geral, apresentam-se tabulares, conferindo à rocha um aspecto de desplacamento (Figura 20). Mais raramente, foram observadas disjunções prismáticas (semelhantes às disjunções colunares típicas de basaltos; Figura 21 - detalhe). Assim como o fraturamento associado ao fluxo magmático, as disjunções podem apresentar espaçamento variado. Em alguns casos, as disjunções podem ocorrer em direções distintas e perpendiculares entre si e, quando associadas ao fraturamento de fluxo, geram um aspecto blocado no corpo vulcânico.Em outros casos, as disjunções podem superpor o fraturamento de fluxo, mascarando-o.

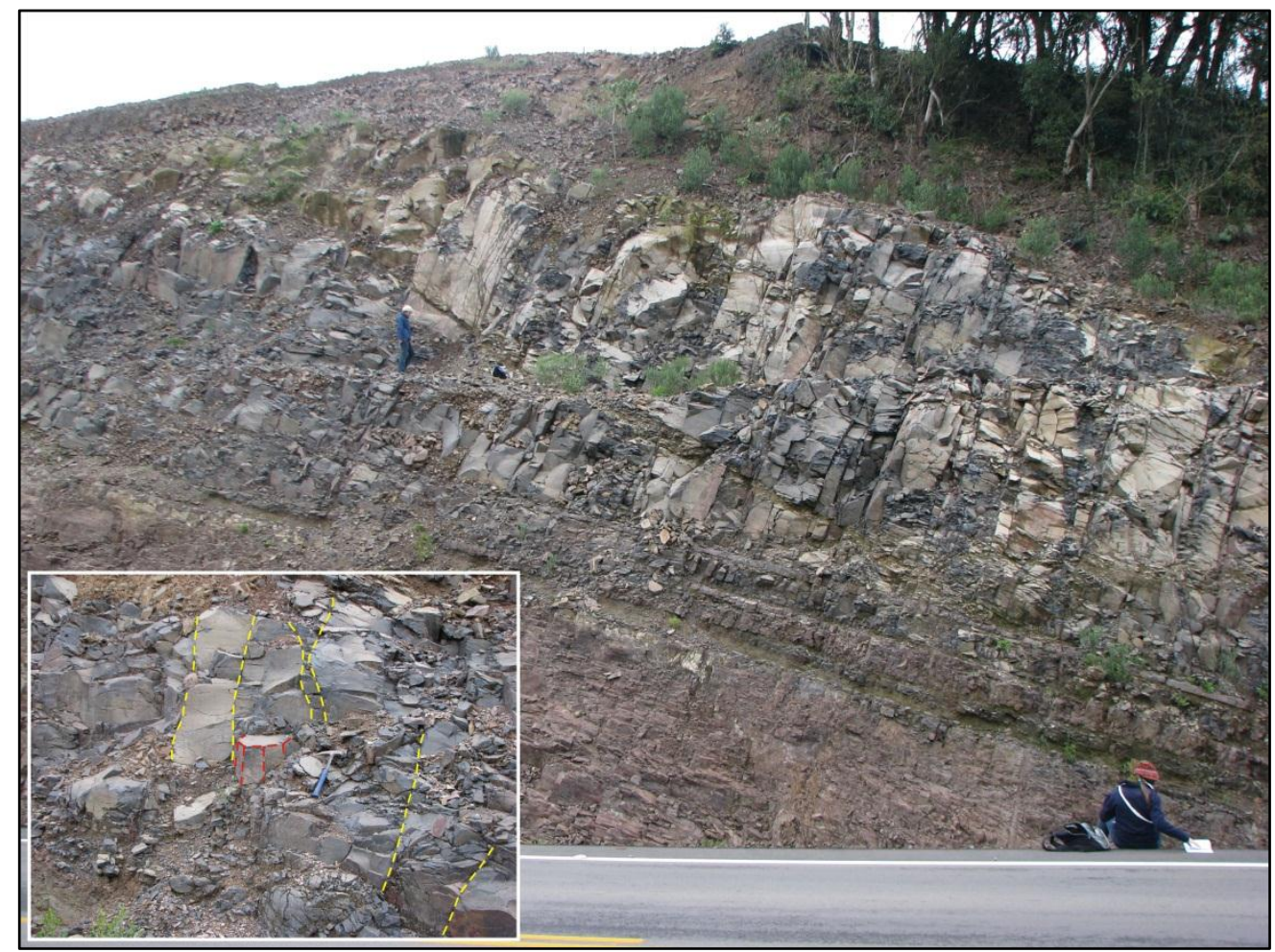

Figura 20: Afloramento RS-74. Padrão de disjunção associada a resfriamento (predominante na porção superior do afloramento, onde ocorre rocha vítrea - obsidiana) com espaçamento decimétrico. No detalhe, observa-se disjunção com geometria tabular (linhas amarelas) e disjunção de geometria prismática, similar às disjunções colunares típicas de basaltos (linhas vermelhas). 


\section{IV.1.5. VESÍCULAS}

As vesículas são estruturas que denunciam a presença de uma fase fluida (gasosa) coexistente com o magma, devido à exsolução de voláteis antes dissolvidos. A exsolução ocorre principalmente como resultado da descompressão associada à ascensão do magma. No caso de magmas menos viscosos que tendem a extrudir efusivamente (através de derrames de lavas), a deformação das vesículas evidencia a movimentação do fluxo.

As vesículas observadas na unidade Santa Maria apresentam grande variação na sua forma de ocorrência e abundância, podendo apresentar-se em escalas variáveis, desde submilimétricas (observadas em microscópio petrográfico) a centimétricas, com formatos arredondados ou estirados, podendo ocorrer em forma de gota (Figuras 21 e 22).

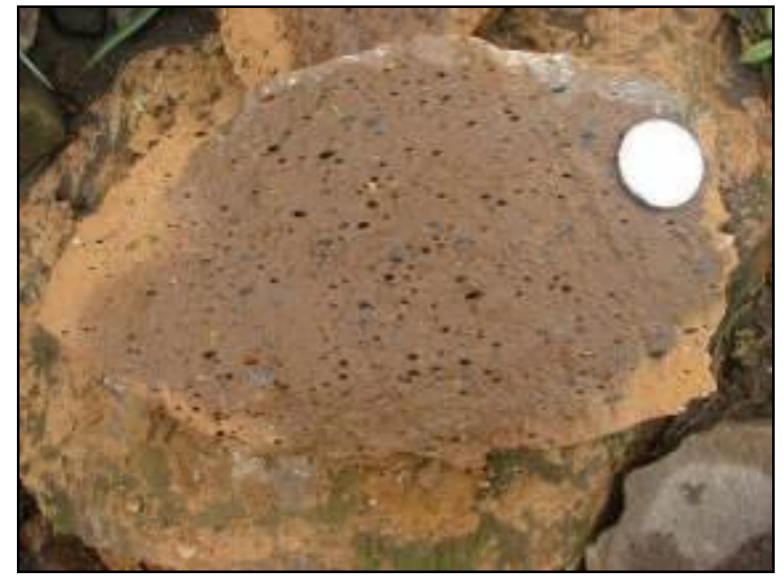

Figura 21: Amostra GX-124. Rocha avermelhada, caracterizada por matriz intensamente desvitrificada, com vesículas milimétricas com geometria arredondada a ovalada. As vesículas podem ocorrer parcial ou completamente preenchidas por quartzo.

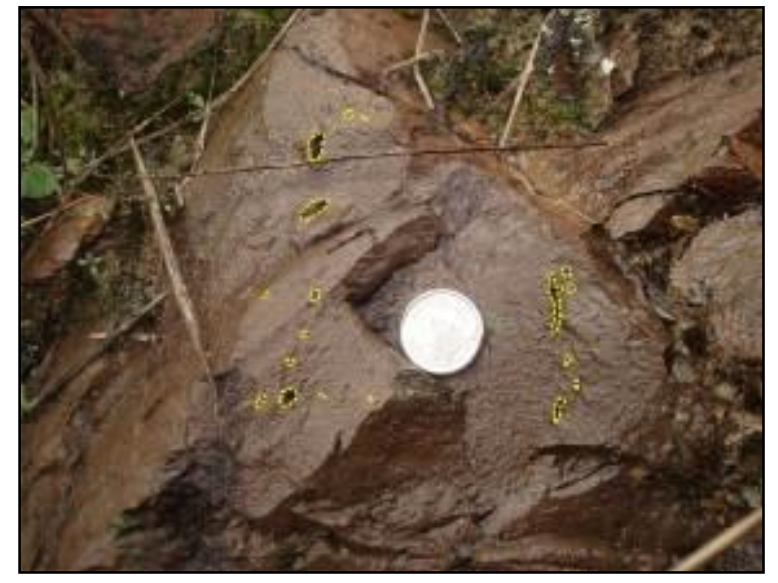

Figura 22: Rocha apresentando matriz parcialmente desvitrificada, com vesículas milimétricas estiradas (destacadas em amarelo). As vesículas podem ocorrer parcial ou completamente preenchidas por quartzo. 


\section{IV.1.6. ESTRUTURAS DE INTERAÇÃO COM SEDIMENTOS}

As estruturas de interação com sedimentos estão associadas à intercalação das sequências vulcânicas com depósitos sedimentares e correspondem a peperitos. Ocorrem na base da unidade vulcânica, onde a fragmentação do corpo vulcânico permite a percolação de arenitos através das fraturas. A ocorrencia de grandes fragmentos de rocha vulcânica imersos em uma matriz de arenito "cozido" e vesiculado permitem inferir que os sedimentos ainda encontravam-se úmidos e inconsolidados (Figura 23).
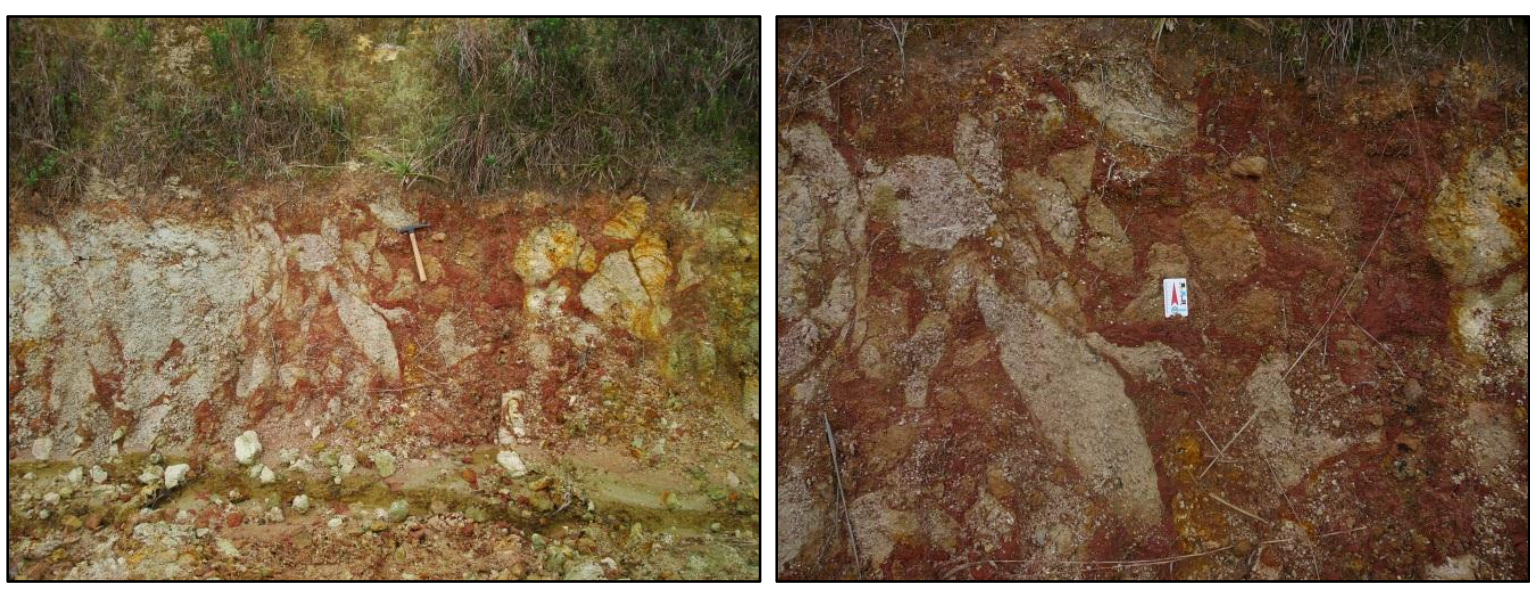

Figura 23: Brechas peperíticas - porções esbranquiçadas correspondem a fragmentos angulosos de rocha vulcânica; porções avermelhadas correspondem a arenito cozido e vesiculado. Nota-se que os fragmentos de rocha vulcânica não sofreram retrabalhamento, sendo possível notar "encaixe" entre os fragmentos adjacentes. A presença de arenitos cozidos e vesiculados preenchendo as fraturas indicam que o sedimento ainda encontrava-se inconsolidado e úmido quando foi recoberto pela lava.

\section{IV.1.7. AUTO-BRECHAS}

Polo (2014) e Polo \& Janasi (2014) descrevem a ocorrência de autobrechas na base, bordas e porção frontal dos fluxos de lava lobados (Figura 24). Estas estruturas ocorrem como carapaças externas irregulares, com espessuras de até $50 \mathrm{~cm}$, localmente clasto-sustentadas. Apresentam elevada proporção de fragmentos de rocha vulcânica angulosa, com até $50 \mathrm{~cm}$ e texturas variáveis (bandadas, maciças e/ou vesiculadas). 


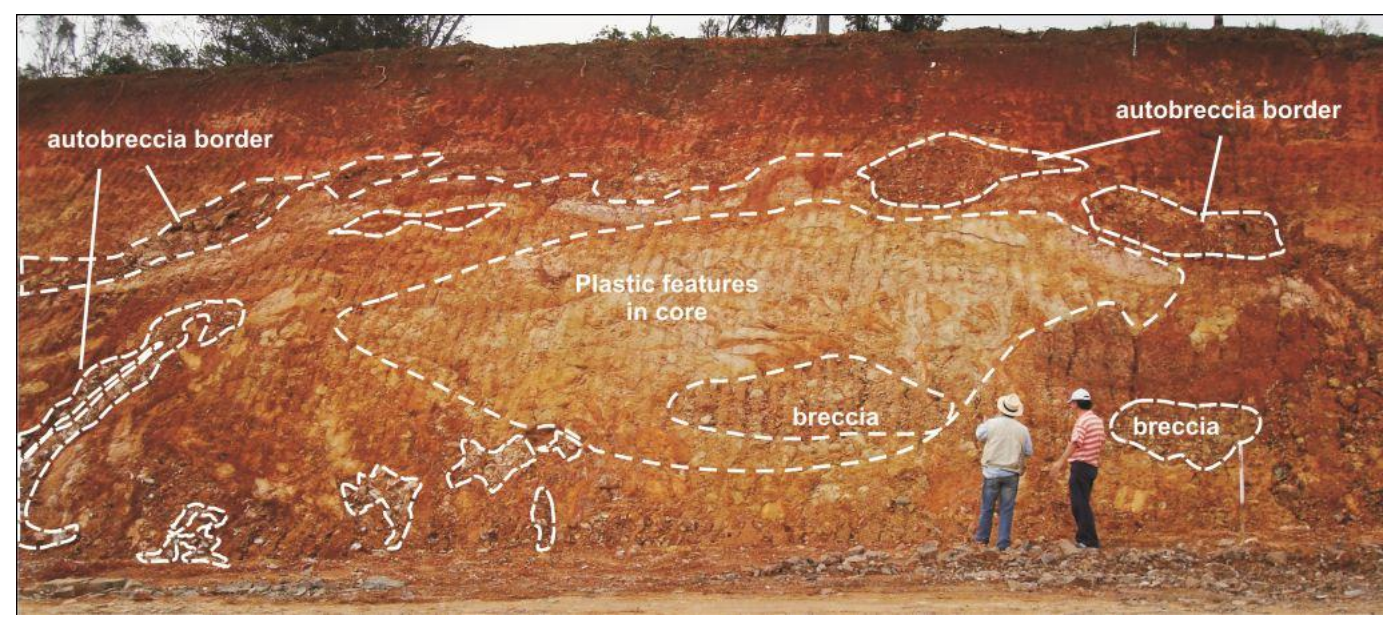

Figura 24: Auto-brecha concêntrica em fluxo lobado composto. Extreaído de Polo \& Janasi (2014).

\section{IV.1.7. ENCLAVES}

É relativamente comum a ocorrência de enclaves centimétricos a decimétricos, de geometria arredondada a sub-arredondada. Tais enclaves caracterizam-se como afaníticos, com contatos abruptos com a rocha encaixante e uma pequena borda de reação (escala centimétrica - Figura 25). Apresentam na parte interna estruturas de fluxo magmático.
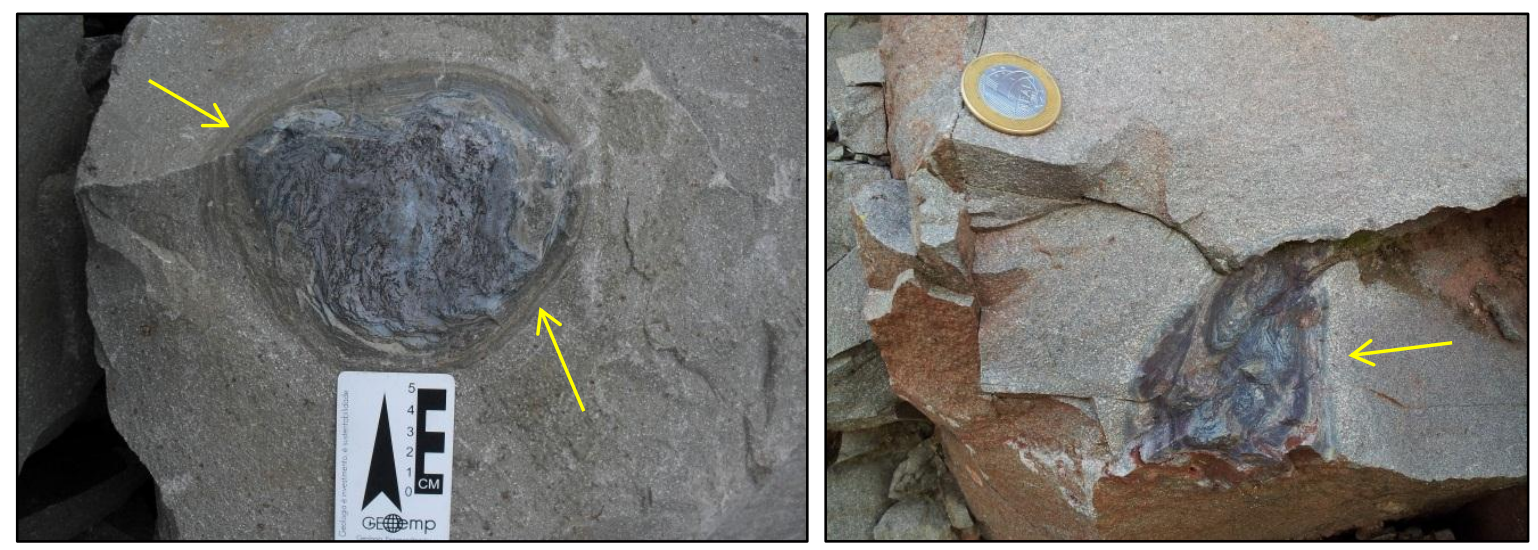

Figura 25: Enclaves centimétricos de geometria arredondada (foto à esqueda) e sub-arredondada (foto à direita). As setas indicam as bordas de reação. 


\section{IV.2. Caracterização estrutural a partir da Anisotropia de Susceptibilidade Magnética (ASM)}

\section{IV.2.1. REVISÃO CONCEITUAL}

A anisotropia de susceptibilidade magnética (ASM) é reconhecida como uma característica das rochas, passível de mensuração uma vez que surge devido à orientação preferencial dos minerais, correspondendo deste modo a uma eficiente metodologia para a determinação da trama estrutural (petrofábrica) das rochas, em especial daquelas de caráter textural isotrópico em escala macroscópica, como é o caso de muitas ocorrências vulcânicas.

A ASM é um tensor escalar definido pela correlação entre um campo magnético aplicado $\left(\mathrm{H}_{\mathrm{A}}\right)$ e a consequente magnetização adquirida $\left(\mathrm{M}_{\mathrm{i}}\right)$ em função deste campo através da equação: $M_{i}=K_{i} \times H$, onde $K$ corresponde à susceptibilidade magnética, sendo, no caso dos materiais anisotrópicos, um tensor de $2^{\circ}$ grau cuja representação quadrática corresponde a um elipsoide (Tarling \& Hrouda, 1993). O elipsoide de ASM, análogo ao elipsoide da geologia estrutural, é expresso em função dos vetores $\kappa_{\max }$, $\kappa_{\text {int }}$ e $\kappa_{\min }$ que definem os eixos máximo, intermediário e mínimo deste elipsoide. Dentro desta conceituação, o elipsoide pode ser definido através dos parâmetros de grau de anisotropia $(\mathrm{P})$ e de forma $(\mathrm{T})$, sendo que geometricamente tal elipsoide pode variar desde oblato $\left(\mathrm{T}=+1 ; \kappa_{\max }=\kappa_{\mathrm{int}}>\kappa_{\min }\right)$ a prolato $\left(\mathrm{T}=-1 ; \kappa_{\max }>\kappa_{\mathrm{int}}=\right.$ $\kappa_{\min }$ ), com um componente intermediário representado pelo elipsoide isotrópico $\left(\mathrm{T}=0 ; \kappa_{\max }=\kappa_{\mathrm{int}}=\kappa_{\min }\right)$.

\section{IV.2.1.1. ASM mineral (em escala de grão)}

Uma vez que todo material, incluindo os minerais, magnetizam-se em resposta à aplicação de um campo magnético $\left(\mathrm{H}_{\mathrm{A}}\right)$, estes podem então ser 
classificados como diamagnéticos, paramagnéticos, ferromagnéticos e antiferromagnéticos (Tarling \& Hrouda, 1993). Os minerais dia- e paramagnéticos apresentam magnetização induzida $\left(\mathrm{M}_{\mathrm{i}}\right)$ linear, proporcional ao campo aplicado, e reversível (i.e. não há magnetização remanente quando o campo é retirado). Nesta classificação, os minerais diamagnéticos são aqueles de comportamento magnético neutro, que adquirem magnetização paralela, mas com sentido inverso ao campo magnético indutor. A suscetibilidade magnética destes minerais (e.g. quartzo $-\mathrm{SiO}_{2}$ ) é negativa e da ordem de 10-6 (SI). Já os minerais que apresentam momentos magnéticos inerentes e adquirem magnetização paralela e de mesmo sentido do campo indutor são chamados paramagnéticos. Tais minerais (e.g. ilmenita - $\mathrm{FeTiO}_{3}$ ) apresentam susceptibilidade positiva, porém fraca (entre $10^{-5}$ e $10^{-3}$ (SI)). $\mathrm{Fe}^{+2}, \mathrm{Fe}^{+3}$ e $\mathrm{Mn}^{+2}$ são as principais fontes de paramagnetismo nos minerais.

Alguns minerais apresentam magnetização induzida $\left(\mathrm{M}_{\mathrm{i}}\right)$ não linear e comumente irreversível em função do campo aplicado. Tal magnetização pode atingir a saturação quando resultante de campos suficientemente fortes, de modo que, após a retirada deste campo, os materiais continuam a apresentar uma magnetização remanente $\left(\mathrm{M}_{\mathrm{r}}\right)$. Os minerais que apresentam uma magnetização espontânea mesmo na ausência de um campo são chamados ferromagnéticos (e.g. magnetita $-\mathrm{Fe}_{3} \mathrm{O}_{4}$ ), sendo três elementos químicos responsáveis por esta característica: Fe, Co e Ni.

A magnetização espontânea é fortemente dependente do campo magnético aplicado, assim como da temperatura. Deste modo, define-se como temperatura de Curie a temperatura acima da qual as forças de troca param de atuar e o ordenamento magnético dos minerais ferromagnéticos desaparece.

Finalmente, a anisotropia corresponde a uma tendência direcional de uma determinada propriedade física (susceptibilidade magnética) de um material, no caso, de um mineral. A anisotropia das partículas minerais é fortemente 
dependente do tamanho e da forma dos grãos magnéticos, podendo ser, de maneira resumida, dividida em anisotropia magnetocristalina e anisotropia de forma. Para os minerais de baixa susceptibilidade intrínseca $\left(\kappa_{\mathrm{i}}\right)$, a ASM é controlada inteiramente pela cristalografia, ou seja, há predomínio da anisotropia magnetocristalina. Já para os minerais de elevada susceptibilidade intrínseca $\left(\kappa_{\mathrm{i}}\right)$, como a magnetita e a titanomagnetita, a ASM é controlada pela forma do grão, estando, nestes casos, o eixo $\kappa_{\text {máx }}$ do elipsoide paralelo ao eixo maior do cristal (multi-domain - MD). Deste modo, quando se considera a anisotropia magnética em escala de grão, é importante levar em conta a possível ocorrência do chamado "single domain (SD) effect", que corresponde a um padrão de "ASM inversa", onde o eixo $\kappa_{\min }$ do elipsoide de anisotropia é paralelo ao eixo maior do grão.

\section{IV.2.1.2. $\underline{\text { ASM de rocha }}$}

Uma vez que rochas são compostas por misturas, em diferentes proporções, de minerais diversos, e que cada uma dessas fases minerais é responsável por alguma contribuição na susceptibilidade total da rocha, pode-se considerar que:

$$
\boldsymbol{K}_{\text {Rocha }}=\sum \boldsymbol{K}_{\mathrm{i}} f_{\mathrm{i}} \text {, sendo que } \sum f_{\mathrm{i}}=1 \text {, }
$$

onde $f_{\mathrm{i}}$ é a fração volumétrica na amostra de rocha da fase mineral $i$ e $\mathrm{K}_{\mathrm{i}}$ corresponde à susceptibilidade volumétrica da fase mineral pura. Fica claro então que a susceptibilidade magnética de uma rocha, e consequentemente a anisotropia a ela associada, dependerá das fases minerais presentes, suas abundâncias relativas, suas susceptibilidades específicas, anisotropias em escala de grão, orientação e distribuição espacial (Borradaile \& Jackson, 2010). 
Com relação ao elipsoide de anisotropia de susceptibilidade magnética, considerando os eixos $\kappa_{\max }$, $\kappa_{\text {int }}$ e $\kappa_{\min }$ em uma população "multidomínio" (MD), ou seja, em um padrão normal de ASM, o eixo $\kappa_{\max }$ corresponderá à lineação, o plano formado pelos eixos $\kappa_{\max }$ e $\kappa_{\text {int }}$ corresponderá ao plano de foliação e o eixo $\kappa_{\min }$ será equivalente ao polo do plano de foliação.

IV.2.1.2.1. ASM em rochas igneas - suas fontes e estruturas relacionadas a fluxos de lava, lava-domos, condutos e diques

Apesar do consenso de que a ASM de qualquer rocha é resultado da combinação em diferentes proporções das anisotropias dos minerais que as compõem, alguns autores (e.g. Borradaile, 1988 e Hrouda \& Kahan, 1991) destacam que os minerais ferromagnéticos, mesmo quando presentes em pequenas proporções volumétricas $(<1 \%)$ podem ser capazes de dominar as propriedades magnéticas e controlar as propriedades (к e ASM) resultantes. No caso de rochas com susceptibilidades altas ( $\kappa>5 \times 10-3$ SI), a contribuição das fases minerais para- e diamagnéticas podem ser negligenciadas, sendo a ASM resultante, nestes casos, controlada pelos minerais ferromagnéticos, como a magnetita e a titonomagnetita em muitas rochas ígneas. Por outro lado, no caso de rochas com susceptibilidades baixas $\left(\kappa<10^{-4}\right.$ SI), a anisotropia pode ser associada à ocorrência das fases minerais paramagnéticas, com alguma contribuição ocasional de fases minerais diamagnéticas. Para os casos intermediários, ressalta-se a importância da definição mais detalhada das fases minerais presentes e suas respectivas contribuições para as propriedades magnéticas finais.

A trama magnética das rochas ígneas é comumente controlada por minerais ferromagnéticos como magnetita, titanomagnetita e hematita, além de alguns minerais paramagnéticos como piroxênios, olivinas, feldspatos. Uma vez que estes minerais apresentam elevado ponto de fusão e são, de maneira 
geral, fases precoces durante a cristalização, pode-se considerar que comportam-se como sólidos carregados pelo fluxo do magma em resfriamento durante sua ascensão e colocação.

A viscosidade elevada dos magmas e as elevadas temperaturas em que cessa o fluxo magmático (muito superiores à temperatura de Curie das fases minerais paramagnéticas) permitem concluir que o campo gravitacional e o campo geomagnético não exercem influência significativa sobre o alinhamento dos cristais, sendo estes orientados apenas por influência do fluxo magmático. Esta importante consideração justifica a aplicação das técnicas de obtenção de dados de ASM para as rochas ígneas, em especial as rochas vulcânicas, que preservam devido ao rápido resfriamento as feições estruturais associadas aos processos de ascensão, colocação e extrusão dos magmas.

Cañón-Tapia (2004) destaca alguns conceitos importantes considerandose os estudos de ASM para as rochas ígneas. Considerando basicamente três grupos de ocorrência - corpos plutônicos de grande dimensão, corpos vulcanoclásticos e corpos vulcânicos e sub-vulcânicos (derrames de lava, lavadomos, diques e sills), o autor destaca importantes diferenças entre eles que irão influenciar a fábrica magnética do produto: a) a dimensão dos corpos, onde o primeiro grupo apresenta-se grande nas 3 dimensões e os demais apresentam-se pequenos em pelo menos uma das dimensões, o que geraria os chamados efeitos de borda; b) as taxas de resfriamento, sendo maiores nos dois últimos grupos, o que facilitaria a obtenção da fábrica magnética primária (aquela adquirida no momento de formação da rocha); c) o tipo de fluxo envolvido, sendo este não laminar e dominado por células de convecção no primeiro grupo e laminar para os demais grupos, o que garante uma direção de fluxo melhor definida para estes casos. Deste modo, o autor destaca a importância dos estudos de ASM para lava-domos, diques e derrames de lava, os quais podem apresentar indicadores estruturais relativamente precisos. 
No que diz respeito à estrutura dos lava-domos, merece destaque o trabalho de Závada et al. (2009) que, de maneira empírica e através da aplicação da metodologia de análise das anisotropias magnéticas, demonstra o grande valor da técnica para a compreensão dos processos envolvidos na colocação destes tipos de estruturas. A partir dos resultados apresentados é interessante destacar o padrão apresentado pelos parâmetros como foliação e lineação magnética, que se mostram variáveis em função da posição dentro do fluxo: considerando-se uma seção vertical na estrutura dômica (Figuras $26 \mathrm{~A}$ e B), observa-se que o conduto caracteriza-se por uma foliação francamente vertical, que tende a se horizontalizar nas porções mais superiores do corpo, principalmente na sua base, entretanto ainda mostrando algumas variações; enquanto que, considerando-se uma seção horizontal na estrutura dômica (Figuras 27 A e B), observa-se que a foliação e a lineação apresentam-se variando paralelamente às bordas do fluxo, ou seja, o mergulho da foliação apresenta-se radial.
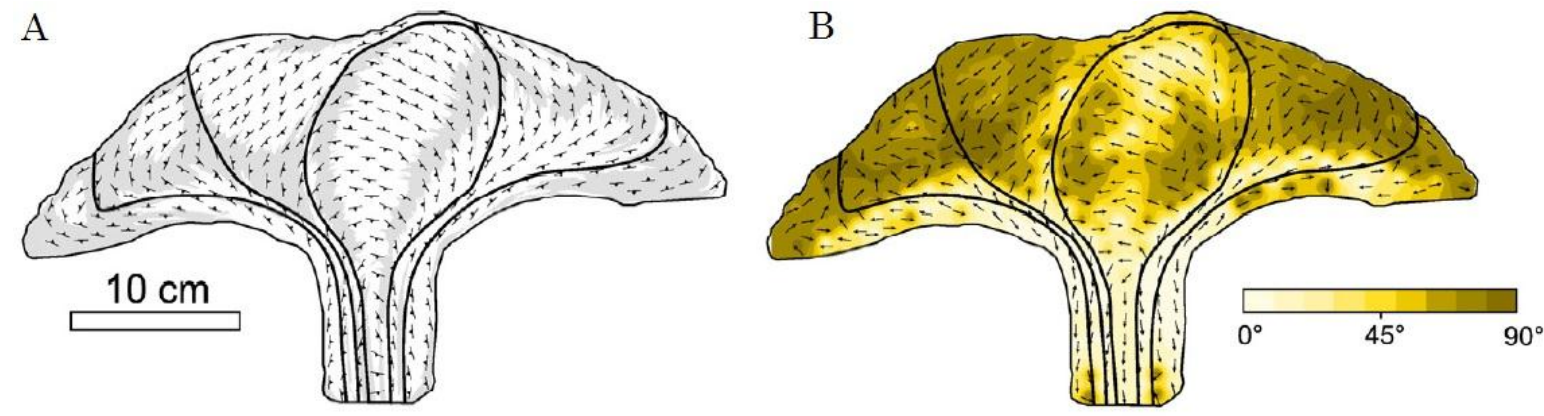

Figura 26: Exemplo de padrão de ASM em estruturas dômicas - obtido para o modelo H4 (de Závada et al., 2009). Este modelo corresponde ao material com maior razão massa/água $(2,6)$, maior fração volumétrica de partículas (48\%) e maiores viscosidades - para maiores detalhes, ver referência. Os limites dos lobos exógenos individuais são demarcados pelas linhas pretas contínuas. A) Representações dos planos de foliação magmáticao; B) Representações das direções e mergulho das lineações magnéticas em seção vertical. As variações dos ângulos de mergulho são representadas de acordo com o padrão de coloração apresentado ao lado. Extraído de Závada et al., 2009. 
A

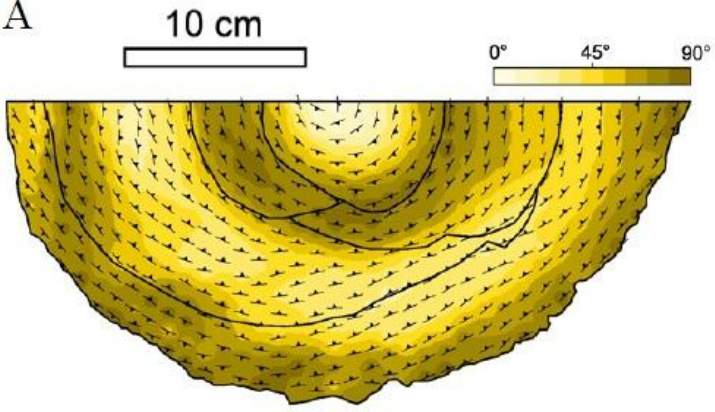

B

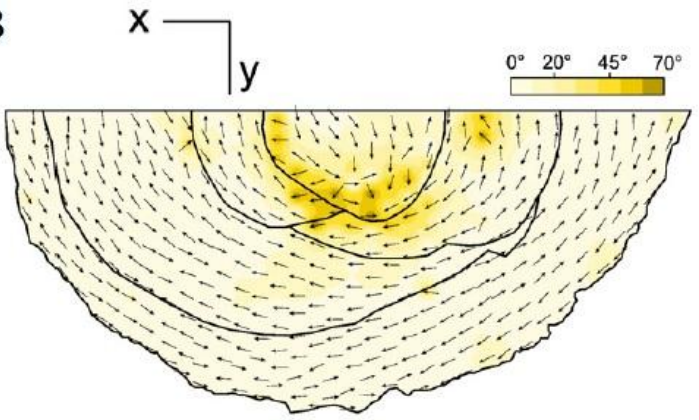

Figura 27: Exemplo de padrão de ASM em estruturas dômicas obtido para o modelo H4 (de Závada et al., 2009). Este modelo corresponde ao material com maior razão massa/água $(2,6)$, maior fração volumétrica de partículas (48\%) e maiores viscosidades - para maiores detalhes, ver referência. Os limites dos lobos exógenos individuais são demarcados pelas linhas pretas contínuas. A) Representações dos planos de foliação magnética sobrepostos em plano horizontal. As variações dos mergulhos são representadas pelas variações de coloração (padrão representado junto à figura); B) Representações das direções e mergulho das lineações magnéticas em seção horizontal. As variações dos ângulos de mergulho são representadas de acordo com o padrão de coloração apresentado acima da figura. Extraído de Závada et al., 2009.

Os autores destacam ainda a variação do parâmetro de forma (T) do elipsoide de ASM e do grau de anisotropia (P) em função da sua posição no corpo (Figuras 28 A e B): maior grau de anisotropia e predominância de elipsoides oblatos na porção central do domo e nas bordas do conduto e menor grau de anisotropia e predomínio de elipsoides prolatos nas bordas da estrutura dômica e no centro do conduto.
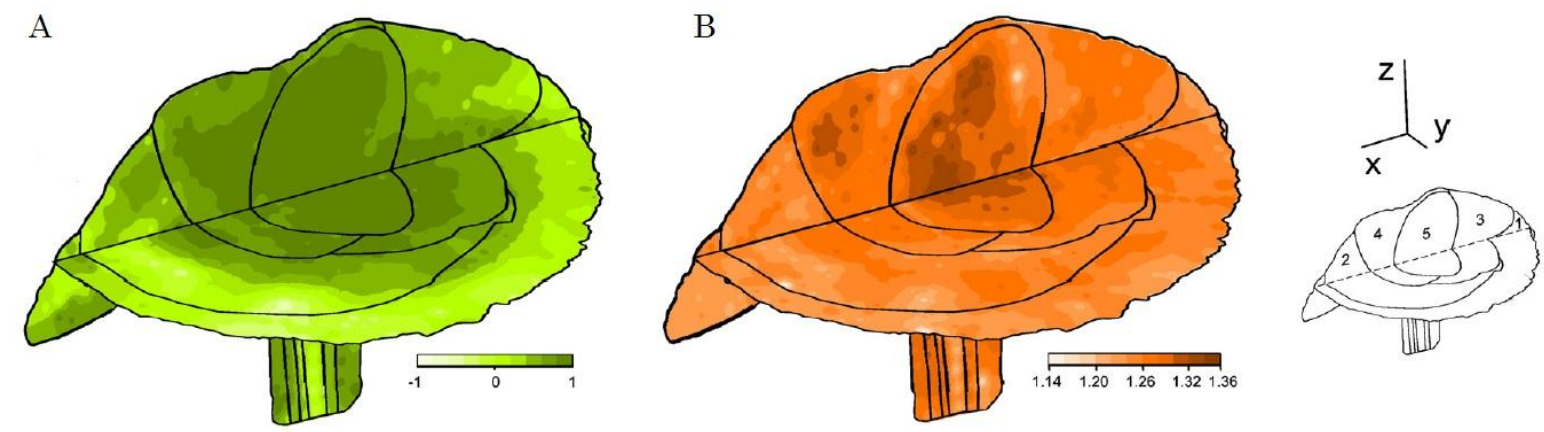

Figura 28: Representação em 3D (junção dos padrões obtidos para corte vertical e horizontal) do diagrama de contorno dos domos exógenos formando estrutura dômica combinado com o parâmetro de forma ( $\mathrm{T}$ - figura A) e grau de anisotropia ( $\mathrm{P}$ - figura B). As variações destes parâmetros são representadas pelas variações de cor, que estão definidas ao lado das figuras. Extraído de Závada et al., 2009. 
Em relação aos estudos de ASM em diques, Knight \& Walker (1988) foram os primeiros a realizar estudos que defiram o eixo $\kappa_{\max }$ paralelo à direção do fluxo magmático. Estes e outros autores (como por exemplo Park et al., 1988) consideram o efeito SD (domínio invertido do elipsoide) ou a ocorrência de deformações posteriores como possíveis explicações para as ocasionais ocorrências de variações nos eixos $\kappa_{\max }$ e $\kappa_{\text {mín. }}$. Entretanto, parece lógico considerar a ocorrência de imbricação do elipsoide definido nas bordas dos diques: sabe-se a partir dos estudos de geologia estrutural que o plano de fluxo real é aquele de referência ao transporte do magma, enquanto que o plano de fluxo aparente é aquele registrado pelos minerais. Devido à variação da velocidade ao longo de um dique (maior velocidade na porção central e menor velocidade nas bordas do dique) e devido à ocorrência de cisalhamento simples no contato entre o dique e a encaixante, os cristais, sólidos carregados pelo magma, sofrerão rotação e definirão o chamado efeito "efeito de pinçagem" nas bordas dos diques (Knight \& Walker (1988); Figura 29). Uma vez que, considerando-se cristais de geometria alongada e elevada $\mathrm{K}$, a ASM será definida pela forma e orientação do grão, o elipsoide definido apresentar-se-á também imbricado em relação às bordas do dique (Figura 29).

Figura 29: Representação do efeito de "pinçagem" dos cristais nas paredes de um dique, como proposto por Knight \& Walker (1988). A seta vermelha indica a

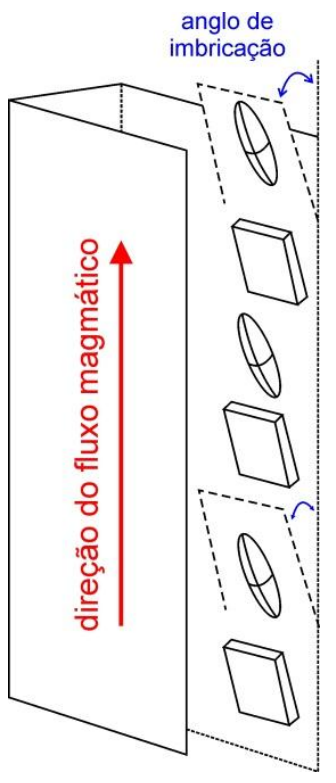
direção do fluxo e a azul, o ângulo de imbricação. Extraído de Cañón-Taipa (2004).

Os primeiros estudos de anisotropia de susceptibilidade magnética em derrames de lava enfrentaram grandes dificuldades frente à variação da orientação dos eixos K. O trabalho de Knight \& Walker (1988) influenciou outros autores como Perroud et al. (1991), MacDolnald et al. (1992) e Cañón- 
Taipa et al. (1994, 1995), os quais consideram o eixo $\kappa_{\max }$ paralelo ao fluxo porém colocam que as variações observadas para a orientação deste eixo podem estar associadas à variações nos tamanhos dos grãos (Perroud et al., 1991) ou a variações no regime de fluxo (Cañón-Taipa et al., 1994, 1995). Cañón-Taipa et al. $(1996,1997)$ destacam que a ASM definida para um fluxo magmático sofre influência da deformação associada ao fluxo em suas três dimensões e que as diferenças observadas para o grau de anisotropia podem estar associadas a diferentes regimes de fluxo e variações na intensidade do cisalhamento a ele associado, mesmo dentro de uma mesma unidade. Os autores consideram ainda que algumas variações na orientação dos eixos podem estar associadas à ocorrência de aglomerados de cristais, que passam a definir um novo elipsoide.

Posteriormente, Cañón-Taipa \& Coe (2002) e Cañón-Taipa (2004) destacaram a importância do reconhecimento da posição dentro do corpo para a definição da ASM e do sentido de escoamento, ressaltando que a movimentação e orientação das partículas são influenciadas pela geometria do fluxo. Mais recentemente, o trabalho de Loock et al. (2008) em um derrame de lava bem exposto na França, utiliza os resultados das análises de ASM - com destaque para o mergulho do eixo $\kappa_{\max }$ e o grau de anisotropia e suas variações - em conjunto com evidências de campo para demonstrar possíveis variações no regime reológico e no sentido de fluxo, definindo assim, distintas unidades dentro de um derrame. Os autores, a partir desta integração de dados, demonstram ainda ser possível obter de forma qualitativa um perfil de velocidade para o fluxo de lava.

Outro modelo importante, porém pouco aceito, é o de Jeffery (1922) que considera a movimentação cíclica (rotação) dos cristais, resultante da ação do fluxo sobre estes. Esta movimentação, que está também associada à forma do cristal e à posição dentro do fluxo magmático, seria responsável pelas variações na orientação dos elipsoides de ASM definidos. 
McPhie et al. (2008) dão um passo importante na interpretação de depósitos lávicos de composição félsica, afirmando, a partir da consideração de que reversões nos mergulhos da foliação e lineação magnética se formam em resposta ao cisalhamento de fluxo, e assim reconhecendo uma extensa e espessa unidade de fluxo para os riolitos Eucarro (Austrália), que a extrusão de lavas félsicas em LIPs de composição bimodal podem ser tão grandiosas quanto a extrusão de lavas basálticas associadas. Os autores destacam ainda que os padrões de reversão e a existência de mergulhos variáveis e íngremes não ocorrem em depósitos ignimbríticos, os quais tendem a desenvolver foliações e lineações horizontais ou com mergulhos muito baixos, com o eixo $\kappa_{\max }$ paralelo ao fluxo de escoamento, de modo a resultar em padrões estratigraficamente bem distintos daqueles formados pelas lavas.

\section{IV.2.2. ANISOTROPIAS MAGNÉTICAS DOS RIOLITOS TIPO SANTA MARIA}

Os estudos das anisotropias magnéticas foram executados visando uma melhor compreensão da estruturação e da forma de ocorrência dos riolitos da unidade Santa Maria a partir da obtenção da foliação e lineação magnéticas associadas à foliação e lineação magmáticas - de mais difícil reconhecimento em campo. Dos 28 sítios amostrados em um trabalho de campo inicial, 14 são referentes à unidade Santa Maria, e são aqui apresentados.

Como já descrito no item precedente, fazem-se necessários estudos completos para o entendimento do conjunto de dados, a começar pela mineralogia magnética atuante e suas características. Tal determinação foi realizada através dos estudos de magnetismo de rocha, o qual incluiu a obtenção de curvas de indução e desmagnetização por AF (alternating field), curvas de histerese e curvas termomagnéticas. Estes estudos foram realizados em amostras representativas de cada afloramento estudado, ou seja, em casos 
de afloramentos com mais de um sítio de amostragem, escolheu-se um amostra representativa.

As histereses obtidas (Figura 30) mostram-se bastante simétricas e estreitas, indicando a presença de apenas uma fase mineral ferromagnética de baixa coercividade controlando a susceptibilidade magnética da rocha, com contribuição paramagnética desprezível ( $\mathrm{K}_{\mathrm{pa}}$ variando de 0,25 a 1,29\%). Os parâmetros de histerese mostram que a fase mineral em questão apresenta valores de coercividade (Hc) entre 6,97 e 18,31 $\mathrm{mT}$ e uma força coerciva remanente (Hcr) variando de 19,38 a 43,89 mT. Estes parâmetros são apresentados na tabela 01 e permitiram a plotagem em gráfico proposto por Day et al. (1977), Figura 31, onde nota-se que para todas as amostras o mineral ferromagnético caracteriza-se como PSD (pseudo-single domain).

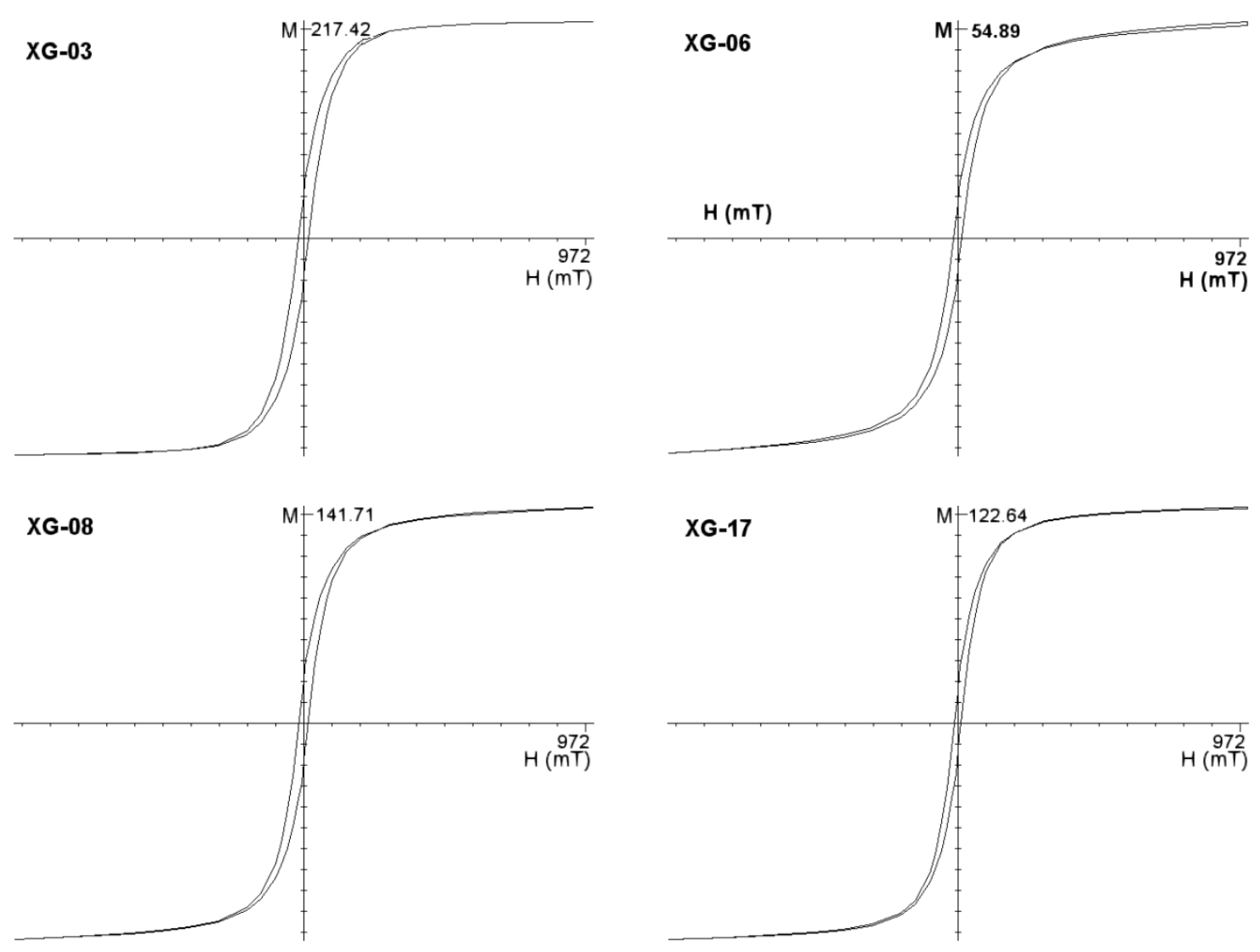

Figura 30: Curvas de histereses obtidas para algumas amostras representativas dos riolitos tipo Santa Maria. $\mathbf{M}$ corresponde à magnetização (unidade: $\mu \mathrm{A} \cdot \mathrm{m}^{2}$ ) e $\mathbf{H}$ corresponde ao campo magnético aplicado. 
Tabela 01: Parâmetros de histerese das amostras representativas dos riolitos tipo Santa Maria. $\mathbf{H}_{\mathbf{c r}}$ corresponde à força coerciva de remanência; $\mathbf{H}_{\mathbf{c}}$ corresponde à força coerciva; $\mathbf{M}_{\mathbf{r s}}$ corresponde à magnetização de saturação remanente; $\mathbf{M}_{\mathbf{s}}$ corresponde à magnetização de saturação.

\begin{tabular}{lcccccc}
\hline Amostra/sítio & $\mathrm{H}_{\mathrm{cr}}$ & $\mathrm{H}_{\mathrm{c}}$ & $\mathbf{H}_{\mathbf{c r}} / \mathbf{H}_{\mathbf{c}}$ & $\mathrm{M}_{\mathrm{rs}}$ & $\mathrm{M}_{\mathrm{s}}$ & $\mathbf{M}_{\mathrm{rs}} / \mathbf{M}_{\mathbf{s}}$ \\
\hline XG-01 & 19.38 & 6.97 & $\mathbf{2 . 7 8 0}$ & 23.19 & 173.17 & $\mathbf{0 . 1 3 4}$ \\
\hline XG-03 & 43.89 & 18.31 & $\mathbf{2 . 3 9 7}$ & 44.45 & 219.7 & $\mathbf{0 . 2 0 2}$ \\
\hline XG-04 & 39.09 & 13.67 & $\mathbf{2 . 8 6 0}$ & 32.83 & 210.02 & $\mathbf{0 . 1 5 6}$ \\
\hline XG-06 & 35.89 & 14.87 & $\mathbf{2 . 4 1 4}$ & 9.11 & 49.07 & $\mathbf{0 . 1 8 6}$ \\
\hline XG-07 & 39.41 & 14.5 & $\mathbf{2 . 7 1 8}$ & 42.8 & 221.41 & $\mathbf{0 . 1 9 3}$ \\
\hline XG-08 & 35.29 & 16.82 & $\mathbf{2 . 0 9 8}$ & 28.62 & 135.84 & $\mathbf{0 . 2 1 1}$ \\
\hline XG-09 & 42.66 & 10.53 & $\mathbf{4 . 0 5 1}$ & 31.59 & 210.4 & $\mathbf{0 . 1 5 0}$ \\
\hline XG-10 & 41.11 & 16.79 & $\mathbf{2 . 4 4 8}$ & 15.15 & 90.09 & $\mathbf{0 . 1 6 8}$ \\
\hline XG-17 & 31.1 & 11.93 & $\mathbf{2 . 6 0 7}$ & 18.81 & 119.22 & $\mathbf{0 . 1 5 8}$ \\
\hline
\end{tabular}

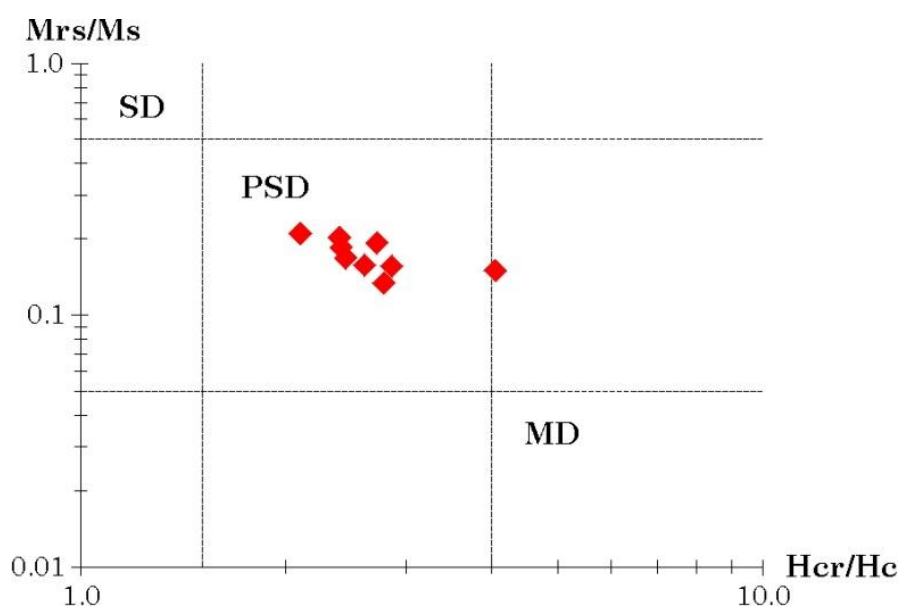

Figura 31: Gráfico Mrs/Ms vs Hcr/Hc - as linhas tracejadas correspondem aos limites propostos por Day et al. (1977). $\mathbf{H}_{\mathbf{c r}}$ corresponde à força coersiva de remanência; $\mathbf{H}_{\mathbf{c}}$ corresponde à força coersiva; $\mathbf{M}_{\mathbf{r s}}$ corresponde à magnetização de saturação remanente; $\mathbf{M}_{\mathbf{s}}$ corresponde à magnetização de saturação.

As curvas termomagnéticas (Figura 32) mostram que, naquelas de baixa temperatura, algumas amostras apresentam um pico de susceptibilidade em aproximadamente $-150^{\circ} \mathrm{C}$, conhecido como transição de Verwey. Já nas curvas de alta temperatura, as amostras apresentam uma queda brusca de susceptibilidade em torno de $580^{\circ} \mathrm{C}$, caracterizando a temperatura de Curie da fase mineral. Estas características permitem identificar a magnetita, empobrecida em Ti (Ti-magnetita), como fase mineral responsável pela susceptibilidade magnética dos riolitos Santa Maria. Vale ressaltar que apenas uma amostra (XG-10) apresentou uma curva termomagnética aproximadamente reversível, com as demais indicando consumo de fase mineral após o aquecimento (oxidação do mineral opaco). 

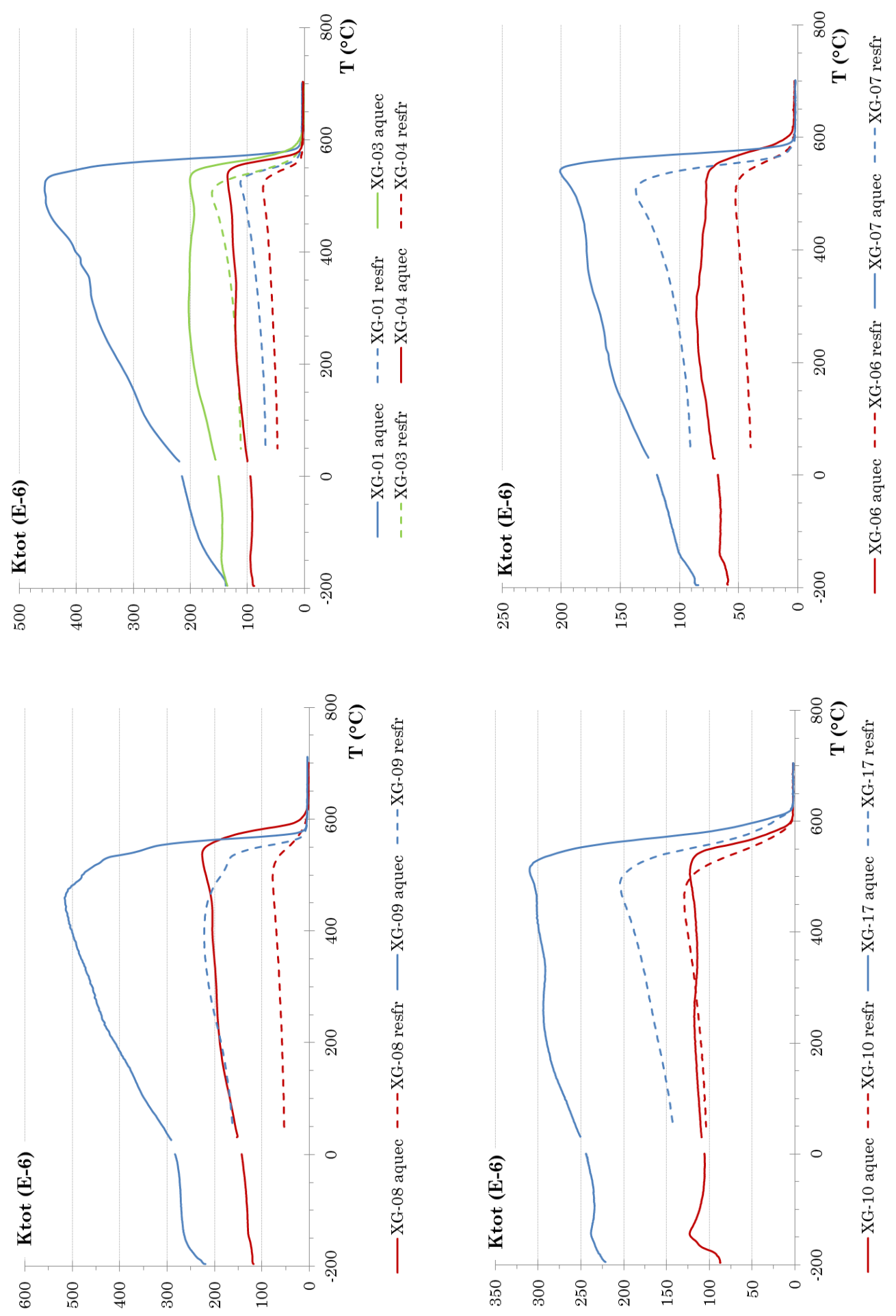

Figura 32: Curvas termomagnéticas dos riolitos Santa Maria, mostrando as variações da susceptibilidade magnética (K) em função da temperatura (T). As linhas cheias representam curvas de aumento de temperatura $\left(-150^{\circ} \mathrm{C}\right.$ a $0^{\circ} \mathrm{C}$ e $50^{\circ} \mathrm{C}$ a $\left.700^{\circ} \mathrm{C}\right)$, enquanto que as curvas tracejadas representam $\mathrm{o}$ experimento de redução da temperatura $\left(700^{\circ} \mathrm{C}\right.$ a $\left.50^{\circ} \mathrm{C}\right)$. 
A desmagnetização por AF da MRN forneceu curvas (Figura 33) onde observa-se que as amostras dos sítios XG-03 e XG-07 perdem sua magnetização quase totalmente com campos de até $30 \mathrm{mT}$, indicando uma baixa coercividade dos minerais destas amostras, enquanto que as amostras dos sítios XG-01 e XG-08 desmagnetizam-se de modo menos abrupto, perdendo a magnetização em campo de até $100 \mathrm{mT}$, o que estaria relacionado a cristais com maior coercividade. Já as amostras dos sítios XG-04 e XG-06 apresentam um comportamento anômalo, adquirindo uma magnetização inicial para posteriormente se desmagnetizarem.
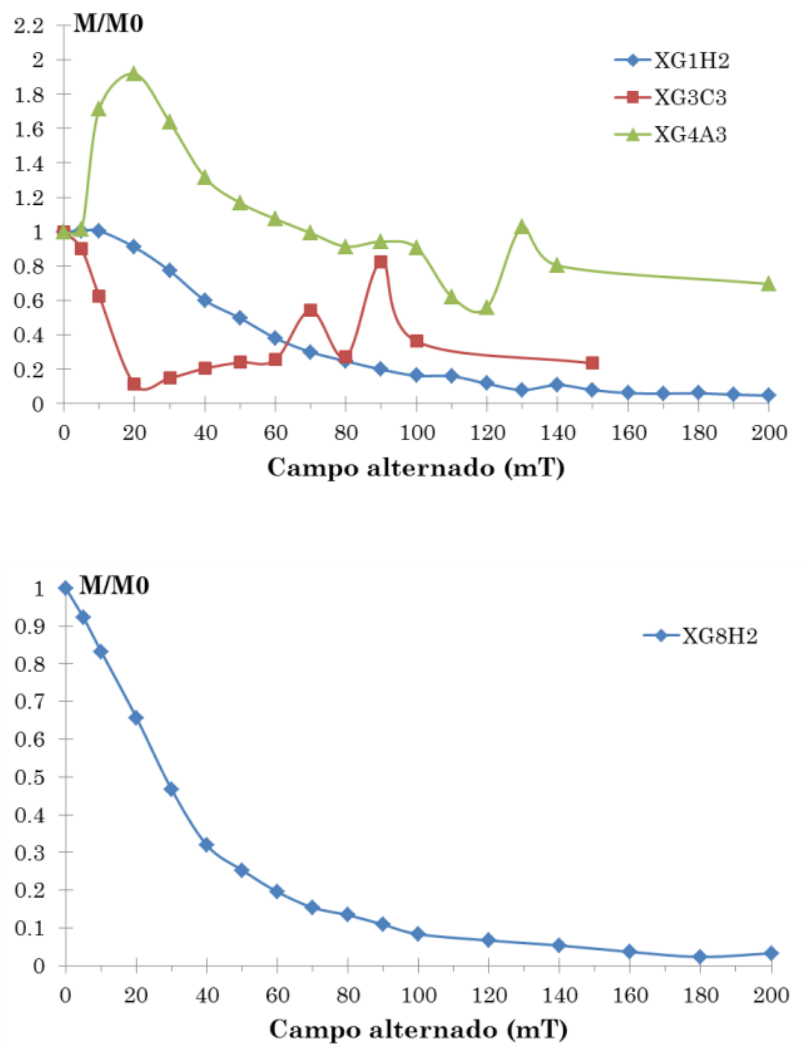

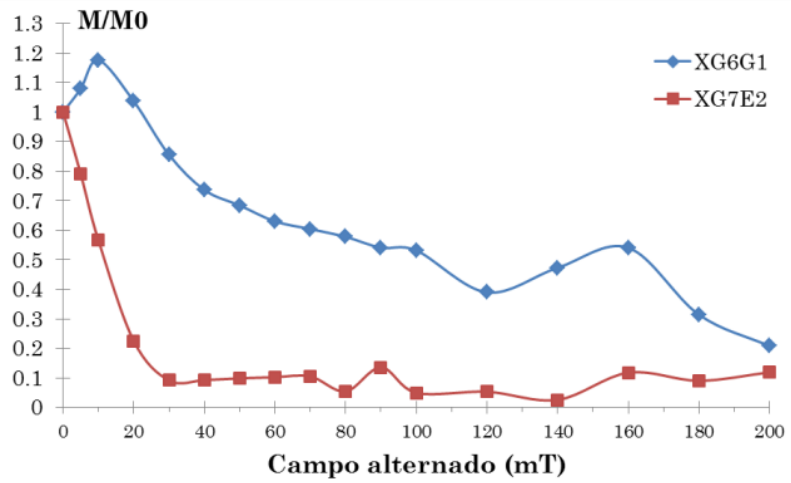

Figura 33: Curvas de desmagnetização inicial das amostras representativas dos riolitos tipo Santa Maria. Legendas indicadas junto aos gráficos. 
Para um melhor estudo da coercividade do mineral magnético as amostras foram também submetidas à magnetização remanente anisterética parcial (pARM). Jackson et al. (1988) propõem a correlação entre as curvas obtidas pela pARM e a coercividade dos minerais magnéticos, a qual está intimamente relacionada ao tamanho dos cristais - picos de AFs elevados correspondem a cristais menores. A análise das curvas obtidas para os riolitos tipo Santa Maria (Figura 34) mostram que as titanomagnetitas apresentam coercividades baixas, em intervalos de 0 a $10 \mathrm{mT}$, sugerindo cristais de até 25 um. Apenas duas amostras (XG-03 e XG-06) apresentaram curvas com pico em intervalo de 20 a $30 \mathrm{mT}$, indicando cristais com uma coercividade um pouco mais elevada, ou seja, mais finos $(2-5 \mu \mathrm{m})$.
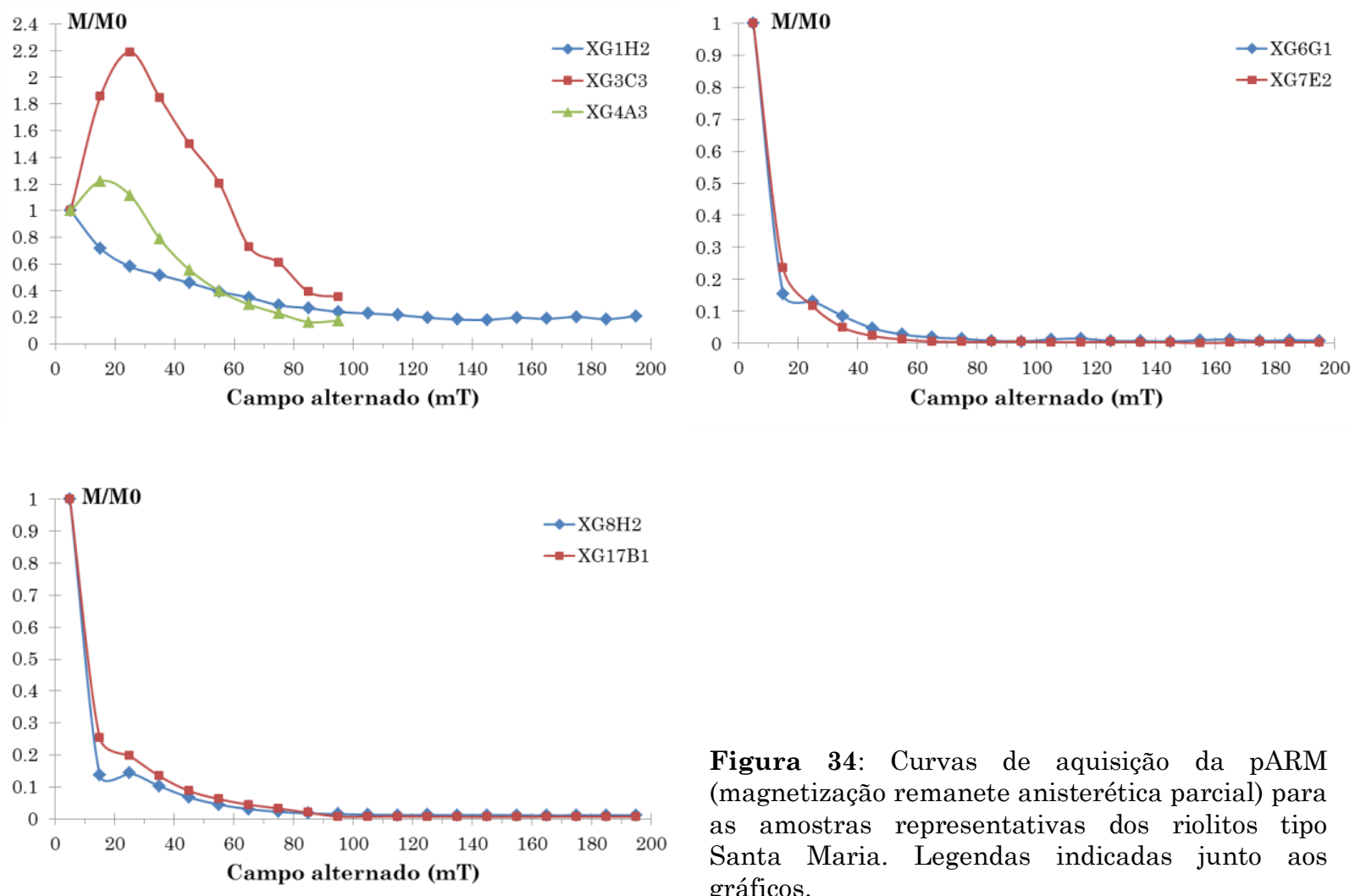

Figura 34: Curvas de aquisição da pARM (magnetização remanete anisterética parcial) para as amostras representativas dos riolitos tipo Santa Maria. Legendas indicadas junto aos gráficos. 
Adicionalmente, com estudo da saturação da magnetização do mineral magnético obtiveram-se curvas (Figura 35) onde as amostras atingem uma saturação inicial em torno de 100 mT, mantendo-se estáveis até cerca de 200 $\mathrm{mT}$, quando sofrem um pequeno aumento em sua magnetização, atingindo finalmente sua saturação - resultados que confirmam a titanomagnetita como fase mineral responsável pela magnetização e susceptibilidade das amostras. Após esta etapa efetuou-se novamente a desmagnetização por AF das amostras, as quais perdem totalmente sua magnetização em campos próximos a $100 \mathrm{mT}$ (Figura 36).
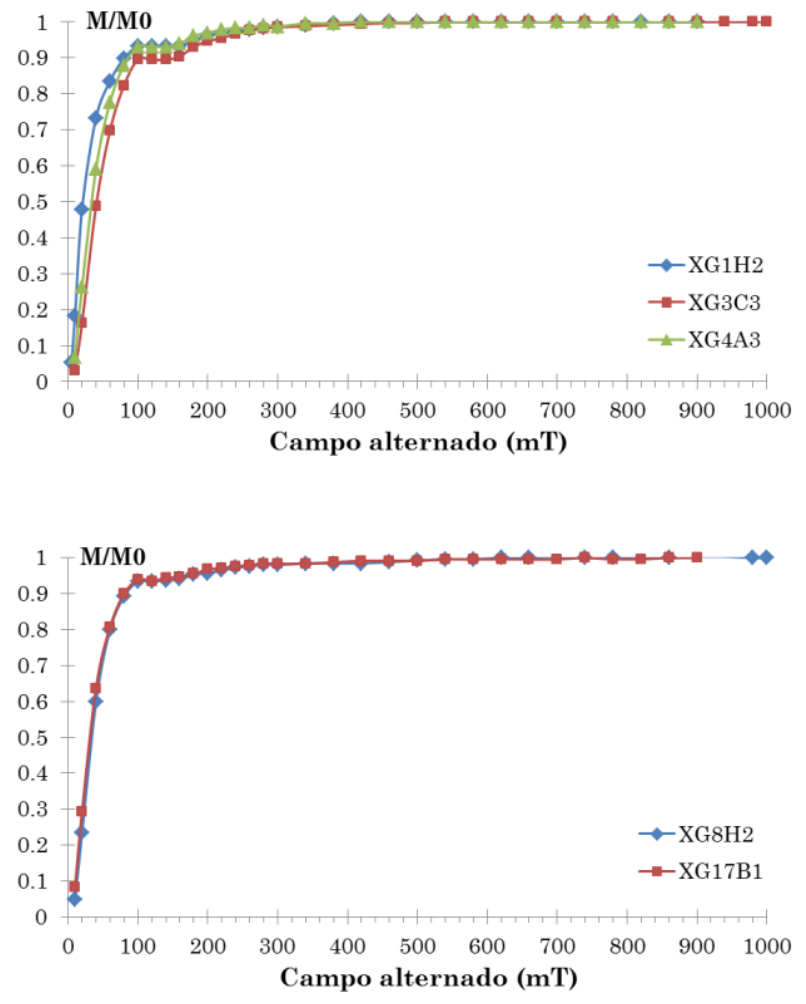

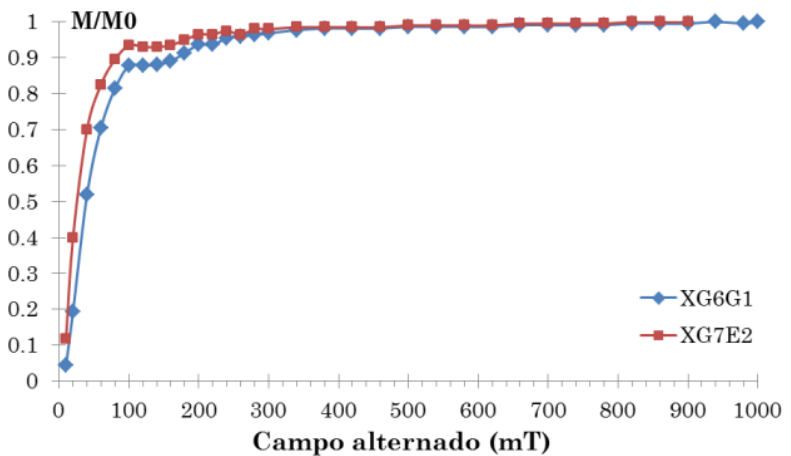

Figura 35: Curvas de aquisição de IRM para as amostras representativas dos riolitos tipo Santa Maria. Legendas indicadas junto aos gráficos. 

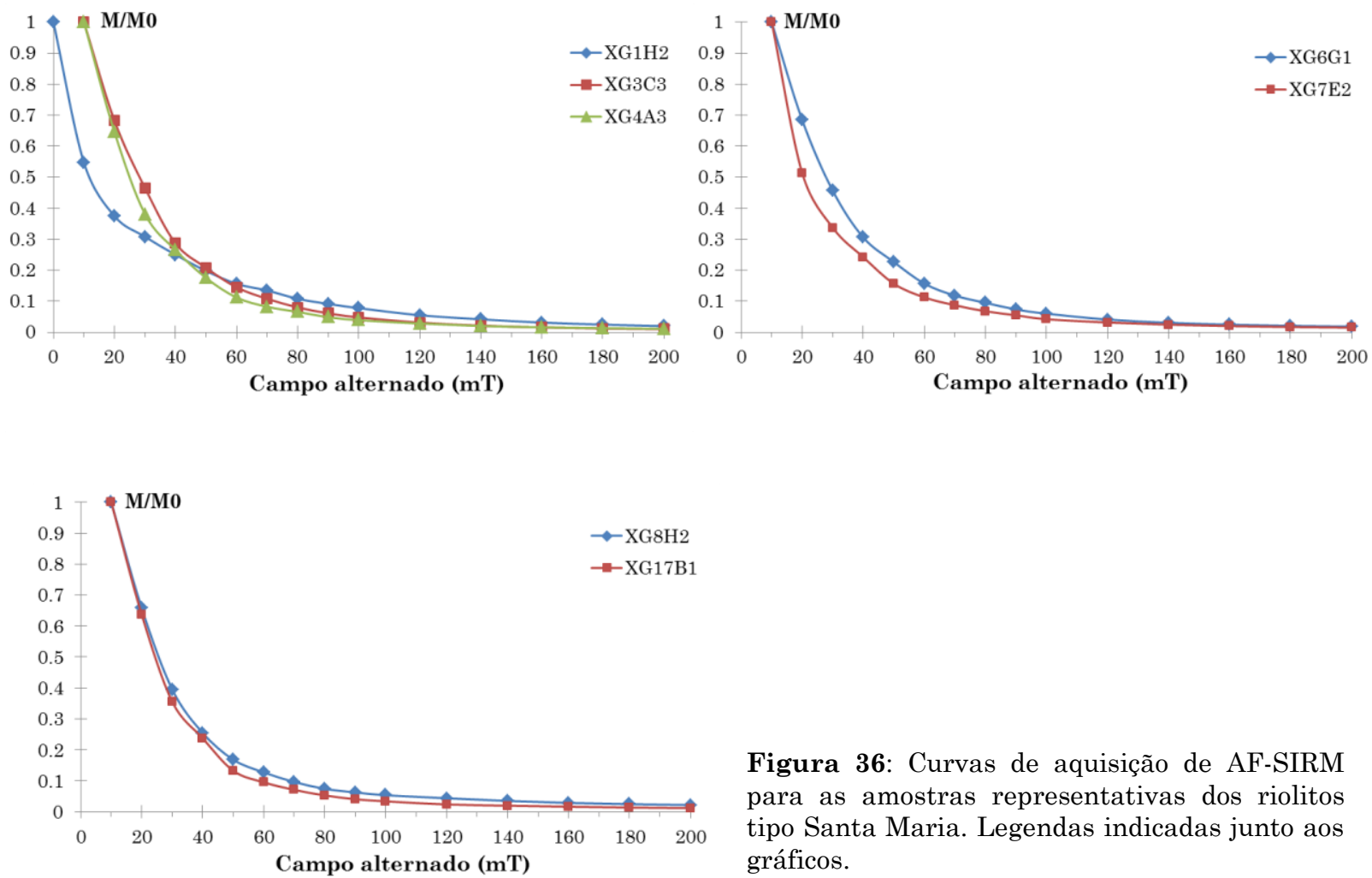

Figura 36: Curvas de aquisição de AF-SIRM para as amostras representativas dos riolitos tipo Santa Maria. Legendas indicadas junto aos gráficos.

Os resultados obtidos para os estudos de ASM são apresentados na tabela 02. Os eixos $\kappa_{\max } \geq \kappa_{\text {int }} \geq \kappa_{\min }$ apresentam-se de maneira geral com pequena dispersão e a susceptibilidade magnética total (expressa por: $\kappa_{\mathrm{t}}=\left[\kappa_{\max }+\kappa_{\mathrm{int}}+\right.$ $\left.\kappa_{\min }\right] / 3$ ) é genericamente da ordem de $10^{-2} \mathrm{SI}$, com valor médio de $1,187 \times 10^{-2}$ SI. 
Tabela 2: Dados obtidos através das análises de ASM para cada amostra obtida e suas respectivas coordenadas geográficas.

\begin{tabular}{lllllllll}
\hline \multirow{2}{*}{ Sitio } & \multicolumn{2}{c}{ Coordenadas } & \multicolumn{2}{c}{ Parâmetros escalares } & \multicolumn{2}{c}{ Parâmetros direcionais } \\
\cline { 2 - 8 } XG-01 & Latitude & Longitude & $\mathrm{K}_{\mathrm{t}} 10^{-2}[\mathrm{SI}]$ & $\mathrm{P}$ & $\mathrm{T}$ & $\mathrm{K}_{\max }$ & $\mathrm{K}_{\text {int }}$ & $\mathrm{K}_{\min }$ \\
\hline XG-02 & $29^{\circ} 16^{\prime} 23.3^{\prime \prime}$ & $52^{\circ} 38^{\prime} 57.5^{\prime \prime}$ & 1.716 & 1.012 & 0.195 & $198 / 8$ & $288 / 3$ & $38 / 81$ \\
\hline XG-03 & $29^{\circ} 16^{\prime} 25.2^{\prime \prime}$ & $52^{\circ} 39^{\prime} 00.9^{\prime \prime}$ & 1.801 & 1.038 & -0.492 & $65 / 0$ & $155 / 21$ & $334 / 69$ \\
\hline XG-04 & $29^{\circ} 16^{\prime} 22.9^{\prime \prime}$ & $52^{\circ} 38^{\prime} 57.6^{\prime \prime}$ & 1.073 & 1.011 & 0.329 & $265 / 5$ & $355 / 1$ & $102 / 85$ \\
\hline XG-05 & $29^{\circ} 16^{\prime} 16.4^{\prime \prime}$ & $52^{\circ} 38^{\prime} 53.3^{\prime \prime}$ & 1.183 & 1.017 & -0.512 & $129 / 2$ & $219 / 6$ & $24 / 84$ \\
\hline XG-06 & $29^{\circ} 16^{\prime} 38.6^{\prime \prime}$ & $52^{\circ} 39^{\prime} 08,1^{\prime \prime}$ & 0.984 & 1.014 & -0.428 & $253 / 19$ & $151 / 32$ & $8 / 52$ \\
\hline XG-07 & $29^{\circ} 16^{\prime} 31.6^{\prime \prime}$ & $52^{\circ} 39^{\prime} 05.1^{\prime \prime}$ & 1.362 & 1.011 & 0.216 & $164 / 40$ & $35 / 36$ & $281 / 29$ \\
\hline XG-08 & $29^{\circ} 16^{\prime} 53.8^{\prime \prime}$ & $52^{\circ} 38^{\prime} 27.7^{\prime \prime}$ & 1.211 & 1.012 & -0.059 & $65 / 5$ & $333 / 13$ & $174 / 76$ \\
\hline XG-09 & $29^{\circ} 16^{\prime} 44.1^{\prime \prime}$ & $52^{\circ} 38^{\prime} 31.8^{\prime \prime}$ & 1.676 & 1.013 & 0.620 & $234 / 43$ & $341 / 17$ & $86 / 42$ \\
\hline XG-10 & $29^{\circ} 17^{\prime} 25.5^{\prime \prime}$ & $52^{\circ} 38^{\prime} 39.1^{\prime \prime}$ & 0.715 & 1.009 & 0.172 & $271 / 24$ & $11 / 20$ & $137 / 58$ \\
\hline XG-15 & $29^{\circ} 14^{\prime} 46.7^{\prime \prime}$ & $52^{\circ} 39^{\prime} 34.4^{\prime \prime}$ & 0.869 & 1.022 & 0.394 & $276 / 7$ & $182 / 25$ & $21 / 64$ \\
\hline XG-16 & $29^{\circ} 14^{\prime} 46.4^{\prime \prime}$ & $52^{\circ} 39^{\prime} 35.1^{\prime \prime}$ & 0.897 & 1.018 & -0.450 & $305 / 19$ & $51 / 39$ & $195 / 45$ \\
\hline XG-17 & $29^{\circ} 14^{\prime} 45.7^{\prime \prime}$ & $52^{\circ} 39^{\prime} 36.1^{\prime \prime}$ & 1.143 & 1.031 & -0.350 & $245 / 4$ & $335 / 0$ & $67 / 86$ \\
\hline XG-18 & $29^{\circ} 14^{\prime} 44.8^{\prime \prime}$ & $52^{\circ} 39^{\prime} 35.6^{\prime \prime}$ & 1.130 & 1.027 & 0.497 & $249 / 12$ & $341 / 9$ & $107 / 75$ \\
\hline
\end{tabular}

$\mathrm{O}$ grau de anisotropia das amostras $\left(\mathrm{P}=\kappa_{\max } / \kappa_{\min }\right)$ varia de 1.008 a 1.038, sendo possível notar uma pequena correlação onde o grau de anisotropia aumenta com a susceptibilidade total da amostra (Figura 37). A relação entre a forma dos cristais (T) e o grau de anisotropia (P) é apresentada na Figura 38, onde nota-se que as amostras dos riolitos tipo Santa Maria apresentam cristais tanto oblatos quanto prolatos. 


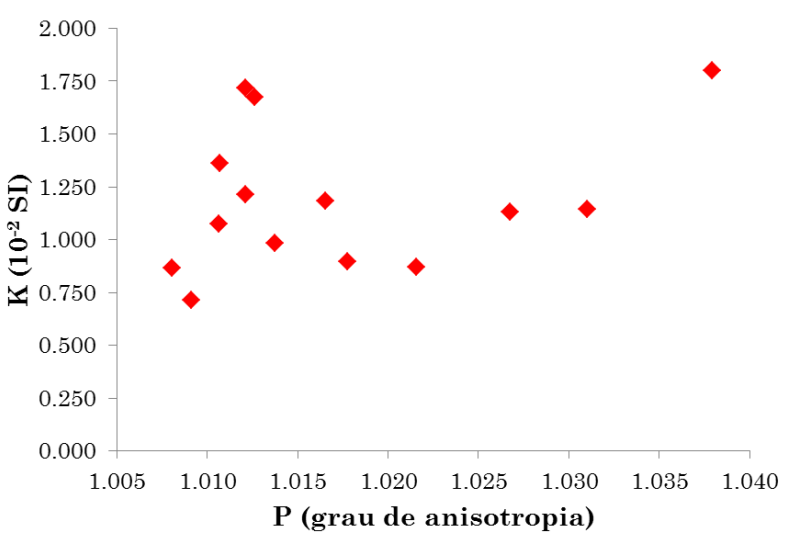

Figura 37: Diagrama de correlação entre a susceptibilidade total da amostra (K) e o grau de anisotropia $(\mathrm{P})$.

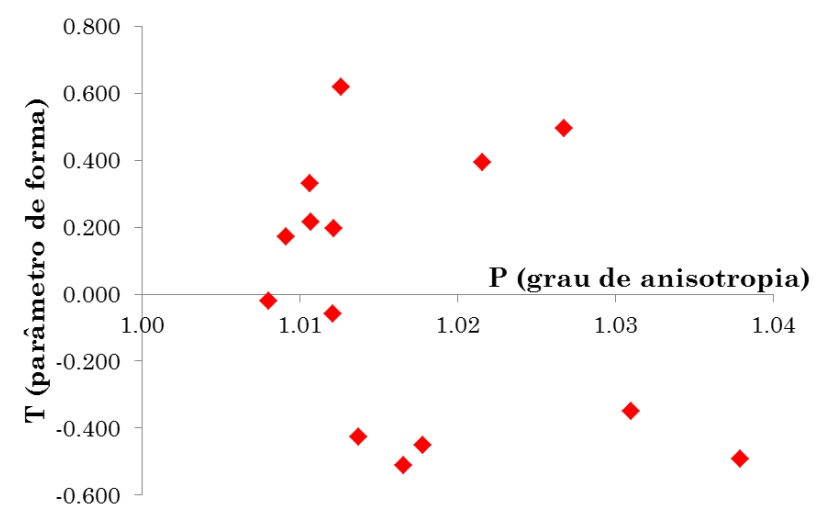

Figura 38: Diagrama de correlação entre os parâmetros de forma $(\mathrm{T})$ e grau de anisotropia $(\mathrm{P})$ para os riolitos Santa Maria.

\section{IV.2.2.1. Resultados da ASM para os riolitos tipo Santa Maria}

As anisotropias de susceptibilidade magnética dos riolitos tipo Santa Maria permitiram a obtenção de dados estruturais como foliação e lineação magnéticas, estreitamente relacionadas às estruturas magmáticas equivalentes, de difícil determinação em sistemas vulcânicos. No caso de tramas normais, o eixo $\kappa_{\max }$ do elipsoide de anisotropia coincide com o eixo maior do cristal, o qual se alinha de acordo com o fluxo magmático. Deste modo, a lineação é definida pelo eixo $\kappa_{\max }$ e o plano de foliação é definido pelos eixos $\kappa_{\max }$ e $\kappa_{\text {int }}$, sendo o eixo $\kappa_{\min }$ o polo desta foliação (como já descrito no item IV.2.1.2). Os resultados obtidos são apresentados na tabela 03, a seguir, e o anexo 01 traz os mapas geológicos e os croquis dos afloramentos com os dados estruturais (tanto de atitudes das disjunções - feições-guia utilizadas em campo, quanto das foliações magnéticas). 
Tabela 3: Coordenadas UTM dos sítios de amostragem, dados estruturais obtidos em campo (1 correspondentes à fraturas e disjunções associadas à resfriamento) e dados estruturais magnéticos (foliação e lineação).

\begin{tabular}{|c|c|c|c|c|c|c|}
\hline \multirow{3}{*}{ Sitio } & \multirow{2}{*}{\multicolumn{2}{|c|}{ Coordenadas (UTM - zona 22S) }} & \multirow{3}{*}{ Dados estruturais (campo) $^{1}$} & \multicolumn{3}{|c|}{ Dados estruturais magnéticos (ASM) } \\
\hline & & & & \multirow{2}{*}{ Foliação } & \multicolumn{2}{|c|}{ Lineação } \\
\hline & Latitude & Longitude & & & Rumo & Mergulho \\
\hline XG-01 & 339763 & 6760578 & - & N52W / 09SW & 198 & 8 \\
\hline XG-02 & 339672 & 6760518 & N65E/44SE & N64E / 21SE & 65 & 0 \\
\hline XG-03 & 339763 & 6760590 & $\begin{array}{c}\text { N68W/15SW ; N10E/25NW ; } \\
\text { N22E/17NW ; N-S/20W ; } \\
\text { N25W/15SW }\end{array}$ & $\mathrm{N} 12 \mathrm{E} / 05 \mathrm{NW}$ & 265 & 5 \\
\hline XG-04 & 339875 & 6760693 & - & N66W / 06SW & 129 & 2 \\
\hline XG-05 & 339990 & 6760793 & $\begin{array}{c}\text { N70E/74NW ; N74E/74NW ; } \\
\text { N70E/70NW }\end{array}$ & N82W / 38SW & 253 & 19 \\
\hline $\mathrm{XG}-06$ & 339484 & 6760103 & $\begin{array}{c}\text { N22E/32SE ; N32E/15SE ; } \\
\text { N25E/17SE }\end{array}$ & N07W / 28NE & 170 & 2 \\
\hline XG-07 & 339562 & 6760319 & $\begin{array}{c}\mathrm{N} 16 \mathrm{E} / 28 \mathrm{SE} ; \mathrm{N}-\mathrm{S} / 24 \mathrm{SE} ; \\
\mathrm{N} 15 \mathrm{E} / 25 \mathrm{SE}\end{array}$ & N11E / 61SE & 164 & 40 \\
\hline XG-08 & 340581 & 6759650 & - & N84E / 14NW & 65 & 5 \\
\hline XG-09 & 340466 & 6759947 & $\begin{array}{c}\text { N06E/65SE ; N04E/61SE; } \\
\text { N25E/64SE }\end{array}$ & N04W / 48SW & 234 & 43 \\
\hline XG-10 & 340287 & 6758670 & $\begin{array}{c}\text { N34E/18SE ; N20E/20SE ; } \\
\text { N40E/vert ; N45E/vert ; } \\
\text { N50E/vert } \\
\end{array}$ & N47E / 32NW & 271 & 24 \\
\hline XG-15 & 338725 & 6763537 & N84E/71NW ; N71E/79NW & N69W / 26SW & 276 & 7 \\
\hline$X G-16$ & 338706 & 6763546 & $\begin{array}{c}\mathrm{N} 75 \mathrm{E} / 62 \mathrm{NW} ; \mathrm{N} 86 \mathrm{E} / 50 \mathrm{NW} ; \\
\mathrm{N} 83 \mathrm{E} / 62 \mathrm{NW}\end{array}$ & N75W / 45NE & 305 & 19 \\
\hline XG-17 & 338679 & 6763567 & $\begin{array}{c}\mathrm{N} 67 \mathrm{E} / 25 \mathrm{NW} ; \mathrm{N} 45 \mathrm{E} / 35 \mathrm{NW} ; \\
\mathrm{N} 74 \mathrm{E} / 36 \mathrm{NW} ; \mathrm{N} 64 \mathrm{E} / 50 \mathrm{NW} ; \\
\mathrm{N} 72 \mathrm{E} / 60 \mathrm{NW} ; \mathrm{N} 64 \mathrm{E} / 74 \mathrm{NW} ; \\
\mathrm{N} 66 \mathrm{E} / 80 \mathrm{NW} ; \mathrm{N} 80 \mathrm{E} / 50 \mathrm{SE} ; \\
\mathrm{N} 46 \mathrm{E} / 46 \mathrm{SE} ; \mathrm{N} 25 \mathrm{~W} / 75 \mathrm{SW} ; \\
\mathrm{N} 24 \mathrm{~W} / 80 \mathrm{SW}\end{array}$ & N28W / 04SW & 245 & 4 \\
\hline XG-18 & 338692 & 6763595 & $\begin{array}{c}\text { N44W/47SW ; N53W/50SW ; } \\
\text { N45W/54SW ; N60W/50NE ; } \\
\text { N56W/56NE }\end{array}$ & N17E / 15NW & 249 & 12 \\
\hline
\end{tabular}

As foliações e lineações magnéticas apresentam-se dispersas, e a análise dos eixos principais de máxima $\left(\mathrm{K}_{\mathrm{max}}\right)$, intermediária $\left(\mathrm{K}_{\mathrm{int}}\right)$ e mínima $\left(\mathrm{K}_{\min }\right)$ suscetibilidade magnética permitiu identificar quatro grupos distintos de trama magnética. Em todos os tipos o elipsóide de suscetibilidade magnética é triaxial, ou seja, os três eixos principais são independentes e bem agrupados, 
com exceção dos três sítios onde ocorre uma guirlanda entre $\mathrm{K}_{\max }$ e $\mathrm{K}_{\text {int }}$ (XG-03, XG-10 e XG-18).

O primeiro tipo de trama magnética é predominante e caracteriza-se pelo pólo da foliação magnética $\left(\mathrm{K}_{\mathrm{min}}\right)$ vertical a sub-vertical, perpendicular à foliação magnética (plano formado pelos eixos $\mathrm{K}_{\max }-\mathrm{K}_{\mathrm{int}}$ ). Nestes casos, a lineação magnética (eixo $\mathrm{K}_{\max }$ ) é horizontal (mergulhos de até $12^{\circ}$ ) e as foliações apresentam mergulhos de até $\sim 20^{\circ}$, com direções bastante dispersas (Figura $39)$.
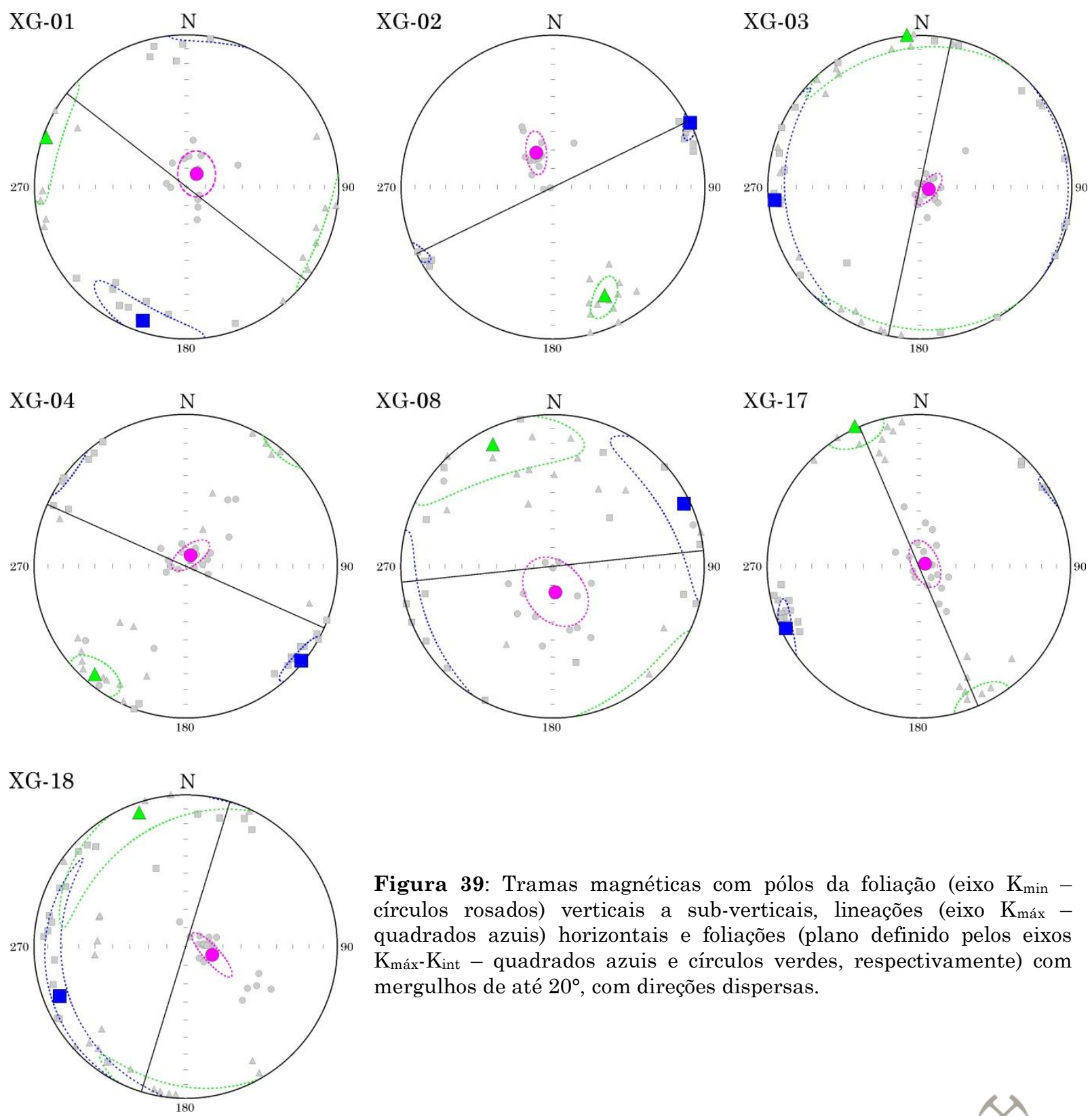

Figura 39: Tramas magnéticas com pólos da foliação (eixo $K_{\min }-$ círculos rosados) verticais a sub-verticais, lineações (eixo $K_{\text {máx - }}$ quadrados azuis) horizontais e foliações (plano definido pelos eixos $\mathrm{K}_{\text {máx }}-\mathrm{K}_{\text {int }}$ - quadrados azuis e círculos verdes, respectivamente) com mergulhos de até $20^{\circ}$, com direções dispersas. 
No segundo tipo de trama magnética, o pólo da foliação é mais inclinado $\left(\mathrm{K}_{\min }=62^{\circ}-64^{\circ}\right)$, com foliações magnéticas com mergulhos entre $25^{\circ}$ e $30^{\circ} \mathrm{e}$ lineações horizontais, com mergulhos inferiores a $10^{\circ}$ e orientações aproximadamente N-S e E-W (Figura 40).
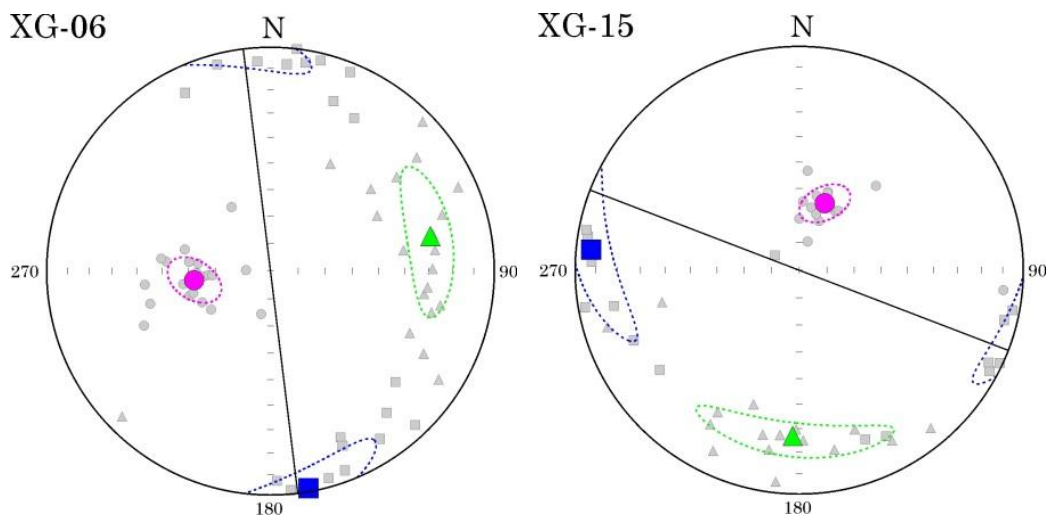

Figura 40: Tramas magnéticas com pólos de foliação (eixo Kmin círculos rosados) com caimentos em torno de $60^{\circ}$, foliações (planos definidos pelos eixos $\mathrm{K}_{\text {máx }}-\mathrm{K}_{\text {int }}$ quadrados azuis e círculos verdes, respectivamente) com mergulhos entre $25^{\circ}$ e $30^{\circ}$ e lineações (eixo $K_{\text {máx }}$ - quadrados azuis) horizontais.

O terceiro tipo de trama magnética caracteriza-se por pólos de inclinações entre $50^{\circ}$ e $60^{\circ}$, com lineações apresentando direção aproximadamente E-W com maiores caimentos em relação dois primeiros grupos $\left(19^{\circ}\right.$ e $\left.24^{\circ}\right)$ e foliações magnéticas apresentando mergulhos de entre $30^{\circ}$ e $40^{\circ}$ (Figura 41).
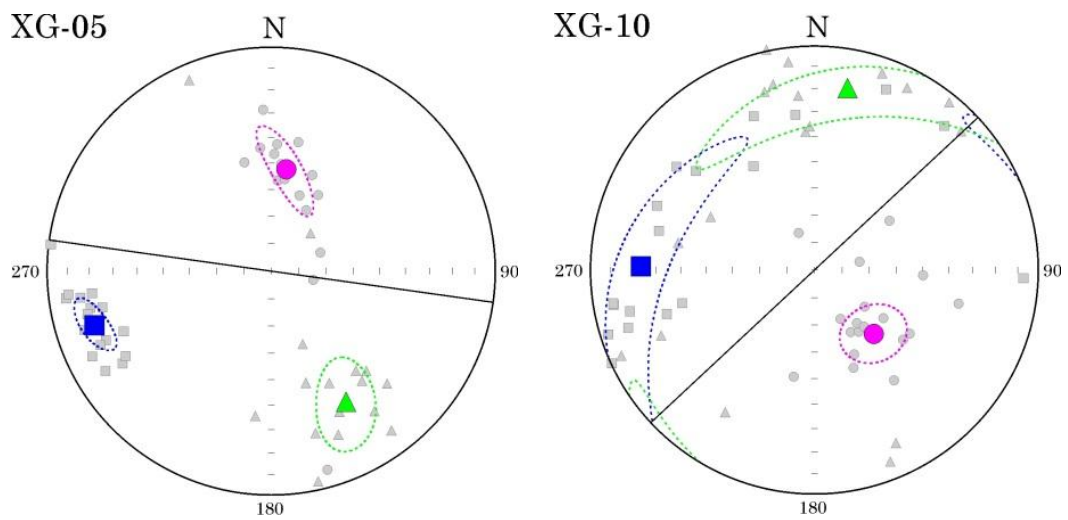

Figura 41: Tramas magnéticas com pólo da foliação (eixo Kmin - círculos rosados) com caimentos de 50-60, lineações aproximadamente E-W com caimentos de $19^{\circ}-24^{\circ}$ (eixo $\mathrm{K}_{\text {máx }}$ - quadrados azuis) e foliações (planos definidos pelos eixos $\mathrm{K}_{\text {máx }}-\mathrm{K}_{\text {int }}$ - quadrados azuis e círculos verdes, respectivamente) com mergulhos entre $30^{\circ}$ e $40^{\circ}$. 
O último grupo apresenta trama magnética com o polo da foliação menos inclinado, variando entre $29^{\circ}$ e $45^{\circ}$, com lineações NW-SE e NE-SW com mergulhos intermediários, de $19^{\circ}$ a $43^{\circ}$ e foliações com maiores mergulhos, de $45^{\circ}$ a $61^{\circ}$ (Figura 42 ).
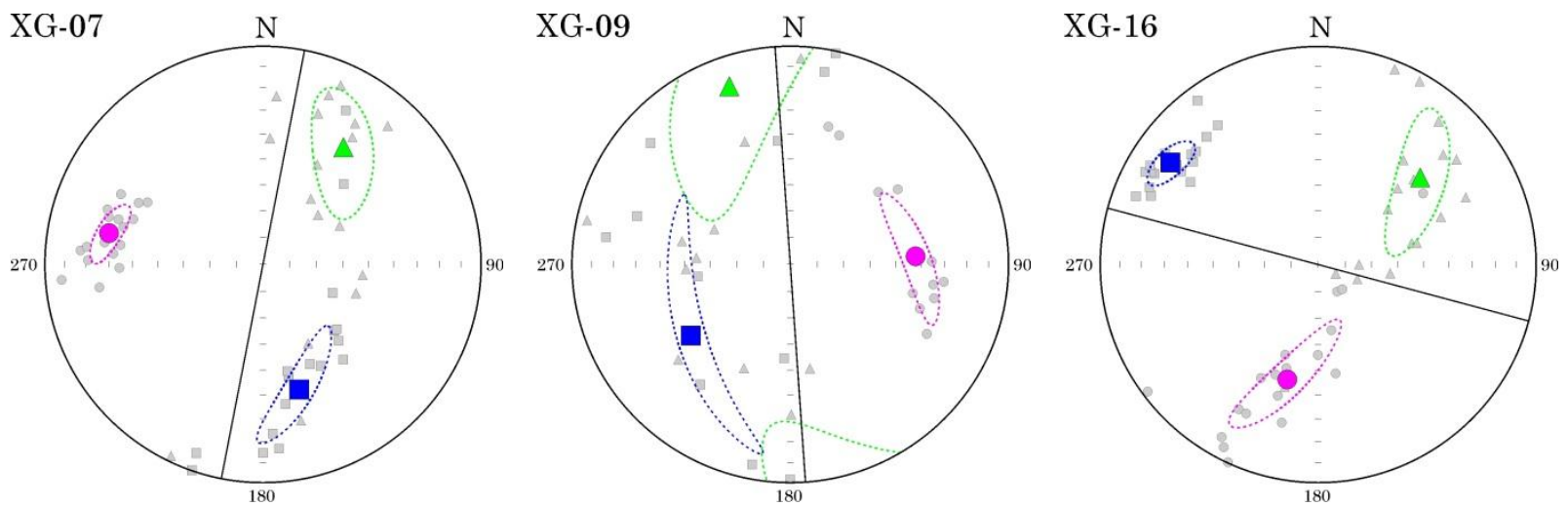

Figura 42: Tramas magnéticas com pólo da foliação (eixo $K_{\min }$ - círculos rosados) com caimentos de 29$45^{\circ}$, lineações aproximadamente NW-SE e NE-SW com caimentos de $19^{\circ}-43^{\circ}$ (eixo $\mathrm{K}_{\text {máx }}$ - quadrados azuis) e foliações (planos definidos pelos eixos $\mathrm{K}_{\text {máx }}-\mathrm{K}_{\text {int }}$ - quadrados azuis e círculos verdes, respectivamente) com maiores mergulhos, entre $45^{\circ}$ e $61^{\circ}$.

Apesar da dispersão dos dados de foliação e lineação, é possível reconhecer mergulhos preferenciais para SW e NW no caso da foliação, e para SW no caso da lineação (Figura 43 - diagrama em roseta para a distribuição das atitudes das lineações magnéticas).

Figura 43: Diagrama em roseta mostrando a frequência para as diferentes direções das lineações magnéticas dos riolitos Santa Maria $\left(\right.$ direção média $\left.=231.4^{\circ}\right)$.

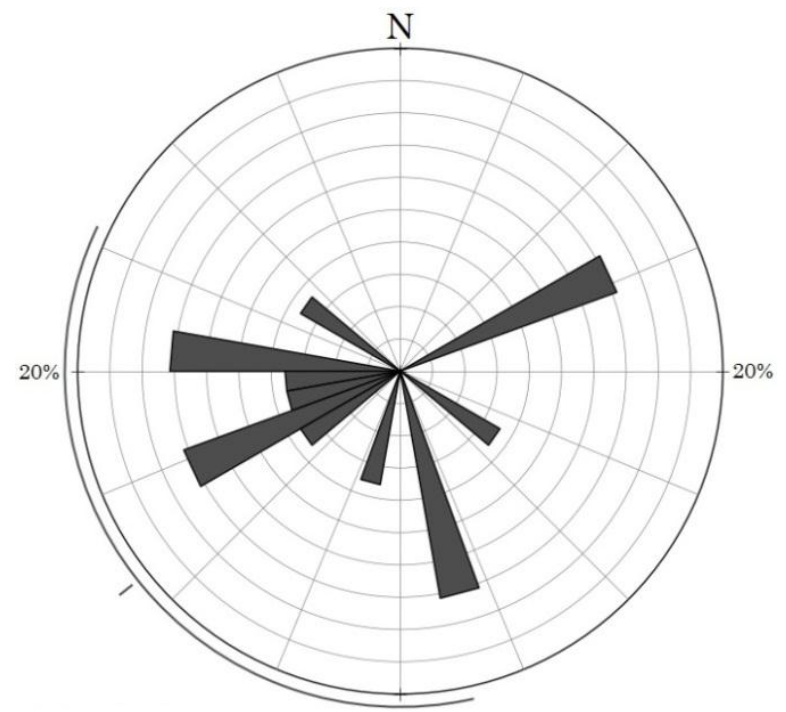


As direções das foliações magnéticas, quando comparadas aos dados estruturais obtidos em campo (referentes às disjunções de resfriamento e a fraturas associadas ao cisalhamento resultante do fluxo de lava), mostram-se coincidentes em alguns sítios de amostragem, como é o caso dos pontos XG-01, XG-02, XG-03 e XG-07. A distribuição espacial das direções magnéticas evidencia estruturas de geometria circular com caimento centrípeto, as quais, quando tomadas em conjunto com medidas estruturais obtidas em campo, e com sua associação com morros de morfologia dômica, configuram evidência importante da existência de estruturas do tipo lava-domos.

Quanto às lineações, os dados mostram padrões de inversão (e.g. SW para NE), quando considerada a estratigrafia dos sítios de amostragem, que podem estar associados a diferentes porções do corpo magmático extrudido e/ou mesmo à sucessão de pulsos magmáticos durante a formação do corpo vulcânico. Estes padrões de reversão em seções verticais são considerados por McPhie et al. (2008) como resultantes de variações no cisalhamento associado ao fluxo da lava e são utilizados por Loock et al. (2008) para a definição de diferentes unidades e sistemas reológicos dentro de um mesmo corpo.

Os valores de mergulho, tanto das foliações quando das lineações, apresentam-se bastante variáveis, o que pode estar associado à localização dentro da própria estrutura vulcânica em formação ou mesmo à presença de paleo-relevos originados pelas ocorrências vulcânicas precedentes (possivelmente viabilizada pela ocorrência local de corpos dômicos, como descrito por Polo \& Janasi, 2014 - diferentemente do que ocorreria caso o sistema vulcânico correspondesse a fluxos reoignimbríticos, como sugerido na literatura: tais fluxos tenderiam a aplainar o terreno e a exibir foliação e lineação horizontalizadas). 


\section{CAPITULO V - PETROGRAFIA E QUÍMICA MINERAL}

A Sequência Vulcânica Santa Maria é constituída por rocha hipohialina afanítica, caracterizada, de maneira geral, por matriz vítrea, com grau de desvitrificação variável, onde ocorrem dispersos microfenocristais de plagioclásio, pigeonita e Ti-magnetita.

O processo de desvitrificação é responsável pelas texturas microgranofírica (Figura 44) e esferulítica, i.e. intercrescimento de cristais fibrosos de quartzo e feldspato potássico com um padrão esférico (Figura 45).

É comum a ocorrência de vesículas e amígdalas, geralmente preenchidas por calcedônia, com geometria arredondada apresentando diâmetros de até 2 mm (Figura 45) ou estirada, em formato de "gota", com diâmetro de até 4 milímetros (Figura 46).

Feições de fluxo magmático são evidentes não apenas pelo estiramento das vesículas e amígdalas, mas também pela orientação dos micro-cristais e microfenocristais (Figuras 44 e 47).

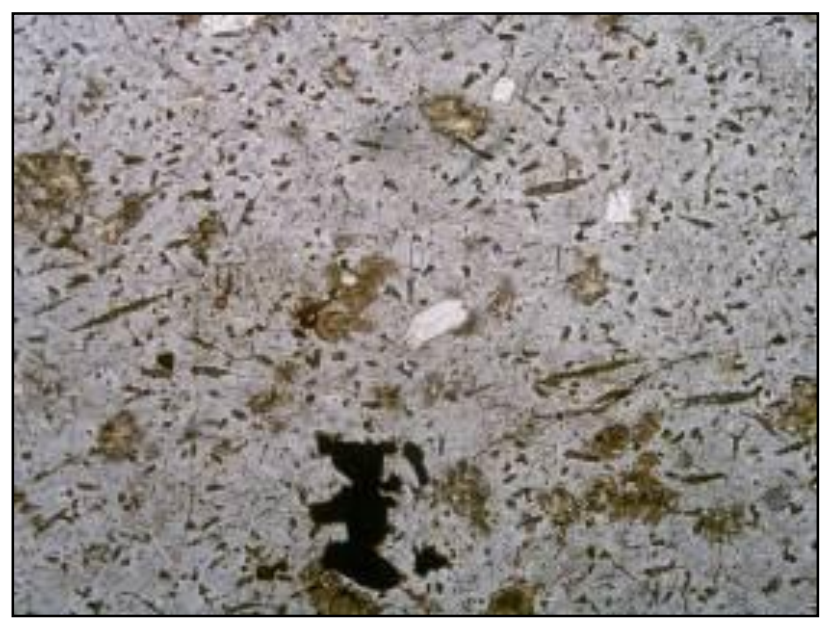

Figura 44: Fotomicrografia da amostra GX-125. Riolito com matriz vítrea, e pequenas porções afetadas por desvitrificação (coloração acastanhada). Notar orientação dos cristais de piroxênio e plagioclásio devido fluxo magmático. Escala: Lado maior apresenta 5,20 mm. 

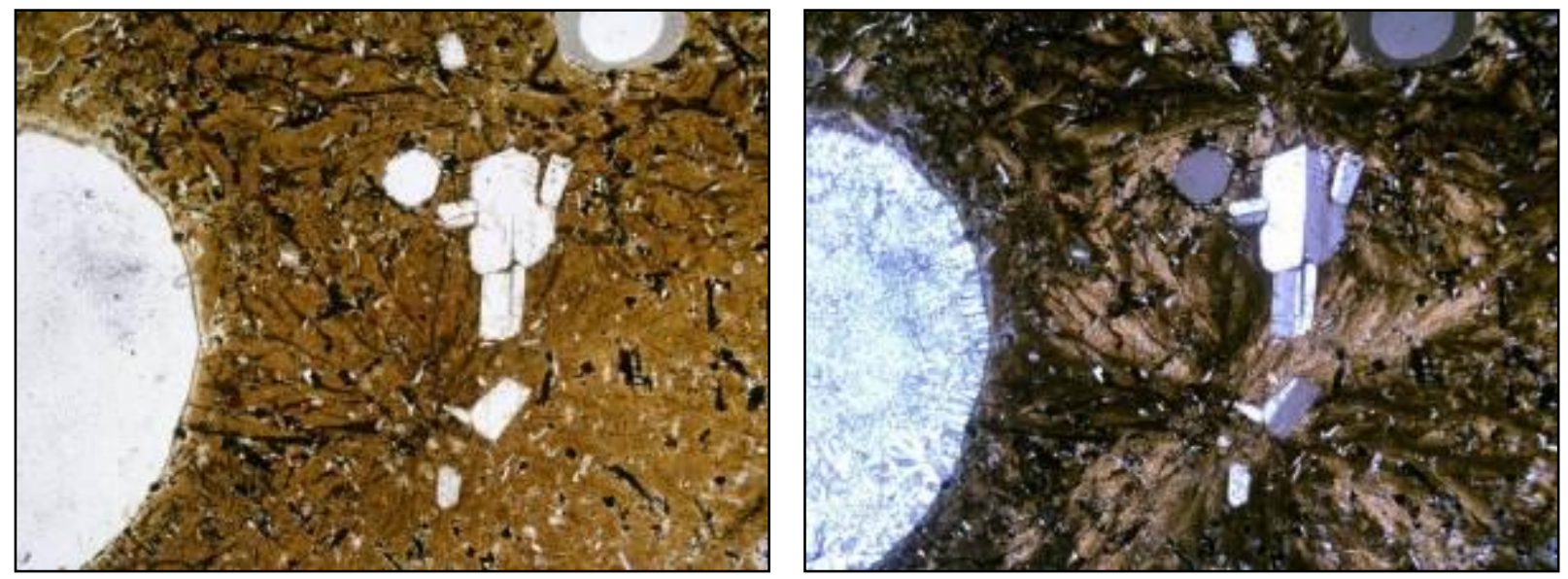

Figura 45: Fotomicrografia da amostra GX-124 - Polarizadores paralelos à esquerda e cruzados à direita. Riolito com matriz intensamente desvitrificada, onde é possível notar o padrão radial de intercrescimento entre quartzo e feldspato potássico (esferulitos). Observa-se aglomerado de microfenocristais de plagioclásio e vesícula arredondada preenchida por calcedônia. Escala: Lado maior apresenta $3,25 \mathrm{~mm}$.
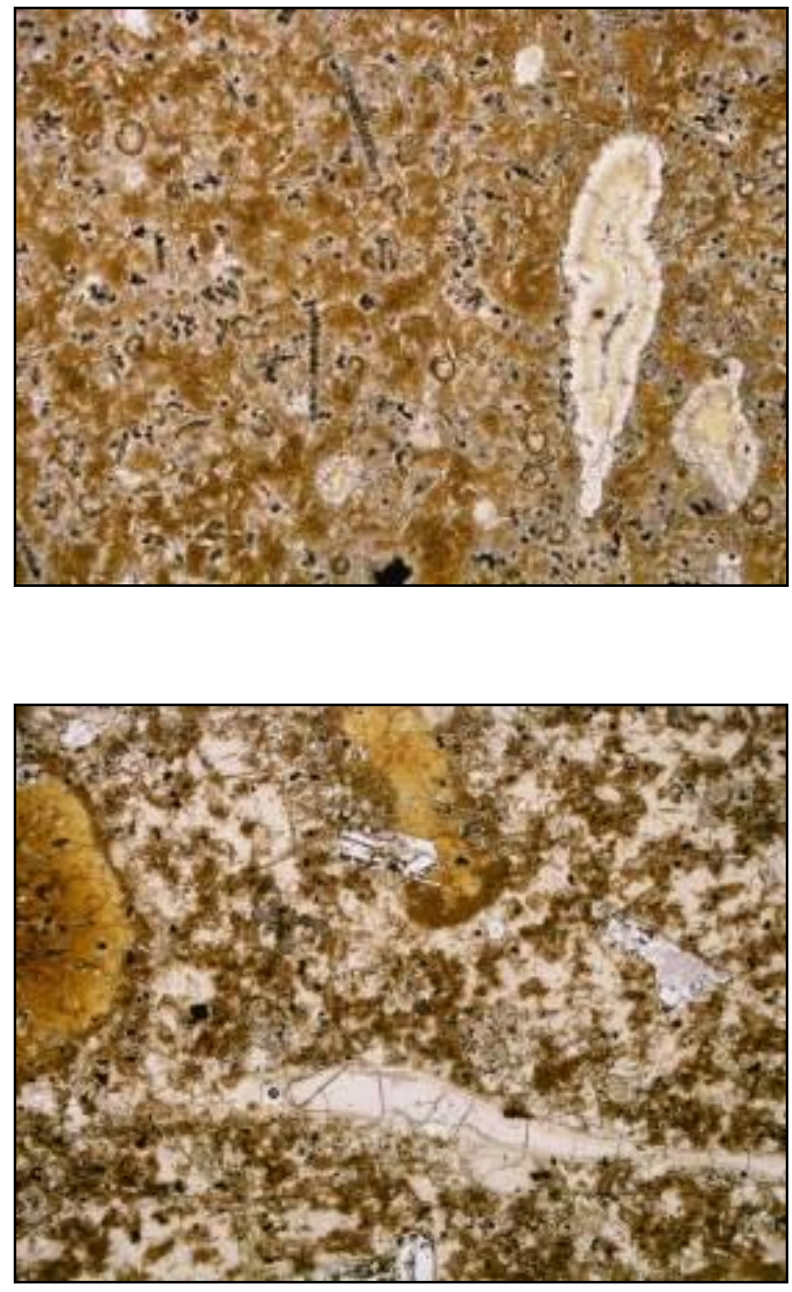

Figura 46: Fotomicrografia da amostra GX-127. Riolito com matriz vítrea, com porções afetadas por desvitrificação (coloração acastanhada). Notar vesículas estiradas e preenchidas por calcedônia e cristais de piroxênio orientados segundo o estiramento das vesículas, evidenciando direção do fluxo magmático. Escala: Lado maior apresenta $3,25 \mathrm{~mm}$.

Figura 47: Fotomicrografia da amostra GX-140. Riolito com matriz vítrea, com pequenas porções desvitrificadas (esferulitos de coloração acastanhada). Notar vesículas estiradas e cristais de piroxênio e plagioclásio orientados segundo o estiramento das vesículas, evidenciando direção do fluxo magmático. Escala: Lado maior apresenta $3,25 \mathrm{~mm}$. 


\section{V.1. $\underline{\text { VIDRO }}$}

$\mathrm{O}$ vidro é o principal constituinte da matriz da rocha. Apresenta-se incolor quando não alterado; entretanto, em muitos casos, foi afetado por processos de desvitrificação, passando a apresentar coloração acastanhada, na qual pode ocorrer textura microgranofírica. Os produtos de desvitrificação podem se formar nos contatos com os cristais ou ainda apresentar-se fibro-radiados, gerando esferulitos.

Do ponto de vista químico, o vidro foi analisado por microssonda eletrônica com o objetivo de conhecer sua composição e fazer uma comparação entre a fase vítrea e a fase desvitrificada (cristalina), ambas caracterizadas com composições riolíticas, como é possível observar na Figura 48, onde é apresentado o diagrama classificatório para rochas vulcânicas de Le Bas et. al. (1986).

TAS (Le Bas et al. 1986)

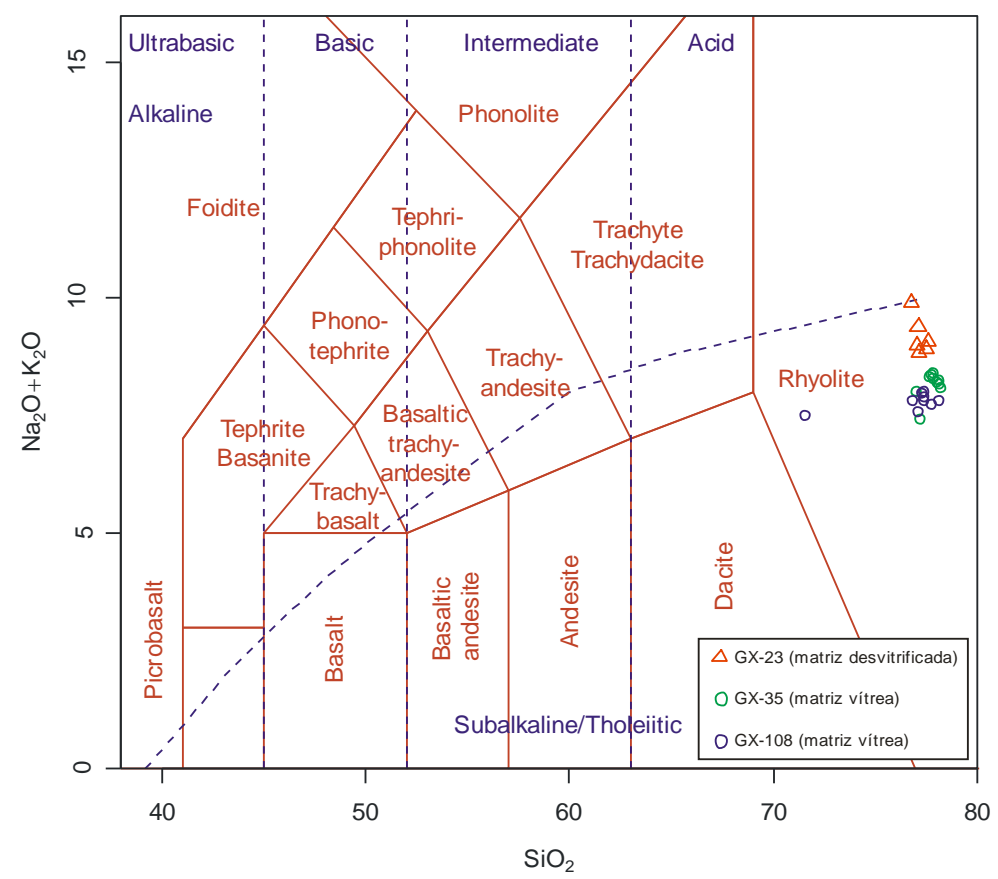

Figura 48: Diagrama classificatório para as análises de vidro obtidas por microssonda (Le Bas et. al., 1986). 
A comparação dos teores dos elementos maiores (Figura 49) permite observar que a amostra desvitrificada apresenta teores menores de $\mathrm{TiO}_{2}$ e $\mathrm{FeO}_{\mathrm{t}}$ e maiores de $\mathrm{K}_{2} \mathrm{O}$ e $\mathrm{MgO}$ em relação às amostras vítreas. Além disto, as amostras vítreas apresentam o fechamento das análises inferior ao das amostras desvitrificadas, refletindo maior proporção de voláteis.
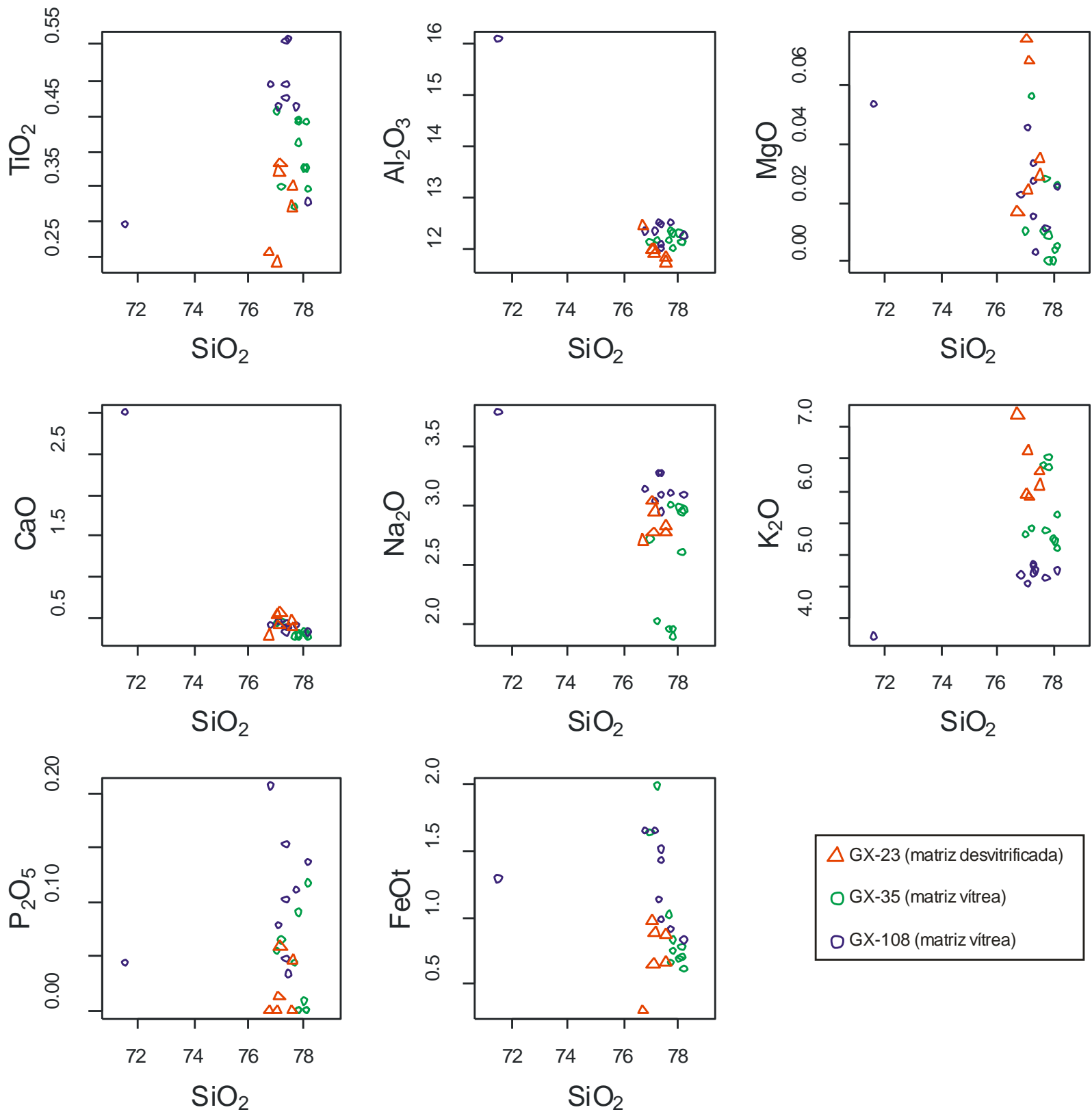

Figura 49: Diagramas tipo Harker (elementos maiores vs SiO2 para as análises de vidro (matriz). A simbologia utilizada é indicada junto aos diagramas. 


\section{V.2. PLAGIOCLÁSIO}

O plagioclásio pode ocorrer em proporções de até $8 \%$ do volume da rocha, sob a forma de micrólitos (cristais esqueléticos), microcristais euédricos de até 0,2 $\mathrm{mm}$, podendo apresentar feições de resfriamento rápido (terminação tipo "rabo de andorinha"), e microfenocristais de até $1,5 \mathrm{~mm}$ dispersos na matriz (Figuras 50 e 51).

Os microfenocristais chegam a perfazer até $4 \%$ da rocha e exibem, comumente, geminação polissintética. Podem apresentar-se euédricos (Figura 50), com geometria tabular, ou subédricos a anédricos, com geometria arredondada e superfície lisa, claramente mostrando feições de reabsorção. Estas feições podem afetar apenas as bordas dos cristais ou caracterizar-se como pervasivas, afetando todo o cristal (Figura 52).

Zonamentos composicionais oscilatórios ou tipo núcleo-borda são comuns nos microfenocristais e apresentam-se concêntricos, oscilatórios ou em "degraus" (Streck, 2008) (Figura 50). Esses padrões foram estudados através de microscopia eletrônica de varredura (MEV - imagens e tabelas de resultados apresentadas no anexo 02) a fim de direcionar as análises de química mineral descritas adiante.
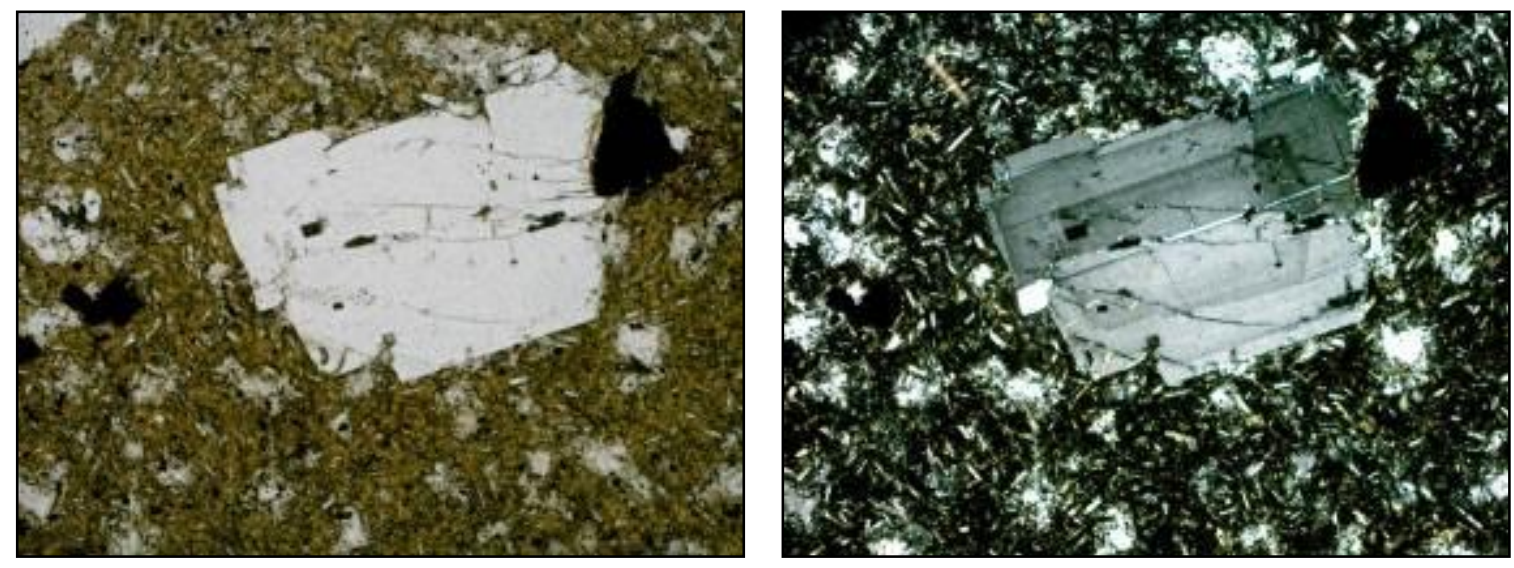

Figura 50: Fotomicrografia da amostra RS-73. Riolito apresentando matriz intensamente desvitrificada (coloração acastanhada) e microfenocristal de plagioclásio euédrico, com zoneamento oscilatório concêntrico. Escala: lado maior da foto $3,25 \mathrm{~mm}$. 

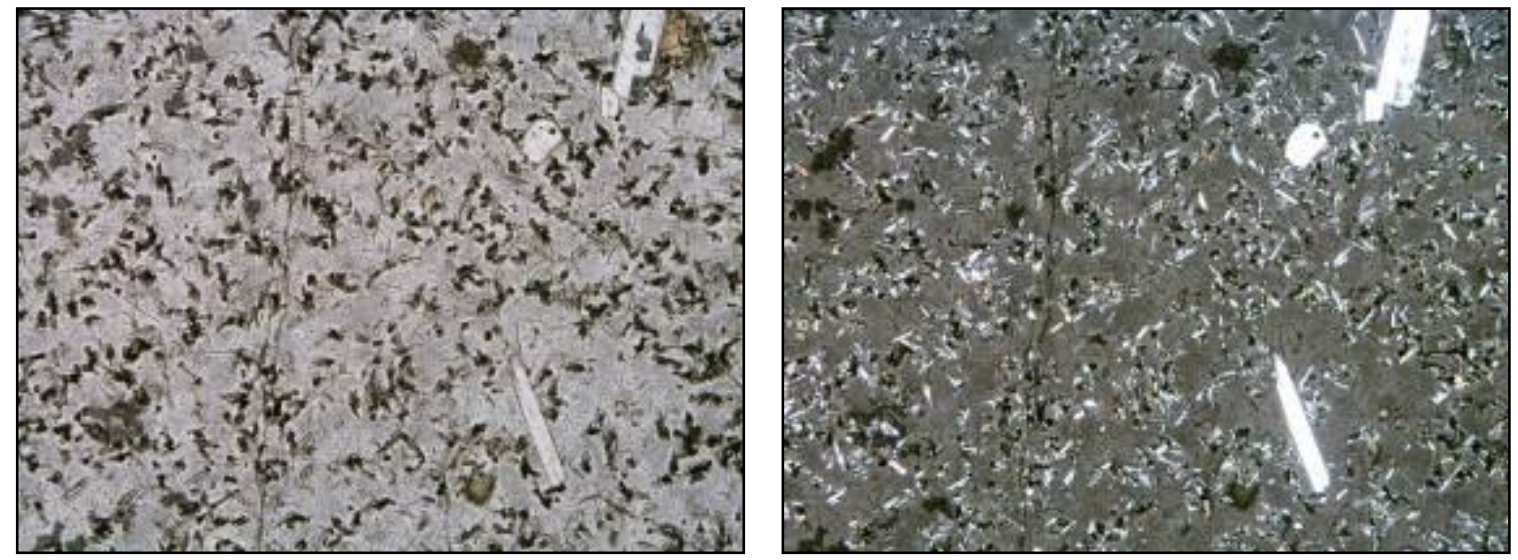

Figura 51: Fotomicrografia da amostra TF-02E (RS-74A). Riolito apresentando matriz vítrea e cristais de plagioclásio euédricos, sob a forma de micrólitos dispersos na matriz e microfenocristais de geometria tabular (canto direito da foto). Escala: lado maior da foto 2,60 $\mathrm{mm}$.
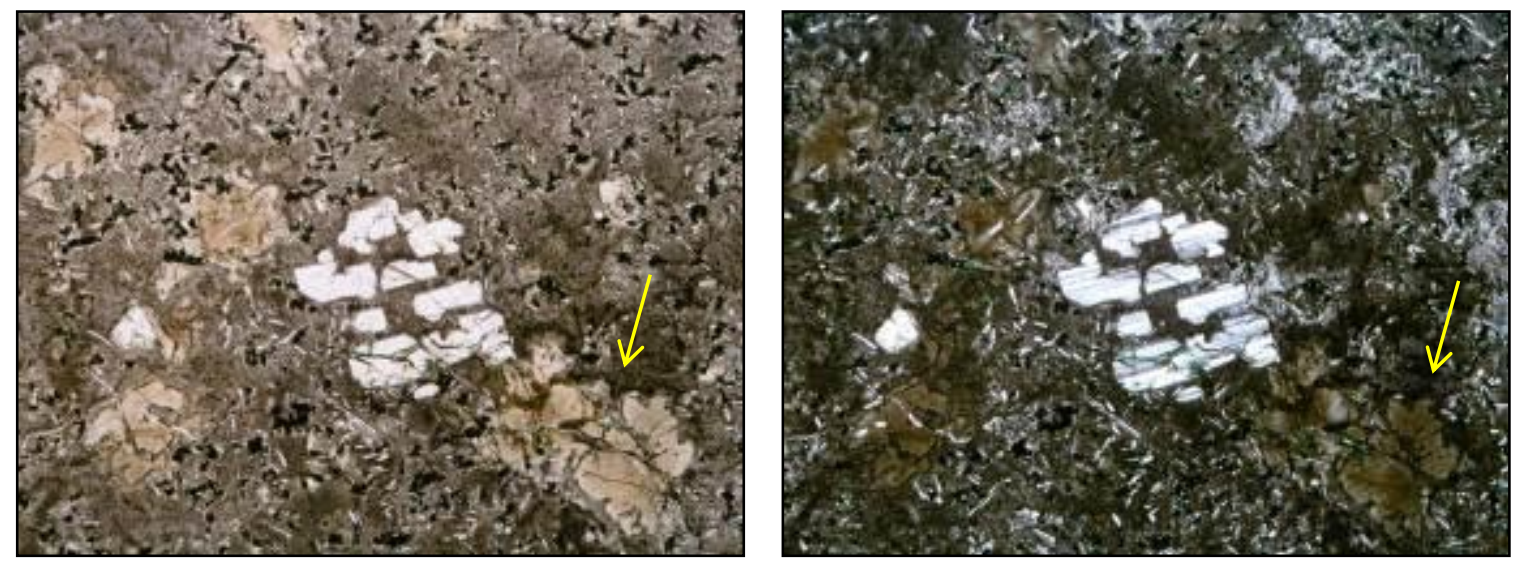

Figura 52: Fotomicrografia da amostra TF-02F (RS-74B). Riolito apresentando matriz desvitrificada, localmente caracterizada por textura granofírica e em padrão radial (esferulitos - seta amarela) e microfenocristal de plagioclásio apresentando lei da albita, anédrico, afetado por reações de reabsorção (gerando feições tipo "esponja”). Escala: lado maior da foto 2,60 mm.

Do ponto de vista químico, os plagioclásios caracterizam-se por proporções do componente An que variam de 46\% a 60\%, apresentando composições predominantes no campo da labradorita; os menores conteúdos, correspondendo à composição de andesina, são típicos dos microcristais (Figura 53). De maneira geral, os teores de potássio não mostram variações significativas, apresentando-se entre 0,42 e 0,79\%. Os teores de $\mathrm{Fe}_{2} \mathrm{O}_{3}$ e $\mathrm{MgO}$ apresentaram maiores variações, entre 0,69 e $1,31 \%$ e 0,03 e 0,15\%, respectivamente. 


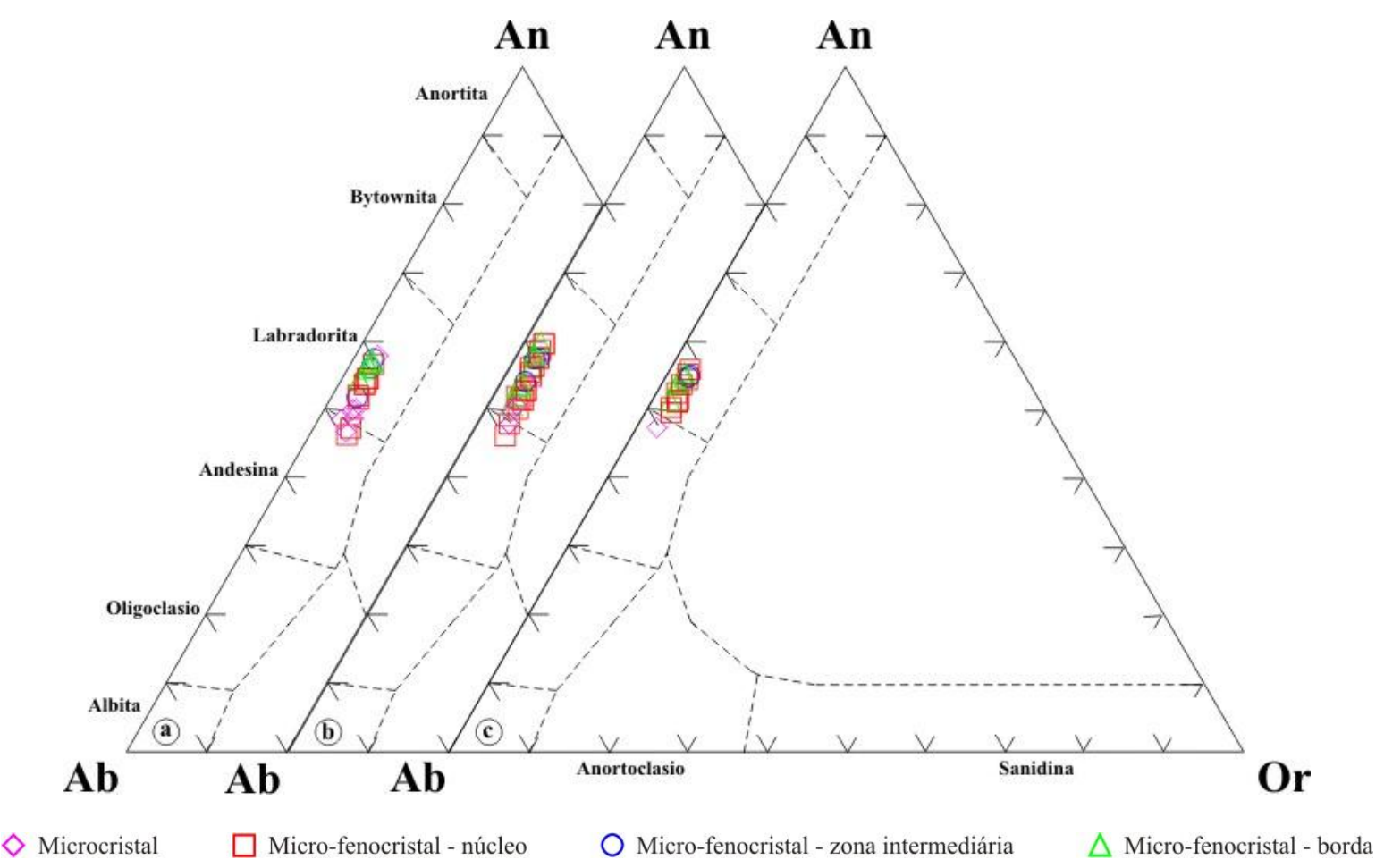

Figura 53: Diagramas ternários An-Ab-Or para classificação dos plagioclásios da SVSM. a) Amostra GX35; b) Amostra GX-108; c) Amostra GX-23. A simbologia utilizada é indicada acima.

Com relação à variação dos teores de An, os zonamentos composicionais apresentam caráter tanto normal, quanto inverso, sendo o último francamente predominante. No caso dos zonamentos de padrão normal ${ }^{1}$, os teores de An variam de $54,7 \%$ a $59,5 \%$ nos núcleos dos cristais e de $50,8 \%$ a $56,5 \%$ nas bordas. Já no caso dos zonamentos de padrão inverso - caso dos microfenocristais, os teores de An variam de $46 \%$ a 54,5\% nos núcleos e de $52,1 \%$ a $60 \%$ nas bordas. É possível observar que, no caso dos padrões inversos, o contato entre as zonas apresenta um caráter irregular, evidenciando um sistema em desequilíbrio.

Pode ocorrer também, mais raramente, um zoneamento inicialmente inverso, que finaliza com padrão normal. Este aspecto pode parecer comum nos

\footnotetext{
${ }^{1}$ Observados em microcristais ou em casos de microfenocristais com zonamento oscilatório onde não foi possível fazer uma análise contínua de todas as zonas. Neste último caso o padrão "normal" não é verdadeiro, uma vez que o zonamento oscilatório não foi caracterizado em detalhe.
} 
cristais quando se observa a presença de uma borda representativa da fase final de cristalização que, devido a sua pequena espessura, impossibilitou a realização pontos de análise química mineral. Tal feição é muito bem observada nos cristais cC,p17 e cC,-18 da amostra GX-35 (ver imagens no anexo 02).

As Figuras 54 a 56 indicam a variação dos teores de anortita vs ortoclásio a fim de se observar as variações composicionais do núcleo à borda dos microfenocristais. Os principais microfenocristais das amostras GX-23, GX35 e GX-108 - utilizados para caracterização via LA-ICPMS - apresentam padrão de zonamento inverso e a partir deles é possível caracterizar uma sequência de cristalização contínua, correlacionando as zonas de equivalência entre os cristais de acordo com os teores de anortita (definidos de acordo com as condições do sistema) - tabela 04 .

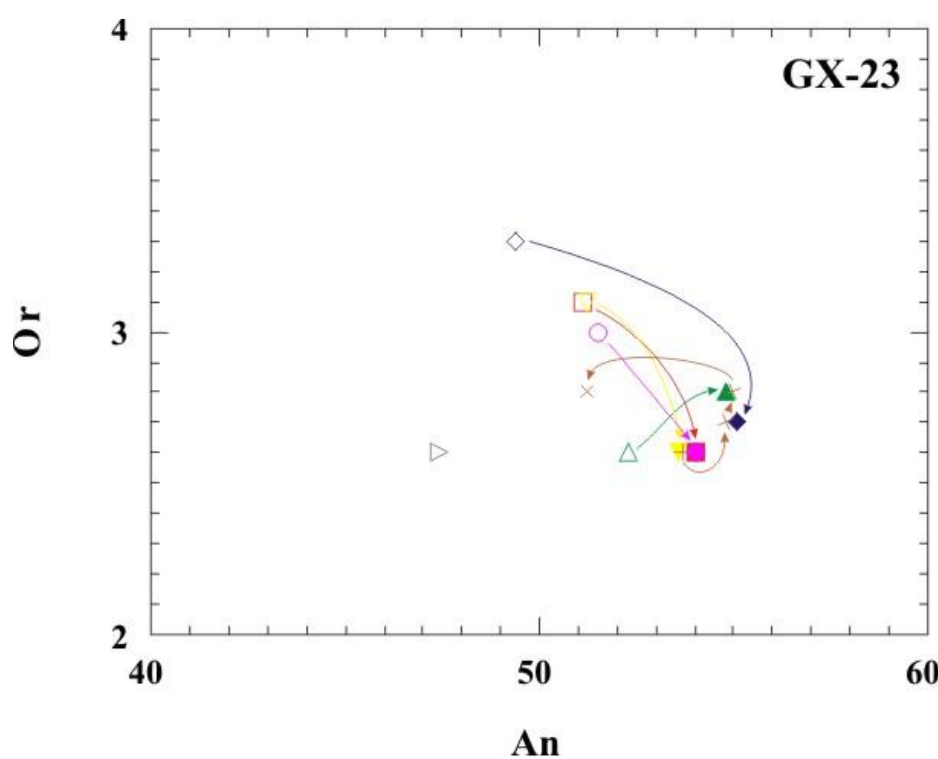

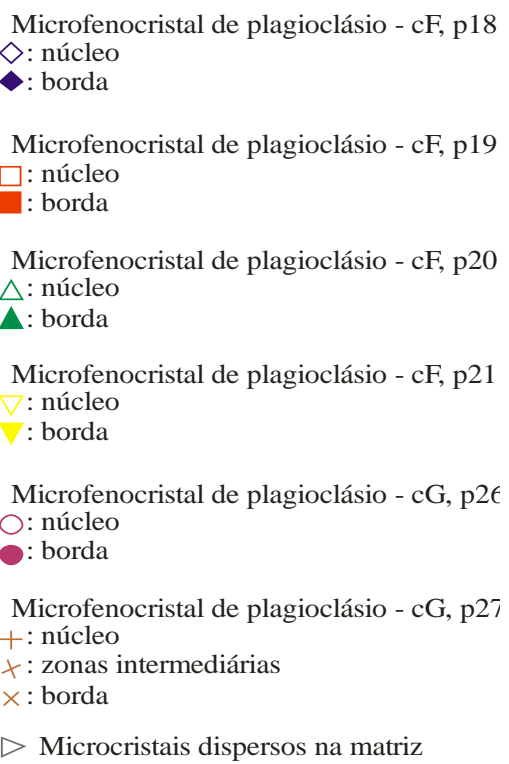

Figura 54: Diagrama de variação dos teores de An vs Or para os plagioclásios da amostra GX-23 (fácies bandada (cristalina) da SVSM). A nomenclatura e a descrição dos pontos analisados encontra-se ao lado do diagrama. Para identificar as variações núcleo-borda deve-se acompanhar as setas nas cores correspondentes. 


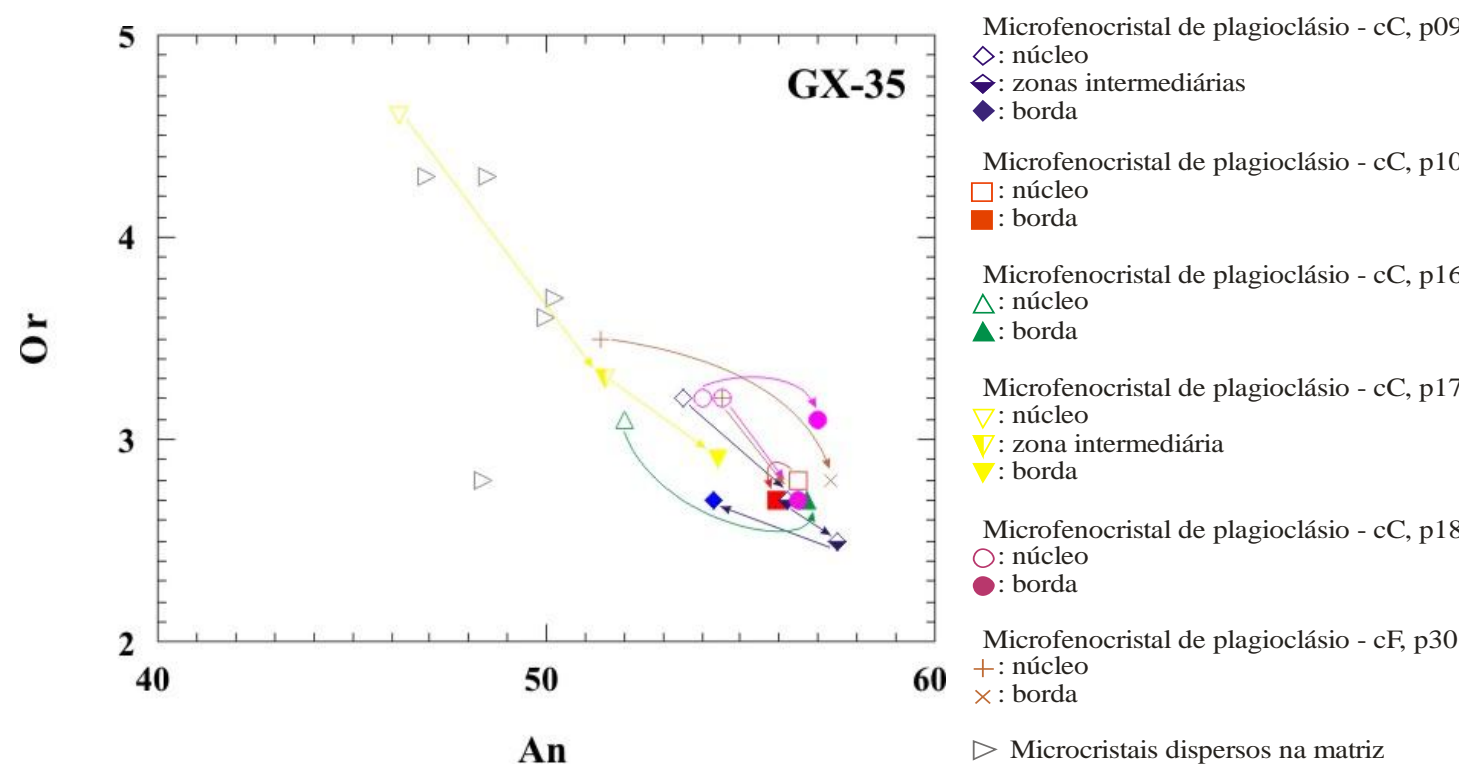

Figura 55: Diagramas de variação dos teores de An vs Or para os plagioclásios da amostra GX-35 (fácies obsidiana da SVSM). A nomenclatura e a descrição dos pontos analisados encontra-se ao lado do diagrama. Para identificar as variações núcleo-borda deve-se acompanhar as setas nas cores correspondentes.

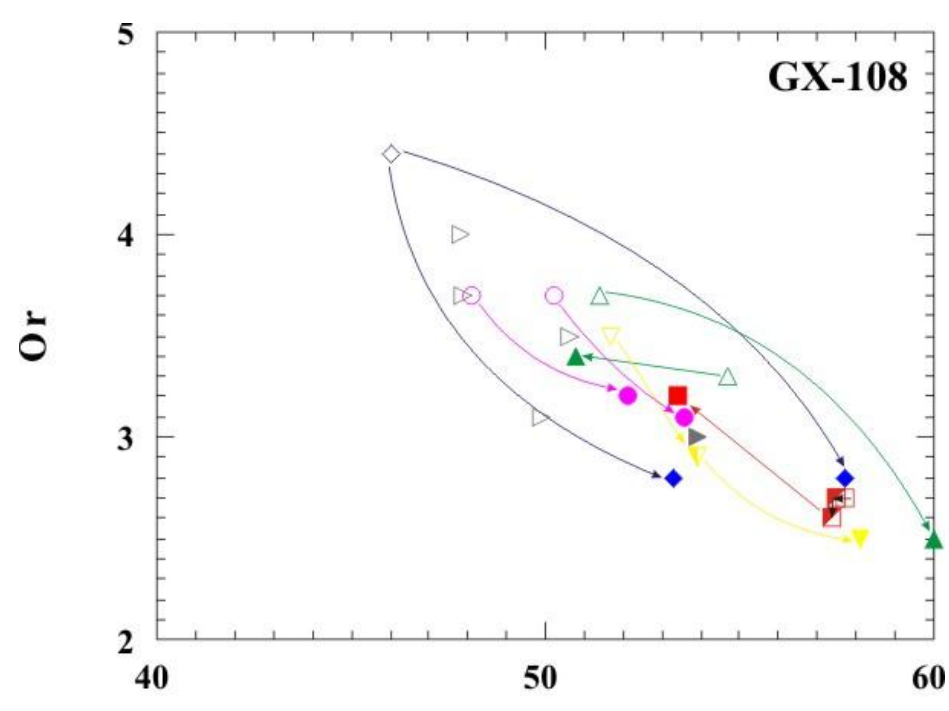

An
Microfenocristal de plagioclásio - cC, p1C $\square$ : núcleo

$\square$ : zonas intermediárias

: borda

Microfenocristal de plagioclásio - cE, p34

$\diamond:$ núcleo

: borda

Microfenocristal de plagioclásio - cJ, p47

$\triangle$ : núcleo

$\triangle$ : borda

Microfenocristal de plagioclásio - cJ, p48

: núcleo

7 : zona intermediária

: borda

Microfenocristal de plagioclásio - cJ, p49

○: núcleo

60

$\triangleright$ Microcristais dispersos na matriz

Figura 56: Diagrama de variação dos teores de An vs Or para os plagioclásios da amostra GX-108 (fácies obsidiana da SVSM). A nomenclatura e a descrição dos pontos analisados encontra-se ao lado do diagrama. Para identificar as variações núcleo-borda deve-se acompanhar as setas nas cores correspondentes. 
Tabela 4: Estimativa de ordem de cristalização com base na variação dos teores de An dos principais microfenocristais de plagioclásio das amostras GX-23, GX-35 e GX-108. As zonas são indicadas por letras: "n" - núcleo; "z" - zona intermediária; "b" - borda; "—" indica zona não analisada e "**" indica cristal com zonamento oscilatório onde foram feitas 2 análises de maneira aleatória.

\begin{tabular}{|c|c|c|c|c|c|c|c|c|c|}
\hline & \multicolumn{2}{|c|}{ GX-23 } & \multicolumn{4}{|c|}{ GX-35 } & \multicolumn{3}{|c|}{ GX-108 } \\
\hline & cG,p26 & $c G, p 28$ & $\mathrm{cC}, \mathrm{p} 16$ & $\mathrm{cC}, \mathrm{p} 17$ & $c C, p 18$ & cF,p30 & $\mathrm{cJ}, \mathrm{p} 47$ & $\mathrm{cJ}, \mathrm{p} 48$ & $c C, p 10$ \\
\hline \multirow{4}{*}{ 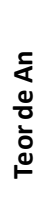 } & & & & $n=0.462$ & & & & & \\
\hline & $\mathrm{n}=0.515$ & & $n=0.52$ & $z 1=0.515$ & $\mathrm{n}=\mathrm{NA} *$ & $\mathrm{n}=0.514$ & $n=0.514$ & $\mathrm{n}=0.517$ & \\
\hline & $b=0.54$ & $n=0.552$ & - & $b=0.544$ & $z=0.54-0.545$ & $n^{\prime}=0.545$ & $\mathrm{z}=\mathrm{NA} *$ & $z=0.539$ & \\
\hline & & & $b=0.567$ & & $b=0.565-0.57$ & $b=0.56-0.57$ & $b=0.60$ & $b=0.581$ & $* *$ \\
\hline
\end{tabular}

\section{3. PIROXÊNIO}

O piroxênio corresponde a até $5 \%$ do volume da rocha e ocorre preferencialmente como microcristais euédricos a subédricos, com até $0,3 \mathrm{~mm}$, geralmente apresentando inclusões de minerais opacos (Figura 57). Pode apresentar-se também como microfenocristais (Figura 58) de geometria ripiforme, atingindo até $1 \mathrm{~mm}$ de comprimento ou manteando os minerais opacos (Figura 59).

Os cristais de piroxênio ocorrem quase sempre muito oxidados, sendo possível observar, localmente, alteração de coloração esverdeada.
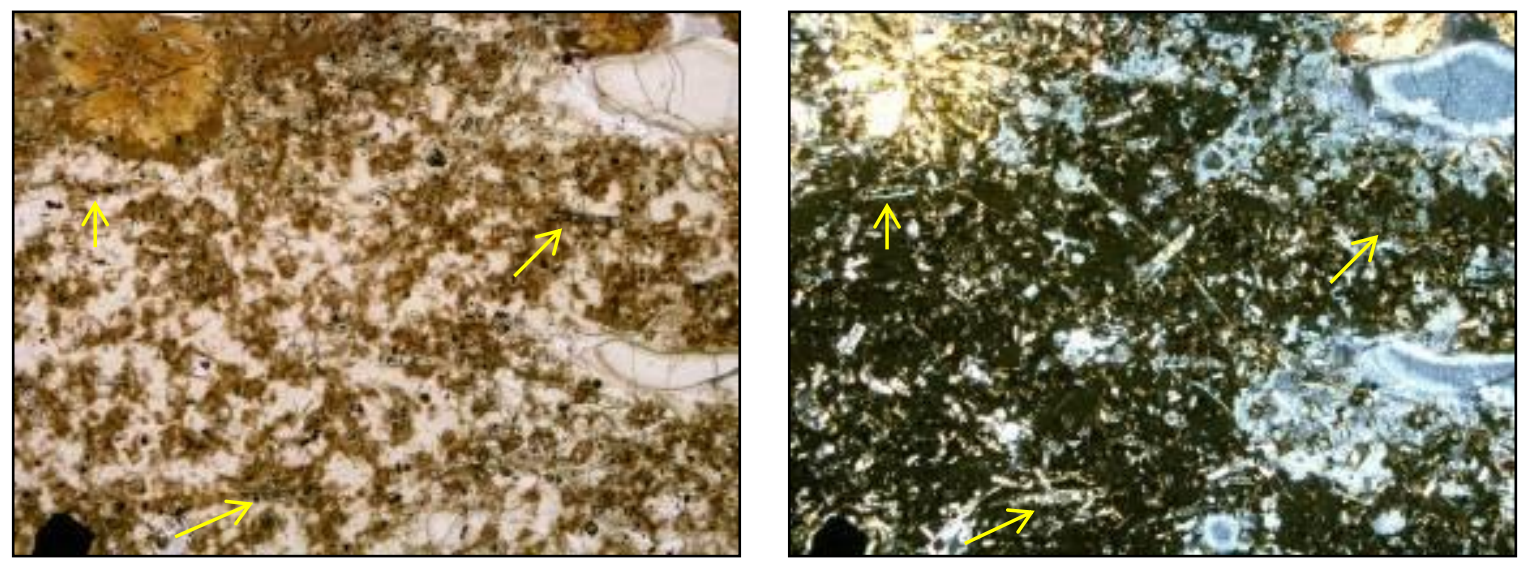

Figura 57: Fotomicrografia da amostra GX-140. Riolito apresentando matriz parcialmente desvitrificada (apresentando coloração acastanhada) com destaque para microcristais orientados de piroxênio (setas amarelas) com inclusões de opacos. Escala: lado maior da foto 2,60 $\mathrm{mm}$. 

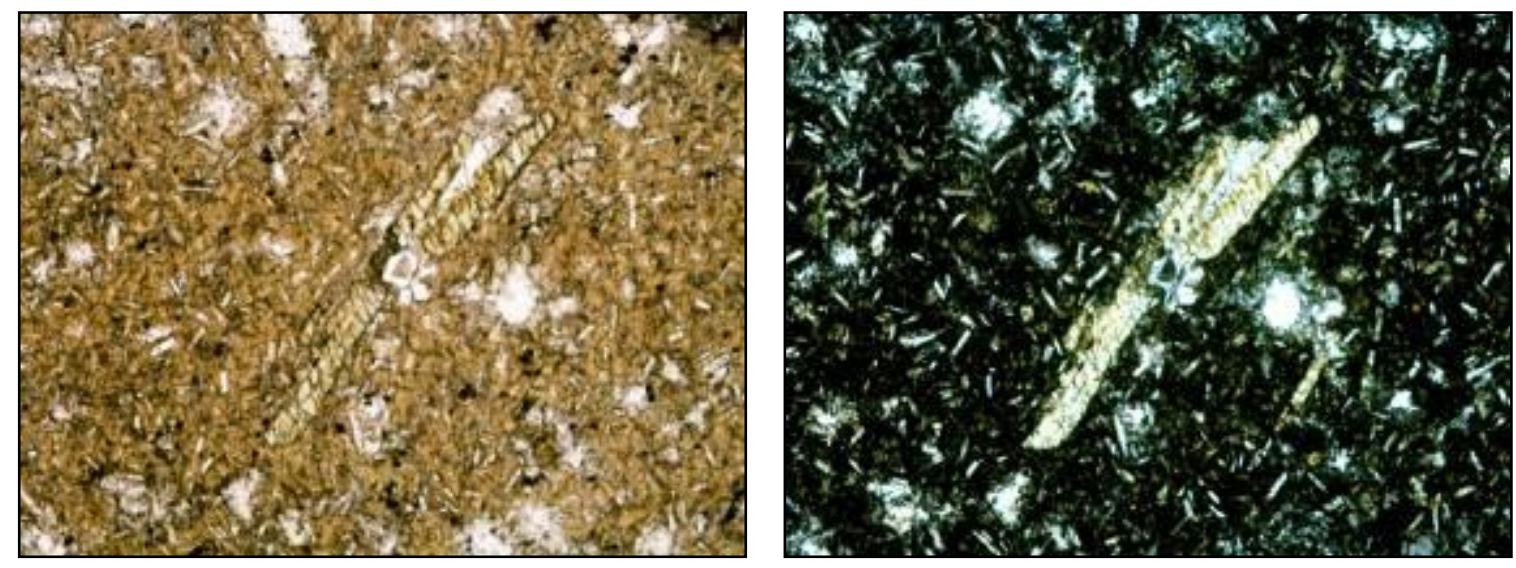

Figura 58: Fotomicrografia da amostra RS-73C. Riolito apresentando matriz desvitrificada (coloração acastanhada) com destaque para microfenocristal de piroxênio. Escala: lado maior da foto 2,60 $\mathrm{mm}$.
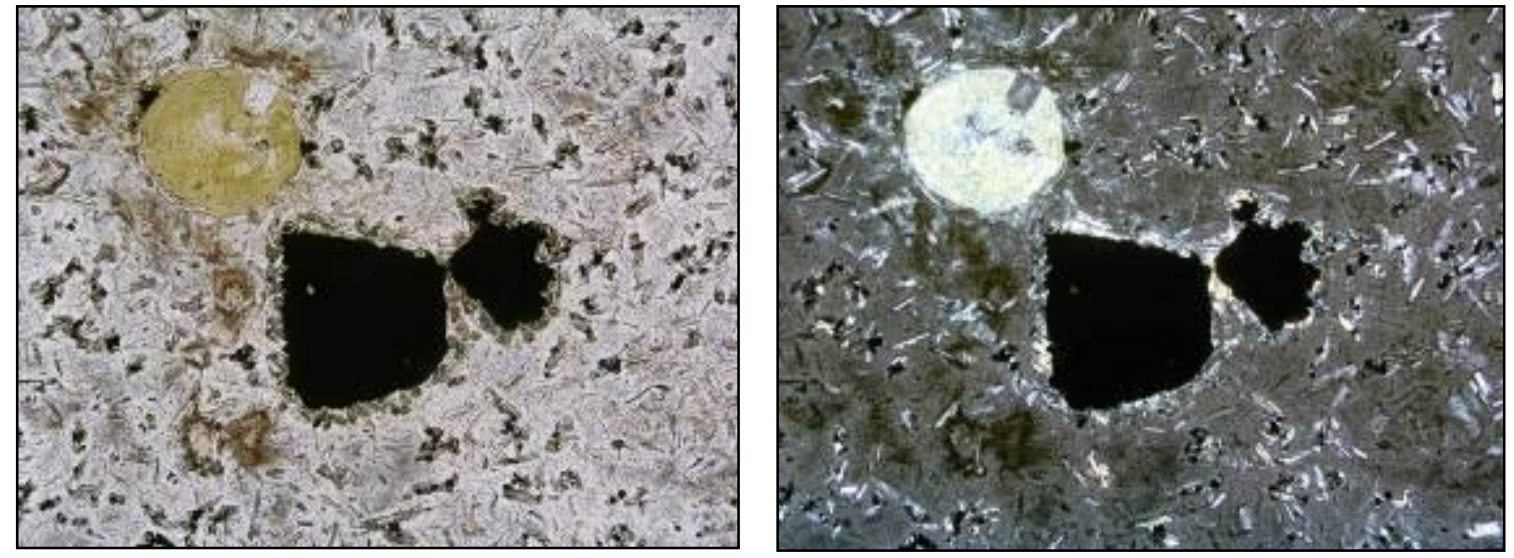

Figura 59: Fotomicrografia da amostra TF-02D. Riolito apresentando matriz vítrea. Notar vesícula arredondada preenchida por calcedônia e cristal subédrico de mineral opaco com borda de piroxênio. Escala: lado maior da foto $1,30 \mathrm{~mm}$.

Do ponto de vista químico, os piroxênios foram classificados de acordo com o sistema $\mathrm{CaSiO}_{3}$ (wollastonita) - $\mathrm{MgSiO}_{3}$ (enstatita) - $\mathrm{FeSiO}_{3}$ (ferrosilita) como mostrado na Figura 60 de Morimoto (1990). Os piroxênios caracterizamse por baixos teores em $\mathrm{Ca}$, apresentando-se no campo da pigeonita, com composições que variam no intervalo $\mathrm{Wo}_{(6-11)} \operatorname{En}_{(38-50)} \mathrm{Fs}_{(44-53)}$ e \#mg variando de 39 a 53 quando considerando-se todas as amostras analisadas. Nota-se que as composições não apresentam diferenças significativas entre o modo de ocorrência dos minerais, seja como microcristal ou como cristalização em borda 
de mineral opaco, não sendo possível também observar zoneamento composicional.

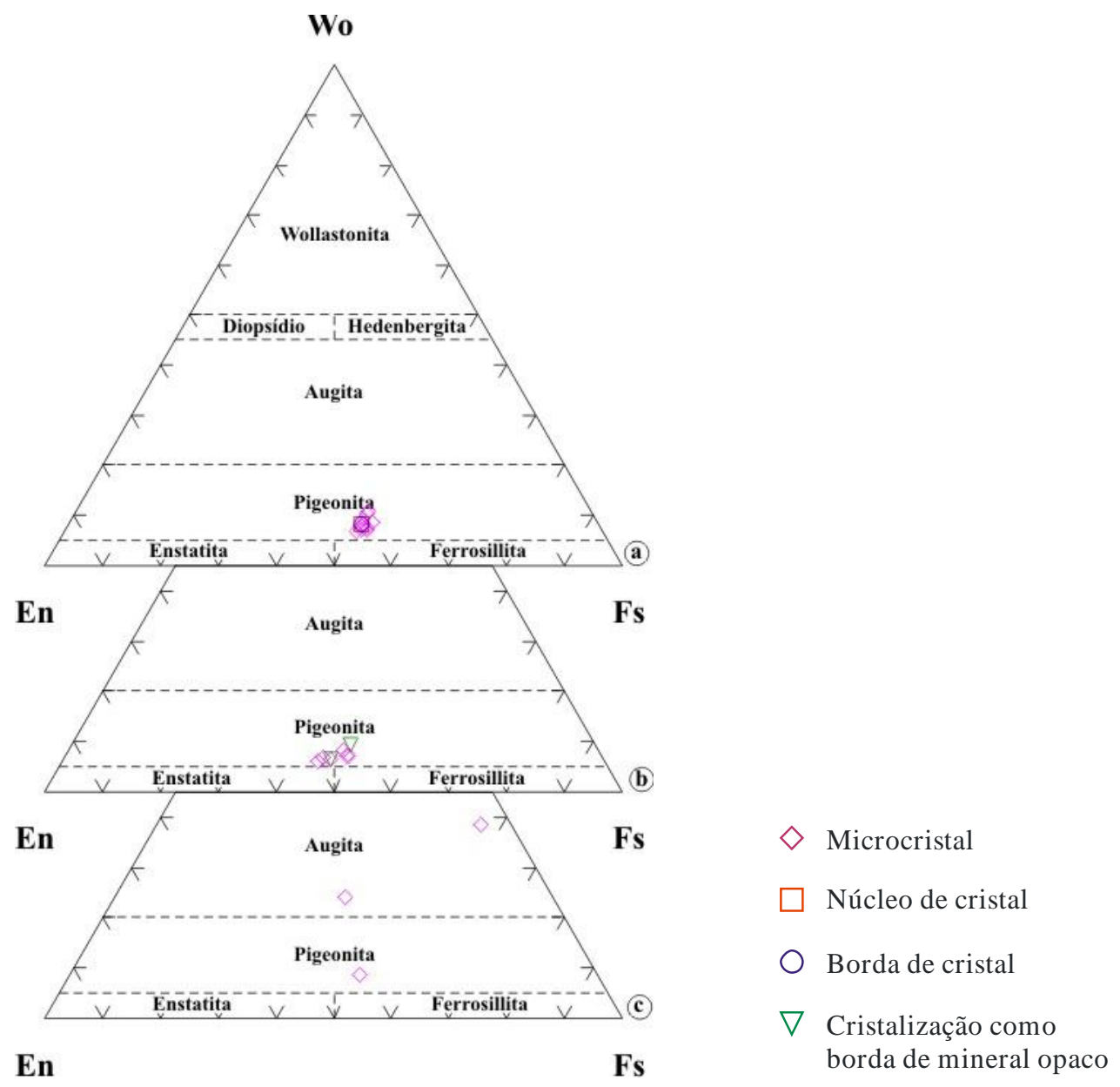

Figura 60: Diagramas ternários Wo-En-Fs para classificação dos piroxênios da SVSM. a) Amostra GX-35; b) Amostra GX-108; c) Amostra GX-23. A legenda da simbologia utilizada apresenta-se acima, junto aos diagramas.

\section{4. MINERAIS OPACOS}

Os óxidos de $\mathrm{Fe}$ e $\mathrm{Ti}$ podem chegar a $4 \%$ do volume da rocha e apresentam uma bimodalidade quanto à granulometria e forma dos cristais. Podem ocorrer dispersos pela matriz, euédricos a subédricos, com tamanhos médios de até $0,1 \mathrm{~mm}$, comumente sob a forma de inclusões nos piroxênios; ou em aglomerados, onde apresentam tamanhos médios de até $0,5 \mathrm{~mm}$, geometria 
subédrica a anédrica, nestes casos arredondados, com superfície lisa, podendo estar afetados por feições de reabsorção e interação com o magma (observadas através de MEV - imagens apresentadas no anexo 02).

Os minerais opacos ocorrem geralmente manteados por microcristais anédricos a subédricos de pigeonita, e as imagens de MEV permitiram o reconhecimento de cristais subédricos de apatita associados a estes minerais.

Quimicamente os minerais caracterizam-se como Ti-magnetitas, apresentando teores de $\mathrm{TiO}_{2}$ variando entre 10,2 e $17,7 \%$ - sendo raros os cristais empobrecidos neste componente (com concentrações de $\mathrm{TiO}_{2}$ de 0,2 a 1,8); de $\mathrm{Fe}_{2} \mathrm{O}_{3}$ de 19,9 a $61,4 \%$ e $\mathrm{FeO}$ de 29,9 a 47,4\% (Figura 61). Os teores de $\mathrm{MgO}$ apresentam-se bastante variáveis, ficando entre 0,01 e 4,65\%.

Figura 61: Diagrama ternário para a composição dos óxidos de Fe e Ti da unidade Santa Maria. Triângulos azuis: amostra GX23; quadrados vermelhos: amostra GX-35; círculos verdes: amostra GX-108.

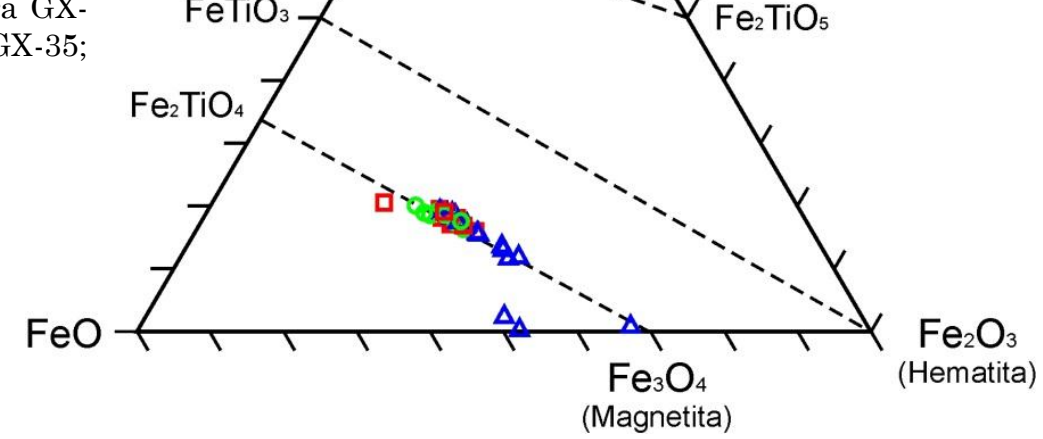




\section{CAPITULO VI - GEOQUÍMICA E ISOTOPIA}

\section{VI.1. Geoquímica de rocha total}

\section{VI.1.1. CLASSIFICAÇÃO E AFINIDADES GEOQUÍMICAS}

As análises químicas de elementos maiores e menores em rocha total por FRX foram realizadas em um conjunto de 34 amostras representativas das variedades texturais e provenientes de diferentes localidades dentro da área de ocorrência dos riolitos Santa Maria. Um subgrupo foi analisado para elementos menores e traços por ICPMS. Para fins de representação em diagramas, as amostras foram divididas em fácies obsidiana e fácies cristalina, a fim de verificar eventuais variações associadas à cristalinidade da rocha. Foram utilizadas ainda, para fins comparativos, análises de rochas das unidades Caxias do Sul e Barros Cassal de Polo (2010) e Polo \& Janasi (2014).

Os dados químicos (apresentados no anexo 03) evidenciam que a unidade Santa Maria é relativamente homogênea, e ambas as variedades texturais têm composições muito semelhantes. $\mathrm{O}$ diagrama classificatório para rochas vulcânicas (TAS - Le Bas et al. 1986) apresentado na Figura 62 mostra que estas rochas caracterizam-se como riolitos, com os teores de $\mathrm{SiO}_{2}$ variando de $71 \%$ a $73 \%$.

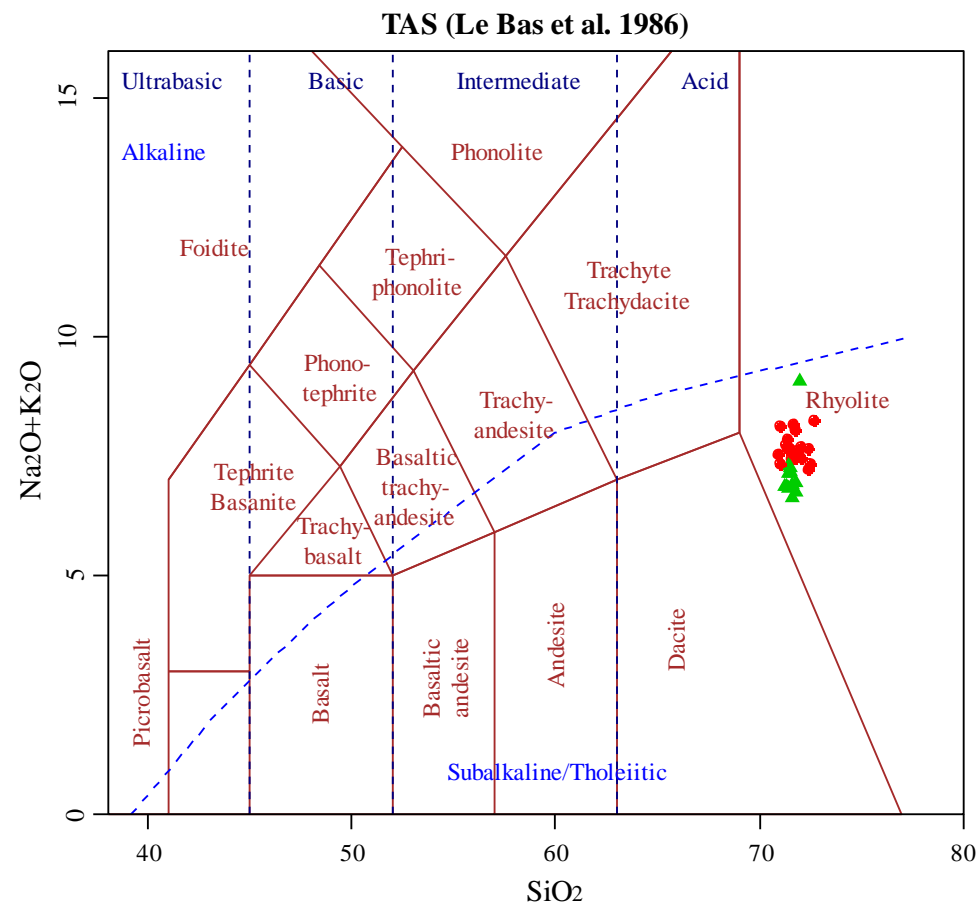

Figura 62: Diagrama TAS para classificação geoquímica das rochas da unidade Santa Maria (Le Bas et al., 1986). Os círculos vermelhos correspondem às rochas de matriz cristalina enquanto que os triângulos verdes correspondem às rochas de matriz vítrea. 
No diagrama classificatório R1-R2 de La Roche et al. (1980) (Figura 63), ambas as variedades também se situam no campo dos riolitos, mas as rochas da fácies obsidiana encontram-se mais próximas do campo dos riodacitos. No diagrama AFM, os riolitos Santa Maria se situam ao longo da linha que delimita os campos toleítico e cálcio-alcalino (Figura 64).

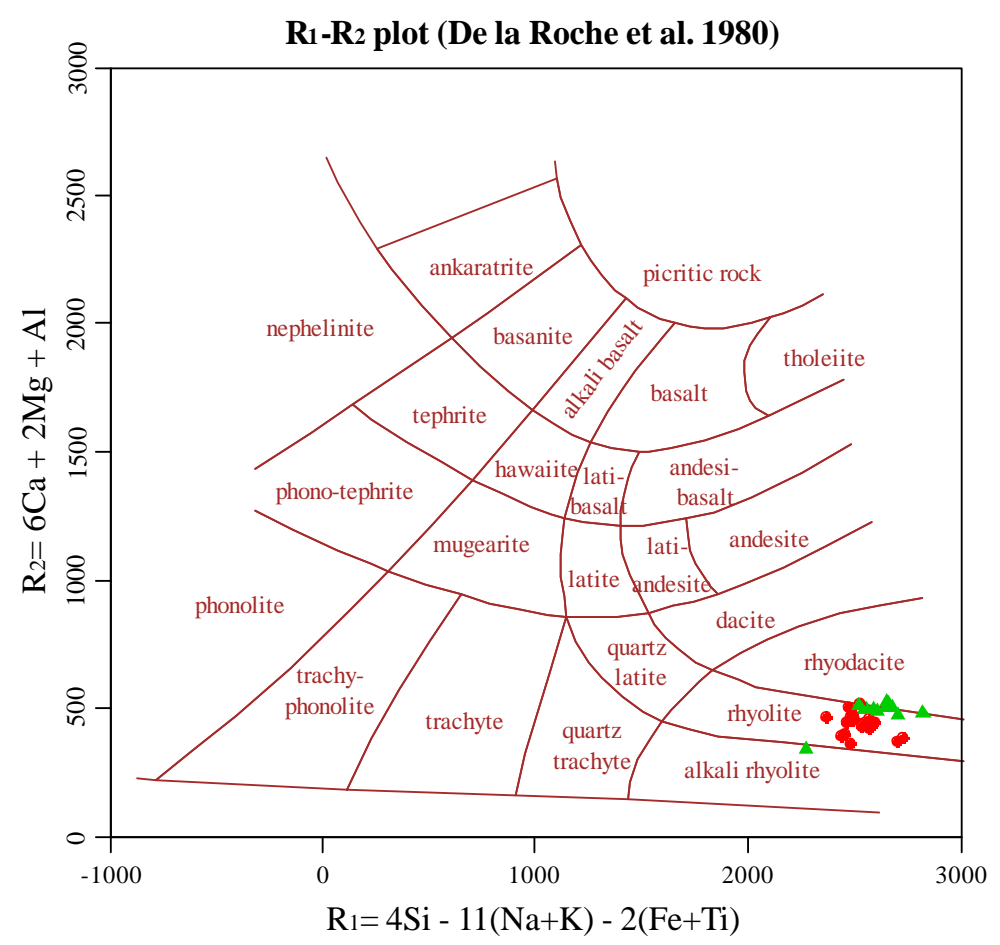

Figura 63: Diagrama classificatório R1-R2 para as rochas da unidade Santa Maria (De La Roche et al., 1980). Os círculos vermelhos correspondem às rochas de matriz cristalina enquanto que os triângulos verdes correspondem às rochas de matriz vítrea.

No diagrama A/CNK vs A/NK, com campos definidos por Maniar \& Piccoli (1989) com base nos parâmetros de Shand (1943) (Figura 65), os riolitos Santa Maria mostram caráter metaluminoso, transicional para peraluminoso. 


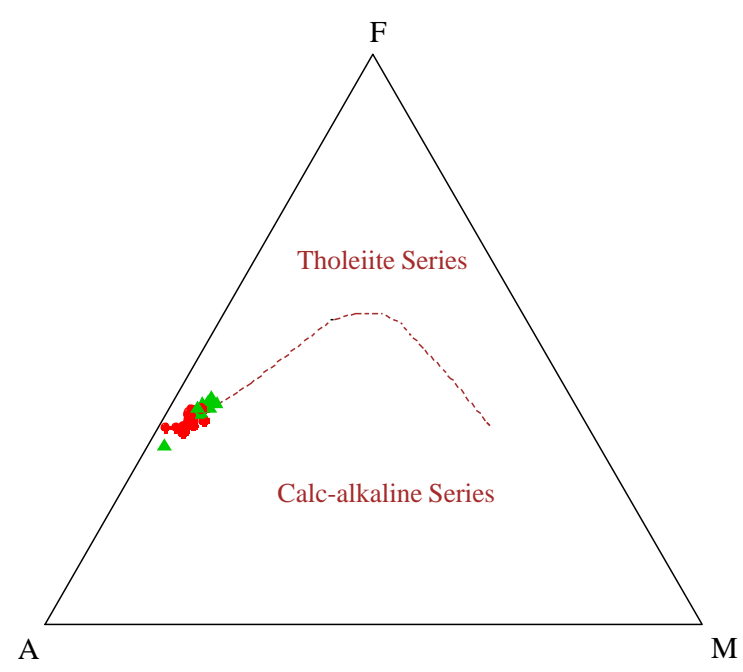

Figura 64: Diagrama classificatório AFM para as rochas da unidade Santa Maria. Os círculos vermelhos correspondem às rochas de matriz cristalina enquanto que os triângulos verdes correspondem às rochas de matriz vítrea.

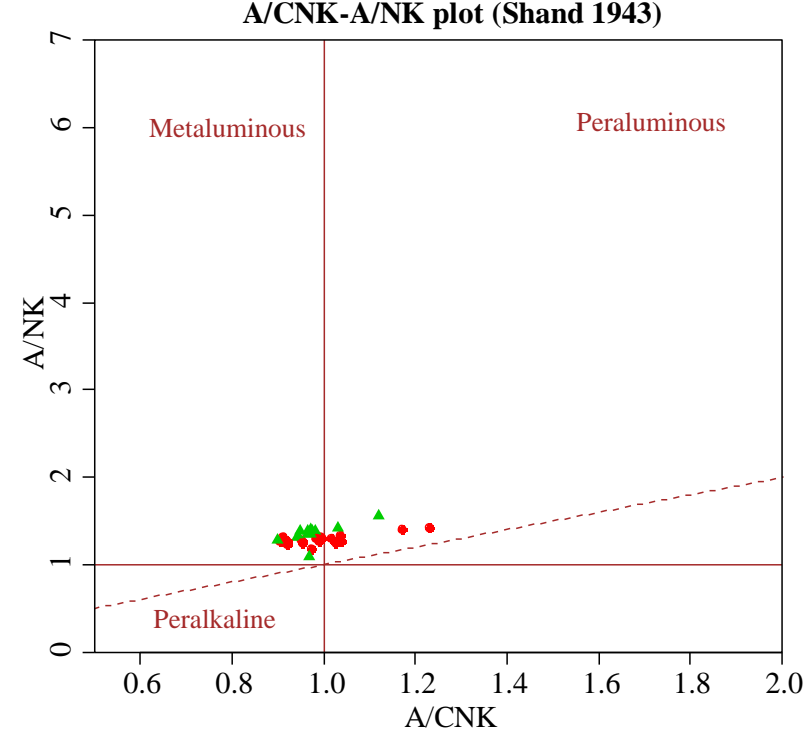

Figura 65: Diagrama classificatório com base na saturação em alumina para as rochas da unidade Santa Maria. Os círculos vermelhos correspondem às rochas de matriz cristalina enquanto que os triângulos verdes correspondem às rochas de matriz vítrea.

\section{VI.1.2. VARIAÇÕES DE ELEMENTOS MAIORES E TRAÇOS \& COMPARAÇÃO COM OUTRAS UNIDADES DE ROCHAS ÁCIDAS}

Os riolitos Santa Maria correspondem à unidade mais diferenciada dentre as sequências de vulcânicas ácidas aflorantes na área de estudos, com maiores teores de $\mathrm{SiO}_{2}$ (71-73\%, contra 68$70 \%$ e $\sim 55-66 \%$ para as unidades Caxias do Sul e Barros Cassal, respectivamente) e menores \#mg (5-25, contra 20-35 e 20-30 para as unidades Caxias do Sul e Barros Cassal, respectivamente), como se observa na Figura 66. Entretanto, o \#mg apresenta significativa dispersão para os riolitos

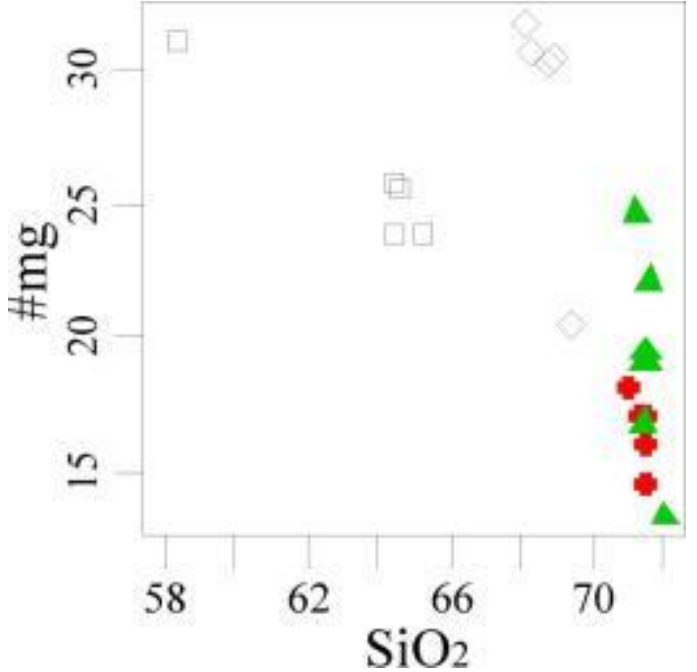

Figura 66: Diagrama \#mg vs $\mathrm{SiO} 2$ comparativo entre os riolitos Santa Maria (os círculos vermelhos correspondem às rochas de matriz cristalina enquanto que os triângulos verdes correspondem às rochas de matriz vítrea) e as rochas da unidadeBarros Cassal (quadrados pretos) e Caxias do Sul (losangos pretos). 
Santa Maria, o que compromete seu uso como parâmetro de diferenciação. Quando comparados às demais unidades, utilizando-se então $\mathrm{SiO}_{2}$ como índice de diferenciação, os riolitos Santa Maria apresentam claramente menores teores de $\mathrm{TiO}_{2}, \mathrm{CaO}, \mathrm{P}_{2} \mathrm{O}_{5}, \mathrm{Fe}_{2} \mathrm{O}_{3}$ e $\mathrm{MgO}$, e teores mais elevados de $\mathrm{K}_{2} \mathrm{O}$, feições consistentes com seu caráter mais diferenciado (Figura 67).

De maneira semelhante ao observado nas análises de vidro por microssonda eletrônica, nota-se que os riolitos Santa Maria apresentam uma dispersão composicional para alguns óxidos, em particular Ca, Na e K. Quando se considera a variação textural, fica evidente que as amostras de matriz vítrea diferenciam-se claramente por apresentar maiores teores de $\mathrm{Na}$ e $\mathrm{Ca}$ e menores teores de $\mathrm{K}$ quando comparadas às amostras de matriz desvitrificada.

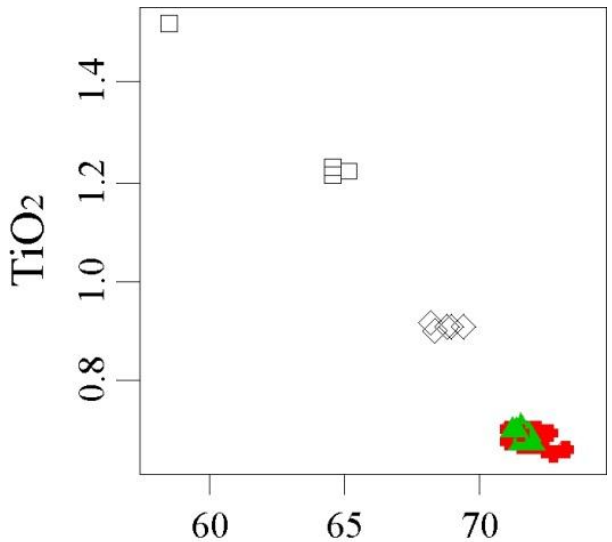

$\mathrm{SiO}_{2}$

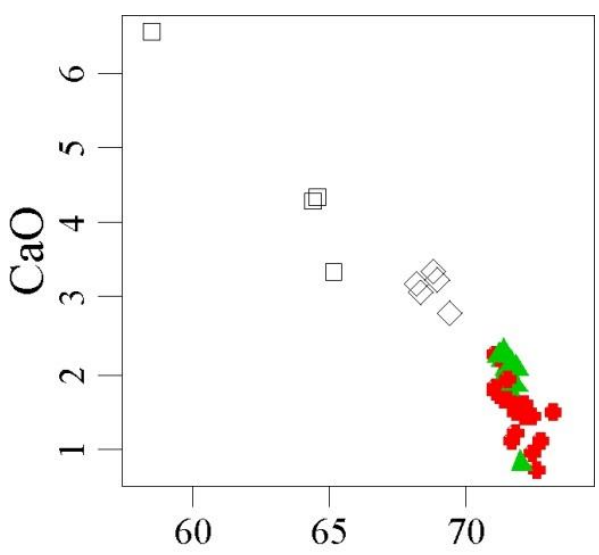

$\mathrm{SiO}_{2}$

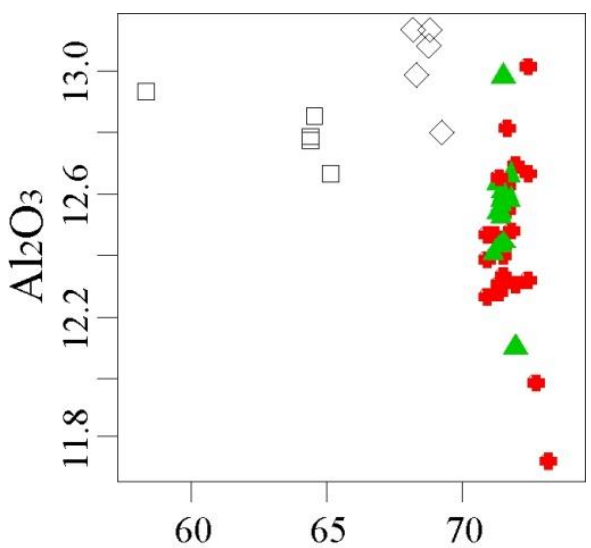

$\mathrm{SiO}_{2}$

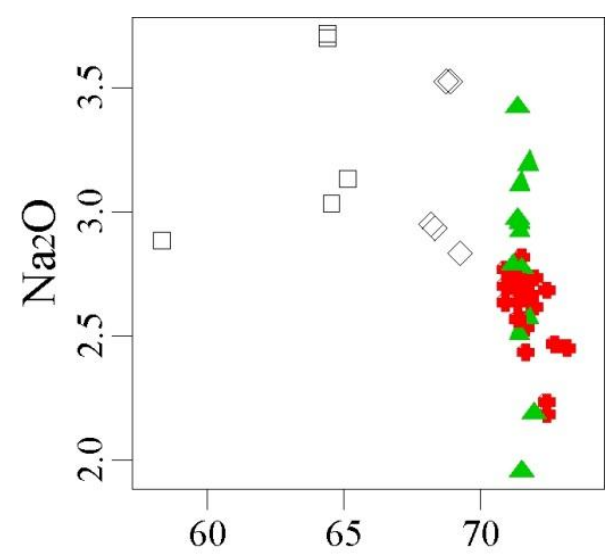

$\mathrm{SiO}_{2}$

Figura 67 (1/2): Legenda na próxima página. 

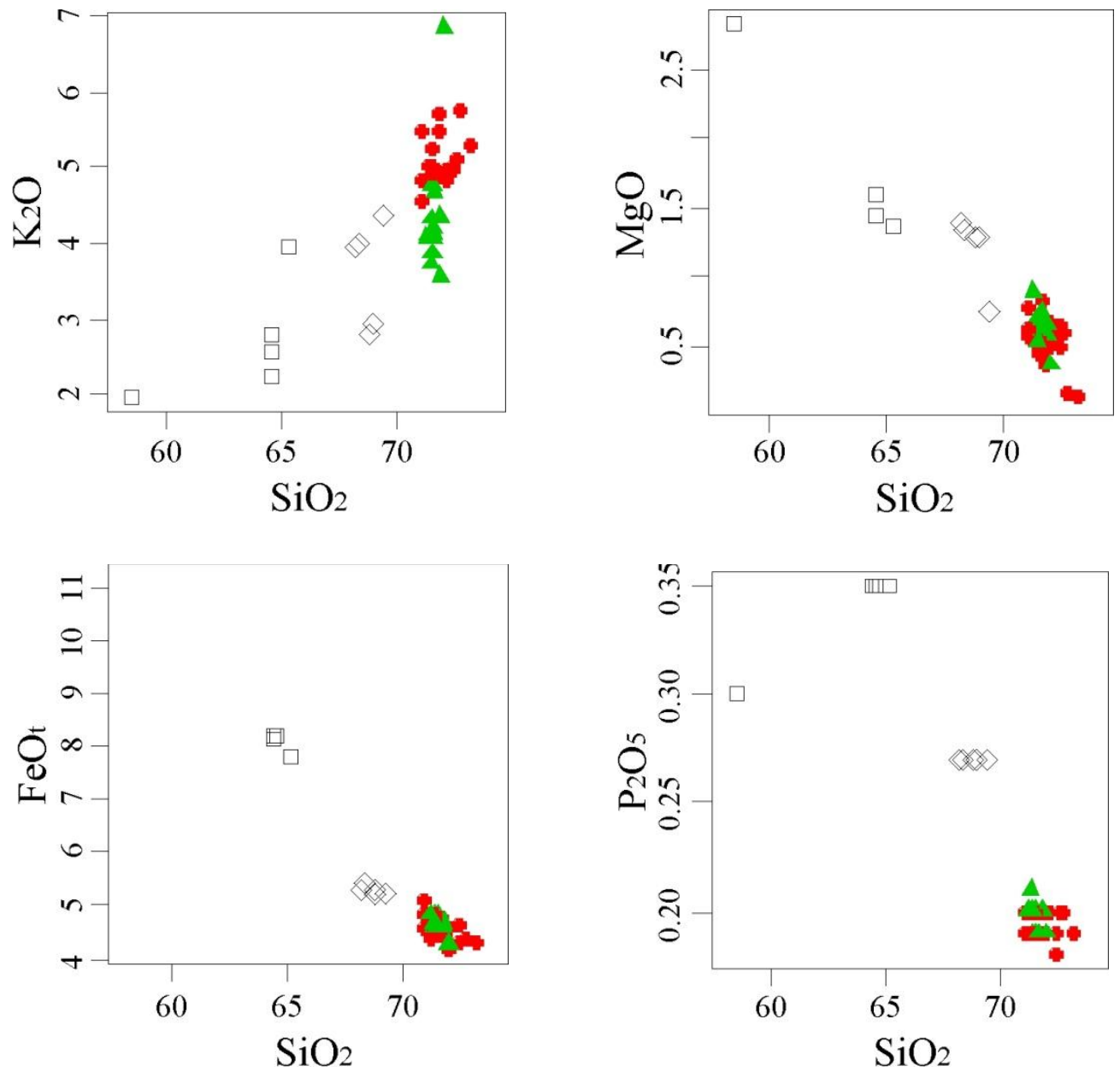

Figura 67 (2/2): Diagramas tipo Harker para variação dos teores de elementos maiores usando $\mathrm{SiO}_{2}$ como índice de diferenciação. Para a unidade Santa Maria os círculos vermelhos correspondem às rochas de matriz cristalina e os triângulos verdes correspondem às rochas de matriz vítrea; losangos pretos: unidade Caxias do Sul - Polo \& Janasi (2014); quadrados pretos: unidade Barros Cassal - Polo \& Janasi (2013).

Os elementos traço também apresentam variações composicionais importantes quando comparados com as unidades dacíticas precedentes. Os riolitos Santa Maria apresentam-se mais ricos em elementos incompatíveis como o Rb, Zr, La, Ce, Th e Nd e mais pobres em elementos compatíveis como o Sr (Figura 68). Ressalta-se ainda que, também para os elementos traço, são observadas variações dentro das diferentes fácies dos riolitos Santa Maria. O Sr tende a apresentar teor mais elevado nas fácies vítreas, padrão que é bem marcado para o Rb. Desde modo, as rochas da fácies cristalina apresentam 
razões $\mathrm{K} / \mathrm{Rb}$ mais elevadas que as da fácies vítrea (média $\mathrm{K} / \mathrm{Rb}=189$ para as rochas da fácies cristalina e média $\mathrm{K} / \mathrm{Rb}=167$ para as das fácies vítrea).
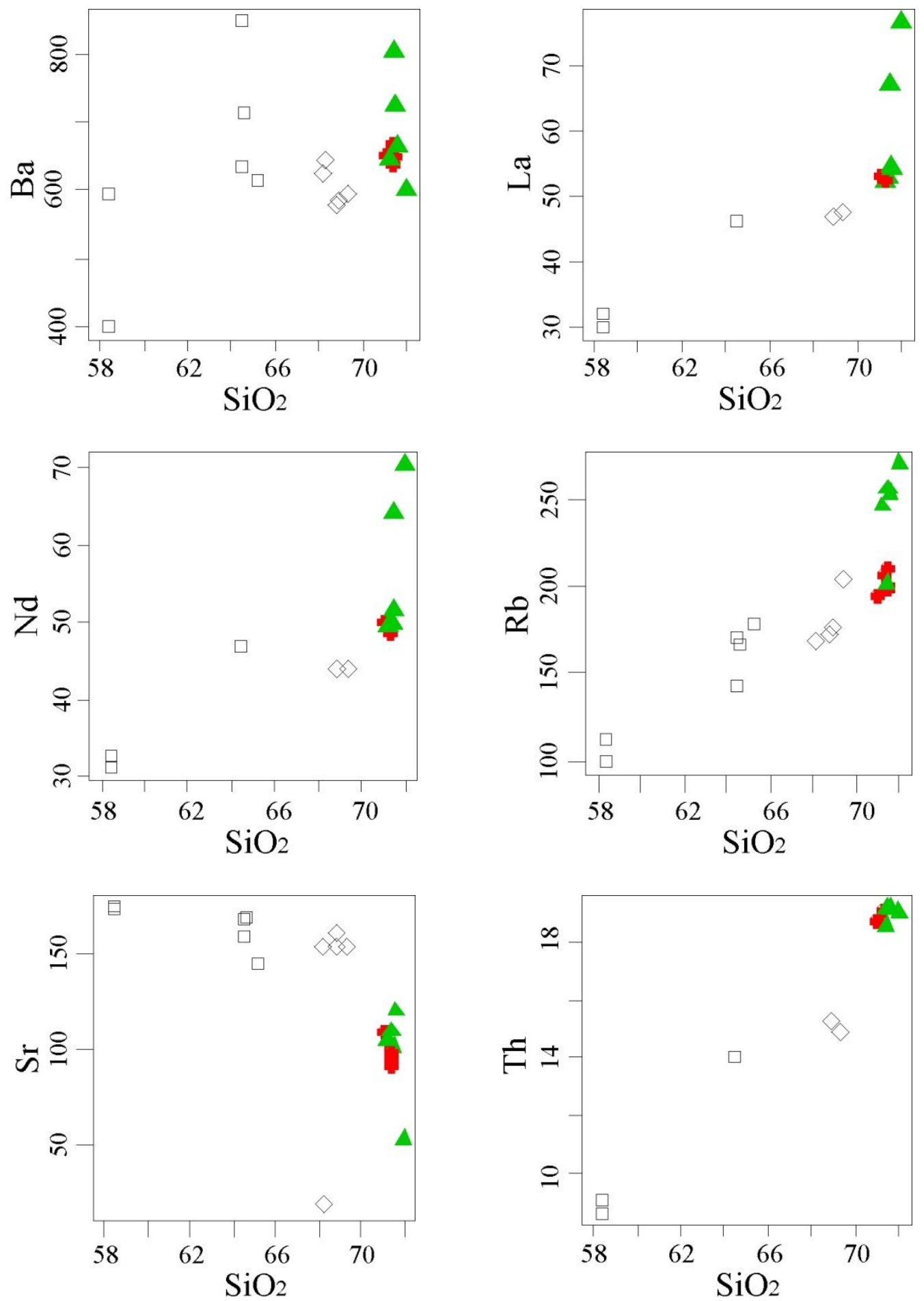

Figura 68 (1/2): Legenda na próxima página 

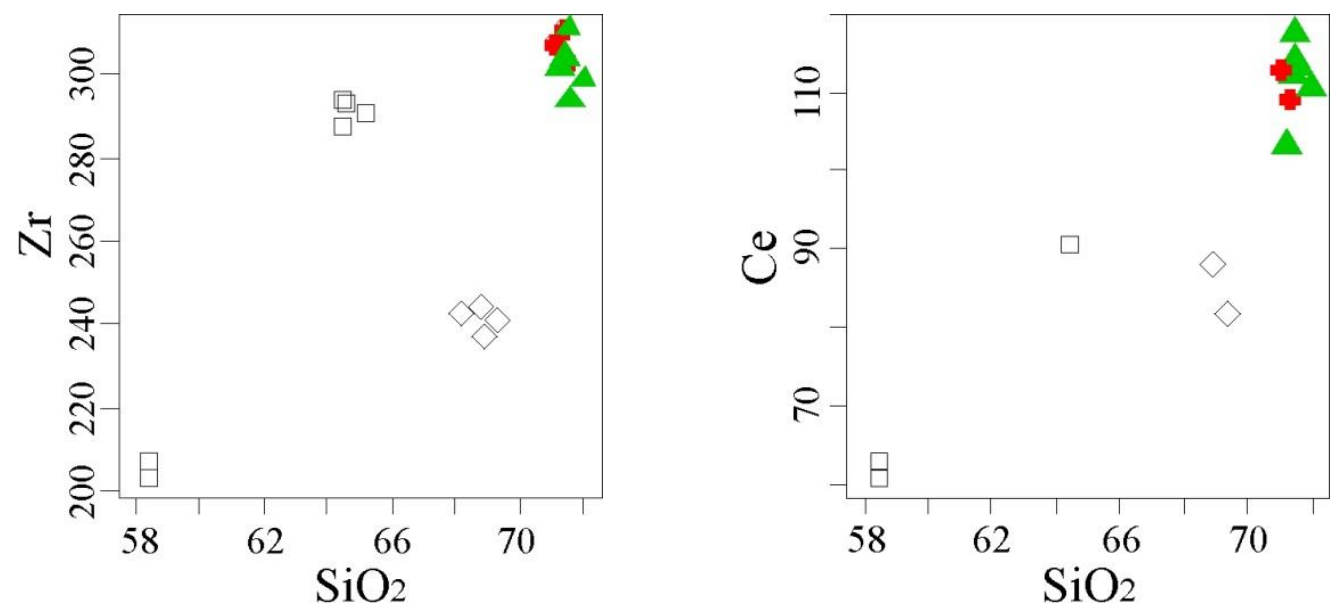

Figura 68 (2/2): Diagramas de variação nos teores de elementos traços, utilizando-se $\mathrm{SiO}_{2}$ como índice de diferenciação, para os riolitos Santa Maria (círculos vermelhos correspondem às rochas de matriz cristalina e o triângulos verdes correspondem às rochas de matriz vítrea) e as rochas das unidades Caxias do Sul (losangos pretros) e Barros Cassal (quadrados pretos).

As análises de elementos terras-raras (ETR) (anexo 03) foram representadas em diagramas normalizados pelo condrito (Boynton, 1984 Figura 69), e mostram que os riolitos Santa Maria exibem perfis de ETR fracamente fracionados, com razões $(\mathrm{La} / \mathrm{Yb})_{\mathrm{N}}$ variando de 6,6 a 9,1 e $(\mathrm{La} / \mathrm{Sm})_{\mathrm{N}}$ de 3,1 a 3,5, e teores totais de ETR entre 240 e 280 ppm. Os padrões mostram caracteristicamente anomalias negativas de $\mathrm{Eu}$ bem definidas $\left(\mathrm{Eu} / \mathrm{Eu}^{*}=0.55\right)$; duas amostras (GX-35 e GX-108) exibem anomalias negativas de Ce.

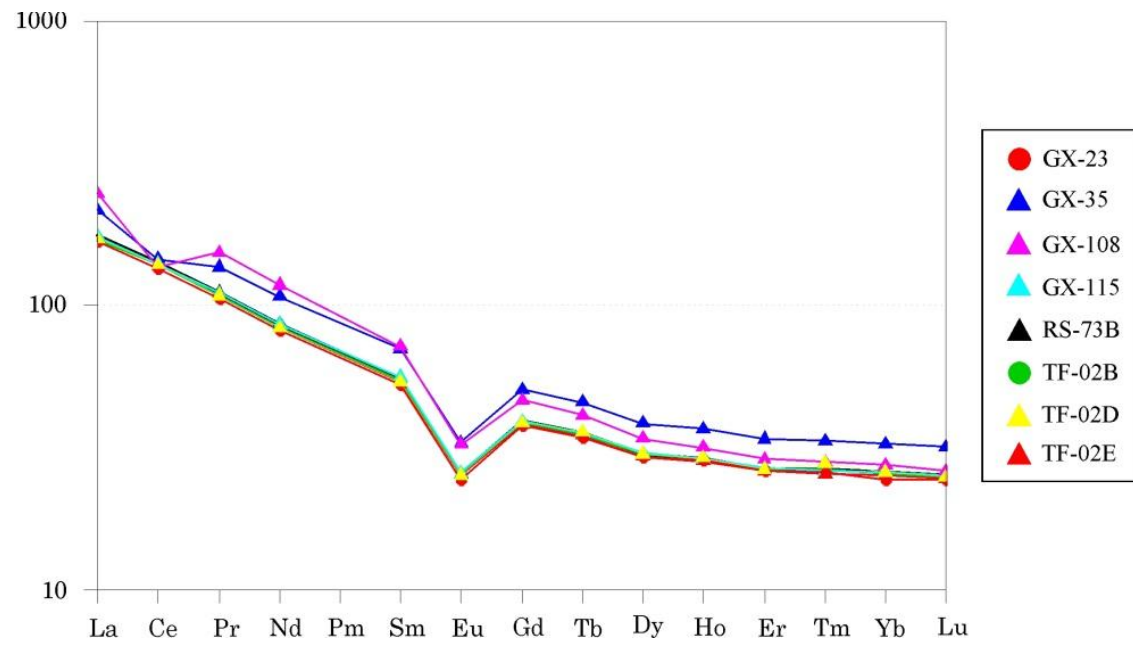

Figura 69: Diagrama com os teores de elementos traço (ETR) para as amostras da unidade Santa Maria. Valores normalizados pelo condrito de Boynton (1984). 


\section{VI.2. Geoquímica de elementos traço em plagioclásio (por LA-ICPMS)}

As análises de elementos traço e ETR (elementos terras raras) foram realizadas apenas em plagioclásio - única fase mineral com tamanho adequado para incidência do feixe do laser; os resultados são apresentados no anexo 04; Os dados foram lançados em diagramas normalizados pelo manto primitivo (Sun \& McDonald, 1989) para o conjunto de elementos traço e pelo condrito (Boynton, 1984) para os elementos terras raras.

Os resultados mostram alguma dispersão nos teores de $\mathrm{Cs}, \mathrm{Rb}, \mathrm{Th}, \mathrm{U}$, $\mathrm{Nb}, \mathrm{P}, \mathrm{Zr}$ e Sm (Figura 66 - A.1, B.1, C.1), que deve estar associada à presença de inclusões. Para os demais elementos os teores são pouco dispersos.

Os padrões de elementos terras raras (Figura 70 - A.2, B.2, C.2) mostram fortes anomalias positivas de $\mathrm{Eu}\left(\mathrm{Eu} / \mathrm{Eu}^{*}=5,8\right.$ a 22,6) e um fracionamento moderado entre os ETR leves e pesados $\left((\mathrm{La} / \mathrm{Yb})_{\mathrm{N}}\right.$ variando de 14,2 a 187 e $(\mathrm{La} / \mathrm{Sm})_{\mathrm{N}}$ de 5,1 a 22,6$)$, como mostrado na tabela 05 . Os teores dos ETR leves mostram variação muito pequena, com exceção do Sm. As variações observadas para os ETR pesados refletem, em boa parte, as incertezas analíticas, pois os teores se encontram próximos aos limites de deteç̧ão do método. 

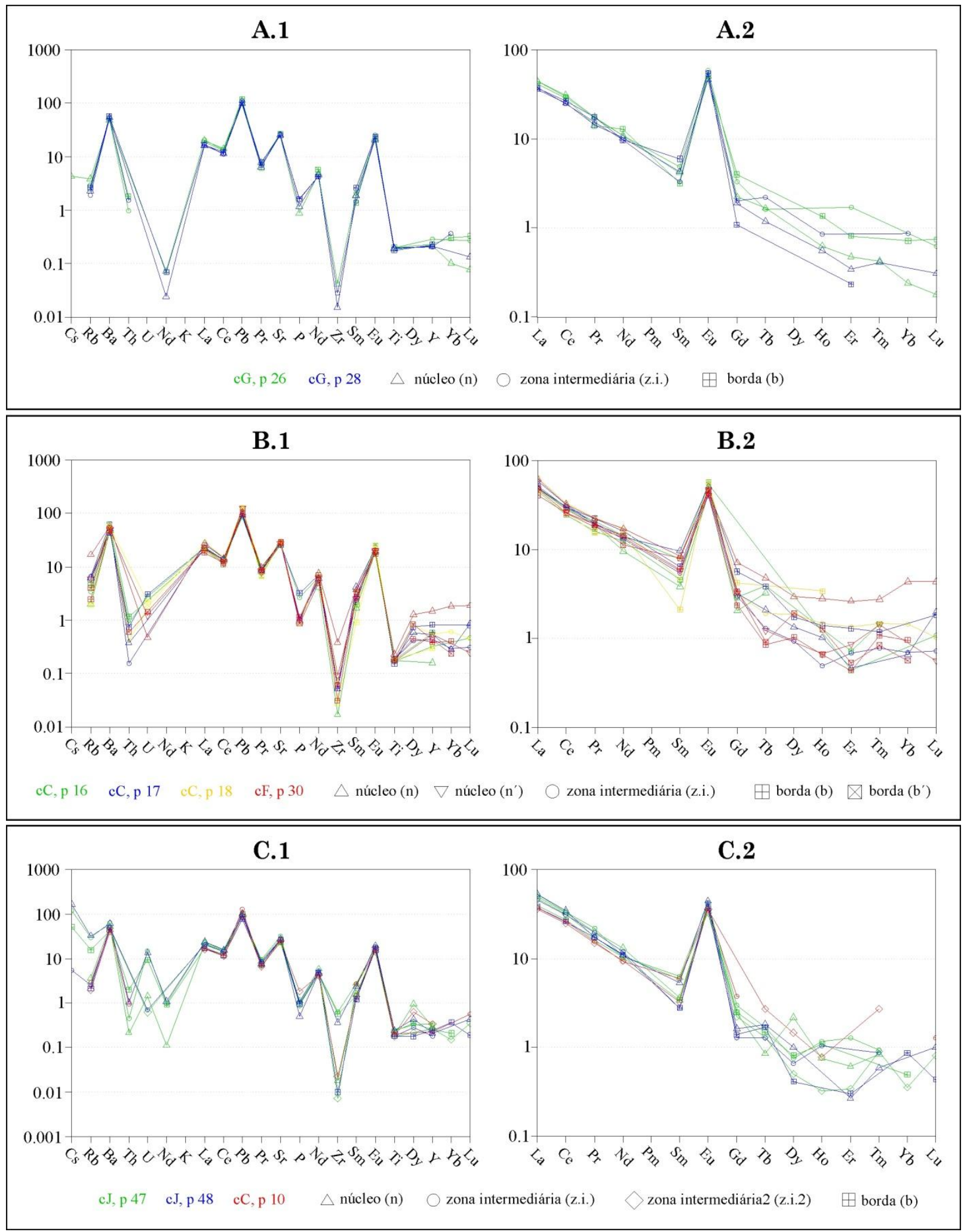

Figura 70: Diagramas spider para elementos traço (A.1; B.1 e C.1) e elementos terras raras (ETR - A.2; B.2 e C.2) das amostras GX-23, GX-35 e GX-108, representativas dos riolitos Santa Maria. A simbologia utilizada encontra-se junto de cada amostra. 
Tabela 5: Razões (La/Sm)N, (La/Yb)N e (Eu/Eu)* e teores totais de elementos terras raras (ETR) obtidos via análises LA-ICPMS para os microfenocristais de plagioclásio das amostras GX-23, GX-35 e GX-108.

\begin{tabular}{|c|c|c|c|c|c|}
\hline & Ponto (cristal/zona) & $(\mathrm{La} / \mathrm{Sm})_{\mathrm{N}}$ & $(\mathbf{L a} / \mathbf{Y b})_{N}$ & $(\mathbf{E u} / \mathbf{E u})^{*}$ & $\Sigma$ ETR \\
\hline \multirow{6}{*}{ 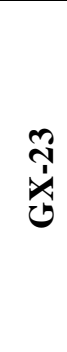 } & cGp26 nucleo & 10.79 & 187.29 & 16.51 & 53.05 \\
\hline & cGp26 meio & 9.37 & NA & 14.81 & 53.46 \\
\hline & cGp26 borda & 13.06 & 57.85 & 14.16 & 51.56 \\
\hline & cGp28 nucleo & 8.32 & NA & 16.38 & 44.45 \\
\hline & cGp28 meio & 11.63 & 44.31 & 21.57 & 45.39 \\
\hline & cGp28 borda & 6.29 & NA & 21.46 & 46.64 \\
\hline
\end{tabular}

\begin{tabular}{|c|c|c|c|c|c|}
\hline & Ponto (cristal/zona) & $(\mathbf{L a} / \mathbf{S m})_{\mathbf{N}}$ & $(\mathbf{L a} / \mathbf{Y b})_{N}$ & $(\mathbf{E u} / \mathbf{E u})^{*}$ & $\Sigma$ ETR \\
\hline \multirow{12}{*}{ 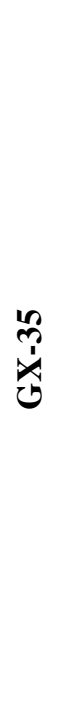 } & cCp16 nucleo & 13 & NA & 15.18 & 51.89 \\
\hline & cCp16 meio & 6.26 & NA & NA & 55.62 \\
\hline & cCp16 borda & 9.97 & NA & 15.83 & 49.66 \\
\hline & cCp17 nucleo & 5.05 & 73.72 & 9.28 & 57.93 \\
\hline & cCp17 meio & 10.93 & 86.24 & 10.49 & 60.38 \\
\hline & cCp17 borda & 8.06 & NA & 7.81 & 59.86 \\
\hline & cCp18 meio & 14.09 & 45.31 & 12.95 & 67.02 \\
\hline & cCp18 borda & 22.55 & NA & 18.84 & 52.62 \\
\hline & cFp30 nucleo & 7.34 & 14.18 & 5.81 & 68.09 \\
\hline & cFp30 borda & 6.81 & 42.68 & 10.82 & 50.04 \\
\hline & cFp30 nucleo2 & 8.39 & NA & 10.53 & 51.95 \\
\hline & cFp30 borda2 & 6.19 & 87.93 & 8.9 & 54.03 \\
\hline
\end{tabular}

\begin{tabular}{|c|c|c|c|c|c|}
\hline & Ponto (cristal/zona) & $(\mathbf{L a} / \mathbf{S m})_{N}$ & $(\mathbf{L a} / \mathbf{Y b})_{\mathbf{N}}$ & $(\mathbf{E u} / \mathbf{E u})^{*}$ & $\Sigma$ ETR \\
\hline \multirow{9}{*}{ 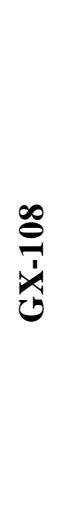 } & cJ47 nucleo & 13.84 & NA & 12.29 & 57.22 \\
\hline & cJ47 meio & 8.41 & NA & 9.55 & 58.04 \\
\hline & cJ47 meio2 & 8.16 & 134.75 & 9.18 & 53.2 \\
\hline & cJ47 borda & 11.57 & 79.46 & 13.27 & 46.81 \\
\hline & cJ48 nucleo & 10.01 & NA & 15.25 & 58.33 \\
\hline & cJ48 meio & 16.54 & NA & 22.6 & 53.37 \\
\hline & cJ48 borda & 13.51 & 43.45 & 18.52 & 45.37 \\
\hline & cC10 meio & 6.19 & NA & 7.78 & 44.89 \\
\hline & cC10 meio2 & 11.15 & NA & NA & 42.81 \\
\hline
\end{tabular}




\section{VI.3. Geoquímica isotópica}

\section{VI.3.1. SISTEMAS Rb/Sr e Sm/Nd EM ROCHA TOTAL}

Os resultados de determinações isotópicas obtidas em amostras de rochas vulcânicas representativas da unidade Santa Maria são apresentados na Tabela 06, ao lado de dados obtidos por Polo (2014) para rochas das unidades subjacentes Barros Cassal e Caxias do Sul, que são aqui utilizados para fins de comparação. Os teores de Rb e Sr utilizados para o cálculo das razões isotópicas iniciais foram os obtidos por FRX e os teores de $\mathrm{Sm}$ e $\mathrm{Nd}$ (ppm) os obtidos por ICP-MS, tendo sido considerada uma idade de $134 \mathrm{Ma}$ (conforme indicado por Janasi et al., 2011) para a cristalização magmática destas rochas.

Tabela 6: Resultados das análises isotópicas para os sistemas $\mathrm{Rb} / \mathrm{Sr}$ e $\mathrm{Sm} / \mathrm{Nd}$ em rocha total para os riolitos Santa Maria e as unidades subjacentes Barros Cassal e Caxias do Sul (dados de Polo, 2014).

\begin{tabular}{|c|c|c|c|c|c|c|c|c|c|c|}
\hline & \multicolumn{4}{|c|}{ Santa Maria } & \multicolumn{3}{|c|}{ Barros Cassal } & \multicolumn{3}{|c|}{ Caxias do Sul } \\
\hline & GX-23 & GX-35 & GX-108 & TF-02D & GX-22 & GX-94 & GX-113 & GX-07ob & GX-98b & GX-118 \\
\hline $\mathbf{R b}$ & 207 & 257 & 254 & 247 & 142 & 111 & 98 & 177 & 206 & 205 \\
\hline $\mathrm{Sr}$ & 99 & 101 & 120 & 105 & 159 & 173 & 174 & 153 & 155 & 153 \\
\hline Rb/Sr (elemental) & 6.0690 & 7.3872 & 6.1423 & 6.8279 & 2.5872 & 1.8585 & 1.6314 & 3.3544 & 3.854 & 3.8854 \\
\hline${ }^{87} \mathrm{Sr} /{ }^{86} \mathrm{Sr}$ & 0.737095 & 0.739150 & 0.734683 & 0.737100 & 0.717443 & 0.716050 & 0.716258 & 0.726479 & 0.727500 & 0.727563 \\
\hline Erro & 0.000056 & 0.000054 & 0.000066 & 0.000050 & 0.000049 & 0.000058 & 0.000058 & 0.000053 & 0.000053 & 0.000059 \\
\hline${ }^{87} \mathrm{Sr} /{ }^{86} \mathrm{Sr}_{(134)}$ & 0.725536 & 0.725080 & 0.722984 & 0.724096 & 0.712516 & 0.712510 & 0.713150 & 0.720090 & 0.720160 & 0.720162 \\
\hline$\varepsilon \mathrm{Sr}_{(0)}$ & 462.67 & 491.84 & 428.43 & 462.74 & 183.72 & 163.94 & 166.89 & 311.98 & 326.47 & 327.36 \\
\hline$\varepsilon \mathrm{Sr}_{(134)}$ & 300.87 & 294.4 & 264.64 & 280.42 & 116.01 & 115.93 & 125.02 & 223.55 & 224.54 & 224.58 \\
\hline Idade (Ma) & 134 & 134 & 134 & 134 & 134 & 134 & 134 & 134 & 134 & 134 \\
\hline Nd & 48.7 & 64.4 & 51.6 & 49.7 & 46.8 & 31.1 & 32.8 & 44 & 45 & 44 \\
\hline $\mathrm{Sm}$ & 10.3 & 13.7 & 10.9 & 10.7 & 10.2 & 7.1 & 7.4 & 9.1 & 9.4 & 9.1 \\
\hline${ }^{147} \mathrm{Sm} /{ }^{144} \mathrm{Nd}$ & 0.1286 & 0.1293 & 0.1284 & 0.131 & 0.1325 & 0.139 & 0.1372 & 0.1257 & 0.1270 & 0.1257 \\
\hline${ }^{143} \mathrm{Nd} /{ }^{144} \mathrm{Nd}$ & 0.512160 & 0.512151 & 0.512156 & 0.512157 & 0.512222 & 0.512239 & 0.512237 & 0.512145 & 0.512151 & 0.512156 \\
\hline${ }^{143} \mathrm{Nd} /{ }^{144} \mathrm{Nd}_{(134)}$ & 0.512047 & 0.512038 & 0.512043 & 0.512042 & 0.512106 & 0.512117 & 0.512117 & 0.512035 & 0.512040 & 0.512046 \\
\hline$\varepsilon N d_{(0)}$ & -9.32 & -9.50 & -9.40 & -9.38 & -8.11 & -7.78 & -7.82 & -9.62 & -9.50 & -9.40 \\
\hline$\varepsilon N d_{(134)}$ & -8.16 & -8.35 & -8.24 & -8.26 & -7.02 & -6.79 & -6.81 & -8.41 & -8.31 & -8.19 \\
\hline TDM (Ma) & 1565 & 1595 & 1569 & 1667 & 1524 & 1611 & 1585 & 1541 & 1553 & 1522 \\
\hline Idade (Ma) & 134 & 134 & 134 & 134 & 134 & 134 & 134 & 134 & 134 & 134 \\
\hline
\end{tabular}


Os resultados para o sistema $\mathrm{Rb} / \mathrm{Sr}$ mostram que os riolitos Santa Maria são mais radiogênicos que os dacitos das outras duas unidades, com razões ${ }^{87} \mathbf{S r} / 86 \mathbf{S r}_{(134)}$ bastante elevadas variando de $\mathbf{0 , 7 2 3 0}$ a $\mathbf{0 , 7 2 5 5}$, enquanto as outras unidades apresentam razões da ordem de 0,7125 a 0,7132 (Barros Cassal) e de 0,7201 a 0,7202 (Caxias do Sul). As Figuras 71 A e B mostram que, considerando todo o conjunto de rochas félsicas do tipo Palmas, existe uma correlação positiva de ${ }^{87} \mathrm{Sr} /{ }^{86} \mathrm{Sr}_{(134)}$ com $\mathrm{SiO}_{2}$ e $\mathrm{Rb} / \mathrm{Sr}$. Observa-se, contudo, que estas correlações não ficam caracterizadas dentro das unidades.

A

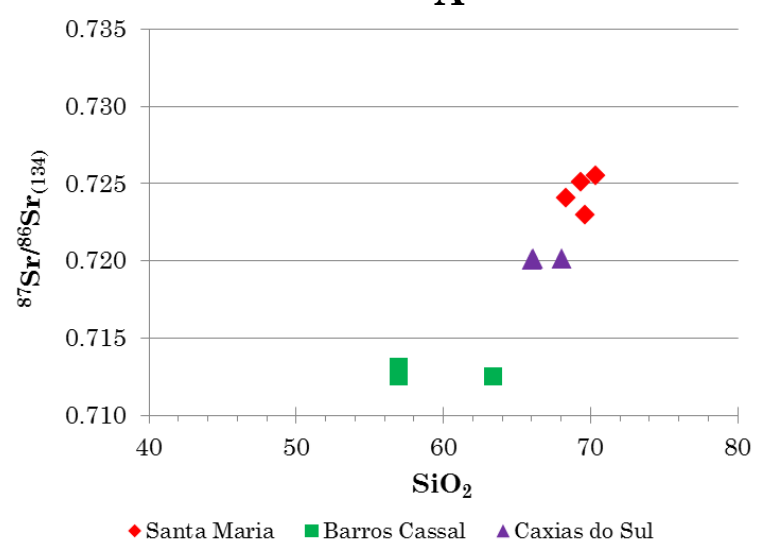

B

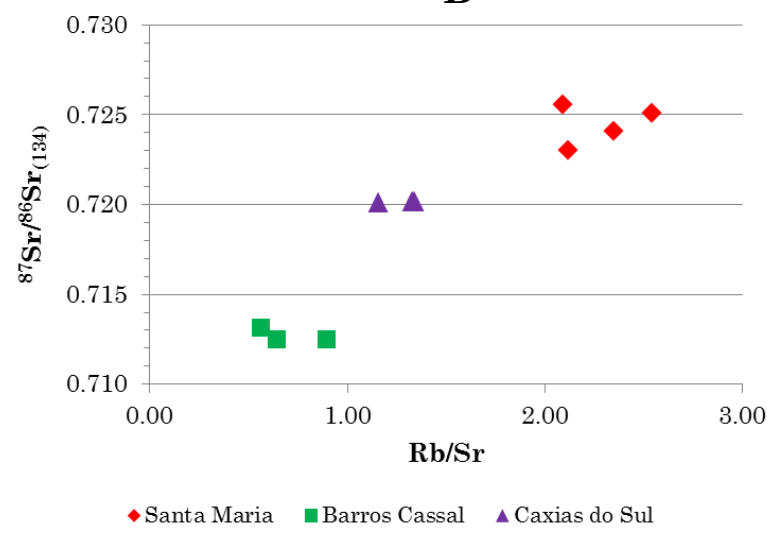

Figura 71: Diagramas ${ }^{87} \mathrm{Sr} /{ }^{86} \mathrm{Sr}$ iniciais versus $\mathrm{SiO}_{2}(\mathrm{~A})$ e $\mathrm{Rb} / \mathrm{Sr}$ (B) dos dados apresentados nesse trabalho para os riolitos Santa Maria comparados aos dados de Polo (2014) para as rochas das unidades Caxias do Sul e Barros Cassal. A simbologia utilizada encontra-se junto aos diagramas.

Para o sistema isotópico $\mathrm{Sm} / \mathrm{Nd}$, as razões ${ }^{143} \mathrm{Nd} /{ }^{144} \mathbf{N d}(134)$ dos riolitos Santa Maria são muito homogêneas, variando de $\mathbf{0 , 5 1 2 0 4}$ a $\mathbf{0 , 5 1 2 0 5}$, equivalentes a $\boldsymbol{E N d}_{(134)}$ entre $\mathbf{- 8 , 2}$ e 8,4. Quando plotados em gráficos utilizando-se a $\mathrm{SiO}_{2}$ como índice de diferenciação, fica claro que as unidades Santa Maria e Caxias do Sul correspondem às unidades menos radiogênicas, com valores mais negativos para $\mathcal{E N d}_{(134)}$ (Figura 72 ). 


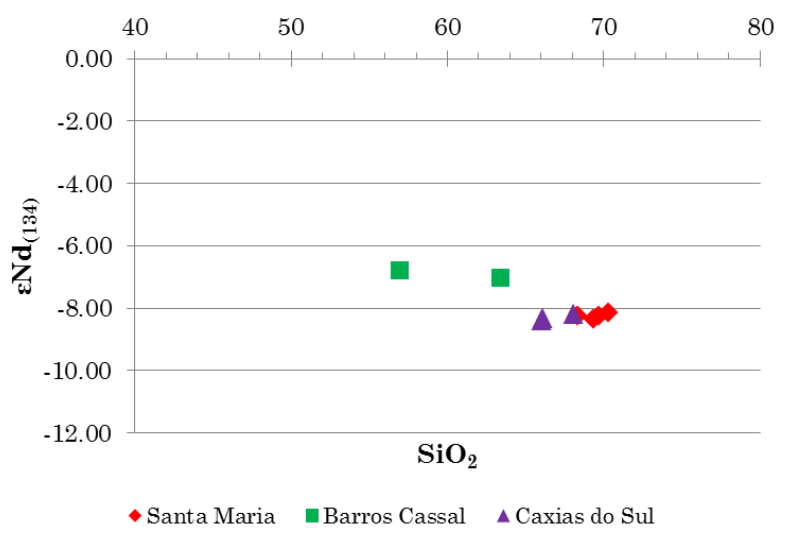

Figura 72: Diagrama $E N d$ inicial versus $\mathrm{SiO}_{2}$ dos dados apresentados nesse trabalho para os riolitos Santa Maria comparados aos dados de Polo (2014) para as rochas das unidades Caxias do Sul e Barros Cassal.

As idades-modelo Nd T $\mathrm{DM}$ calculadas segundo DePaolo (1981) são da ordem de 1,5 a 1,6 Ga para os três conjuntos, como pode ser observado na Figura 73.

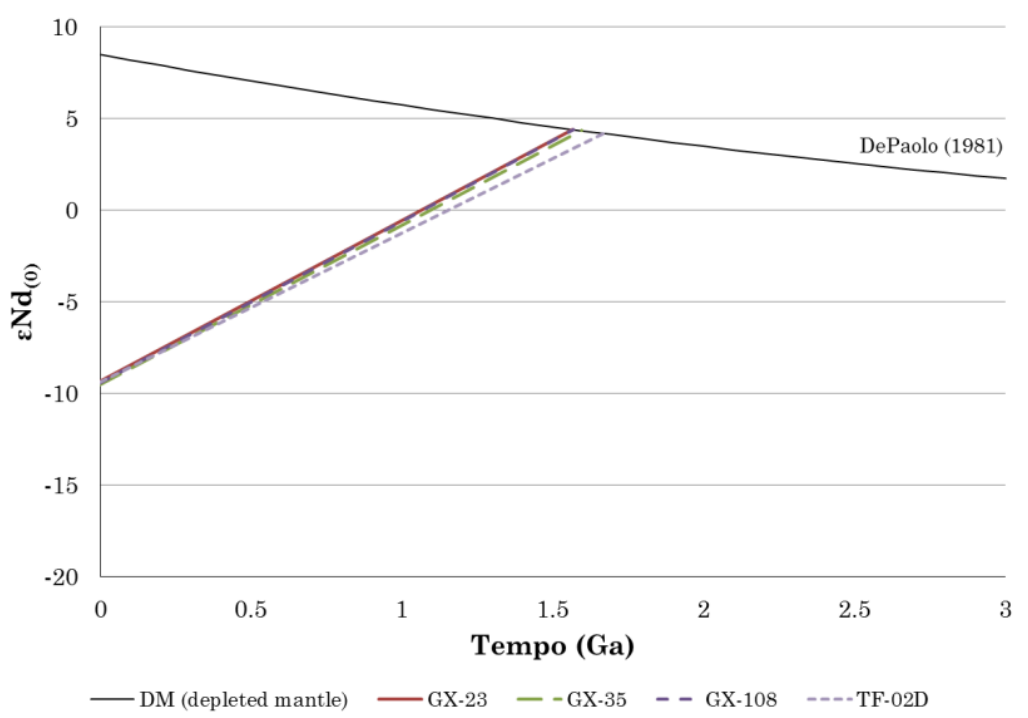

Figura 73: Diagrama evolutivo para o sistema $\mathrm{Sm} / \mathrm{Nd}$. A linha preta contínua (DM) corresponde à linha de evolução do manto empobrecido (depleted mantle) de DePaolo (1981). As linhas coloridas (simbologia junto ao diagrama) correspondem à evolução para as amostras do riolito Santa Maria.

\section{VI.3.2. SISTEMA Rb/Sr e RAZÕES ${ }^{87} \mathrm{Sr} / 86 \mathrm{Sr}$ EM MICROFENOCRISTAIS DE PLAGIOCLÁSIO - UMA COMPARAÇÃO COM ROCHA TOTAL}

Foram obtidas razões isotópicas ${ }^{87} \mathrm{Sr} / 86 \mathrm{Sr}$ em fenocristais de plagioclásio por LA-MC-ICPMS para comparação com as razões obtidas em rocha total, de 
modo a verificar se ambos se encontram em equilíbrio. A pequena dimensão dos cristais de plagioclásio impediu a resolução de eventuais variações associadas ao zonamento químico, uma vez que foi necessário utilizar um feixe de $100 \mu \mathrm{m}$ - tamanho necessário para obter um sinal suficiente para alcançar a precisão necessária.

As razões isotópicas ${ }^{87} \mathrm{Sr} / 86 \mathrm{Sr}$ obtidas em microfenocristais de plagioclásio (Tabela 07) foram recalculadas para a idade de $134 \mathrm{Ma}$; como as razões ${ }^{87} \mathrm{Rb} / 86 \mathrm{Sr}$ são baixas (tipicamente, variando entre 0,1 e 0,2), as diferenças entre os dois valores são sempre pequenas, e a razão inicial é estimada com boa precisão. Os valores de razão inicial são comparados com os valores da rocha total equivalente nas Figuras $74 \mathrm{~A}$ e B. Nota-se que os plagioclásios apresentam razões ${ }^{87} \mathbf{S r} /{ }^{86} \mathbf{S r}_{(134)}$ bastante homogêneas, variando de 0,7267 a 0,7280. Esses valores são sistematicamente mais elevados que os

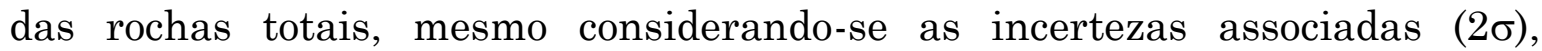
indicadas pelas barras de erro.

Tabela 7: Resultados das análises $87 \mathrm{Sr} / 86 \mathrm{Sr}$ obtidas em cristais de plagioclásio via LA-ICPMS.

\begin{tabular}{|c|c|c|c|c|c|c|c|}
\hline $\begin{array}{c}\text { Cristal } \\
\text { amostrado }\end{array}$ & ${ }^{\mathbf{8 7}} \mathbf{R b} /{ }^{\mathbf{8 6}} \mathbf{S r}$ & $\mathbf{2 \sigma}$ & ${ }^{\mathbf{8 7}} \mathbf{S r}{ }^{\mathbf{8 6}} \mathbf{S r}$ & $\mathbf{2 \sigma}$ & ${ }^{\mathbf{8 4}} \mathbf{S r}{ }^{\mathbf{8 6}} \mathbf{S r}$ & $\mathbf{2 \sigma}$ & ${ }^{\mathbf{8 7}} \mathbf{S r}{ }^{\mathbf{8 6}} \mathbf{S r} \mathbf{1 3 4}$ \\
\hline GX35-1 & 0.20606 & 0.04336 & 0.72761 & 0.00046 & 0.05596 & 0.00011 & 0.72721 \\
\hline GX35-2 & 0.16964 & 0.05140 & 0.72775 & 0.00024 & 0.05621 & 0.00010 & 0.72742 \\
\hline GX35-3 & 0.43688 & 0.14188 & 0.72775 & 0.00051 & 0.05613 & 0.00009 & 0.72692 \\
\hline GX35-4 & 0.26517 & 0.02294 & 0.72779 & 0.00028 & 0.05605 & 0.00009 & 0.72728 \\
\hline GX35-5 & 0.20046 & 0.05487 & 0.72789 & 0.00036 & 0.05563 & 0.00014 & 0.72751 \\
\hline GX108-1 & 0.07201 & 0.01799 & 0.72767 & 0.00042 & 0.05555 & 0.00015 & 0.72754 \\
\hline GX108-2 & 0.09907 & 0.02573 & 0.72732 & 0.00037 & 0.05558 & 0.00018 & 0.72713 \\
\hline GX108-3 & 0.27040 & 0.08469 & 0.72784 & 0.00049 & 0.05568 & 0.00011 & 0.72732 \\
\hline GX108-4 & 0.15449 & 0.04708 & 0.72755 & 0.00046 & 0.05529 & 0.00020 & 0.72725 \\
\hline GX108-5 & 0.16561 & 0.03602 & 0.72726 & 0.00028 & 0.05545 & 0.00016 & 0.72695 \\
\hline GX108-6 & 0.21093 & 0.03150 & 0.72706 & 0.00040 & 0.05552 & 0.00017 & 0.72666 \\
\hline GX108-7 & 0.21422 & 0.04341 & 0.72838 & 0.00058 & 0.05559 & 0.00012 & 0.72797 \\
\hline
\end{tabular}




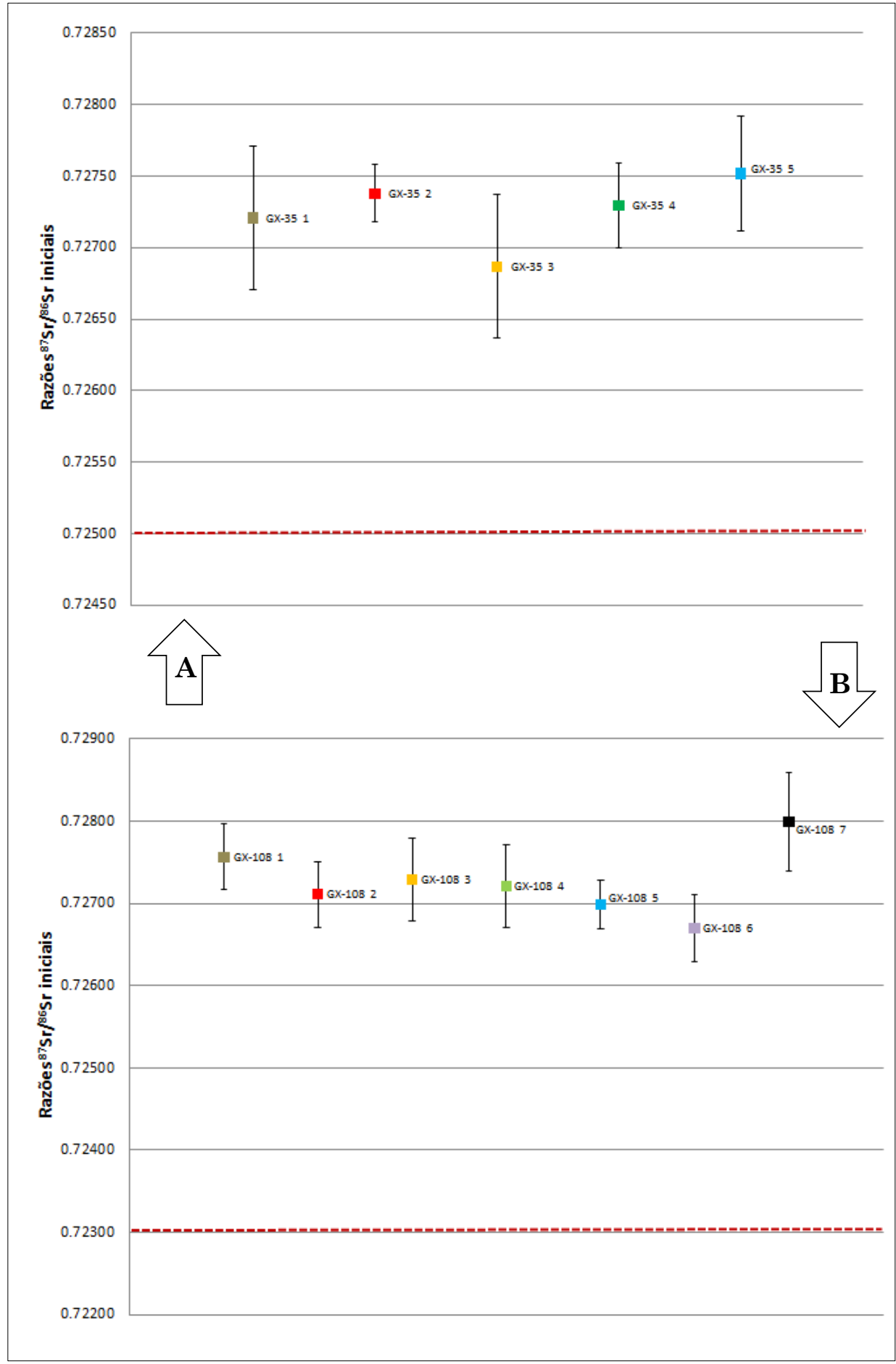

Figura 74: Gráficos comparativos entre as razões de ${ }^{87} \mathrm{Sr} /{ }^{86} \mathrm{Sr}$ iniciais e seus respectivos erros para os cristais de plagioclásio e a razão obtida para análise em rocha total (linhas vermelhas). A) Análises correspondentes à amostra GX-35; B) Análises correspondentes à amostra GX-108. 


\section{CAPITULO VII - PETROGÊNESE}

A formação de ocorrências vulcânicas, a despeito de sua aparente monotonia mineral e/ou textural em escala de afloramento, pode envolver complexos processos de geração, e evolução de magmas, mesmo durante sua ascensão. Estas ocorrências podem ainda apresentar uma grande variedade em sua forma de extrusão, a depender de parâmetros como temperatura, composição, conteúdo de voláteis e viscosidade.

O principal mecanismo na geração de magmas é a fusão parcial, seja de rochas do manto ou da crosta. Desde modo, o magma resultante será função da composição da rocha-fonte e do grau de fusão por ela sofrido. Uma vez gerado, este magma poderá passar por processos evolutivos que podem envolver diferenciação por cristalização fracionada, contaminação ou ambos (processo conhecido como AFC - assimilation and fractional crystallization), gerando assim uma vasta possibilidade composicional para o produto final. A caracterização do magma parental e dos processos que o modificam pode ser feita com estudos de geoquímica mineral, de rocha e geoquímica isotópica.

No caso das rochas vulcânicas, a complexidade da geração e evolução dos magmas estende-se ainda para sua forma de ocorrência. A depender de sua composição e de parâmetros como temperatura, teor de água e viscosidade, o magma poderá apresentar uma erupção efusiva ou explosiva, resultando assim em uma infinidade de estruturas. Para uma inferência e caracterização da forma de ocorrência dos depósitos vulcânicos, fazem-se necessários estudos detalhados de estruturas tanto em escala macro quanto microscópica, abrangendo detalhamentos de campo e análises petrográficas.

Os capítulos anteriores apresentaram a caracterização estrutural e geoquímica dos riolitos Santa Maria, e podem ser usados como base para a elaboração de modelos petrogenéticos. Deste modo, o presente capítulo apresenta uma breve contribuição de modelamentos geoquímicos para os 
riolitos Santa Maria através da estimativa da composição do líquido em equilíbrio com a principal fase mineral (plagioclásio) no momento de sua cristalização, da elaboração de modelos de fracionamento e AFC através da utilização do software Petrograph e, por fim, da integração dos dados apresentados.

\section{VII.1. Estimativa da composição da fusão em equilíbrio a partir de teores de elementos traço em plagioclásio}

Modelamentos inversos são úteis para avaliar a existência de equilíbrio entre fenocristais e seus magmas hospedeiros (Ramos et al., 2005). Os riolitos Santa Maria são rochas com pequeno conteúdo de fenocristais, e a composição da rocha total pode ser considerada uma aproximação razoável da composição do líquido original.

Utilizando os resultados das análises químicas pontuais por LA-ICPMS para os microfenocristais de plagioclásio, foram calculados os teores de elementos terras-raras leves esperados no líquido a partir do qual eles teriam se cristalizado, segundo os procedimentos de Bédard (2006). Os resultados foram plotados em diagramas onde são comparados com a composição da rocha total (Figura 75).

Nas amostras GX-23 e GX-108, os teores dos elementos La, Ce, Pr e Nd observados na rocha total são sistematicamente inferiores aos obtidos para a fusão em equilíbrio calculada. $\mathrm{Na}$ amostra GX-35, existe concordância entre os teores dos elementos $\mathrm{Pr}, \mathrm{Nd}$ e Sm calculados para a fusão em equilíbrio e os observados na rocha total (cf. Figura 74; os resultados numéricos são apresentados na Tabela 08). 


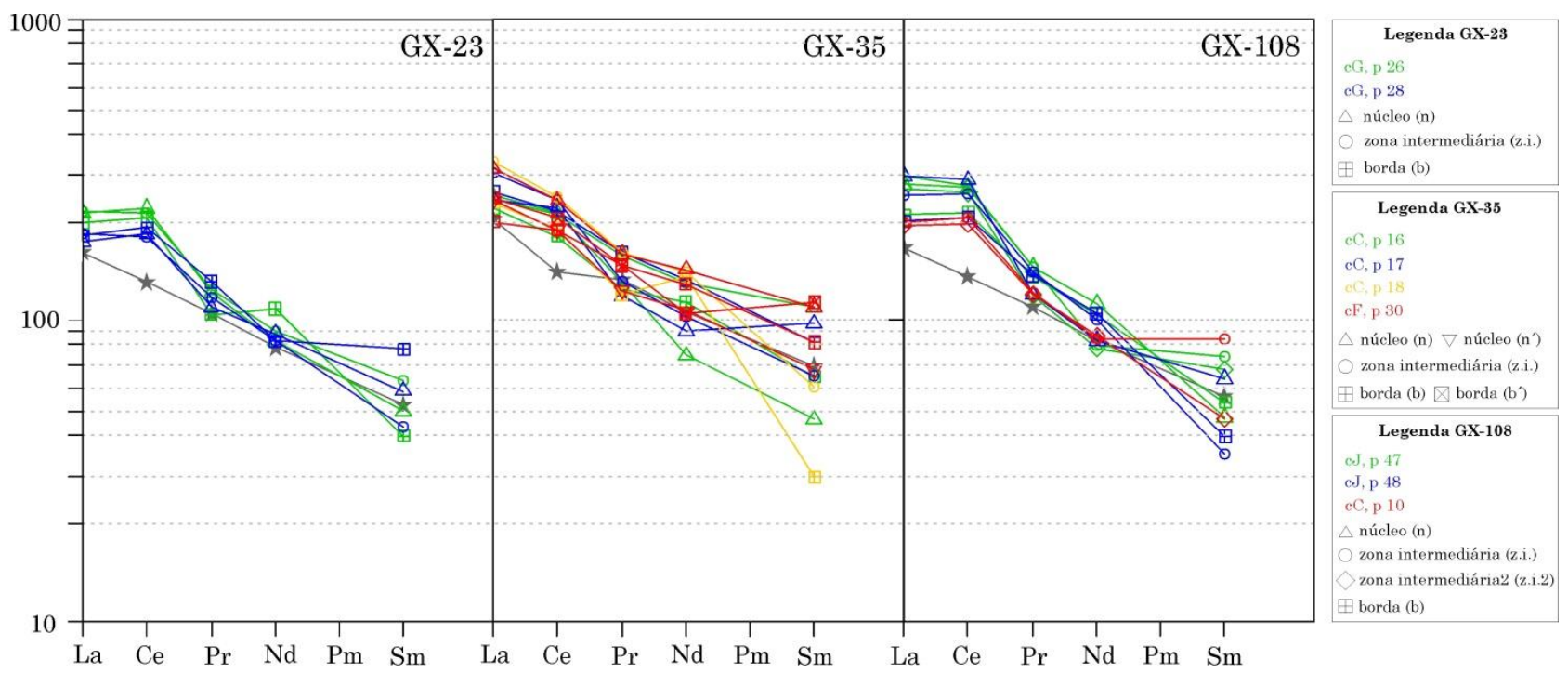

Figura 75: Representação dos líquidos em equilibrio calculados para as amostras GX-23, GX-35 e GX-108 com base nas análises de elementos traço em plagioclásio via LA-ICPMS. As linhas coloridas representam os diferentes cristais das amostras, sendo que os símbolos representam diferentes zonas composicionais. Os valores obtidos são comparados com os resultados de rocha total representados pelas linhas cinzas e simbolizados por estrelas.

Esses resultados sugerem que os fenocristais de plagioclásio não estariam em equilíbrio perfeito com o magma (rocha total), sendo possivelmente associados a uma fonte mais rica nesses elementos.

Estas características, somadas ao fato dos cristais apresentarem razões isotópicas ${ }^{87} \mathrm{Sr} / 86 \mathrm{Sr}$ iniciais mais altas que as obtidas para rocha total (conforme apresentado no item VI.3.2), sugerem que os microfenocristais de plagioclásio correspondem a antecristais. Conforme definição de Davidson et al. (2007), antecristais não cristalizaram diretamente do magma no qual estão hospedados, mas correspondem a fenocristais formados previamente, em diferentes estágios e locais durante a evolução do mesmo sistema magmático, que são carregados por esse magma. 
Tabela 8: Composição obtida para fusão em equilibrio calculado de acordo com Bédard (2006). Os cálculos são feitos utilizando-se os teores obtidos para elementos traço no plagioclásio via LA-ICPMS e com base nos coeficientes de partição $(\mathrm{Kd})$ dos elementos.

\begin{tabular}{|c|c|c|c|c|c|c|c|c|c|}
\hline & \multicolumn{8}{|c|}{ Composição do melt em equilíbrio calculado } \\
\hline & & La & Ce & $\operatorname{Pr}$ & Nd & Sm & $\mathbf{R b}$ & $\mathbf{S r}$ & $\mathbf{B a}$ \\
\hline \multirow{14}{*}{$\begin{array}{l}\stackrel{n}{\breve{~}} \\
\ddot{x}\end{array}$} & cC,p16 n & 80.6 & 184.2 & 16.3 & 45.9 & 9.2 & 36.1 & 200.3 & 747.0 \\
\hline & cC,p16 z.i. & 78.6 & 182.5 & 20.1 & 79.8 & 21.6 & 76.0 & 222.5 & 971.1 \\
\hline & cC,p16 b & 73.3 & 153.8 & 15.4 & 68.9 & 12.6 & 101.5 & 222.8 & 1132.6 \\
\hline & cC,p17 n & 78.4 & 192.1 & 14.7 & 55.4 & 19.1 & 89.4 & 211.0 & 650.6 \\
\hline & cC,p17 z.i. & 95.8 & 202.0 & 16.5 & 61.8 & 12.7 & 118.6 & 236.9 & 956.1 \\
\hline & cC,p17 b & 83.2 & 187.4 & 20.5 & 82.0 & 16.5 & 116.5 & 209.2 & 739.8 \\
\hline & cC,p18 z.i. & 104.8 & 209.2 & 20.4 & 86.9 & 11.7 & 109.6 & 242.4 & 991.4 \\
\hline & cC,p18 b & 76.4 & 163.7 & 14.9 & 84.0 & 5.9 & 43.4 & 235.9 & 1038.9 \\
\hline & cF,p30 n & 99.5 & 202.2 & 20.3 & 88.6 & 21.7 & 341.8 & 220.4 & 972.7 \\
\hline & cF,p30 b & 65.8 & 161.5 & 18.7 & 79.1 & 16.5 & 54.3 & 230.1 & 843.4 \\
\hline & cF,p30 n' & 77.7 & 161.9 & 15.3 & 64.5 & 13.4 & 105.3 & 212.4 & 749.0 \\
\hline & cF,p30 b' & 79.3 & 177.0 & 18.6 & 63.3 & 22.4 & 91.2 & 235.4 & 964.9 \\
\hline & \multicolumn{9}{|c|}{ Rocha Total } \\
\hline & GX-35 & 67.2 & 117.8 & 16.7 & 64.4 & 13.7 & 276.2 & 107.6 & 852.7 \\
\hline
\end{tabular}

\begin{tabular}{|c|c|c|c|c|c|c|c|c|c|}
\hline & \multicolumn{8}{|c|}{ Composição do melt em equilíbrio calculado } \\
\hline & & $\mathbf{L a}$ & $\mathrm{Ce}$ & Pr & Nd & Sm & $\mathbf{R b}$ & $\mathbf{S r}$ & $\mathbf{B a}$ \\
\hline \multirow{11}{*}{ 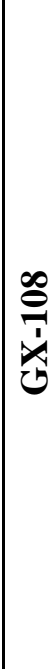 } & cJ,p47 n & 88.1 & 224.7 & 18.4 & 68.1 & 9.3 & 74.4 & 225.4 & 889.7 \\
\hline & cJ,p47 z.i. & 94.1 & 227.4 & 18.5 & 49.5 & 14.7 & 533.8 & 251.1 & 970.0 \\
\hline & cJ,p47 z.i.2 & 84.6 & 214.9 & 14.7 & 48.4 & 13.4 & 47.6 & 203.0 & 711.8 \\
\hline & cJ,p47 b & 69.5 & 184.9 & 17.0 & 62.8 & 10.4 & 403.2 & 190.2 & 870.8 \\
\hline & cJ,p48 n & 93.8 & 237.4 & 14.9 & 51.5 & 12.5 & 582.1 & 217.1 & 918.1 \\
\hline & cJ,p48 z.i. & 81.3 & 213.6 & 17.6 & 60.6 & 7.0 & 49.6 & 212.4 & 826.4 \\
\hline & cJ,p48 b & 66.4 & 177.7 & 17.2 & 63.4 & 8.0 & 51.0 & 211.8 & 858.1 \\
\hline & cC,p10 z.i. & 65.9 & 178.1 & 15.1 & 52.0 & 17.0 & 67.9 & 212.3 & 838.4 \\
\hline & cC,p10 z.i. 2 & 63.9 & 170.1 & 14.8 & 53.3 & 9.2 & 44.7 & 198.8 & 756.9 \\
\hline & \multicolumn{9}{|c|}{ Rocha Total } \\
\hline & GX-108 & 54.3 & 113.4 & 13.5 & 51.6 & 10.9 & 285.4 & 126.6 & 716.6 \\
\hline
\end{tabular}




\section{VII.2. Modelamentos geoquímicos}

O modelo mais aceito para a geração e evolução dos magmas ácidos do tipo Palmas envolve cristalização fracionada a partir dos magmas basálticos de baixo $\mathrm{Ti}$ associados. Garland et al. (1995) admitem que os basaltos tipo Gramado seriam o magma parental para os riolitos tipo Palmas, que teriam sido originados a partir de processos de cristalização fracionada e assimilação crustal (AFC) em nível raso. Em modelamentos geoquímicos, esses autores assumiram a composição de um típico produto de anatexia crustal como assimilado, escolhendo o leucogranito himalaiano Langtang. Os resultados obtidos por esses autores a partir de composições mais primitivas dos basaltos Gramado mostram que, para alcançar as composições mais primitivas (andesíticas/dacíticas) das rochas ácidas tipo Palmas, seriam necessários 50\% de cristalização e $20 \%$ de assimilação.

Para o caso dos riolitos tipo Santa Maria, as razões isotópicas iniciais ${ }^{87} \mathrm{Sr} /{ }^{86} \mathrm{Sr}$ e ${ }^{143} \mathrm{Nd} / 144 \mathrm{Nd}$, que os caracterizam como a unidade mais evoluída entre as rochas vulcânicas ácidas tipo Palmas, são uma importante evidência de sua geração e evolução através de processos de AFC. Processos mais simples como cristalização fracionada a partir dos basaltos associados ou fusão parcial da crosta não seriam capazes, por si só, de gerar rochas com tais características isotópicas.

As razões iniciais calculadas e apresentadas no item VI.3.1 foram plotadas no mesmo diagrama apresentado por Garland et al. (1995) para fins de comparação (Figura 76). Entretanto, devido à continuidade química e isotópica observada entre as unidades da área de estudos, os modelamentos realizados consideraram as rochas da sequência Barros Cassal como magma parental, minimizando assim a elevada taxa de cristalização necessária para a obtenção de composições riolíticas (no que diz respeito aos teores de elementos maiores e traços) a partir dos basaltos Gramado (da ordem de mais de $80 \%$, 
como mencionado por Garland et al., 1995) e reduzindo as incertezas associadas.

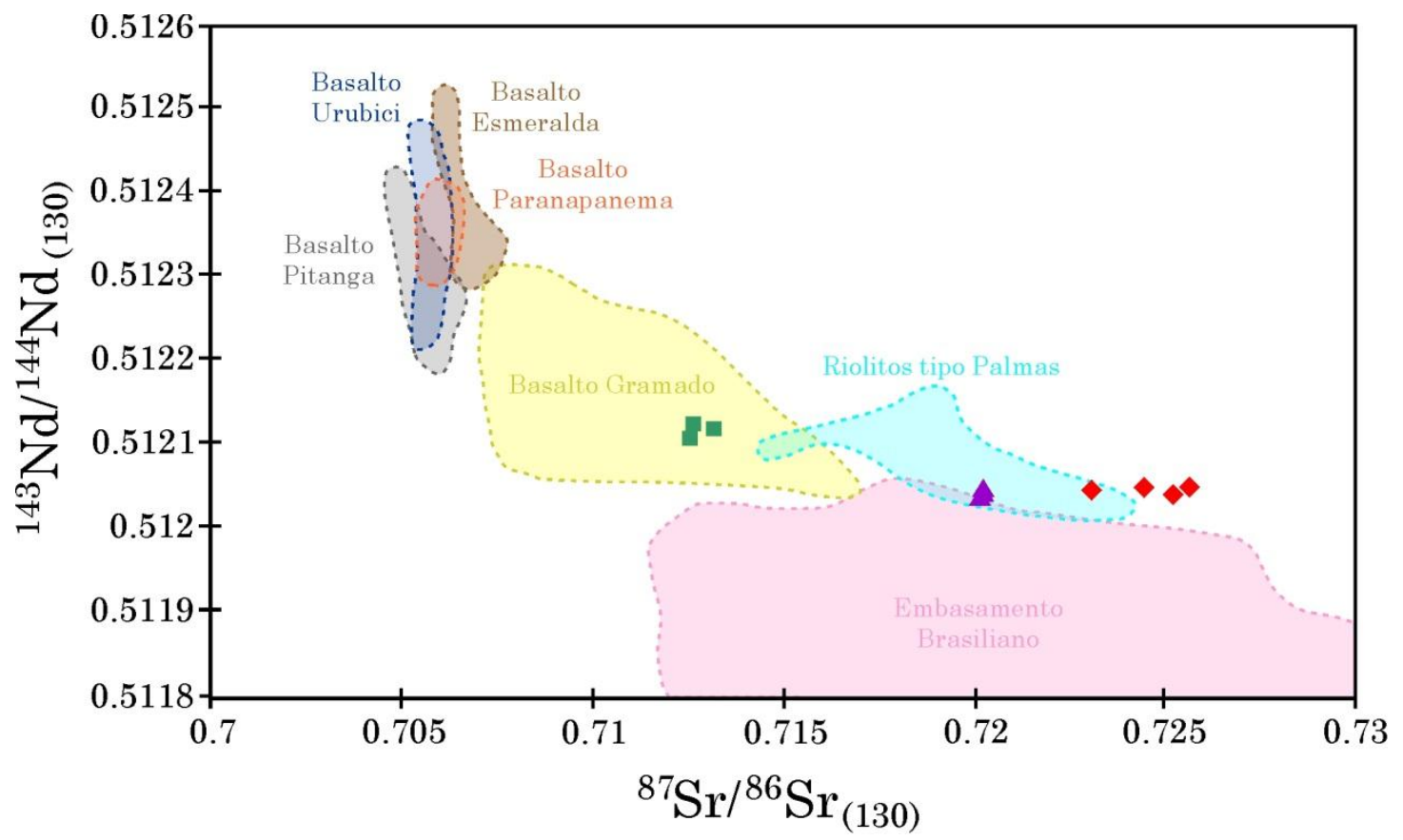

Figura 76: Dados isotópicos dos riolitos Santa Maria (losangos vermelhos) e das unidades subjacentes Barros Cassal (triângulos verdes) e Caxias do Sul (triângulos roxos) plotados em diagrama ${ }^{143} \mathrm{Nd} /{ }^{144} \mathrm{Nd}$ inicial versus ${ }^{87} \mathrm{Sr} /{ }^{86} \mathrm{Sr}$ inicial (calculados para $130 \mathrm{Ma}$ ) extraído de Garland et al. (1995), mostrando os campos ocupados por rochas vulcânicas de outras regiões da PMP e por rochas do embasamento cristalino.

\section{VII.2.1. CRISTALIZAÇÃO FRACIONADA}

Embora as evidências isotópicas mostrem que a geração dos magmas riolíticos a partir de rochas mais primitivas como as da sequência Barros Cassal não pode ter ocorrido em sistema fechado, modelamentos de cristalização fracionada foram testados inicialmente para elementos maiores e traços através de balanços de massa realizados com auxílio do software Petrograph. Isto é importante para estabelecer parâmetros limitantes para o modelo final. 
Os modelamentos para elementos maiores envolveram balanço de massa pela metodologia de Stormer \& Nicholls (1978), e consideraram um magma parental de composição de andesito basáltico e dacito (unidade Barros Cassal) com extração de plagioclásio, piroxênio e magnetita - fases minerais presentes e de cristalização precoce nas rochas da unidade Barros Cassal, conforme petrografia descrita por Polo (2014). Os resultados, apresentados no anexo 05, mostram que é possível obter um magma riolítico correspondente à composição média da unidade Santa Maria a partir de um magma: a) andesito basáltico com aproximadamente $57 \%$ de cristalização (de onde são extraídos $\sim 45 \%$ de plagioclásio, $\sim 38 \%$ de piroxênio e $\sim 17 \%$ de magnetita); b) andesítico com aproximadamente $49 \%$ de cristalização (de onde são retirados $\sim 46 \%$ de plagioclásio, $\sim 38 \%$ de piroxênio e $\sim 16 \%$ de magnetita); c) dacítico com aproximadamente $27 \%$ de cristalização (com cristalização de $\sim 50 \%$ de plagioclásio, $\sim 34 \%$ de piroxênio e $\sim 16 \%$ de magnetita). Destaca-se que, a depender do magma parental, o que varia é a proporção de cristalização (de cerca de $60 \%$ para aproximadamente $30 \%$ ), enquanto que a proporção extraída das fases minerais se mantém praticamente inalterada, e é condizente com as proporções descritas petrograficamente.

Os resultados mais satisfatórios foram obtidos para cristalização fracionada a partir de composições andesito basálticas $\left(\sum \mathrm{res}^{2}=0,35\right)$, estando os erros mais elevados (como no caso de magmas parentais de composição mais dacítica onde $\sum$ res $^{2}=2,31$ ) associados ao ajuste para os elementos $\mathrm{Na}$ e K.

O modelamento a partir de elementos traço é uma importante ferramenta que permite o modelamento de diferentes processos geoquímicos envolvidos na geração de um magma. Para este fim, foram elaborados diagramas binários com os principais elementos de interesse, sendo os cálculos realizados segundo a equação definida por Neuman et al. (1957):

$$
C_{L}=C_{0} \times F^{(D-1)}
$$


onde $\mathrm{C}_{\mathrm{L}}$ corresponde à concentração do elemento traço no líquido final, $\mathrm{C}_{0}$ corresponde à concentração inicial do elemento traço, $\mathrm{F}$ corresponde à fração de líquido residual e D corresponde ao coeficiente de partição global. Os coeficientes foram calculados considerando-se as proporções modais obtidas a partir do modelamento dos elementos maiores $(50 \%$ de plagioclásio, $30 \%$ de piroxênio e 15\% de magnetita) e são apresentados junto aos Kds na Tabela 09.

Tabela 9: Coeficientes de partição para os elementos selecionados das fases minerais cristalizadas e o coeficiente global (D) resultante. ${ }^{1}$ - Calculados a partir de Bédard (2006); ${ }^{2}$ - Extraídos de Bellieni et al. (1986b); ${ }^{3}$ - Extraídos de Renner et al. (2011).

\begin{tabular}{|c|c|c|c|c|c|c|c|}
\hline \multirow{2}{*}{$\begin{array}{c}\text { Fase } \\
\text { mineral }\end{array}$} & \multicolumn{7}{|c|}{ Elementos } \\
\cline { 2 - 8 } & $\mathrm{Ba}$ & $\mathrm{Rb}$ & $\mathrm{Sr}$ & $\mathrm{Zr}$ & $\mathrm{La}$ & $\mathrm{Th}$ & $\mathrm{Nd}$ \\
\hline Plagioclásio & $0.47^{1}$ & $0.038^{1}$ & $2.65^{1}$ & $0.01^{1}$ & $0.202^{1}$ & $0.03^{3}$ & $0.13^{1}$ \\
\hline Augita (cpx) & $0.02^{2}$ & $0.03^{2}$ & $0.1^{2}$ & $0.27^{2}$ & $0.02^{2}$ & $0.03^{3}$ & $0.31^{2}$ \\
\hline Magnetita & $0.29^{2}$ & $0.18^{2}$ & $0.15^{2}$ & $0.4^{2}$ & $0.29^{2}$ & 0 & $0.75^{2}$ \\
\hline D & $\mathbf{0 . 2 8}$ & $\mathbf{0 . 0 6}$ & $\mathbf{1 . 3 8}$ & $\mathbf{0 . 1 5}$ & $\mathbf{0 . 1 6}$ & $\mathbf{0 . 0 2}$ & $\mathbf{0 . 2 7}$ \\
\hline
\end{tabular}

Os resultados mostram que alguns elementos como Ba e Zr (Figura 77) apresentam resultados satisfatórios para os processos de cristalização fracionada. Neste caso, líquidos de composição andesítica a dacítica (grupo representado pela amostra GX-22) necessitam apenas 10 a $20 \%$ de cristalização para geração de magmas riolíticos com a composição adequada, enquanto líquidos andesíticos basálticos e basálticos com maiores teores de Ba e menores teores de $\mathrm{Zr}$ necessitam mais de 20\% (e.g. amostra GX-113) e 45-55\% (e.g. amostra GX-157) de cristalização. Já os líquidos de composição equivalente ao grupo representado pelas amostras GX-94 e GX-137 nunca alcançam o enriquecimento em $\mathrm{Ba}$ observado, descartando o processo de cristalização fracionada ou demandando processos adicionais. 


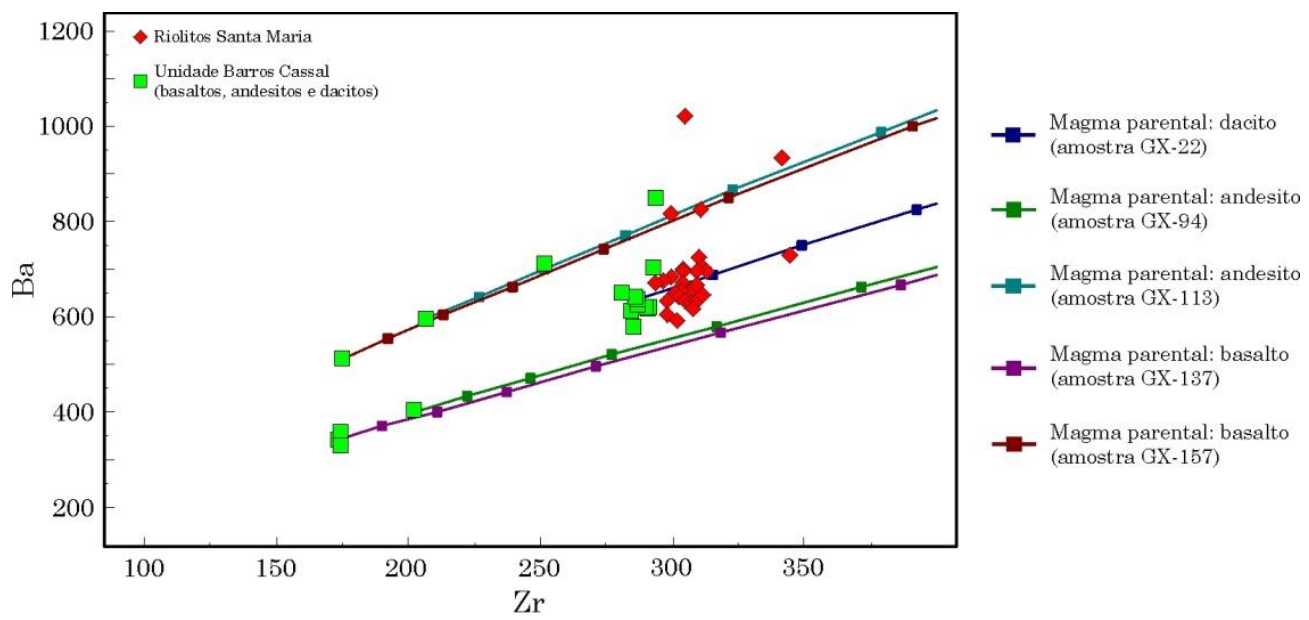

Figura 77: Modelo de cristalização fracionada de geração de magmas riolíticos (Santa Maria) a partir de magmas intermediários (basaltos, andesitos e dacitos Barros Cassal) inseridos em diagrama binário Ba versus Zr. Losangos vermelhos: riolitos Santa Maria; quadrados verdes: rochas da unidade Barros Cassal. As linhas de evolução da cristalização fracionada apresentam diferentes cores para cada magma parental e cada quadrado representa um aumento de $10 \%$ na taxa de cristalização (com início em $0 \%$ no ponto da amostra).

Em contrapartida, para outros elementos traço observa-se que não é possível atingir os teores equivalentes às composições dos riolitos tipo Santa Maria por simples processo de cristalização fracionada. A Figura 78 mostra que, no caso do Rb, apenas em alguns casos as amostras de composição mais diferenciada (dacíticas) poderiam gerar, a partir da cristalização fracionada de no mínimo cerca de $40 \%$ do líquido, magmas riolíticos com os teores de $\mathrm{Rb}$ característicos da unidade Santa Maria. De maneira semelhante, é possível observar que o Th (Figura 77) também não atingiria os teores observados a partir de processos de simples cristalização fracionada, sendo necessário processo adicional responsável para alcançar o enriquecimento observado. Os resultados também não são satisfatórios para Sr, uma vez que necessitaria $\mathrm{Kd}$ mais elevado do que o calculado, da ordem de 5, por exemplo; quando analisado através do diagrama $\mathrm{Nd}$ vs $\mathrm{Sr}$ também apresentado na Figura 77, nota-se que apenas o processo de cristalização fracionada não seria suficiente para se obter os teores observados, sendo necessária a assimilação de um contaminante com teor mais elevado de $\mathrm{Nd}$ e menos elevado de $\mathrm{Sr}$. 

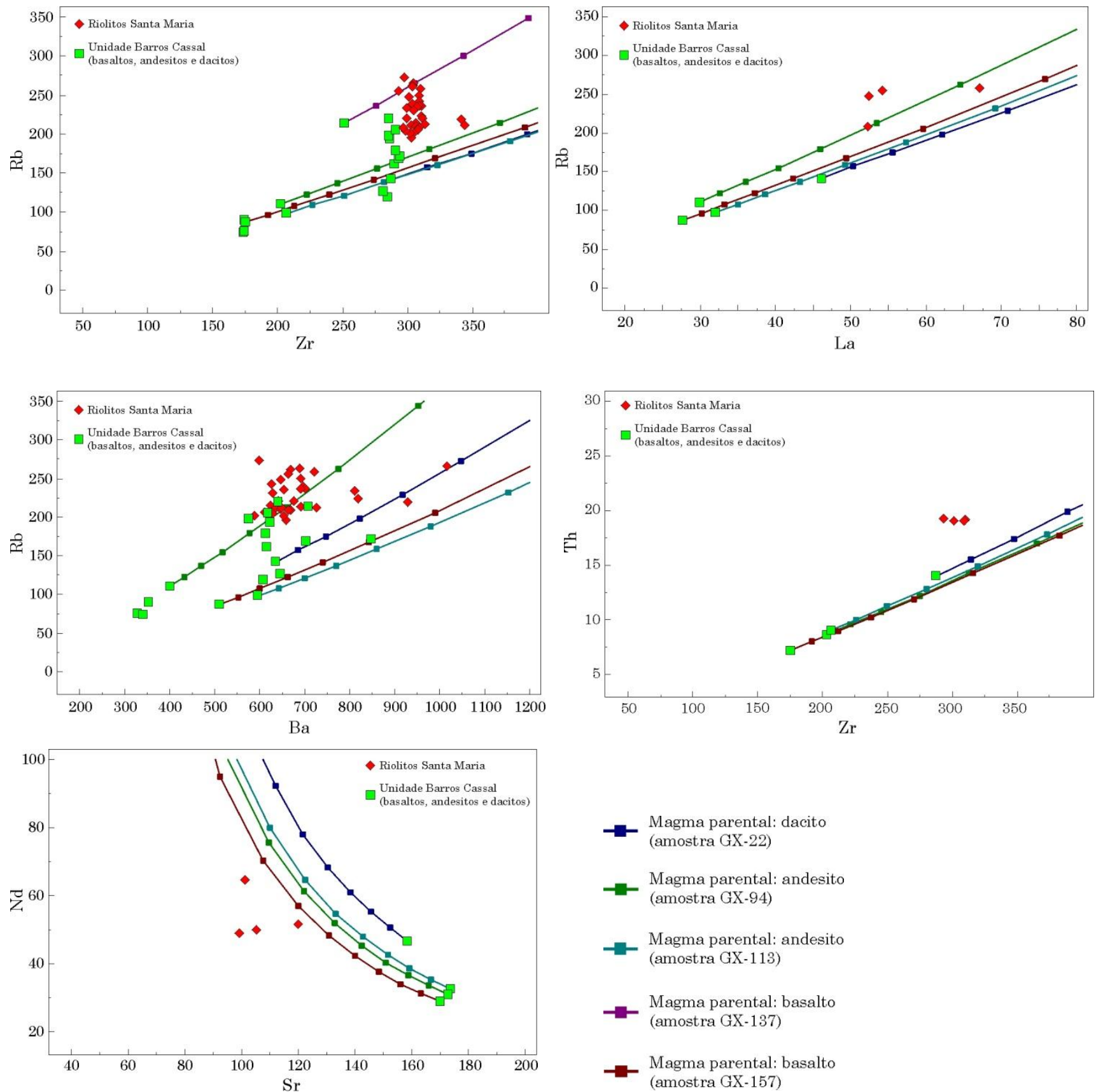

Figura 78: Modelo de cristalização fracionada de geração de magmas riolíticos (Santa Maria) a partir de magmas intermediários (basaltos, andesitos e dacitos Barros Cassal) inseridos em diagramas binários. Losangos vermelhos: riolitos Santa Maria; quadrados verdes: rochas da unidade Barros Cassal. As linhas de evolução da cristalização fracionada apresentam diferentes cores para cada magma parental e cada quadrado representa um aumento de $10 \%$ na taxa de cristalização (com início em $0 \%$ no ponto da amostra). 


\section{VII.2.2. ASSIMILAÇÃO CRUSTAL E CRISTALIZAÇÃO FRACIONADA (AFC)}

Para os modelos de AFC, primeiramente fez-se uma avaliação dos potenciais contaminantes, considerando as assinaturas isotópicas requeridas pela variação observada entre possíveis parentais básicos a intermediários (unidade Barros Cassal) e os riolitos Santa Maria.

Foram consideradas as rochas típicas do embasamento cristalino da região sul do Brasil, com base em trabalhos realizados em domínios tectônicos compatíveis com o esperado para a crosta que teria contribuído para a geração dos magmas riolíticos. O batólito Florianópolis (Silva, 1999), situado no Escudo Catarinense, compreende rochas graníticas neoproterozóicas de natureza póscolisional (Bitencourt \& Nardi, 1993), dentre as quais a Suíte Paulo Lopes, composta entre outras unidades, pelos granitóides Garopaba (dados obtidos de Florisbal et al., 2009). Os Granitóides Garopaba, selecionados como contaminantes para os modelamentos realizados, apresentam composição isotópica de $\mathrm{Sr}$ e $\mathrm{Nd}$ mais adequada para um provável material assimilado ${ }^{87}{ }^{8 r} /{ }^{86} \operatorname{Sr}_{(134)}=0.7310$ a $0.7361 ;{ }^{143} \mathrm{Nd} /{ }^{144} \mathrm{Nd}_{(134)}=0.51196$ a $0.51199 ; \varepsilon \mathrm{Nd}_{(134)}=$ 9.4 a -9.9), como é possível observar na Figura 79, que traz uma nova comparação com o diagrama de Garland et al. (1995). Observa-se, em contrapartida, que as granitos do tipo Rio Pequeno e Serra dos Macacos (dados obtidos de Florisbal et al., 2012), que ocorrem em um domínio tectônico distinto, localizado a norte Batólito Florianópolis, não configuram contaminantes adequados, uma vez que apresentam valores de $\mathcal{E N d}$ muito negativos e ${ }^{87} \mathrm{Sr}^{86} \mathrm{Sr}_{(134)}$ pouco elevados, inconsistentes com uma tendência de mistura a partir dos basaltos que levaria até os riolitos Santa Maria. 


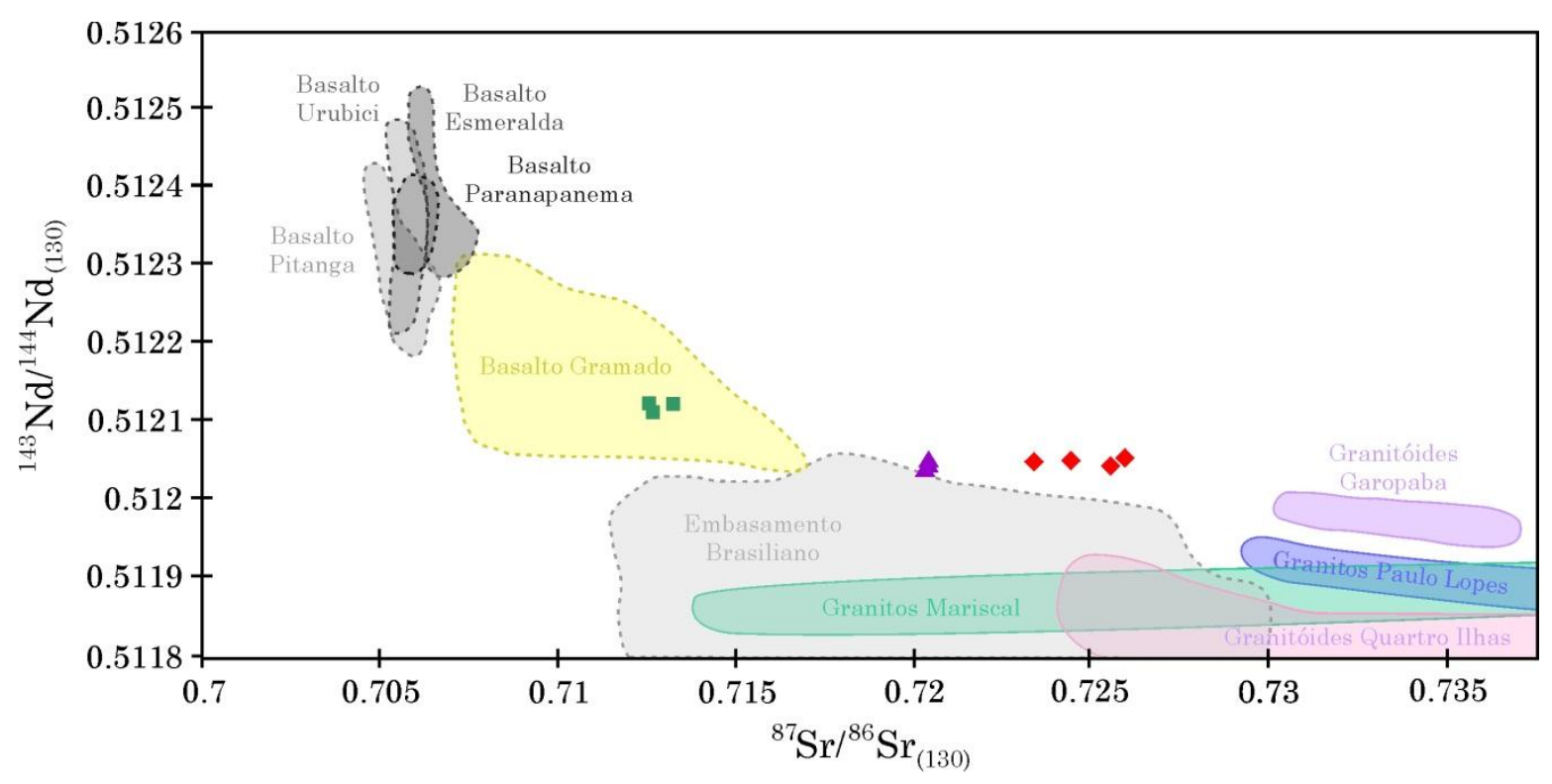

Figura 79: Dados isotópicos dos riolitos Santa Maria (losangos vermelhos) e das unidades subjacentes Barros Cassal (quadrados verdes) e Caxias do Sul (triângulos roxos) plotados em diagrama ${ }^{143} \mathrm{Nd} /{ }^{144} \mathrm{Nd}$ inicial versus ${ }^{87} \mathrm{Sr} /{ }^{86} \mathrm{Sr}$ inicial (calculados para $130 \mathrm{Ma}$ ) extraído de Garland et al. (1995), que contem valores das rochas vulcânicas de outras regiões da PMP, do embasamento Brasiliano e das unidades neoproterozóicas do Escudo Catarinense - Granitóides Garopaba, Granitos Paulo Lopes, Granitos Mariscal e Granitóides Quatro Ilhas.

Com auxílio do software Petrograph, as razões isotópicas foram inseridas em diagramas binários ${ }^{87} \mathrm{Sr} / 86 \operatorname{Sr}_{(134)}$ vs $\mathrm{Sr}$ para as unidades em questão (Figura 80). Os resultados mostram que, a partir de dacitos e andesitos da unidade Barros Cassal pode-se obter magmas com as razões ${ }^{87} \mathrm{Sr} / 86 \operatorname{Sr}_{(134)}$ apresentadas pelos riolitos Santa Maria após cristalização de 20 a 30\%, com 16 a 21\% de assimilação de material (por exemplo, fusão parcial) derivado de um granito Garopaba. 

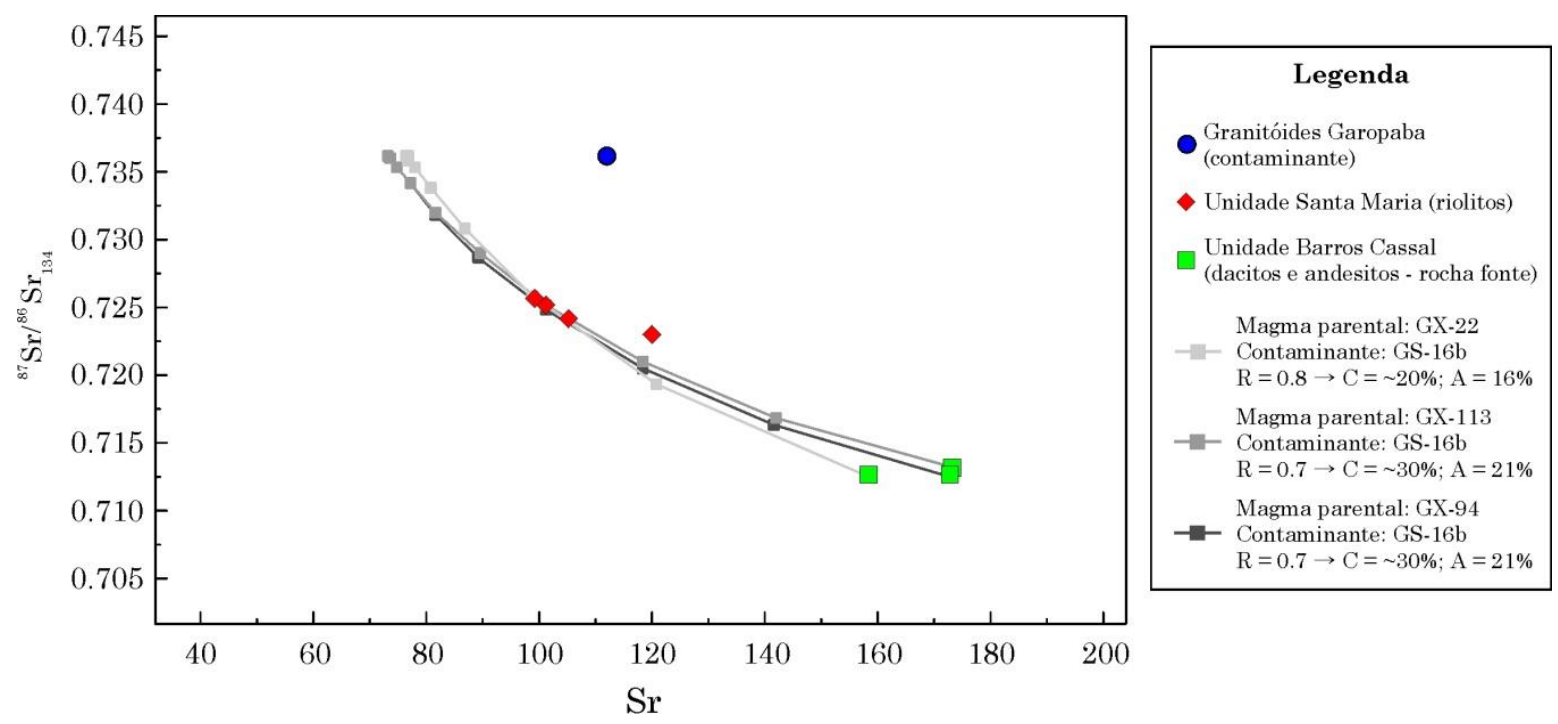

Figura 80: Modelos de cristalização fracionada com assimilação crustal (AFC) para a geração de magma riolítico (Santa Maria - losangos vermelhos) a partir de magmas intermediários (andesitos e dacitos Barros Cassal - quadrados verdes). O círculo azul representa a amostra do Granitóide Garopaba usada como contaminante. As linhas cinzas representam a trajetória AFC - cada quadrado equivale a um acréscimo de $10 \%$ da taxa de cristalização, com início em $0 \%$ na composição básica. Foram consideradas diferentes razões assimilação/cristalização (" $r$ "), a depender do magma parental, para que se obtivesse as retas de melhores ajustes.

Para o modelamento de elementos traço utilizaram-se, primeiramente, as composições médias dos basaltos, andesitos e dacitos da unidade Barros Cassal (magmas parentais) e dos granitoides Garopaba (contaminante) para a obtenção dos teores de elementos traço em um líquido final através da fórmula:

$$
\frac{C_{L}}{C_{0}}=f^{\prime}+\frac{r}{(r-1+D)} \times \frac{C_{A}}{C_{0}}\left(1-f^{\prime}\right)
$$

onde $\mathrm{C}_{\mathrm{L}}$ representa a concentração do elemento traço no líquido final, $\mathrm{C}_{0}$ é a concentração no magma parental, $\mathrm{C}_{\mathrm{A}}$ é a concentração no magma assimilado, $\mathrm{r}$ é a razão entre assimilação e cristalização, D é o coeficiente de partição global entre os minerais extraídos e o magma parental e $f^{\prime}$ equivale a: $f^{\prime}=\mathrm{F}-(\mathrm{r}-1+\mathrm{D}) /(\mathrm{r}-$ 1). O objetivo foi comparar, para diferentes valores de $\mathrm{F}$ (proporção de líquido residual), a concentração de um elemento traço no líquido obtido $\left(\mathrm{C}_{\mathrm{L}}\right)$ com sua concentração média nos riolitos tipo Santa Maria $\left(\mathrm{C}_{\mathrm{SM}}\right)$. Os resultados mais satisfatórios (medidos pela razão entre a concentração calculada e observada, 
$\mathrm{C}_{\mathrm{L}} / \mathrm{C}_{\mathrm{SM}}$ ) foram obtidos para um magma parental de composição basáltica com $\mathrm{F}$ $=0,7$ (cristalização de 30\%) com taxas de assimilação variando de 12 a $21 \% \mathrm{e}$ para um magma parental de composição andesítica com $\mathrm{F}=0,8$ (cristalização de 20\%) com taxas de assimilação variando de 2 a 16\%. Os resultados numéricos são apresentados no anexo 05; a Figura 81 mostra graficamente quanto a composição do líquido final obtido se aproxima da composição dos riolitos Santa Maria.

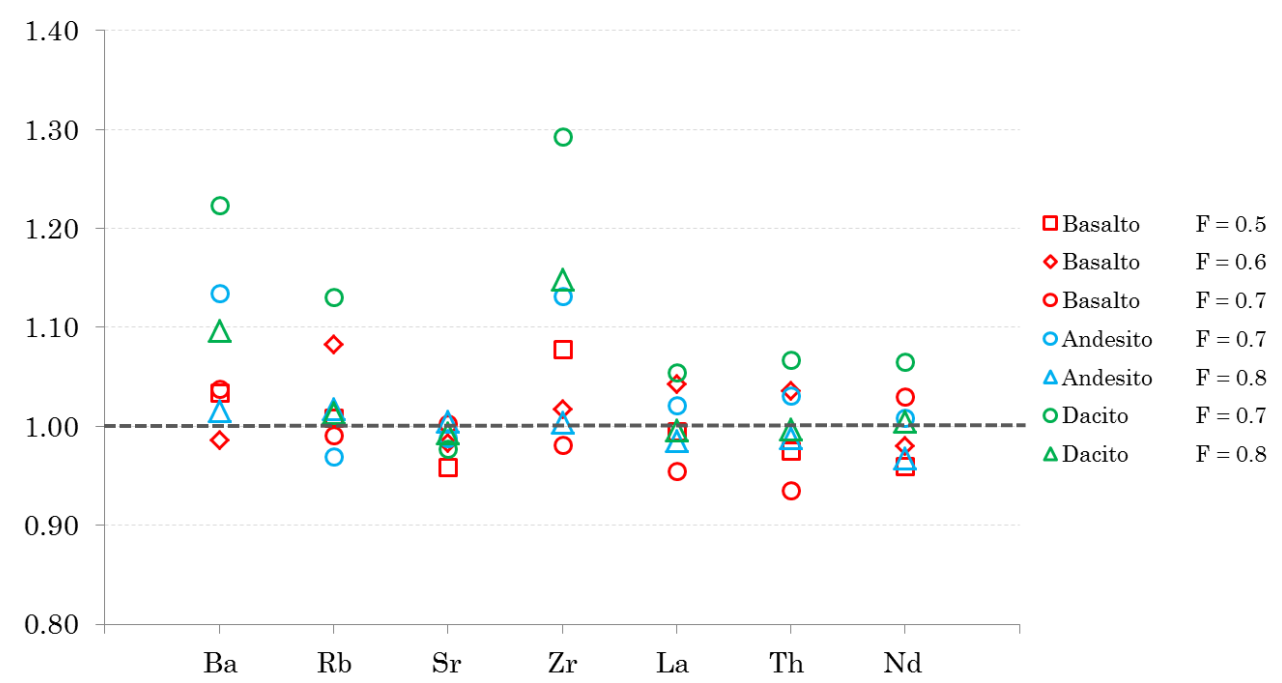

Figura 81: Diagrama representativo da comparação entre o líquido obtido $\left(\mathrm{C}_{\mathrm{L}}\right)$ a partir um modelamento de AFC (considerando-se cristalização de magmas com composições equivalentes às composições médias dos basaltos, andesitos e dacitos da unidade Barros Cassal e assimilação de uma composição equivalente à composição média dos Granitódes Garopaba) e a composição média dos riolitos Santa Maria (CSM). Cada símbolo representa um valor de " $F$ ", enquanto as cores representam diferentes composições de magma parental a sofrer cristalização fracionada.

Posteriormente, os teores de elementos traço foram plotados em diagramas binários para testar o modelo de contaminação dos magmas a partir da assimilação de líquidos de composição equivalente aos Granitóides Garopaba. Nestes diagramas não foram consideradas as composições médias, sendo plotadas as diferentes amostras de cada unidade, mostrando assim as variações composicionais características de cada uma.

Os diagramas apresentados na Figura 82 mostram os resultados obtidos. Foram consideradas como magmas parentais as amostras da unidade Barros 
Cassal composições andesito basáltica e andesítica, uma vez que foram as que apresentaram melhores resultados nas primeiras etapas de modelamento (cf. Figura 81). As amostras de composição dacítica não apresentaram bons ajustes na evolução para os magmas riolíticos, como pode ser observado nas figuras 82 A, B, e E, onde se nota se tratar de um grupo com elevado teor de Zr e Nd. Este comportamento pode ser indicativo da evolução da própria unidade Barros Cassal, não discutida neste trabalho, distinta daquela envolvida na geração dos magmas riolíticos a partir dos basaltos e andesitos envolvendo os processos de AFC.

Os resultados mostram ser possível obter magmas riolíticos com as características dos riolitos Santa Maria a partir de cristalização de 10 a $60 \%$ dos magmas basálticos e andesíticos associados a 6-25\% de assimilação de composições semelhantes às dos Granitóides Garopaba, sendo o intervalo de $30-40 \%$ de cristalização e $8-15 \%$ de assimilação o mais satisfatório para os elementos considerados. É importante ressaltar que a variação geoquímica dos riolitos Santa Maria para alguns elementos remetem à necessidade de processos contínuos e mais complexos de contaminação, devendo ser também considerado o fato de que as rochas utilizadas como contaminante (granitoides Garopaba) apresentam grande variação composicional, o que pode resultar em ampla variação do líquido resultante. Por fim, deve-se considerar ainda que os modelos apresentados correspondem a simplificações, uma vez que consideram a composição de rocha total para as amostras usadas como contaminantes, o que se sabe não ocorrer, já que serão incorporados líquidos resultantes de fusão parcial da rocha encaixante, o que necessitaria modelamentos de fusão parcial que não foram realizados no presente trabalho. De todo modo, os granitos escolhidos como contaminantes têm composição bastante evoluída, e suas composições globais não são muito distintas das esperadas para líquidos derivados de sua refusão. 

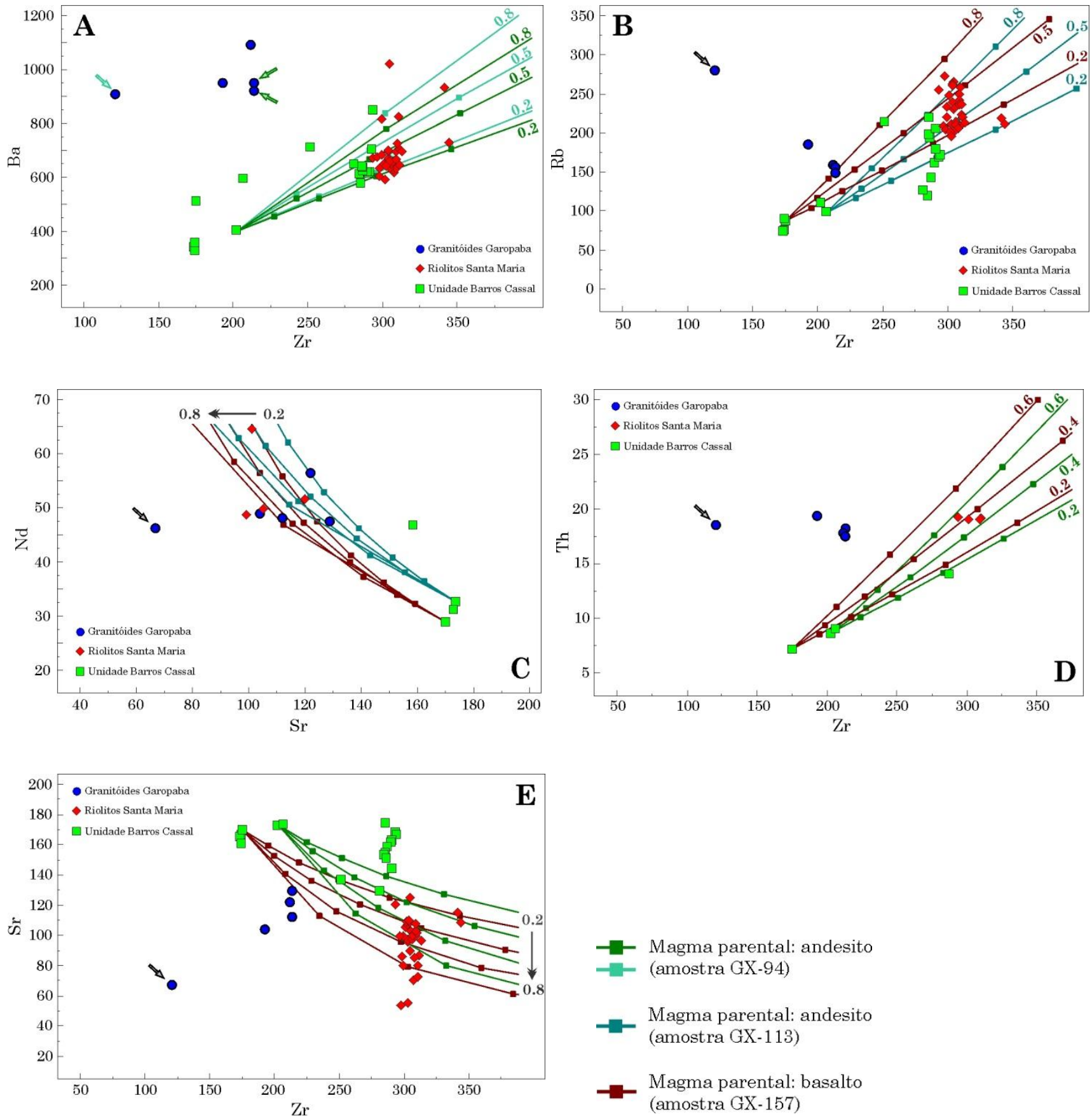

Figura 82: Modelos de cristalização fracionada com assimilação crustal (AFC) para a geração de magma riolítico (Santa Maria - losangos vermelhos) a partir de magmas intermediários (andesitos e dacitos Barros Cassal - quadrados verdes). Os círculos azuis correspondem às amostras dos Granitóides Garopaba - as setas indicam a amostra selecionada como contaminante (por apresentar o melhor ajuste da reta). Foram consideradas diferentes razões assimilação/cristalização (" $r$ "), a depender do magma parental, para que se obtivesse as retas de melhores ajustes - os valores de " $r$ " são indicados junto às curvas de evolução do processo AFC. 


\section{CAPITULO VIII - PARÂMETROS INTENSIVOS E SUA RELAÇÃO COM A FORMA DE OCORRÊNCIA}

As erupções vulcânicas e seus produtos correspondem à manifestação em superfície dos processos magmáticos que ocorrem no interior do planeta. Deste modo, a vulcanologia torna-se um complexo estudo interdisciplinar que envolve, além da geologia estrutural e da geoquímica (descritas nos itens precedentes), estimativas de parâmetros intensivos (e.g., temperatura, conteúdo de água, viscosidade) que controlam a forma de ocorrência destas erupções, se mais ou se menos explosiva, e definem, portanto, seus produtos. A tabela 10, extraída de Sigurdsson et al. (2000) resume os principais fatores controladores das erupções, os quais operam de modo conjunto, sendo interdependentes.

Tabela 10: Fatores controladores dos processos vulcânicos. Modificado de Sigurdsson et al. (2000)

\begin{tabular}{lcl}
\hline \multicolumn{1}{c}{ Fator } & Intervalo típio & \multicolumn{1}{c}{ Comentários } \\
\hline Temperatura do magma & $800-1250^{\circ} \mathrm{C}$ & $\begin{array}{l}\text { Influencia a viscosidade do magma e afeta a energia disponível para a } \\
\text { pluma eruptiva ascender }\end{array}$ \\
\hline Teor de água do magma & $0.1-6 \%$ em peso & $\begin{array}{l}\text { Controla a viscosidade e a fragmentação do magma através dos processos } \\
\text { de vesiculação }\end{array}$ \\
\hline Viscosidade & $10^{1}-10^{9} \mathrm{Pa.s}$ & $\begin{array}{l}\text { Determina as propriedades do fluxo magmático, vesiculação e crescimento } \\
\text { de bolhas; controla a ascensão e o escape das bolhas no magma }\end{array}$ \\
\hline Água externa & $0.01-0.5$ vol. frac. & $\begin{array}{l}\text { Fração volumétrica de água externa que se mistura ao magma no conduto } \\
\text { ou caldeira }\end{array}$ \\
\hline Conteúdo de cristais & $0-50 \%$ & Afeta a viscosidade do magma e consequentemente sua reologia \\
\hline
\end{tabular}

A temperatura exerce importante papel no controle da viscosidade e densidade das fusões: o principal efeito da diminuição da temperatura é a cristalização do magma, e o conteúdo de cristais passa então a afetar a viscosidade, a densidade e a reologia deste magma.

Entende-se por viscosidade a "razão entre a tensão cisalhante e a taxa de cisalhamento", i.e., a viscosidade pode ser definida como a resistência interna de um fluido ao movimento. Os magmas, quando em temperaturas mais 
elevadas que a temperatura de liquidus e a baixas taxas de deformação, podem ser classificados como fluidos newtonianos, ou seja, apresentam uma relação linear entre a tensão e a taxa de deformação. Quando este fluido passa a apresentar uma resistência interna, ele passa a se comportar como um material "binghamniano", ou seja, necessita uma tensão inicial para que haja deformação. Essa resistência interna pode ser devida à cristalização do magma, com a formação de cristais interativos entre si.

A cristalinidade $(\phi)$ equivale à proporção dos cristais presentes no magma (variando de 0 - liquidus - a 1 - solidus) e interfere significativamente na viscosidade do sistema. O diagrama reológico (Fernandez, 1984) apresentado na Figura 83 mostra a relação entre viscosidade do magma, a cristalinidade e a tensão cisalhante. O campo I definido no diagrama corresponde a $0<\phi<0,3-0,35$, onde o magma apresenta um comportamento newtoniano, baixa viscosidade e alta mobilidade. O campo II corresponde a 0,3$0,35<\phi<0,65$, onde o magma passa a comportar-se como fluido nãonewtoniano, com uma viscosidade crescente, enquanto que no campo III ( $\phi>$ 0,65) o magma passa a se comportar como um sólido.

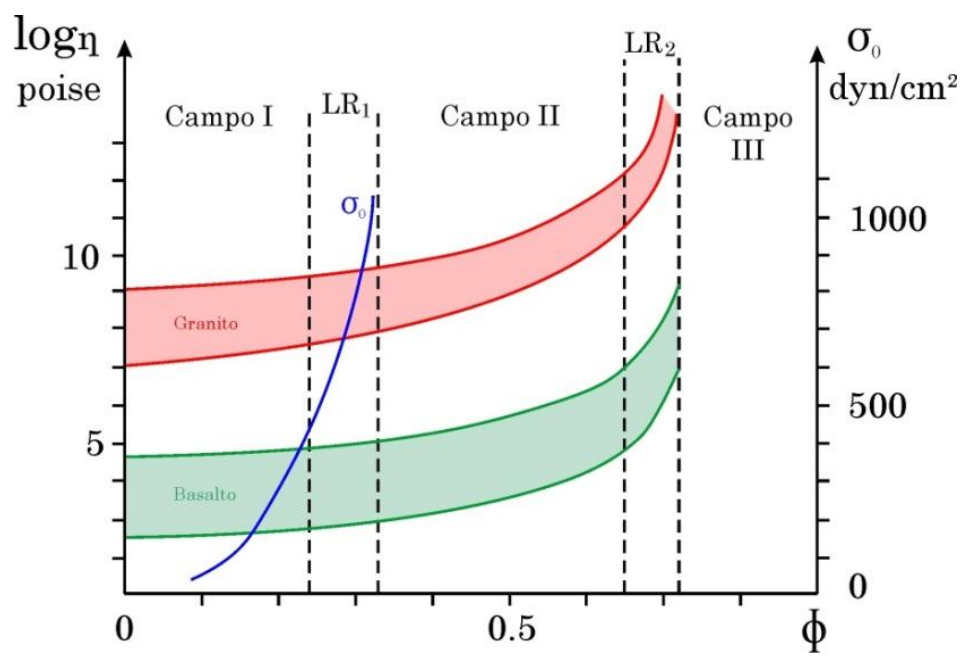

Figura 83: Diagrama reológico representativo de uma composição granítica e uma composição basáltica (segundo Fernandez, 1984). A viscosidade (representada no eixo à esquerda) apresenta correlação positiva com a tensão cisalhante (eixo à direita) e a cristalinidade (eixo horizontal), sendo definidos três campos de comportamento reológico distintos. O campo III caracteriza-se pela perda da mobilidade do magma. 
Além de condicionar a cristalinidade do magma, a temperatura influencia a solubilidade dos voláteis que serão dissolvidos no magma (embora de maneira menos significativa que a pressão no caso da água como fase volátil). A solubilidade refere-se ao conteúdo máximo de uma fase volátil que pode ser dissolvida (incorporada) no magma em determinadas condições. Os voláteis dissolvidos no magma afetam drasticamente a densidade e a viscosidade dos magmas, sendo fundamentais no controle de sua ascensão, intrusão e erupção e, principalmente, na fragmentação do magma devido à exsolução e formação de bolhas como consequência da descompressão sofrida durante a ascensão.

Para os riolitos Santa Maria, será considerada a água como única fase volátil (indicado por dados obtidos por LECO). A dissolução da $\mathrm{H}_{2} \mathrm{O}$ envolve despolimerização das fases silicáticas e/ou alumino-silicáticas, sendo que este "componente" pode se apresentar dissolvido no magma sob duas formas: íons hidroxila $\left[\mathrm{OH}^{-}\right]$e água molecular $\left[\mathrm{H}_{2} \mathrm{O}_{(\mathrm{m})}\right]$. Os mecanismos de dissolução dependem basicamente da composição do magma e do conteúdo de água presente, e podem ser expressos pelas equações, segundo (Moulson \& Roberts, 1961 apud Mysen \& Richet, 2005):

$$
\mathrm{H} 2 \mathrm{O}(\mathrm{m})+\mathrm{O}(\text { melt }) \leftrightarrow 2 \mathrm{OH}(\text { fusão) }
$$

ou ainda,

$$
\mathrm{Si}-\mathrm{O}-\mathrm{Si}+\mathrm{H} 2 \mathrm{O} \leftrightarrow \mathrm{Si}-\mathrm{OH} \ldots \mathrm{OH}-\mathrm{Si}
$$

onde a abundância relativa entre os espécimes depende do teor de água dissolvido, sendo que até conteúdos da ordem de 3-5\% de água, há predomínio da espécie hidroxila (Behren \& Gaillard, 2006; Wallace \& Anderson Jr, 2000). 
Os estudos de Stolper (1982) e Silver et. al. (1990) (apud Mysen \& Richet, 2005) indicam que a solubilidade da água aumenta de maneira diretamente proporcional ao conteúdo de $\mathrm{SiO}_{2}$. A influência da composição e da pressão na solubilidade de água pode ser observada na figura $84 \mathrm{~A}$, onde observa-se a curva de aumento da solubilidade com o aumento da pressão e nota-se que, para um mesmo valor de $\mathrm{P}$, magmas riolíticos apresentam maiores solubilidades (para $\mathrm{P}>0,5 \mathrm{kbar}$ ).

Uma vez que a incorporação de água em magmas silicáticos é responsável pela "quebra" das cadeias alumino-silicáticas polimerizadas, a adição de água em sistemas magmáticos passa a ter um papel fundamental na diminuição da viscosidade e no controle da forma de extrusão. A figura 84B ilustra o efeito da água sobre a viscosidade e nota-se que o papel da água é mais efetivo quando em teores de até $3 \%$, já que este é o limite para a predominância dos íons hidroxila, responsáveis pela incorporação da água envolvendo a quebra da estrutura cristalina.

Por fim, ressalta-se ainda o papel da água na densidade da fusão, propriedade física responsável pelo controle da ascensão dos magmas. A adição de água no sistema é responsável por uma queda significativa na densidade, como pode ser observado na figura $84 \mathrm{C}$. 

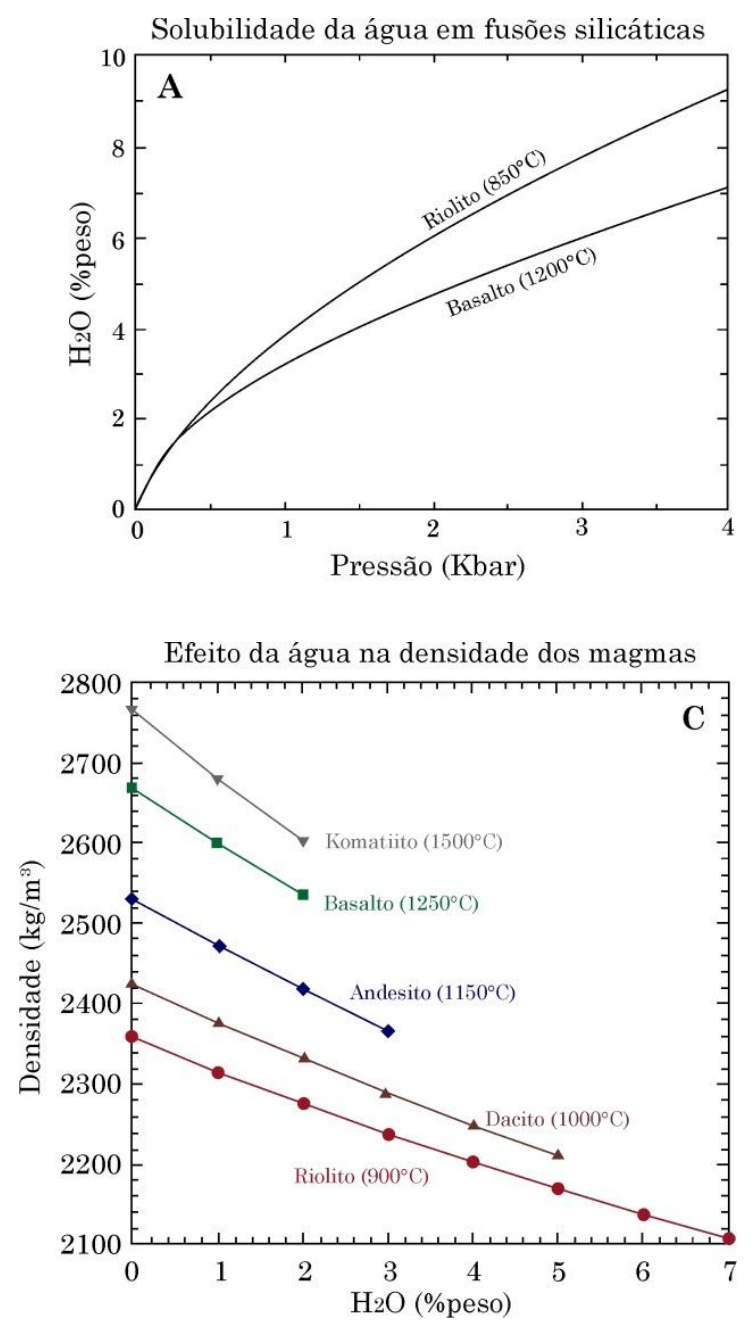

Efeito da água (e temperatura) na viscosidade dos liquidos silicáticos

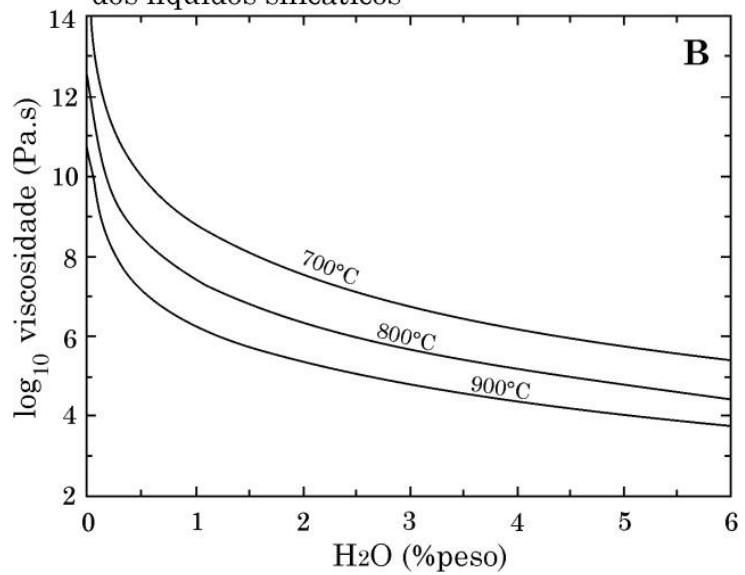

Figura 84: A) Determinação experimental da solubilidade de água em fusões basálticas e riolíticas a temperaturas típicas. A solubilidade da água é maior em magmas riolíticos do que em magmas basálticos a pressões acima de 0,5 Kbar. Extraído de Carroll \& Holloway (1994) in Wallace \& Anderson Jr (2000). B) Efeito da água dissolvida na viscosidade de fusão granítica (riolítica). Notar que a baixas concentrações de água as curvas de $700^{\circ} \mathrm{C}$ e $800^{\circ} \mathrm{C}$ são para magmas super-resfriados, uma vez que as temperaturas são inferiores à temperatura de solidus para um líquido granítico desidratado $\left(\sim 900^{\circ} \mathrm{C}\right)$. Calculado a partir de Hess \& Dingwell (1996), extraído de Wallace \& Anderson Jr (2000). C) Densidade de fusões com composições variando desde komatiíticas até riolíticas em função do conteúdo de água dissolvida. As temperaturas consideradas são as típicas para as respectivas composições. Densidades calculadas para pressão de 1 bar (10-4 GPa). Extraído de Spera (2000).

Fica evidente, portanto, a importância da determinação de parâmetros como temperatura, pressão e teor de água para uma melhor compreensão dos processos envolvidos na evolução e ascensão dos magmas. Com esta finalidade, muitos modelos físico-químicos e matemáticos foram desenvolvidos a partir de estudos empíricos, dando origem aos termômetros, barômetros e higrômetros que comumente baseiam-se nas reações químicas de troca entre fases minerais ou fase mineral e o líquido em equilíbrio, como é o caso, por exemplo, dos barômetros baseados na troca de $\mathrm{Al}$ (alumínio) entre um piroxênio ou anfibólio e a fusão. Entretanto, é importante ressaltar que estes modelos precisam ser 
usados com cautela, já que podem ser bastante imprecisos uma vez que: 1) os parâmetros são interdependentes e um termômetro pode ser sensível à pressão e ao teor de água e um barômetro pode ser sensível à temperatura - deste modo, estimativas imprecisas podem ocasionar propagação de erro; 2) muitas das trocas e reações químicas utilizadas como referência para os cálculos se dão em um intervalo relativamente grande de pressão e temperatura, o que não permite inferir com precisão o parâmetro desejado; 3) os resultados obtidos de termômetros e barômetros baseados em trocas e reações químicas podem ser imprecisos devido processos posteriores de reequilíbrio das fases. Deste modo, é fundamental verificar as condições de aplicação das metodologias utilizadas e, sempre que possível, buscar modelos que independem de determinações prévias destes parâmetros, para que se tenha uma melhor confiabilidade dos dados obtidos.

\section{VIII.1. Temperatura}

Uma vez que os termômetros costumam ser dependentes da pressão e dos teores de água, optou-se primeiramente por uma metodologia que fosse independente desses parâmetros, como é o caso do termômetro baseado na saturação em apatita (Harrison \& Watson, 1984), que se embasa na premissa de que a atividade de $\mathrm{P}_{2} \mathrm{O}_{5}$ é dependente exclusivamente do teor de $\mathrm{SiO}_{2}$ e da temperatura do magma. Deste modo, em magmas nos quais a apatita é uma fase mineral precoce, sua temperatura de saturação pode ser tomada como uma boa aproximação para a temperatura de liquidus. A relação entre os parâmetros é definida segundo a equação:

$$
\ln D_{P}^{\frac{\text { apatita }}{\text { liquido }}}=8400+\left[\frac{\left(\left(\mathrm{SiO}_{2}-0.5\right) 2.64 \times 10^{4}\right)}{T}\right]-\left[3.1+\left(12.4\left(\mathrm{SiO}_{2}-0.5\right)\right)\right]
$$


onde $D_{P}^{\frac{\text { apatita }}{\text { liquido }}}$ corresponde ao coeficiente de partição do fósforo entre a apatita e o líquido, $\mathrm{T}$ à temperatura absoluta e o teor de $\mathrm{SiO}_{2}$ é dado em fração em peso, sendo o modelo calibrado para teores de $45-75 \%$ e de $0-10 \%$ de $\mathrm{H}_{2} \mathrm{O}$.

Os riolitos Santa Maria apresentam teores de $\mathrm{P}_{2} \mathrm{O}_{5}$ de 0,19 a 0,20\% (em peso), e as temperaturas obtidas para as amostras são apresentadas na tabela 11 e variam de $962^{\circ} \mathrm{C}$ a $994^{\circ} \mathrm{C}$.

Tabela 11: Temperaturas obtidas a partir da saturação em apatita (Harrison \& Watson, 1984) para os riolitos Santa Maria.

\begin{tabular}{|l|c|c|c|}
\hline \multicolumn{1}{|c|}{ Amostra } & $\mathbf{S i O}_{2}$ & $\mathbf{P}_{2} \mathrm{O}_{\mathbf{5}}$ & $\begin{array}{c}\text { Temperatura } \\
\text { estimada }\left({ }^{\circ} \mathbf{C}\right)\end{array}$ \\
\hline GX-23 & 70,34 & 0,19 & 977 \\
\hline GX-35 & 69,36 & 0,19 & 967 \\
\hline GX-108 & 69,06 & 0,19 & 964 \\
\hline TF-02A & 70,15 & 0,20 & 980 \\
\hline TF-02B & 70,05 & 0,20 & 979 \\
\hline TF-02C & 70,00 & 0,20 & 979 \\
\hline TF-02D & 68,31 & 0,20 & 962 \\
\hline RS-74A & 68,55 & 0,20 & 964 \\
\hline RS-74B & 72,19 & 0,19 & 994 \\
\hline
\end{tabular}

A média das temperaturas obtidas $\left(974^{\circ} \mathrm{C}\right)$ foi então utilizada como ponto de partida para os modelos de termômetros, barômetros e higrômetros que se utilizam de trocas químicas para se estimar os parâmetros desejados. Com esta finalidade, foram empregados aqueles apresentados por Putirka (2008), que correspondem a recalibramentos de modelos anteriores. 
O termômetro "plagioclásio-líquido" é baseado na troca dos componentes anortita-albita (reação de troca $\mathrm{Na}+\mathrm{Si} \leftrightarrow \mathrm{Ca}+\mathrm{Al}$ ) entre o plagioclásio e o líquido em equilíbrio ${ }^{2}$, a qual é função da pressão, do teor de água e das proporções (frações catiônicas) dos componentes albita e anortita no plagioclásio e no líquido segundo a equação (Eq 24a de Putirka, 2008):

$$
\begin{aligned}
\frac{10^{4}}{T(K)}=6.4706 & +0.3128 \ln \left(\frac{X_{A n}^{p l}}{X_{C a O}^{l i q}\left(X_{A l O_{1.5}}^{l i q}\right)^{2}\left(X_{\text {Sio }_{2}}^{l i q}\right)^{2}}\right)-8.103\left(X_{S_{i O_{2}}}^{l i q}\right) \\
+ & 4.872\left(X_{K O_{0.5}}^{l i q}\right)+1.5346\left(X_{A b}^{l i q}\right)^{2}+8.661\left(X_{\text {Sio }_{2}}^{l i q}\right)^{2}-3.341 \\
\times & 10^{-2}(\text { P }(\text { Kbar }))+0.18047\left(H_{2} O^{l i q}\right)
\end{aligned}
$$

cujo erro é de $\pm 36^{\circ} \mathrm{C}$. Para este termômetro foi utilizado como "input" o teor de água obtido pelo higrômetro de Lange et al. (inédito) - ver item VIII.2 - e pressões de 3 a 4 Kbar (para fenocristais; segundo os resultados do equilíbrio clinopiroxênio-líquido de Putirka (2008) - ver item VIII.3) e de 0,5 kbar para os micrólitos. Nestas condições, os cristais de plagioclásio mostram temperaturas de cristalização variando de $963^{\circ} \mathrm{C}$ (micrólito) a $977^{\circ} \mathrm{C}$, com temperaturas de saturação de $977^{\circ} \mathrm{C}$ a $989^{\circ} \mathrm{C}$ - os resultados são apresentados na tabela 12 .

\footnotetext{
${ }^{2}$ Para teste de equilíbrio os autores sugerem a constante de equilíbrio $\mathrm{K}_{\mathrm{D}}$ para a troca $\mathrm{An}-\mathrm{Ab}$ onde, para temperaturas inferiores a $1050^{\circ} \mathrm{C}, \mathrm{K}_{\mathrm{D}}(\mathrm{An}-\mathrm{Ab})=0,10 \pm 0,05$ e para temperaturas superiores a $1050^{\circ} \mathrm{C} \mathrm{K}_{\mathrm{D}}(\mathrm{An}-\mathrm{Ab})=0,27 \pm 0,11$.
} 


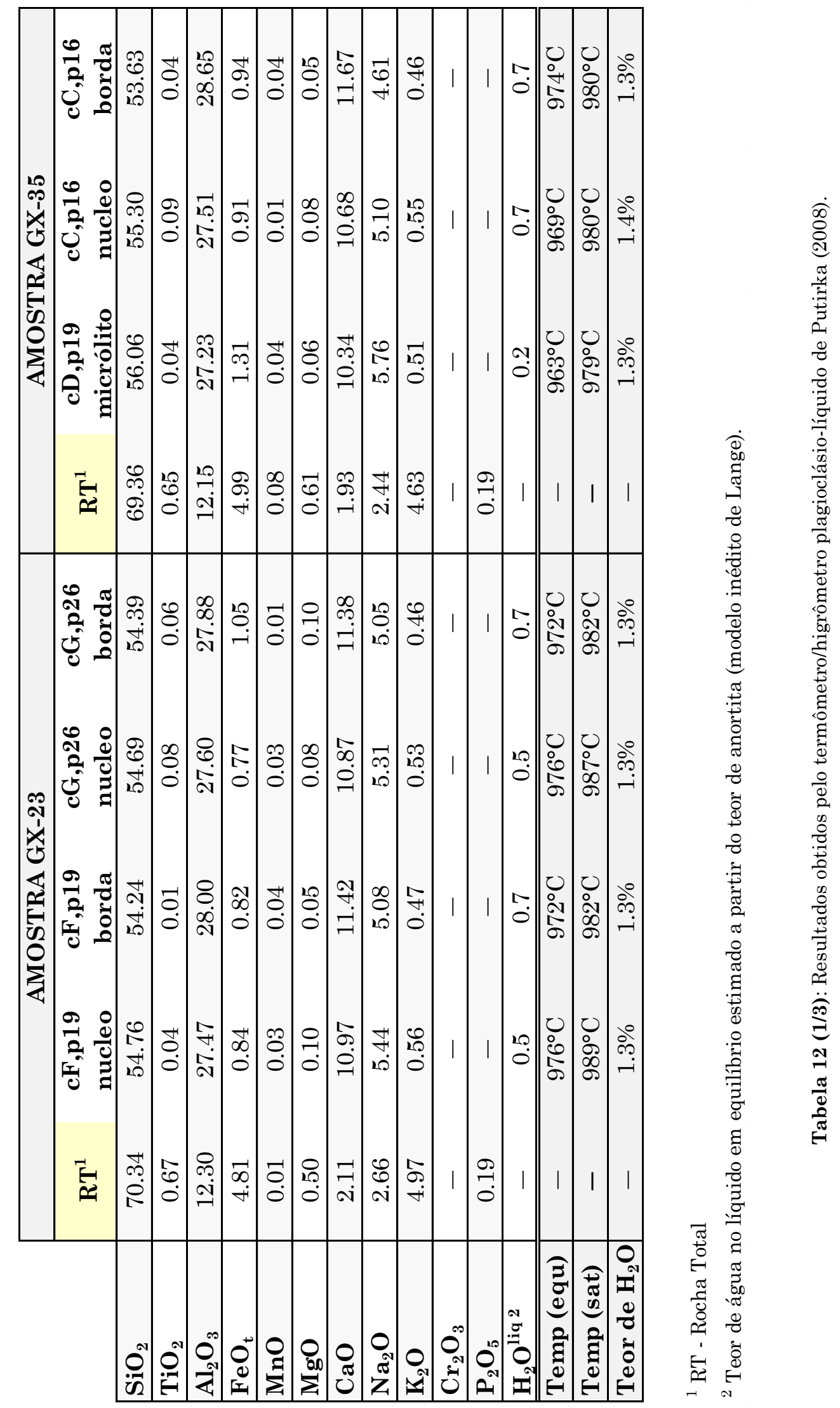




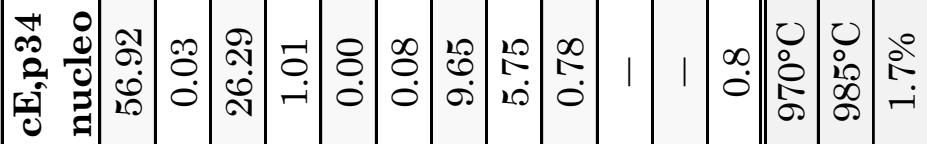

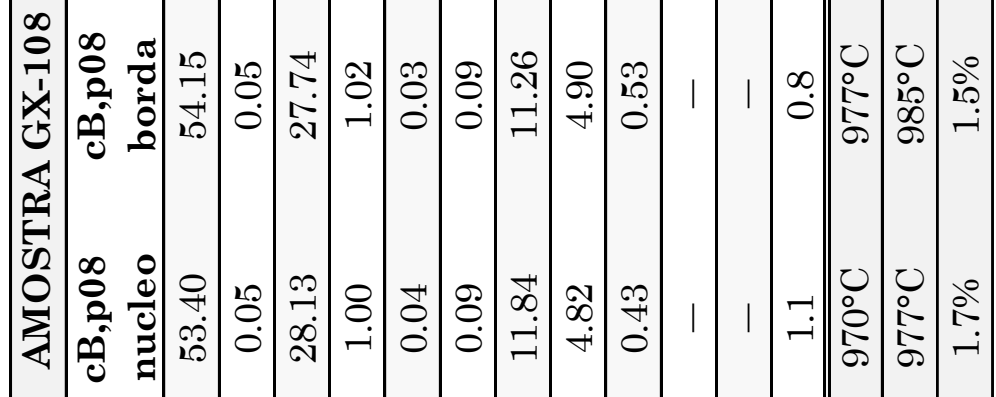

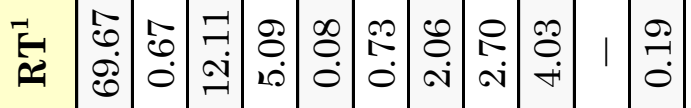

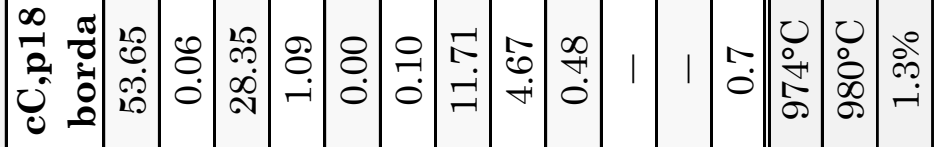

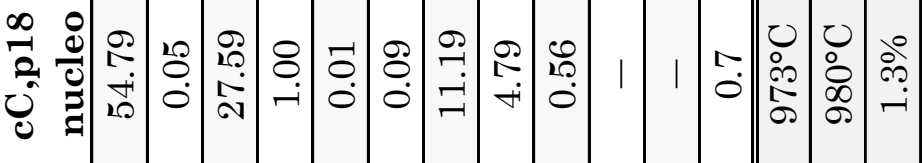

战

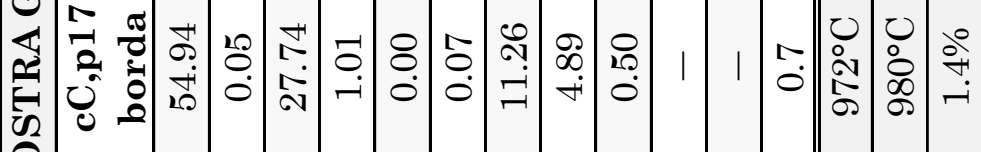

资

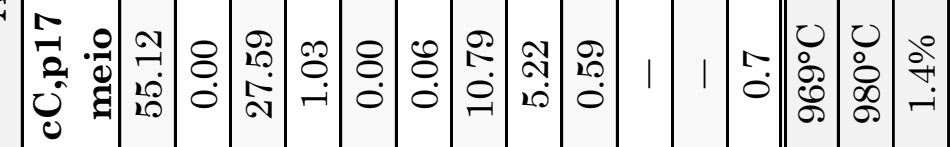

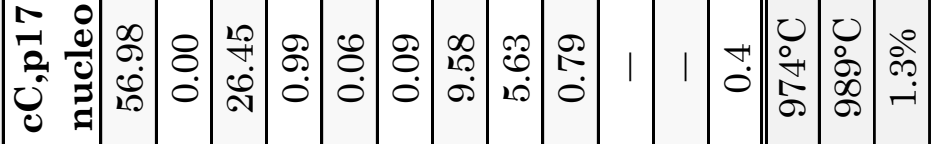

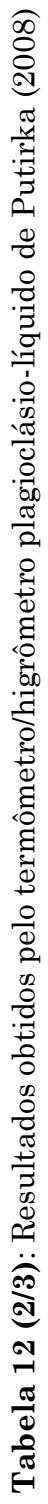

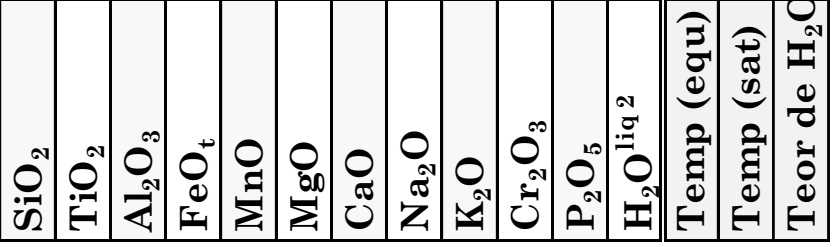

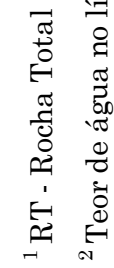




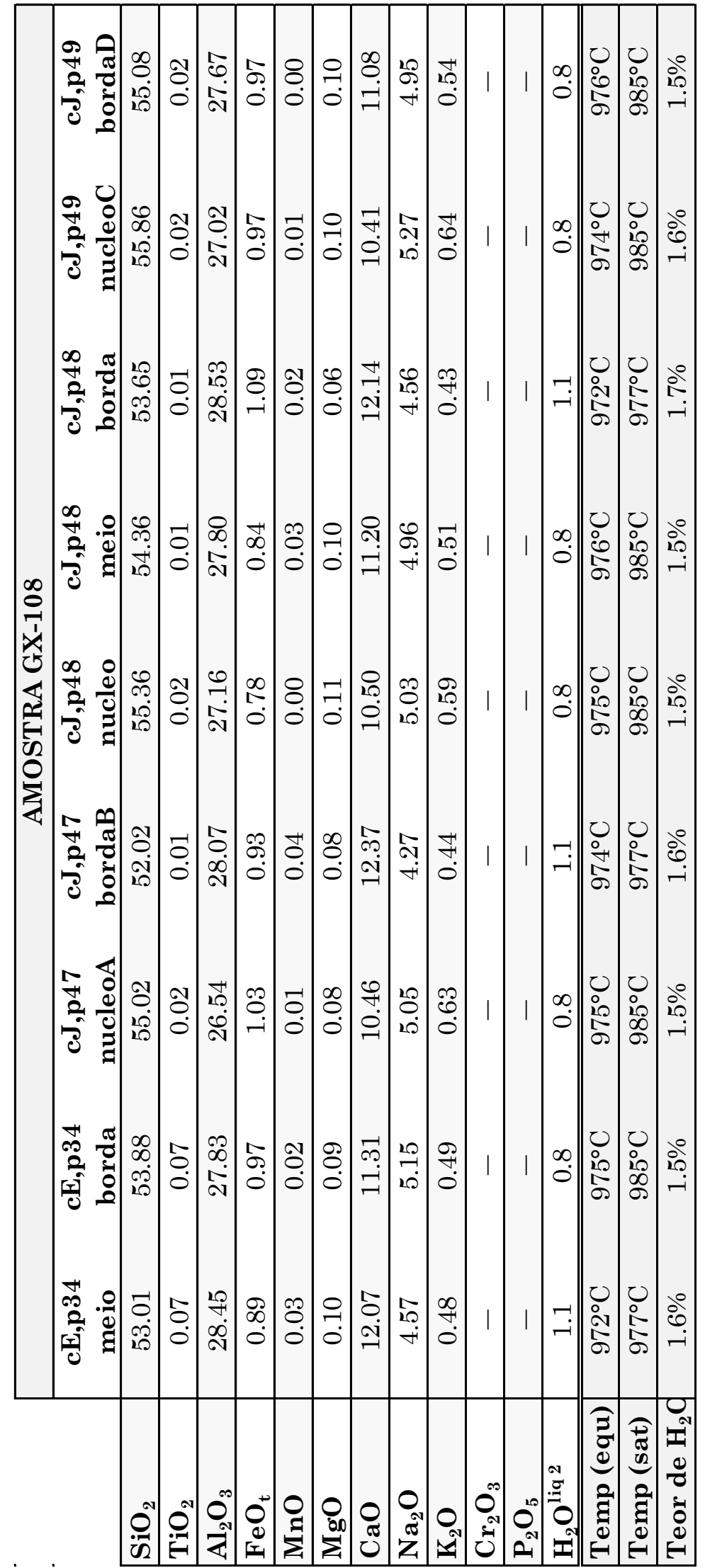

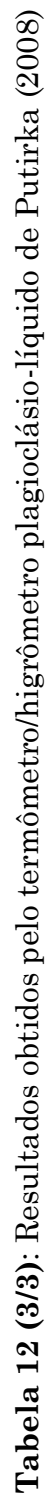

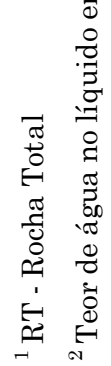


O termômetro clinopiroxênio-líquido é baseado na troca Jd-DiHd (jadeíta-diopsidio + hedenbergita) ${ }^{3}$ entre o clinopiroxênio e o líquido em equilíbrio ${ }^{4}$, sendo função da pressão, do teor de água e das proporções (frações catiônicas) de $\mathrm{SiO}_{2}, \mathrm{TiO}_{2}, \mathrm{CaO}, \mathrm{NaO}_{0.5}$ e $\mathrm{KO}_{0.5}$ e $\mathrm{Al}$ e dos componentes jadeíta, diopsídio+hedenbergita e enstatita-ferrosilita no clinopiroxênio e no líquido segundo a equação (Eq. 33 de Putirka, 2008):

$$
\begin{aligned}
\frac{10^{4}}{T(K)}=0.73- & 0.14 \ln \left(\frac{X_{J d}^{c p x} X_{C a O}^{l i q} X_{F m}^{l i q}}{X_{D i H d}^{c p x} X_{N a}^{l i q} X_{A l}^{l i q}}\right)+0.07\left(H_{2} O^{l i q}\right)-14.9\left(X_{C a O^{l i q}}^{l i q} X_{S i O_{2}}^{l i q}\right) \\
- & 0.08 \ln \left(X_{\text {Tio }}^{l i q}\right)-3.62\left(X_{N a O_{0.5}}^{l i q}+X_{K O_{0.5}}^{l i q}\right)-1.1\left(M g \#^{l i q}\right) \\
- & 0.18 \ln \left(X_{E n F S}^{c p x}\right)-0.027 P(\text { Kbar })
\end{aligned}
$$

Esta equação representa uma recalibração do termômetro de Putirka et al. (2003), possibilitando a redução em cerca de $10-20^{\circ} \mathrm{C}$ do erro associado (anteriormente equivalente a $\pm 52-60^{\circ} \mathrm{C}$ ).

A partir deste termômetro, os piroxênios dos riolitos Santa Maria apresentaram temperaturas de equilíbrio de $983^{\circ} \mathrm{C}$ a $1022^{\circ} \mathrm{C}-$ os resultados detalhados são apresentados na tabela 13.

\footnotetext{
${ }^{3}$ Componentes do piroxênio: Jd (jadeíta), DiHd (diopsidio + hedenbergita) e EnFs (enstatitaferrossilita) calculados segundo procedimentos descritos em Putirka et al. (2003)

${ }^{4}$ De maneira semelhante ao termômetro plagioclásio-líquido, para teste de equilíbrio os autores sugerem a condição para a constante de equilíbrio: $K_{D}(F e-M g)^{c p x-l i q}=0,27 \pm 0,03$
} 
Tabela 13: Resultados obtidos pelo termômetro/barômetro clinopiroxênio-líquido de Putirka (2008).

\begin{tabular}{|c|c|c|c|c|c|c|}
\hline & \multicolumn{6}{|c|}{ AMOSTRA GX-35 } \\
\hline & $R T^{1}$ & cF,p31 & $\begin{array}{l}\text { cC,p14 } \\
\text { nucleo }\end{array}$ & $\begin{array}{l}\text { cF,p14 } \\
\text { borda }\end{array}$ & $\mathbf{c C , p A}$ & $\mathrm{cC}, \mathrm{pB}$ \\
\hline $\mathrm{SiO}_{2}$ & 69.36 & 51.09 & 50.35 & 51.00 & 50.63 & 49.83 \\
\hline $\mathrm{TiO}_{2}$ & 0.65 & 0.34 & 0.36 & 0.39 & 0.26 & 0.33 \\
\hline $\mathrm{Al}_{2} \mathrm{O}_{3}$ & 12.15 & 0.67 & 0.99 & 0.79 & 0.77 & 0.77 \\
\hline $\mathrm{FeO}_{\mathrm{t}}$ & 4.99 & 29.12 & 29.16 & 28.99 & 29.17 & 28.89 \\
\hline MnO & 0.08 & 1.31 & 1.30 & 1.30 & 1.35 & 1.26 \\
\hline MgO & 0.61 & 13.67 & 13.82 & 13.69 & 14.43 & 13.01 \\
\hline $\mathrm{CaO}$ & 1.93 & 4.30 & 3.94 & 3.88 & 3.11 & 4.82 \\
\hline $\mathrm{Na}_{2} \mathrm{O}$ & 2.44 & 0.05 & 0.05 & 0.05 & 0.06 & 0.07 \\
\hline $\mathbf{K}_{2} \mathbf{O}$ & 4.63 & 0.02 & 0.02 & 0.02 & 0.02 & 0.05 \\
\hline $\mathrm{Cr}_{2} \mathrm{O}_{3}$ & 0.00 & 0.00 & 0.00 & 0.00 & 0.02 & 0.02 \\
\hline $\mathbf{P}_{2} \mathbf{O}_{5}$ & 0.19 & - & - & - & - & - \\
\hline $\mathrm{H}_{2} \mathrm{O}^{\text {liq } 2}$ & - & 0.7 & 0.7 & 0.7 & 0.7 & 0.7 \\
\hline Temp (equ) & - & $983^{\circ} \mathrm{C}$ & $987^{\circ} \mathrm{C}$ & $987^{\circ} \mathrm{C}$ & $997^{\circ} \mathrm{C}$ & $987^{\circ} \mathrm{C}$ \\
\hline Pressão & - & 3.8 & 3.6 & 4.0 & 4.0 & 3.9 \\
\hline
\end{tabular}

\begin{tabular}{|c|c|c|c|c|c|}
\hline & \multicolumn{5}{|c|}{ AMOSTRA GX-108 } \\
\hline & $\mathrm{RT}^{1}$ & cC,p18 & $\mathbf{c G}, \mathbf{p A}$ & cB,p09 & cC,p11 \\
\hline $\mathrm{SiO}_{2}$ & 69.67 & 51.21 & 52.39 & 51.63 & 50.54 \\
\hline $\mathrm{TiO}_{2}$ & 0.67 & 0.41 & 0.22 & 0.13 & 0.30 \\
\hline $\mathrm{Al}_{2} \mathrm{O}_{3}$ & 12.11 & 0.68 & 0.88 & 0.72 & 1.08 \\
\hline $\mathrm{FeO}_{\mathrm{t}}$ & 5.09 & 28.36 & 26.82 & 27.42 & 27.76 \\
\hline $\mathrm{MnO}$ & 0.08 & 1.25 & 1.11 & 1.21 & 1.29 \\
\hline MgO & 0.73 & 14.58 & 14.24 & 16.50 & 14.55 \\
\hline $\mathrm{CaO}$ & 2.06 & 4.52 & 3.17 & 3.19 & 3.24 \\
\hline $\mathrm{Na}_{2} \mathrm{O}$ & 2.70 & 0.08 & 0.09 & 0.04 & 0.04 \\
\hline $\mathbf{K}_{2} \mathbf{O}$ & 4.03 & 0.01 & 0.07 & 0.02 & 0.22 \\
\hline $\mathrm{Cr}_{2} \mathrm{O}_{3}$ & - & 0.00 & 0.04 & 0.01 & 0.00 \\
\hline $\mathrm{P}_{2} \mathrm{O}_{5}$ & 0.19 & - & - & - & - \\
\hline $\mathrm{H}_{2} \mathrm{O}^{\text {liq } 2}$ & - & 0.9 & 0.9 & 0.9 & 0.9 \\
\hline Temp (equ) & $\overline{-1}$ & $990^{\circ} \mathrm{C}$ & $1022^{\circ} \mathrm{C}$ & $993^{\circ} \mathrm{C}$ & $992^{\circ} \mathrm{C}$ \\
\hline Pressão & - & 3.5 & 5.0 & 2.4 & 0.5 \\
\hline
\end{tabular}

\footnotetext{
${ }^{1}$ RT - Rocha Total

${ }^{2}$ Teor de água no líquido em equilíbrio estimado a partir do teor de anortita (modelo inédito de Lange).
} 
Considerando-se as metodologias utilizadas e os erros associados, os dados obtidos para temperatura são bastante consistentes e mostram que os magmas riolíticos apresentavam temperaturas elevadas, da ordem de $980^{\circ} \mathrm{C}$ a $1000^{\circ} \mathrm{C}$.

\section{VIII.2. Conteúdo de água}

Um dos geohigrômetros bastante utilizados na literatura baseia-se na troca dos componentes $\mathrm{CaAl}_{2} \mathrm{Si}_{2} \mathrm{O}_{8}$ (anortita) e $\mathrm{NaAlSi}_{3} \mathrm{O}_{8}$ (albita) entre o plagioclásio e o líquido em equilíbrio, sendo esta troca dependente da temperatura, do teor de água e, menos significativamente (Lange et al., 2009), da pressão. Deste modo, considerando-se a composição do magma, do plagioclásio e tendo uma boa estimativa para a temperatura de equilíbrio entre o cristal e o líquido, é possível estimar o teor de água.

O modelo de Lange et al. (2009) forneceu teores de água de $2,5 \%$ a 3,7\% para os riolitos Santa Maria (Guimarães, 2011), quando considerados micrólitos e fenocristais. Entretanto, este modelo foi recentemente criticado na literatura (e.g. Mollo et al., 2011; Waters \& Lange, 2013) por fornecer teores superestimados para rochas muito ricas em sílica $\left(\mathrm{SiO}_{2}>70 \%\right)$. Uma recalibração do modelo de Lange et al. (2009), utilizando mais de 200 amostras, incluindo rochas anidras e hidratas, possibilitou o desenvolvimento de um novo modelo ainda a ser publicado (Rebecca Lange, comunicação escrita). Para este novo modelo, considerando-se a cristalização dos microfenocristais, representativa das condições iniciais do magma, foram obtidos teores de água variáveis de 0,4\% (para os núcleos com An46, raramente preservados) a 1,1\%, enquanto para micrólitos (representativos da fase final de cristalização) foram obtidos teores de $0,2 \%$ de água - os dados são detalhados na tabela 14 . 
Tabela 14: Resultados obtidos para o geohigrômetro inédito (ainda não publicado) de Lange. Destacado em azul, núcleo com menor teor de anortita preservado e em amarelo, análise correspondente à micrólito.

\begin{tabular}{|l|cccccccc|}
\cline { 2 - 9 } \multicolumn{1}{c|}{} & \multicolumn{10}{c|}{ GX-23 } \\
\hline Cristal & $\begin{array}{c}\mathrm{cF}, \mathrm{p} 19 \\
\text { nucleo }\end{array}$ & $\begin{array}{c}\mathrm{cF}, \mathrm{p} 19 \\
\text { borda }\end{array}$ & $\begin{array}{c}\mathrm{cF}, \mathrm{p} 20 \\
\text { nucleo }\end{array}$ & $\begin{array}{c}\mathrm{cF}, \mathrm{p} 20 \\
\text { borda }\end{array}$ & $\begin{array}{c}\mathrm{cF}, \mathrm{p} 21 \\
\text { nucleo }\end{array}$ & $\begin{array}{c}\mathrm{cF}, \mathrm{p} 21 \\
\text { borda }\end{array}$ & $\begin{array}{c}\mathrm{cG}, \mathrm{p} 26 \\
\text { nucleo }\end{array}$ & $\begin{array}{c}\mathrm{cG}, \mathrm{p} 26 \\
\text { borda }\end{array}$ \\
\hline Teor de Na & 51.1 & 54 & 52.3 & 54.8 & 51.2 & 53.6 & 51.5 & 54 \\
\hline Conteúdo de água & $0,5 \%$ & $0,7 \%$ & $0,5 \%$ & $0,7 \%$ & $0,5 \%$ & $0,7 \%$ & $0,5 \%$ & $0,7 \%$ \\
\hline
\end{tabular}

\begin{tabular}{|l|cccccccc|}
\cline { 2 - 9 } \multicolumn{1}{c|}{} & \multicolumn{10}{c|}{ GX-35 } \\
\hline Cristal & $\begin{array}{c}\mathrm{cD}, \mathrm{p} 19 \\
\text { microlito }\end{array}$ & $\begin{array}{c}\mathrm{cC}, \mathrm{p} 16 \\
\text { nucleo }\end{array}$ & $\begin{array}{c}\mathrm{cC}, \mathrm{p} 16 \\
\text { borda }\end{array}$ & $\begin{array}{c}\mathrm{cC}, \mathrm{p} 17 \\
\text { nucleo }\end{array}$ & $\begin{array}{c}\mathrm{cC}, \mathrm{p} 17 \\
\text { meio }\end{array}$ & $\begin{array}{c}\mathrm{cC}, \mathrm{p} 17 \\
\text { borda }\end{array}$ & $\begin{array}{c}\mathrm{cC}, \mathrm{p} 18 \\
\text { nucleo (a) }\end{array}$ & $\begin{array}{c}\mathrm{cC}, \mathrm{p} 18 \\
\text { borda (b) }\end{array}$ \\
\hline Teor de Na & 48.4 & 52 & 56.7 & 46.2 & 51.5 & 54.4 & 54.5 & 56.5 \\
\hline Conteúdo de água & $0,2 \%$ & $0,7 \%$ & $0,7 \%$ & $0,4 \%$ & $0,7 \%$ & $0,7 \%$ & $0,7 \%$ & $0,7 \%$ \\
\hline
\end{tabular}

\begin{tabular}{|c|ccccc|}
\cline { 2 - 6 } \multicolumn{1}{c|}{} & \multicolumn{5}{c|}{ GX-108 } \\
\hline Cristal & $\begin{array}{c}\mathrm{cE}, \mathrm{p} 34 \\
\text { nucleo }\end{array}$ & $\begin{array}{c}\mathrm{cE}, \mathrm{p} 34 \\
\text { borda }\end{array}$ & $\begin{array}{c}\mathrm{cE}, \mathrm{p} 34 \\
\text { borda }\end{array}$ & $\begin{array}{c}\mathrm{cJ}, \mathrm{p} 47 \\
\text { nucleo (a) }\end{array}$ & $\begin{array}{c}\mathrm{cJ}, \mathrm{p} 47 \\
\text { borda (b) }\end{array}$ \\
\hline Teor de Na & 46 & 57.7 & 53.3 & 51.4 & 60 \\
\hline Conteúdo de água & $0,8 \%$ & $1,1 \%$ & $0,8 \%$ & $0,8 \%$ & $1,1 \%$ \\
\hline Cristal & $\begin{array}{c}\mathrm{cJ}, \mathrm{p} 48 \\
\text { nucleo }\end{array}$ & $\begin{array}{c}\text { cJ,p48 } \\
\text { meio }\end{array}$ & $\begin{array}{c}\text { cJ,p48 } \\
\text { borda }\end{array}$ & $\begin{array}{c}\mathrm{cJ}, \mathrm{p} 49 \\
\text { nucleo (c) }\end{array}$ & $\begin{array}{c}\mathrm{cJ}, \mathrm{p} 49 \\
\text { borda (d) }\end{array}$ \\
\hline Teor de Na & 51.7 & 53.9 & 58.1 & 50.2 & 53.6 \\
\hline Conteúdo de água & $0,8 \%$ & $0,8 \%$ & $1,1 \%$ & $0,8 \%$ & $0,8 \%$ \\
\hline
\end{tabular}

O modelo de geohigrômetro apresentado por Putirka (2008) (correspondente ao recalibramento do higrômetro apresentado em Putirka, 2005b) apresenta um erro de $\pm 1.1 \%$ - o autor destaca a significativa dependência da temperatura, sendo que para um erro (variação) de $\pm 38^{\circ} \mathrm{C}$, o teor de água varia em 1\%. Assim como nos modelos de Lange, os teores de água estimados são função da temperatura, da pressão e da troca entre os componentes albita e anortita entre o plagioclásio e o líquido em equilíbrio, sendo expressado pela equação (Eq. 25b de Putirka 2008):

$$
\begin{aligned}
\mathrm{H}_{2} \mathrm{O}(w t \%)= & 25.95-0.0032 \mathrm{~T}\left({ }^{\circ} \mathrm{C}\right) \ln \left(\frac{X_{A n}^{p l}}{X_{C a O}^{l i q}\left(X_{A l 0_{1.5}}^{l i q}\right)^{2}\left(X_{S_{i O_{2}}}^{l i q}\right)^{2}}\right)-18.9\left(X_{K O_{0.5}}^{l i q}\right) \\
& +14.5\left(X_{M g O}^{l i q}\right)-40.3\left(X_{C a O}^{l i q}\right)+5.7\left(X_{A n}^{p l}\right)^{2}+0.108 P(\text { Kbar })
\end{aligned}
$$


Os resultados obtidos a partir do higrômetro de Putirka (2008) correspondem a teores de água variáveis de 1,3\% a 1,7\% (resultados apresentados na tabela 12). Os modelos de termômetro e higrômetro pelo equilíbrio entre plagioclásio e o líquido de Putirka (2008) também foram utilizados para determinar, com base nas pressões e temperaturas de saturação obtidas para a fase mineral, quais seriam os teores de água mais adequados. Como pode ser visualizado na figura 85, para as pressões e temperaturas de saturação estimadas, teores de água acima de 1,5\% seriam inadequados.

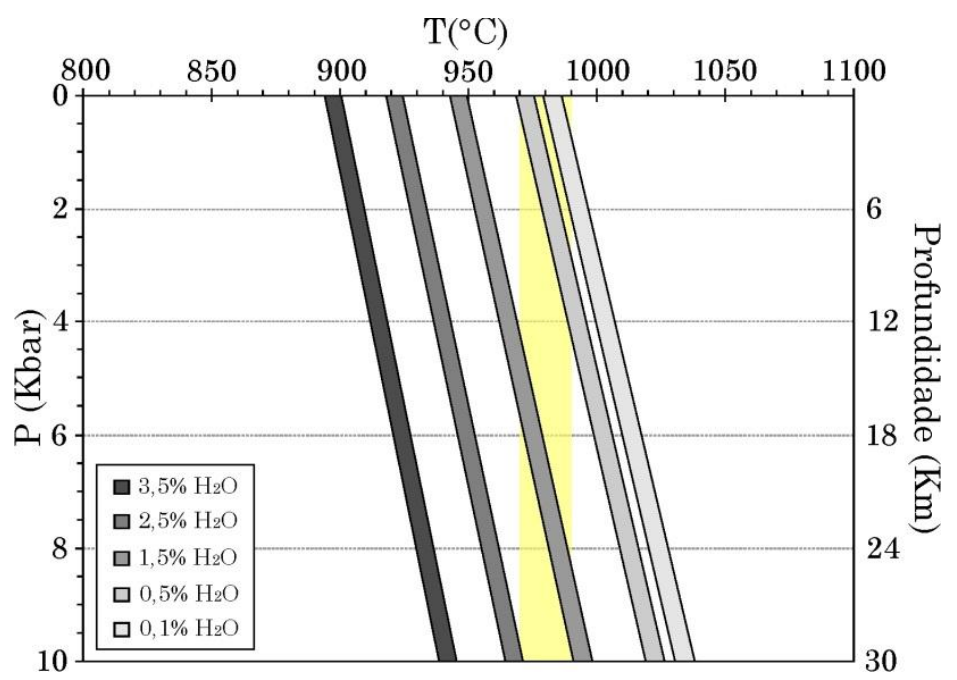

Figura 85: Estimativas de temperatura de saturação em plagioclásio para diferentes conteúdos de água dissolvida nos magmas, calculadas segundo o modelo de Putirka (2008). Os intervalos obtidos a cada teor de água correspondem à variação composicional dos riolitos (considerando-se as amostras GX-23, GX-35 e GX-108). O intervalo em amarelo destaca um intervalo de temperatura estimada para os magmas através das metodologias de saturação em apatita e dos termômetros de equilíbrio plagioclásio-liquido.

\section{VIII.2.1. SOLUBILIDADE E DIFUSIBILIDADE}

A solubilidade e a difusibilidade dos componentes voláteis são importantes parâmetros controladores da forma de ocorrência do vulcanismo, uma vez que influenciarão a perda dos voláteis anteriormente solubilizados (acarretando aumento da viscosidade) e a formação e o crescimento (aglutinação) das bolhas que exercerão expansão volumétrica no magma. Deste modo, uma boa estimativa destes parâmetros permite uma melhor 
compreensão do estilo eruptivo das manifestações vulcânicas. Com este objetivo, inúmeros modelos foram desenvolvidos (e.g. Dingwell et al., 1997; Zhang, 1999; Newman \& Lowenstern, 2002; Liu et al., 2005; Zhang et al., 2007).

O modelo de Zhang et al. (2007) tem sido amplamente empregado e mostra que, como já descrito anteriormente, a solubilidade é função da pressão e, de maneira subordinada, da composição (especialmente a baixas pressões, vide figura $84 \mathrm{~A}$ ) e da temperatura. Os autores desenvolveram um modelo simplificado, combinando modelos anteriores (Moore et al., 1998; Behrens \& Jantos, 2001; Liu et al., 2005), onde a solubilidade da água $\left(\mathrm{C}_{\mathrm{W}}=\%\right.$ em peso) é dependente da pressão $(\mathrm{P}=\mathrm{MPa})$, da temperatura $(\mathrm{T}=\mathrm{K})$ e da composição (mais especificamente do parâmetro $\mathrm{AI}=\mathrm{Na}+\mathrm{K}-\mathrm{Al}$; onde os elementos são dados em fração molar catiônica) segundo a equação:

$$
C_{W}=\left(-0.231+\frac{651.1}{T}\right) \sqrt{P}+\left(0.03421-\frac{32.57}{T}+0.02447 \text { AI }\right) P
$$

a qual é calibrada para o intervalo de temperatura de $700^{\circ} \mathrm{C}$ a $1200^{\circ} \mathrm{C}$ e de pressão de 0 a 5 Kbar.

A figura 86 apresenta o diagrama que define, segundo o modelo supracitado, a curva de solubilidade de água definida para o intervalo de temperatura $950^{\circ} \mathrm{C}$ a $1000^{\circ} \mathrm{C}$ para as composições das amostras GX-23, GX-35 e GX-108. Considerando-se os teores de água obtidos, temos que: (a) teores de água de $0,7 \%$ a $1,1 \%$ obtidos para as zonas intermediárias e bordas dos fenocristais (segundo o modelo de Lange, inédito) são solúveis no magma até pressões de, respectivamente $\sim 0,05$ e $\sim 0,125$ Kbar (equivalentes a $\sim 150$ e $\sim 375$ metros de profundidade); (b) teores de água de $0,2 \%$ obtidos para os micrólitos (Lange, inédito) são solúveis no magma a até $\sim 0,01 \mathrm{Kbar}$ (i.e. aprox. 30 metros); 
(c) teores de $1,3 \%$ a $1,7 \%$ obtidos a partir dos higrômetros de Putirka (2008) seriam possíveis a até cerca de 0.16 e 0,26 Kbar (aproximadamente 480 e 780 metros de profundidade, respectivamente).

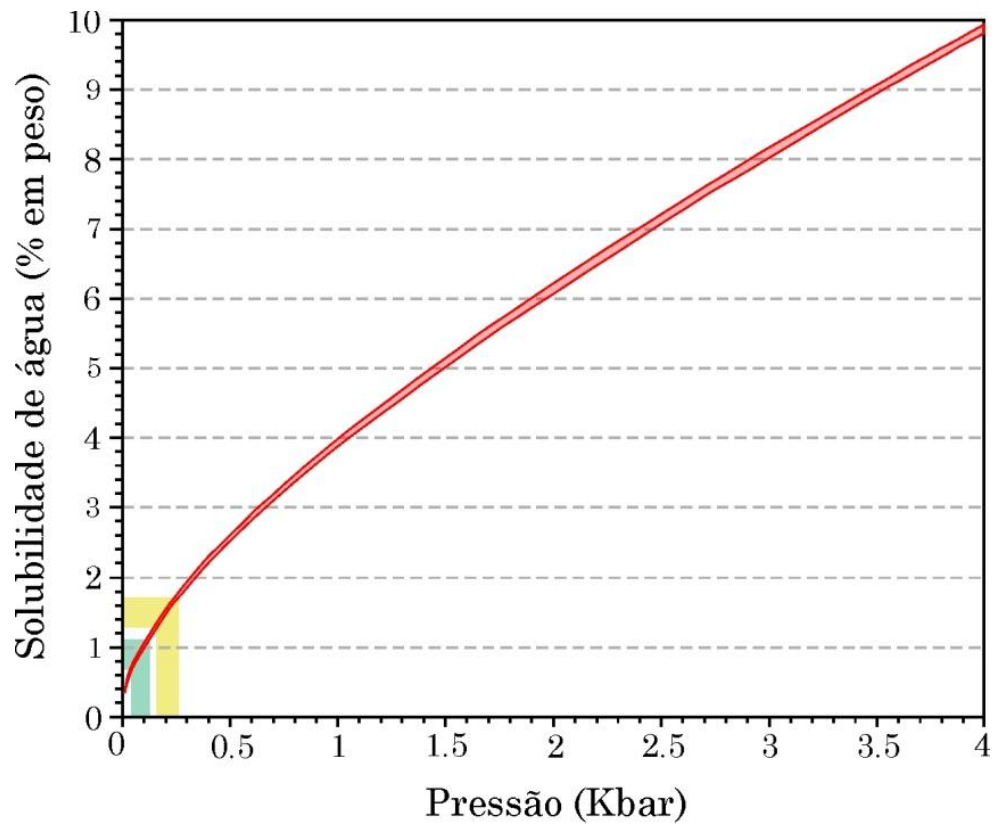

Figura 86: Diagrama de solubilidade em função da pressão para o intervalo composicional representado pelas amostras GX-23, GX-35 e GX-108. O campo verde corresponde aos teores obtidos pelo geohigrômetro inédito de Lange e o campo amarelo corresponde aos teores de água obtidos pelo geohigrômetro de Putirka (2008) de acordo com o equilíbrio plagioclásio-líquido.

No caso da difusibilidade, as estimativas são um tanto mais complexas uma vez que os diferentes espécimes de água dissolvida se comportam de maneiras distintas. Delaney \& Karsten (1981; apud Zhang et al., 2007) mostram que a difusibilidade da água é dependente, de maneira exponencial, da concentração total de água, enquanto que os estudos de Zhang \& Behrens (2000; apud Zhang et al., 2007) tratam essa dependência como válida apenas para a difusibilidade de $\mathrm{H}_{2} \mathrm{O}_{\mathrm{m}}$ (água molecular).

Zhang et al. (1991a; 1991b) mostram que a difusibilidade da espécie hidroxila $\left(D_{\mathrm{OH}}\right)$ é muito menor do que a difusibilidade da água molecular $\left(D_{\mathrm{H}_{2} \mathrm{O}}\right)$, i.e. a água molecular corresponde à espécie mais móvel, sendo que $D_{\mathrm{H}_{2} \mathrm{O}}$ é 
aproximadamente constante para baixos teores de água $\left(\mathrm{H}_{2} \mathrm{O} \leq 1.8 \%\right.$ em peso segundo estes autores, enquanto enquanto Nowak \& Behrens (1997) admitem $3 \%$ em peso). Zhang \& Behrens (2000) apresentam um modelo para estimativas da difusibilidade da água em função da pressão, temperatura e teor de água total $\left(\mathrm{H}_{2} \mathrm{O}_{\mathrm{t}}\right)$, aplicável dentro do intervalo de $\mathrm{H}_{2} \mathrm{O}_{\mathrm{t}}=0.1-7.7 \%$ em peso, $\mathrm{T}=400$ $-1200^{\circ} \mathrm{C}$ e $\mathrm{P}=0.1-810 \mathrm{MPa}$, segundo a equação (Eq. 15 de Zhang et al., 2007):

$$
\ln \frac{D_{H_{2} O_{t}}}{C_{w}}=-17.14-\frac{10661}{T}-1.772 \frac{P}{T}
$$

cuja aplicabilidade se dá para $\mathrm{H}_{2} \mathrm{O}_{\mathrm{t}} \leq 2 \%$ e onde $\mathrm{C}_{\mathrm{w}}$ corresponde à porcentagem em peso de água total dissolvida no magma e a difusibilidade $\left(D_{\mathrm{H}_{2} \mathrm{O}_{t}}\right)$ é dada em $\mathrm{m}^{2} \mathrm{~s}^{-1}$. Zhang et al. (2007) destacam também que a dependência da $D_{H_{2} O_{t}}$ em pressão, temperatura e conteúdo de $\mathrm{H}_{2} \mathrm{O}$ é bem ajustada e definida com base em constatações empíricas e considerações teóricas; entretanto, o modelo necessita aperfeiçoamento no que diz respeito à influência da pressão e da composição do magma, ainda pouco compreendida.

Os resultados obtidos a partir da equação supracitada sugerem, para as condições iniciais (teor médio de água de $0,9 \%$, temperatura média de $970^{\circ} \mathrm{C}$ e pressões de 3-4 Kbar) difusibilidade de, em média, $3,7 \times 10^{-6} \mathrm{~mm}^{2} / \mathrm{s}$, enquanto que as condições finais (teor médio de água de 0,2\%, temperatura média de $970^{\circ} \mathrm{C}$ e pressões de $0,01 \mathrm{Kbar}$ ) sugerem difusibilidade da ordem de $1,35 \times 10^{-6}$ $\mathrm{mm}^{2} / \mathrm{s}$. 


\section{VIII.3. Pressão}

A estimativa de pressões para processos de cristalização pode ser difícil uma vez que os barômetros conhecidos são pouco precisos. Alguns modelos são pouco recomendados, como é o caso do barômetro calibrado para o equilíbrio plagioclásio-líquido de Putirka (2008), com ressalvas feitas pelo próprio autor, uma vez que as trocas dos componentes não se apresentam muito sensíveis às variações de pressão.

Dentre os modelos mais aceitos para rochas vulcânicas estão os propostos por Putirka (2008) para equilíbrios entre ortopiroxênio e líquido e clinopiroxênio e líquido - este último empregado neste estudo. Dentre os diferentes modelos propostos e viáveis dentro das condições, foram selecionados aqueles mais consistentes entre si e de menor erro associado. Estes modelos são baseados nas trocas entre os componentes da fase mineral (de modo semelhante aos termômetros), e são função do número total de átomos de $\mathrm{Al}$ no clinopiroxênio $\left(X_{A l}^{c p x}=X_{A l(I V)}^{c p x}+X_{A l(V I)}^{c p x}\right)$ calculado para 6 oxigênios, do teor de água e da temperatura, conforme as equações (Eq. 31 e 32b de Putirka (2008), respectivamente):

$$
\begin{aligned}
P(\text { Kbar })=- & 40.73+358 \frac{T(K)}{10^{4}} \\
& +21.69 \frac{T(K)}{10^{4}} \ln \left[\frac{X_{N^{c p A} x}^{c p i i_{2} O_{6}}}{X_{N a O_{0.5}}^{l i q} X_{A l O_{1.5}}^{l i q}\left(X_{S i O_{2}}^{l i q}\right)^{2}}\right]-105.7\left(X_{C a O}^{l i q}\right) \\
& -165.5\left(X_{N a O_{0.5}}^{l i q}+X_{K O_{0.5}}^{l i q}\right)^{2}-50.15\left(X_{S i O_{2}}^{l i q}\right)\left(X_{F e O}^{l i q}+X_{M g O}^{l i q}\right) \\
& -3.178 \ln \left(X_{D i H d}^{c p x}\right)-2.205 \ln \left(X_{E n F S}^{c p x}\right)+0.864 \ln \left(X_{A l}^{c p x}\right) \\
& +0.3962\left(H_{2} O^{l i q}\right)
\end{aligned}
$$




$$
\begin{aligned}
P(\text { Kbar })= & 1458+0.197 T(K)-241 \ln T(K)+0.453\left(H_{2} O^{l i q}\right)+55.5\left(X_{A l(V I)}^{c p x}\right) \\
& +8.05\left(X_{F e}^{c p x}\right)-277\left(X_{K}^{c p x}\right)+18\left(X_{J d}^{c p x}\right)+44.1\left(X_{D i H d}^{c p x}\right)+2.2 \ln \left(X_{J d}^{c p x}\right) \\
& -17.7\left(X_{A l}^{c p x}\right)^{2}+97.3\left(X_{F e(M 2)}^{c p x}\right)^{2}+30.7\left(X_{M g(M 2)}^{c p x}\right)^{2}-27.6\left(X_{D i H d}^{c p x}\right)^{2}
\end{aligned}
$$

as quais apresentam incertezas de $\pm 2,9$ e $\pm 2,6 \mathrm{Kbars}$, respectivamente. Os modelos forneceram pressões de 2,3 a 3,9 Kbar e de 3,6 a 4,0 Kbar para a amostra GX-35 e de 2,6 a 6,9 Kbar e de 0,5 a 5,0 Kbar para a amostra GX-108, como pode ser observado na tabela 13 . Tendo em vista que as variações entre os resultados obtidos estão dentro do intervalo de erro, a melhor aproximação para a pressão de cristalização seria a média entre os resultados obtidos, que compreende o intervalo de 3 a 4 Kbar.

\section{VIII.4. Viscosidade}

A viscosidade pode ser considerada o parâmetro mais importante a governar o transporte e a erupção dos magmas, e pode variar em até 15 ordens de magnitude $\left(10^{-1}\right.$ a $10^{14}$ Pa.s) a depender da temperatura, composição do magma e da proporção de fases sólidas e/ou fases fluidas exsolvidas (Giordano et al., 2008).

Os primeiros modelos elaborados para estimativas de viscosidade (e.g. Shaw, 1972 - apud Giordano et al., 2008; Bottinga \& Weill, 1972) adotam um modelo de viscosidade Arrheniana para a definição da dependência da temperatura (a viscosidade apresenta uma correlação negativa e exponencial com a temperatura). Entretanto, Giordano et al. (2008) destacam que o modelo baseado em uma viscosidade Arrheniana só é válido para temperaturas elevadas (próximas à Tliquidus), sendo falho quando extrapolado para baixas temperaturas, uma vez que nessas condições a viscosidade passa a ser 
fortemente influenciada pelo conteúdo de água (Dingwell et al., 1993 apud Giordano et al., 2008).

O modelo utilizado neste trabalho, de Giordano et al. (2008), embasa-se na consideração de uma viscosidade não-Arrheniana envolvendo 3 parâmetros ajustáveis e define a dependência da temperatura e da composição segundo uma equação VFT (Vogel-Fulcher-Tamman) onde:

$$
\log \eta=A+\frac{B}{T(K)-C}
$$

sendo o parâmetro ajustável A correspondente ao valor de $\log \eta$ para um temperatura infinita ${ }^{5}$ e os parâmetros ajustáveis $\mathrm{B}$ e $\mathrm{C}$ correspondentes à dependência composicional (onde se consideram os teores dos principais óxidos e das fases voláteis $\left.{ }^{6}\right)$.

A partir deste modelo foi possível elaborar retas que correlacionam a viscosidade às variações de temperatura e do teor de água para a variação composicional (restrita) dos riolitos Santa Maria, como é mostrado na figura 87. Para os teores de água iniciais do magma ( 0,7 a 1,1\%), a viscosidade dos riolitos Santa Maria apresenta-se na ordem de $10^{5.3}$ a $10^{5.7} \mathrm{~Pa}$.s quando considerada a temperatura média de $970^{\circ} \mathrm{C}$, enquanto que para os teores finais de $\mathrm{H}_{2} \mathrm{O}$ (aprox. 0,2\%), obtidos a partir da composição dos micrólitos, a viscosidade chega a aproximadamente $10^{6.6}$ Pa.s.

\footnotetext{
${ }^{5}$ Representa uma temperatura limite para a definição da viscosidade dos líquidos silicáticos. Assumindo A como uma constante, tem-se que todos os líquidos convergem para um mesmo valor de elevada viscosidade a temperaturas muito elevadas.

${ }^{6}$ Considera os teores de $\mathrm{SiO}_{2}, \mathrm{Al}_{2} \mathrm{O}_{3}, \mathrm{TiO}_{2}, \mathrm{FeO}_{\text {tot }}, \mathrm{CaO}, \mathrm{MgO}, \mathrm{MnO}, \mathrm{Na} 2 \mathrm{O}, \mathrm{K}_{2} \mathrm{O}, \mathrm{P}_{2} \mathrm{O}_{5}, \mathrm{H}_{2} \mathrm{O}$ e $\mathrm{F}_{2} \mathrm{O}_{-1}$.
} 


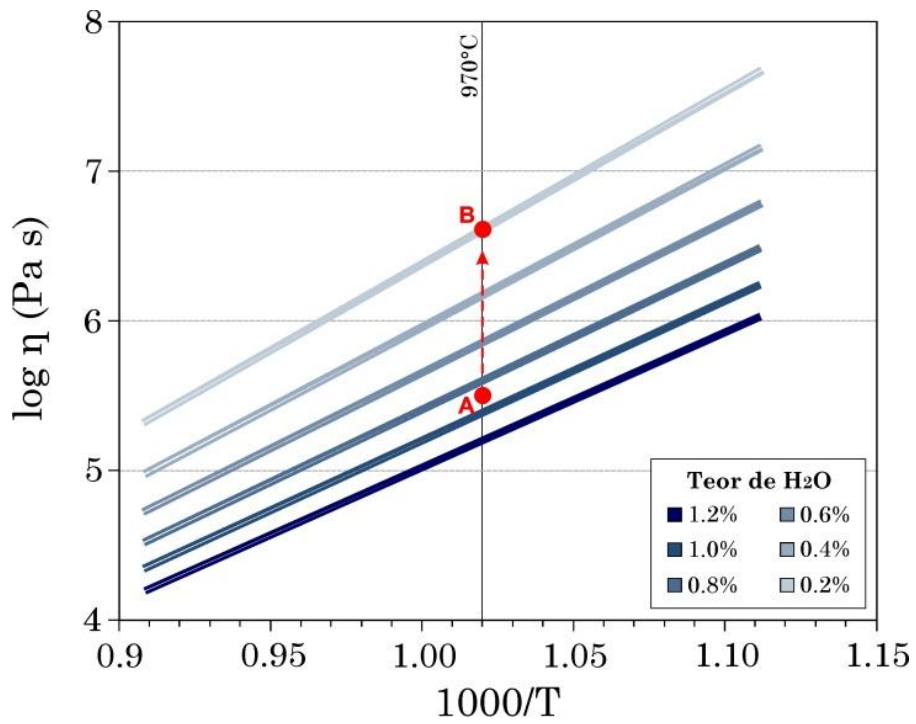

Figura 87: Viscosidades obtidas em função da variação da temperatura para os magmas riolíticos Santa Maria a partir do modelo de Giordano et al. (2008), considerando-se os diferentes teores de água obtidos a partir do geohigrômetro de Lange (cf. recalibração ainda a ser publicada). A linha vertical indica a temperatura média $\left(970^{\circ} \mathrm{C}\right)$ considerada para estes magmas e a seta vermelha representa uma ascensão isotérmica, considerada a partir dos teores de água obtidos através dos fenocristais (média de $0.9 \%$ - ponto A), cristalizados em profundidade, e o teor obtido a partir da composição dos micrólitos (0,2\% - ponto B), cristalizado em próximo ou já em superfície.

\section{VIII.4.1. CONSIDERAÇÕES E RESSALVAS}

O modelo proposto por Giordano et al. (2008) não considera o efeito dos cristais e das vesículas na viscosidade. Esses efeitos podem ser avaliados qualitativamente através das condições de variação de temperatura e teor de água, como mostrado na figura 87; de maneira bastante simplista, a diminuição da temperatura teria como consequência a cristalização do magma e a diminuição do teor de água seria equivalente à exsolução (a trajetória entre os pontos A e B na figura 83 representam uma ascensão adiabática). Contudo, a cristalização do magma e a formação de vesículas envolvem conceitos mais complexos.

A presença de cristais no magma afeta drasticamente a sua viscosidade, sendo que certos intervalos de cristalinidade $(\phi)$ definem os limites reológicos onde há mudança do regime e súbito aumento da viscosidade, conforme já foi 
discutido na introdução do presente capítulo e mostrado na figura 83. Um primeiro ponto de mudança brusca na reologia do magma é atingido quando a cristalização do magma atinge valores da ordem de 30 a $40 \%$ e, ao atingir um grau de cristalização da ordem de 60-70\%, tem-se nova variação, quando o magma passa a se comportar como um sólido (Fernandez, 1984; Petford, 2009).

Petford (2009) destaca que a complexidade da determinação da viscosidade dos magmas consiste no fato destes se constituirem basicamente de duas fases, uma líquida e outra sólida, esta última afetando a viscosidade do sistema de acordo com as variações de forma, tamanho e interação entre as partículas. A partir disto, a viscosidade pode ser definida em termos da viscosidade da fase fluida (sem influência de fases cristalinas), da viscosidade efetiva ou aparente e da viscosidade relativa. A viscosidade relativa $\left(\eta_{R}\right)$ pode ser definida com base na equação de Einstein-Roscoe (ER): $\eta_{R}=\eta_{0}(1-\phi R)^{-2.5}$, desenvolvida para sistemas "diluídos" onde $\phi<20 \%$ (Shaw, 1965 - apud Petford, 2009), sendo $\eta_{0}$ a viscosidade da fase fluida e $\mathrm{R}$ a constante que define $o$ empacotamento das partículas em suspensão. Contudo, para o caso dos riolitos Santa Maria, estes cálculos podem ser negligenciados, uma vez que a pequena proporção de fases sólidas (considerando-se apenas a proporção de fenocristais - portanto $\phi<10 \%$, com cristais pouco interativos entre si) não altera significativamente a viscosidade do magma (cujo comportamento reológico estaria no campo I do diagrama de Fernandez (1984) apresentado na figura 83, onde a variação da viscosidade em função da cristalinidade é praticamente nula).

O efeito das vesículas é mais complexo, e a principal propriedade reológica de um magma com suspensão de fase volátil corresponde à viscosidade cisalhante (shear viscosity - $\eta_{S}$ ), convertida para viscosidade relativa $\left(\eta_{R}\right)$ através da relação com a viscosidade da fase líquida. A viscosidade relativa é função da fração volumétrica das vesículas $\left(\phi_{V}\right)$ e pode ser ampliada 
ou diminuída a depender da do tipo de regime de fluxo (Llwellin \& Manga, 2005). Llwellin \& Manga (2005) definem então dois regimes distintos:

- regime 1: a viscosidade cisalhante aumenta com o aumento da proporção de vesículas

- regime 2: a viscosidade cisalhante diminui com o aumento da proporção de vesículas, sendo estes regimes determinados pela capilaridade $\left(\mathrm{C}_{\mathrm{a}}\right.$ para fluxos estáveis e capilaridade dinâmica $C_{d}$ para fluxos instáveis).

Os autores descrevem como fluxo estável aquele em que o cisalhamento é constante e cujo regime viscoso é controlado pela capilaridade $\left(C_{a}=\lambda \times \gamma-\right.$ onde $\gamma$ corresponde à taxa de deformação cisalhante), que se refere ao equilíbrio entre o estresse que deforma a bolha e o estresse interfacial. Se $C_{a} \ll 1$, há predomínio do estresse interfacial e as bolhas apresentam geometria esférica, que é responsável pela distorção do fluxo magmático e acarretará no aumento da viscosidade com o aumento da fração gasosa (regime 1). Por outro lado, se $C_{a} \gg 1$ o estresse deformacional predomina e as bolhas serão estiradas de modo a não distorcer o fluxo e a gerar uma "superfície livre derrapante" (free-slip surface), resultando na diminuição da viscosidade com o aumento do volume gasoso (regime 2). O fluxo instável, ao contrário, caracteriza-se pela variação na taxa de deformação cisalhante, sendo descrito pela capilaridade dinâmica $\left(C_{d}=\lambda \times \gamma^{\prime} / \gamma\right.$ - onde $\gamma^{\prime}$ corresponde à variação na taxa de deformação cisalhante), que consiste na relação do tempo de resposta das bolhas ao cisalhamento sofrido (tempo de relaxamento - $\lambda$ ) e as variações da taxa de cisalhamento ao longo do tempo (relação $\gamma^{\prime} / \gamma$ ). Se $C_{d} \ll 1$, as bolhas respondem continuamente às variações da tensão cisalhante e consequentemente encontram-se em equilíbrio, acarretando um fluxo estável que será novamente definido por $C_{a}$. Entretanto, se $C_{d} \gg 1$, a variação no regime cisalhante é rápida o suficiente para impedir que as bolhas respondam elasticamente às mudanças impostas e passam a se deformar passivamente de modo a diminuir a distorção 
do fluxo magmático, cuja viscosidade diminui com o aumento da fase gasosa (regime 2).

Colocados esses conceitos, Llwellin \& Manga (2005) acentuam que, dentro de um mesmo fluxo, suas características reológicas, viscosidade e cisalhamento sofrem variações e então definem valores máximos e mínimos para a viscosidade dos magmas de modo que:

- regime $1\left\{\begin{array}{l}\text { mínimo: } \eta_{R}=\left(1-\phi_{V}\right)^{-1} \\ \text { máximo: } \eta_{R}=1+9 \phi_{V}\end{array}\right.$

- regime $2\left\{\begin{array}{l}\text { mínimo: } \eta_{R}=\left(1-\phi_{V}\right)^{\frac{5}{3}} \\ \text { máximo: } \eta_{R}=\frac{1}{1+22.4 \phi_{V}}\end{array}\right.$

Infelizmente os estudos realizados até o momento para os riolitos Santa Maria não contemplaram um detalhamento preciso da forma, tamanho e proporção volumétrica das vesículas e uma estimativa das taxas de fluxo magmático, o que impede a estimativa da viscosidade através do modelo proposto por Llwellin \& Manga (2005). Entretanto, algumas considerações podem ser feitas.

Os riolitos Santa Maria apresentam conteúdo de água relativamente baixo, onde há predomínio da fase hidroxila, forma menos móvel sob a qual a água se solubiliza no magma. Se considerarmos um fluxo magmático rápido e uma taxa de erupção elevada, a baixa mobilidade apresentada pela hidroxila dificulta a exsolução e aglutinação das vesículas - o que pode ser corroborado pela baixa proporção de vesículas em grande parte dos afloramentos descritos. Deste modo, o efeito destas vesículas não promoveria grandes alterações nos valores de viscosidade obtidos pelo modelo de Giordano et al. (2008). Outro 
aspecto importante é que, mesmo que a exsolução e aglutinação da pequena proporção de vesículas tenham ocorrido, esse processo pode ter se dado de modo a favorecer a ocorrência de bandas com maior concentração de água (resultantes do estiramento e cisalhamento das vesículas e proto-vesículas; cf. Seaman et al., 2009), o que também poderia inibir o aumento da viscosidade do magma. Estes bandamentos (descritos no item IV.1.2) correspondem à alternância entre porções vítreas e cristalinas, que apresentam contrastes químicos aparentemente resultantes da mobilidade de alguns elementos (como $\mathrm{K}, \mathrm{Na}$, Sr e $\mathrm{Rb}$ ) na presença/ausência de água. 


\section{CAPITULO IX - DISCUSSÕES E CONSIDERAÇÕES FINAIS}

Os estudos mais recentes nas rochas vulcânicas ácidas da Província Magmática Paraná têm contestado a bibliografia internacional que as considera registros de um evento explosivo de grande proporção, caracterizando-se como reoignimbritos provenientes da porção africana da província. Estas rochas apresentam características muito peculiares, como temperaturas da ordem de $900-1000^{\circ} \mathrm{C}$ (Guimarães, 2011; Nardy et al., 2011), que permitiriam a ocorrência de magmas menos viscosos responsáveis pela formação de estruturas vulcânicas tipo lava-domos. Neste contexto, os riolitos Santa Maria correspondem a uma seqüencia efusiva de rochas vítreas a hipocristalinas aflorantes na porção sul da Província Magmática Paraná, sul do Brasil. Mapeamentos de detalhe na região de Barros Cassal - Gramado Xavier mostraram que correspondem à sequência superior do magmatismo baixo-Ti, que é caracterizado por uma sucessão de basaltos pahoehoe-basaltos aa seguidos por três sequencias vulcânicas ácidas, as quais abrangem, da base para o topo, a Sequência Caxias do Sul (dacitos de 68-69\% $\mathrm{SiO}_{2}$ ), a Sequência Barros Cassal (andesitos basálticos com $54-55 \% \mathrm{SiO}_{2}$, andesitos com $58 \% \mathrm{SiO}_{2}$ e dacitos com 63-65\% $\mathrm{SiO}_{2}$ ) e Sequência Santa Maria.

Os riolitos Santa Maria são quimicamente homogêneos, com teores de $\mathrm{SiO}_{2}$ entre $71 \%$ e $73 \%$ e com razão $\mathrm{A} / \mathrm{CNK}>1$. Considerando-se os elementos maiores, os riolitos apresentam claramente menores teores de $\mathrm{TiO}_{2}, \mathrm{CaO}$, $\mathrm{P}_{2} \mathrm{O}_{5}, \mathrm{Fe}_{2} \mathrm{O}_{3}$ e $\mathrm{MgO}$, e teores mais elevados de $\mathrm{K}_{2} \mathrm{O}$ quando comparados às unidades precedentes, o que ocorre também para os elementos traços, onde observa-se que a unidade Santa Maria é mais rica em elementos incompatíveis como o Rb, Zr, La, Ce, Th e Nd e mais pobres em elementos compatíveis como o $\mathrm{Sr}$ - estas feições são consistentes com o caráter mais diferenciado da unidade. Os padrões de ETRs exibem-se fracamente fracionados, com razões $(\mathrm{La} / \mathrm{Yb})_{\mathrm{N}}$ variando de 6,6 a 9,1 e $(\mathrm{La} / \mathrm{Sm})_{\mathrm{N}}$ de 3,1 a 3,5 (para teores totais de ETR entre 240 e $280 \mathrm{ppm})$, e anomalias negativas de $\mathrm{Eu}$ bem definidas $\left(\mathrm{Eu} / \mathrm{Eu}^{*}=0.55\right.$ - 
0.56). Os dados de geoquímica isotópica mostram a Sequencia Santa Maria como a unidade mais radiogênica, com razões ${ }^{87} \mathrm{Sr}^{86} \mathrm{Sr}_{(134)}$ bastante elevadas, variando de 0,7230 a 0,7255 , e razões ${ }^{143} \mathrm{Nd} / 144 \mathrm{Nd}_{(134)}$ bastante homogêneas, variando de 0,51204 a 0,51205 , com valores mais negativos para $\mathcal{E N d}(134)$ entre 8,2 e 8,4 (equivalentes a uma idade TDM da ordem de 1,5-1,6 Ga).

Mineralogicamente, os riolitos são compostos por microfenocristais de labradorita e pigeonita e microcristais de plagioclásio, pigeonita e Ti-magnetita dispersos em uma matriz vítrea a devitrificada. A pequena proporção e o tamanho milimétrico dos cristais $(\leq 1,5 \mathrm{~mm})$ sugerem curto tempo de residência na câmara magmática, ou até mesmo cristalização no conduto durante a ascensão, uma vez que não são conhecidas câmaras magmáticas rasas na porção brasileira da Província.

Os microfenocristais de labradorita (principal fase mineral) evidenciam texturas de desequilíbrio, onde núcleos homogêneos apresentam composições que variam de An46 a An54, sendo afetados por superfícies de reabsorção às quais se seguem finas zonas mais cálcicas (An57-60). Estes zonamentos inversos podem estar associados a um aumento no teor de água (já que as fases iniciais apresentam-se empobrecidas em água, fazendo com que a fase líquida aumente sua saturação) ou a um aumento de temperatura do sistema, que poderia ser considerado resultante de calor latente de cristalização ou ainda devido a processos de mistura de magmas.

Análises por LA-ICPMS nos fenocristais de plagioclásio forneceram razões ${ }^{87} \mathrm{Sr} / 86 \operatorname{Sr}_{(134)}$ bastante homogêneas, variando de 0,7267 a 0,7280 , valores sistematicamente mais elevados que os das rochas totais, mesmo considerandose as incertezas associadas. Deste modo, admite-se que os fenocristais de plagioclásio correspondem a antecristais cuja cristalização ocorreu provavelmente nas bordas do conduto ou da câmara magmática, permitindo assim contaminação crustal previamente à efusão das lavas. 
Modelamentos geoquímicos foram realizados considerando-se magmas de composições de andesitos e andesitos basálticos (equivalentes aos magmas Barros Cassal) como magmas parentais e composições graniticas equivalentes aos Granitóides Garopaba foram admitidas como composição do material assimilado. A partir destes modelos foi possível se obter magmas com composições químicas e isotópicas equivalentes aos riolitos Santa Maria com cristalização de 10 a $60 \%$ dos magmas basálticos e andesíticos associados a 6$25 \%$ de assimilação de composições semelhantes às dos Granitóides Garopaba, sendo o intervalo de $30-40 \%$ de cristalização e $8-15 \%$ de assimilação o mais satisfatório.

Esta origem associada ao magmatismo básico pode ser responsável pelas elevadas temperaturas e baixos teores de água característicos dos riolitos Santa Maria. Os estudos de termobarometria indicam temperatura média da ordem de $970^{\circ} \mathrm{C}$, com início da cristalização das fases minerais em pressões da ordem de 3 a 4 Kbar. Os teores de água foram estimados em 0,7 a 1,1\% para a fase inicial de cristalização (fenocristais) e em aproximadamente $0,2 \%$ para a fase final (micrólitos), sendo estes valores solúveis no magma riolítico a até profundidades de $\sim 375-150$ metros (maiores teores de água) e aproximadamente 30 metros (menores teores de água) respectivamente.

Deste modo, tem-se então, para a condição inicial de geração dos riolitos tipo Santa Maria, um magma riolítico com temperatura média da ordem de $970^{\circ} \mathrm{C}$ que inicia sua cristalização uma pressão aproximada de 3 a 4 Kbar. A cristalização se deu, provavelmente, nas paredes do conduto, onde há maior contaminação a partir das rochas encaixantes. Interações com magma de maior temperatura, proveniente de possível processo de reabastecimento, são responsáveis pelo retrabalhamento dos cristais formados, que sofrem reabsorção e nova fase de cristalização, originando os zoneamentos inversos observados (Figura 88). 


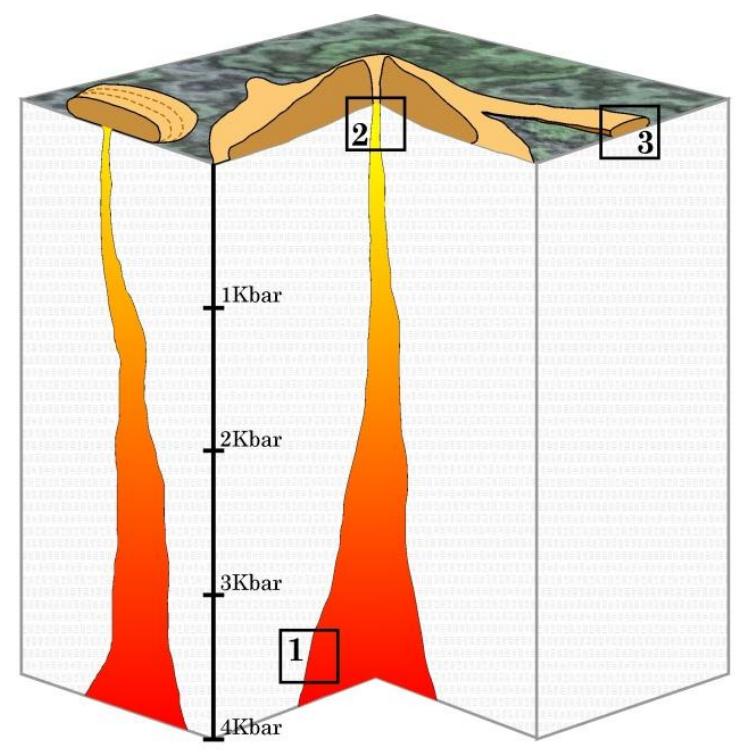

1

Início da cristalização - pressões aproximadas de 3-4 Kbar

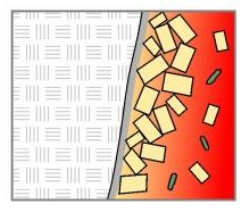

Cristalização iniciada nas bordas do conduto/câmara;

Contaminação crustal

(cristais com alta razão ${ }^{87} \mathrm{Sr} /{ }^{86} \mathrm{Sr}$ )

$\square \mathrm{An}=46-51$

囚 Plagioclásio

$\square$ Piroxênio

Rocha encaixante
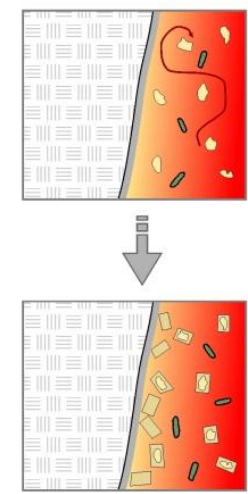

'Descolamento`e reabsorção do material cristalino;

Nova fase de cristalização com aumento de $\mathrm{P}_{\left(\mathrm{H}_{2} \mathrm{O}\right)}$ e temperatura

$\square \mathrm{An}=46-51$

$\square \mathrm{An}=51-57$
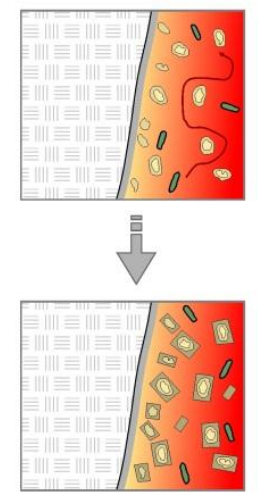

'Descolamento`e reabsorção do material cristalino

Nova fase de cristalização com aumento de $\mathrm{P}_{\left(\mathrm{H}_{2} \mathrm{O}\right)}$ e temperatura

$\square \mathrm{An}=46-51$

$\square \mathrm{An}=51-57$

$\square \mathrm{An}=58-60$
2 Exsolução de voláteis e formação de micrólitos

(próximo à superfície)

ه Plagioclásio

$\square$ Piroxênio

$\square$ Ti-magnetita

Vesículas

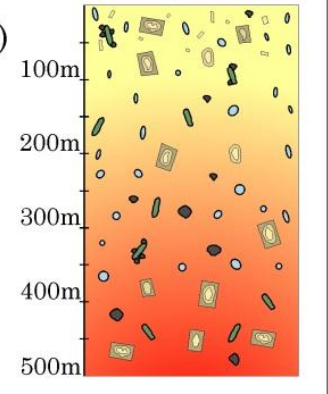

3 Erupção efusiva - formação de fluxos de lava lobados e lava-domos
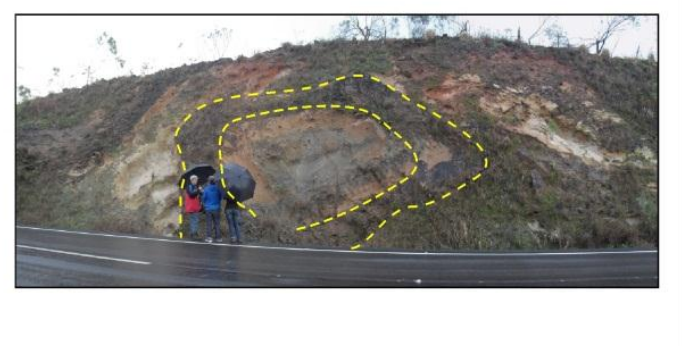

Figura 88: Modelo simplificado para a evolução e erupção dos riolitos Santa Maria. 
Estimativas de viscosidade mostram que os riolitos apresentam-se pouco viscosos para este tipo de magma (viscosidade variando de $10^{5.3}$ a $10^{6.6} \mathrm{~Pa} \mathrm{~s}$ quando considerada a temperatura média de $970^{\circ} \mathrm{C}$ e uma ascensão praticamente isotérmica que poderia ser corroborada pela baixa proporção cristalizada do magma), enquanto que as estimativas de difusividade caracterizam-se como relativamente baixas $\left(1,35 \times 10^{-6} \mathrm{~mm}^{2} / \mathrm{s}\right)$, se comparadas às estimativas realizadas por Polo (2014) para as rochas dacíticas associadas (maiores em cerca de duas ordens de grandeza).

Considerando-se uma ascensão relativamente rápida para estes magmas, a viscosidade e a difusividade apresentadas podem ter sido fatores que retardaram a nucleação de fases minerais e a exsolução de voláteis, que se deu de maneira lenta e incompleta. Devido às variações das taxas de cisalhamento resultantes do regime de fluxo magmático viscoso, a então fase exsolvida tende a migrar, sendo as poucas vesículas até então formadas são intensamente estiradas, dando origem às bandas que facilitam o fluxo (geração de free-slip surfasse) e permitem que o magma atinja a superfície de maneira não explosiva. Se considerarmos ainda uma manifestação vulcânica a partir de fissuras (padrão geral da Província), o atrito com a maior superfície de contato gerada pelas paredes do conduto, associado ao calor latente de cristalização, permitem a manutenção da temperatura, fator que também auxilia o controle da explosividade.

Esta forma de ocorrência resulta na geração das estruturas macro e microscópicas descritas nos riolitos Santa Maria. A extrusão de fluxos de lava em superfícies recobertas por sedimentos inconsolidados gera os peperitos na base dos derrames e a movimentação contínua do fluxo é responsável pela ocorrência de auto-brechas, diagnósticas deste tipo de ocorrência vulcânica. Bandamentos extensos e contínuos, localmente dobrados, também são característicos de derrames lávicos e são estruturas ubíquas na área de estudos. Esses bandamentos se associam, e em parte correspondem a 
intercalações entre porções de rocha vítreas e cristalinas, que apresentam variações composicionais internas (e.g. rochas cristalinas com maiores teores de $\mathrm{K}$ e menores teores de $\mathrm{Rb}$ e $\mathrm{La}$ ). Na hipótese de que o bandamento esteja associado à exsolução e migração do componente volátil previamente à extrusão, pode-se inferir que existe uma relação entre ele e a concentração diferencial de água, que facilita a cristalização e altera a mobilidade dos elementos.

Finalmente, o emprego da técnica de anisotropia de susceptibilidade magnética comprovou-se uma eficiente metodologia para a determinação da trama estrutural (petrofábrica) de rochas vulcânicas. Os resultados forneceram dados estruturais bastante condizentes com aqueles obtidos em campo, onde as tramas magnéticas apresentam pólos de foliação desde verticais (caso predominante, onde as lineações magnéticas apresentam-se horizontais com direções bastante dispersas), passando por inclinações de até $45^{\circ}$, até pólos de foliação com mergulhos mais elevados, até $60^{\circ}$, onde as lineações apresentam direção E-W predominante. As lineações magnéticas apresentam mergulhos preferenciais para SW e a distribuição espacial das direções magnéticas evidencia estruturas de geometria circular com caimento centrípeto, as quais, quando tomadas em conjunto com medidas estruturais obtidas em campo, e com sua associação com morros de morfologia dômica, configuram evidência importante da existência de estruturas do tipo lava-domos. 


\section{REFERÊNCIAS BIBLIOGRÁFICAS}

Bédard, J.H. (2006) - Trace element partitioning in plagioclase feldspar. Geochemica et Cosmochimica Acta, 70: 3717-3742.

Behren, H.; Gaillard, F. (2006) - Geochemical aspects of melts: volatiles and redox behavior. Elements, 2(5):275-280.

Behrens, H.; Jantos, N. (2001) - The effect of anhydrous composition on water solubility in granitic melts. American Mineralogist, 86: 14-20.

Bellieni, G., Brotzu, P., Comin-Chiaramonti, P., Ernesto, M., Melfi, A., Pacca, I.G., Piccirillo, E.M. (1984) - Flood basalt to rhyolite suites in the southern Parana Plateau (Brazil): Palaeomagnetism, petrogenesis and geodynamic implications. Journal of Petrology, 25(3): 579-618.

Bellieni, G., Comin-Chiaramonti, P., Marques, L.S., Melfi, A.J., Nardy, A.J.R., Papatrechas, C., Piccirillo, E.M., Roisenberg, A., Stolfa, D. (1986) Petrogenetic aspects of acid and basaltic lavas from the Paraná Plateau (Brazil): Geological,mineralogical and petrochemical relationships. Journal of Petrology, 27(4): 915-944.

Best, M. G. (2002) - Igneous and Metamorphic Petrology, 2nd ed. Blackwell Publishing, 729 pp.

Bitencourt, M.F., Nardi, L.V.S. (1993) - Late- to post-collisional Brasiliano Magmatism in southernmost Brazil. Anais da Academia Brasileira de Ciências, 65: 3-16.

Bonnichsen, B. \& Kauffman, D.F. (1987) - Physical features of rhyolite lava flows in the Snake River Plain volcanic province, southwestern Idaho. Geological Society of America Spec. Paper, 212: 119-145.

Borradaile, G.J. (1988) - Magnetic susceptibility, petrofabrics, and strain, a review. Tectonophysics, 156: 1-20.

Borradaile, G.J.; Jackson, M. (2010) - Structural geology, petrofabrics and magnetic fabric (AMS, AARM, AIRM). Journal of Structural Geology, 32: 1519-1551.

Bottinga, Y.; Weill, D.F. (1972) - The viscosity of magmatic silicate liquids: A model for calculation. American Journal of Science, 272: 438-475. 
Boynton, W.V. (1984) - Cosmochemistry of the rare-earth elements: meteorite studies. In: Handerson, P. - Rare-earth elements geochemistry. Elsevier, Amsterdam, pp. 63-114.

Bryan, S.E.; Peate, I.U.; Peate, D.W.; Self, S.; Jerram, D.A.; Mawby, M.R.; Marsh, J.S.; Miller, J.A. (2010) - The largest volcanic eruptions on Earth. Earth-Science Reviews, 102: 207-229.

Cañón-Tapia, E.; Herrero-Bervera, E.; Walker, G.P.L. (1994) - Flow directions and paleomagnetic study of rocks from the Azufre Volcano, Argentina. Journal of Geomagnetism and Geoelectricity, 46: 143-159.

Cañón-Tapia, E.; Walker, G.P.L.; Herrero-Bervera, E. (1995) - Magnetic fabric and flow direction in basaltic pahoehoe lava of Xitle volcano, Mexico. Journal of Volcanology and Geothermal Research, 65: 249-263.

Cañón-Tapia, E.; Walker, G.P.L.; Herrero-Bervera, E. (1995) - The internal structure of lava flows - insights from AMS measurements I: near vent aa. Journal of Volcanology and Geothermal Research, 70: 21-36.

Cañón-Tapia, E.; Walker, G.P.L.; Herrero-Bervera, E. (1997) - The internal structure of lava flows - insights from AMS measurements II: Hawaiian pahoehoe, toothpaste lava and 'a'a. Journal of Volcanology and Geothermal Research, 76: 19-46.

Cañón-Tapia, E.; Coe, R. (2002) - Rock magnetic evidence of inflation of a flood basalt lava flow. Bulletin of Volcanology, 64: 289-302.

Cañón-Tapia, E. (2004) - ASM of lava flows and dykes a historial account. Geological Society, London, Special Publications, 238; 205-225.

Carey, S.; Bursik, M. (2000) - Volcanic Plumes. In: Sigurdsson, H. Encyclopedia of Volcanoes. Academic Press, p: 527-544.

Cas, R.A.F.; Wright, J.V. (1987) - Volcanic Successions, modern and ancient: a geological approach to processes, products and sucessions. Allen \& Unwin (Publish) Ltd., U.K., 487 pp.

Cordani, U.G. Sartori, Plp; Kawasita, K. (1980) - Geoquimica dos isótopos de estrôncio e a evolução da atividade vulcânica na bacia do Paraná (sul do Brasil) durante o Cretáceo. Anais da Academia Brasileira de Ciências, 52:811-818. 
Davidson, J.P.; Morgan, D.J.; Charlier, B.L.A. (2007) - Microsampling of Magmatic Rocks. Elements, 3: 253-259.

Day, R.; Fuller, M.; Schmidt, V.A. (1977) - Hysteresis properties of titanomagnetites: grain-size and compositional dependence. Physics of the Earth and Planetary Interiors, 13: 260-267.

Delaney, J.R.; Karsten, J.L. (1981) - Ion microprobe studies of water in silicate melts: Concentration-dependent water diffusion in obsidian. Earth and Planetary Science Letters, 52: 191-202.

DePaolo, D.J. (1981) - Crustal growth and mantle evolution: inferences from models of element transport and $\mathrm{Nd}$ e $\mathrm{Sr}$ isotopes. Geochimica et Cosmochimica Acta, 44: 1185-1196.

Dingwell, D.B.; Bagdassarov, N.S.; Bussod, G.Y.; Webb, S.L. (1993) - Magma rheology. Experiments at high pressures and application to the Earth's mantle. Mineral. Assoc. Canada Short Course Handbook, 21:233-333.

Dingwell, D.B.; Holtz, F.; Behrens H. (1997) - The solubility of $\mathrm{H}_{2} \mathrm{O}$ in peralkaline and peraluminous granitic melts. American Mineralogist, 82: 434-437.

Fernandez, A.N. (1984) - Etude théorique et expérimentale du développement de la fabrique dans les roches magmatiques. Application à l'étude structurale des granitöides. Tese de Doutorado, Univ. Blaise Pascal. Clermont-Ferrand. $238 \mathrm{p}$.

Fink, J.H.; Anderson, S.W. (2000) - Lava domes and coulles. In: Sigurdsson, H. (2000) - Encyclopedia of Volcanoes. Academic Press, p: 307-319.

Florisbal, L.M.; Bitencourt, M.F.; Nardi, L.V.S., Conceição, R.V. (2009) - Early post-collisional granitic and coeval mafic magmatism of medium- to highK tholeiitic affinity within the Neoproterozoic Southern Brazilian Shear Belt. Precambrian Research, 175: 135-148.

Florisbal, L.M.; Janasi, V.A.; Bitencourt, M.F.; Nardi, L.V.S.; Heaman, L.M. (2012) - Contrasted crustal sources as defined by whole-rock and Sr-Nd$\mathrm{Pb}$ isotope geochemistry of neoproterozoic early post-collisional granitic magmatism within the Southern Brazilian Shear Belt, Camboriú, Brazil. Journal of South American Earth Sciences, 39: 24-43. 
Freundt, A., Wilson, C.J.N., Carey, S.N. (2000) - Ignimbrites and block-andash flow deposits. In: Sigurdsson, H. - Encyclopedia of Volcanoes. Academic Press: 581-599.

Garland, F.; Hawkesworth, C.J.; Mantovani, M.S.M. (1995) - Description and petrogenesis of the Paraná rhyolites, southern Brazil. Journal of Petrology, 36(5): 1193-1227.

Giordano, D.; Russell, J.K.; Dingwell, D.B (2008) - Viscosity of magmatic liquids: a model. Earth and Planetary Science Letters, 271: 123-134.

Guimarães, L.F. (2011) - Caracterização geológica-estrutural e geoquímica dos riolitos da Província Magmática Paraná na região de Soledade (RS). Monografia de trabalho de formatura, Instituto de Geociências, Universidade de São Paulo (USP). São Paulo.

Harris, C.; Whittingham, A.M.; Milner Sc, Armstrong, Ra. (1990) - Oxygen isotope geochemistry of the silisic volcanic rocks of the Etendeka-Paraná province: source constraints. Geology, 18: 1119-1121.

Harrison, T.M; Watson, E.B. (1984) - The behavior of apatite during crnstal anatexis: equilibrium and kinetic considerations. Geochimica et Cosmochimica, 48: 1467-1477.

Hawkesworth, C.J.; Mantovanni, M.S.M; Peate, D.W. (1988) - Lithosphere remobilization during Paraná CFB magmatism, in Menzies, M.A. \& Cox, K. (ed.) Oceanic and Continental Lithosphere: Similarities and Differences, Journal of Petrology, Oxford, p: 205-223.

Hawkesworth, C. J.; K.; Gallagher, S.; Kelley, Mantovani, M. S. M.; Peate, D. W.; Regelous M.; Rogers, N. W. (1992) - Parana magmatism and the opening of the South Atlantic, In: Magmatism and the Causes of Continental Break-up, Spec. Publ. 68: 221-240, edited by Storey, B.; Alabaster, A.; Pankhurst, R., The Geological Society, London.

Henry, C.D.; Wolff, J.A. (1992) - Distinguishing strongly rheomorphic tuffs from extensive silicic lavas. Bulletin of Volcanology, 54: 171-186.

Hrouda, F.; Kahan, S. (1991) - The magnetic fabric relationship between sedimentary and basement nappes in the High Tatra Mountains, N. Slovakia. Journal of Structural Geology, 13: 431-442. 
Jackson, M.; Gruber, W.; Marvin, J.; Banerjee, SK. (1988) - Partial anhysteretic remanence and its anisotropy: application and grain-size dependence. Geophysical Research Letters, 15: 440-443.

Janasi, V.A.; Negri, F.A.; Montanheiro, T.J.; Freitas, V.A., Rocha, B.C.; Reis, P.M. (2007 a) - Geochemistry of the eocretacic basalt magmatism in the Piraju-Ourinhos region, SE Brazil, and implications to the stratigraphy of the Serra Geral Formation. Revista Brasileira de Geociências, 37(1): 148162.

Janasi, V.A.; Montanheiro, T.J.; Freitas, V.A.; Reis, P.M.; Negri, F.A.; Dantas, F.A. (2007 b) - Geology, petrography and gechemistry of the acid volcanism of the Paraná Magmatic Province in the Piraju-Ourinhos region, SE Brazil. Revista Brasileira de Geociências, 37(4): 745-759.

Janasi, V.A., Freitas, V.A., Heaman, L.H. (2011) - The onset of flood basalt volcanismo, Northern Paraná Basin, Brazil: A precise U-Pb baddeleyite/zircon age for a Chapecó-type dacite. Earth and Planetary Science Letters, 301: 147-153.

Jeefery, G.B. (1922) - The motion of ellipsoidal particles immersed in a viscous fluid. Proceedings of the Royal Society of London, 102: 161-179.

Knight, M.D.; Walker, G.P.L. (1988) - Magma flow directions in dikes of the Koolau Complex, Oahu, determined from magnetic fabric studies. Journal of Geophysical Research, 93: 4301-4319.

Lange, R.A.; Frey, H.M.; Hector, J. (2009) - A thermodynamic model for the plagioclase-liquid hygrometer/thermometer. American Mineralogist, 94(4): 494-506.

LaRoche, H. de; Leterrier, J.; Grandclaude, P.; Marchal, M. (1980) - A classification of volcanic and plutonic rocks using R1-R2 diagram and major elements analyses. Chemical Geology, 29: 183-210.

Le Bas, M.J.; Le Maitre, R.W.; Streckisen, A.; Zanettin, B. (1986) - A chemical classification of volcanic rocks based on the total alkali-silica diagram. Journal of Petrology, 27: 745-750.

Lima, E.F.; Philipp, R.P.; Rizzon, G.C.; Waichel, B.L.; Rossetti, L.M.M. (2012) Sucessões vulcânicas, modelo de alimentação e geração de domos de lava ácidos da Formação Serra Geral na região de São Marcos - Antônio Prado (RS). Revista Geologia USP - Série Científica, 12(2): 49-64. 
Liu, Y.; Zhang, Y.; Behrens, H. (2005) - Solubility of $\mathrm{H}_{2} \mathrm{O}$ in rhyolitic melts at low pressures and a new empirical model for mixed $\mathrm{H}_{2} \mathrm{O}-\mathrm{CO}_{2}$ solubility in rhyolitic melts. Journal of Volcanology and Geothermal Research, 143: 219-235.

Llwellin, E.W; Manga, M. (2005) - Bubble suspension rheology and implications for conduit flow. Journal of volcanology and geothermal research, 143: 205-217.

Loock, S.; Diot, H.; Vries, B.V.W.; Launeau, P.; Merle, O.; Vadeboin, F.; Petronis, M.S. (2008) - Lava flow internal structure found from ASM and textural data: an exemple in methodology from the Chaîne des Puys, France. Journal of Volcanology and Geothermal Research, 177: 1092-1104.

Luchetti, A.C.F. (2010) - Aspectos vulcanológicos dos traquidacitos da região de Piraju - Ourinhos (SP). Dissertação de Mestrado, Universidade de São Paulo, São Paulo.

Macdonald, W.D.; Palmer, H.C.; Hayatsu, A. (1992) - Egan Range Volcanic Complex, Nevada: geochronology, paleomagnetism and magnetic fabrics. Physics of the Earth and Planetary Interiors, 74, 109-126.

Maniar, P.D.; Piccoli, P.M. (1989) - Tectonic discrimination of Granitoids Geological Society of America Bulletin, 101: 635-643.

Manley, C.R. (1995) - How voluminous rhyolite lavas mimic rheomorphic ignimbrites: eruptive style, emplacement conditions, and formation of tufflike textures. Geology, 23(4): 349-352.

Mantovani, M.S.M.; Marques, L.S.; Souza, M.A.; Atalla, L.; Civeta, L.; Innocenti, F. (1985) - Trace element and strountium isotope constraints of the origin and evolution of Paraná Continental Flood Basalts of Santa Catarina State (south Brazil). Journal of Petrology, 26: 187-209.

Mantovani, M. S. M.; Cordani U . G.; Roisenberg, A. (1985b) - Geoquímica isotópica em vulcânicas ácidas da Bacia do Paraná e implicações genéticas associadas. Revista Brasileira de Geociências, 15(1):61-65.

McPhie, J.; DellaPasqua, F.; Allen, S.R.; Lackie, M.A. (2008) - Extreme effusive eruptions: Palaeoflow data on an extensive felsic lava in the Mesoproterozoic Gawler Range Volcanics. Journal of Volcanology and Geothermal Research, 172: 148-161. 
Milner, S.C., Duncan, A.R., Ewart, A. (1992) - Quartz latite rheoignimbrite flows of the Etendeka Formation, north-western Namibia. Bulletin of Volcanology, 54(3): 200-219.

Milner, S.C., Ewart, A. (1989) - The geology of the Goboboseb Mountain volcanics and ther relationship to the Messum Complex. Communs Geol. Surv. Namibia, 5: 31-40.

Mollo, S.; Putirka, K.D.; Iezzi, G.; Del Gaudio, P.; Scarlato, P. (2011) Plagioclase-melt (dis) equilibrium due to cooling dynamics: implications for thermometry, barometry and hygrometry. Lithos, 125(1), 221-235.

Montanheiro, T.J.; Negri, F.A.; Janasi, V.A; Yamamoto, J.K.; Vogado, F.P. (2011) - Vidro vulcânico maciço: pozolana natural no Oeste Paulista. Geologia USP - Série Científica, 11(1): 59-74.

Moore, G.; Vennemann, T.; Carmichael, I.S.E. (1998) - An empirical model for the solubility of $\mathrm{H}_{2} \mathrm{O}$ in magmas to 3 kilobars. American Mineralogist, 83: 36-42.Morimoto, N. (1990) - Nomenclatura de piroxênios. Tradução do original em inglês "Nomenclature of pyroxenes" realizada com a permissão da IMA por Garda, M.G., Atencio, D.

Moulson, A. J.; Roberts, J. P. (1961) - Water in silica glass. Trans. Faraday Soc. 57: 1208-1216.

Mysen, B.; Richet, P. (2005) - Silicate glasses and melts. Elsevier, 560p.

Nardy, A.J.R. (1996) - Geologia e petrologia do vulcanismo Mesozóico da região central da Bacia do Paraná. Tese de Doutorado, Instituto de Geociências e Ciência Exatas, Universidade Estadual Paulista (UNESP), Rio Claro.

Nardy, A.J.R.; Machado, F.B.; Oliveira, M.A.F. (2008) - As rochas vulcânicas mesozoicas ácidas da Bacia do Paraná: litoestratigrafia e considerações geoquímico-estratigráficas. Revista Brasileira de Geociências, 38(1): 178195.

Nardy, A.J.R.; Rosa, M.C.; Luchetti, A.C.F.; Ferreira, M.L.C.; Machado, F.B.; Oliveira, M.A.F. (2011) - Parâmetros físicos pré-eruptivos do magmatismo ácido da Província Magmática do Paraná: resultados preliminares. Geociências, UNESP, 30(4): 575-588. 
Navarro, M.S. (2004) - A implantação de rotina, e se refinamento, para a determinação de elementos terras raras em materiais geológicos por ICPOES e ICP-MS. Aplicação ao caso dos granitóides de Piedade-Ibiúna (SP) e Cunhaporanga (PR). Dissertação de Mestrado, Instituto de Geociências, Universidade de São Paulo.

Neuman, H.; Mead, J.; Vitaliano, C.J. (1954) - Trace-element variation during fractional crystallization as calculated from the distribution law. Geochimica et Cosmochimica Acta, 6: 90-100.

Newman, S.; Lowenstern, J.B. (2002) - VOLATILECALC: A silicate melt- $\mathrm{H}_{2} \mathrm{O}$ $\mathrm{CO}_{2}$ solution model written in Visual Basic for Excel. Computers and Geoscience, 28: 597-604.

Nowak, M.; Behrens, H. (1997) - An experimental investigation on diffusion of water in haplogranitic melts. Contributions to Mineralogy and Petrology, 126: $365-376$.

Park, J.K.; Tanczyk, E.I.; Desbarats, A. (1988) - Magnetic fabric and its significance in the $1400 \mathrm{Ma}$ Mealy diabase dykes of Labrador, Canada. Journal of Geophysical Research, 93: 13689-13704.

Peate, D. (1997) - The Paraná-Etendeka Province. In: JJ Mahoney \& MF Collin (Eds.): Large Igneous Provinceds. Geophysical Monograph 100, AGU, p. 217-245.

Perroud, H.; Calza, F.; Khattach, D. (1991) - Paleomagnetism of the silurian volcanism at Almaden, southern Spain. Journal of Geophysical Research, 96: $1949-1962$.

Petford, N. (2009) - Which effective viscosity? Mineralogical Magazine, 73(2): $167-191$

Piccirillo, E.M.; Raposo, M.I.B.; Melfi, A.J.; Comin-Chiaramonti, P.; Cordani, U., Kawashita, K. (1987) - Bimodal fissural volcanic suítes from the Paraná Basin (Brazil): K-Ar ages, Sr-isotopes and geochemistry. Gechimical Brasiliensis, 1:55-69.

Pinto, V.M.; Hartmann, L.A.; Santos, J.O.S.; McNaughton; N.J.; Wildner, W. (20110 - Zircon U-Pb geochronology from the Paraná bimodal volcanic province support a brief eruptive cycle at $\sim 135$ Ma. Chemical Geology, 281(1-2): 93-102. 
Polo, L.A. (2010) - Estilo eruptivo do vulcanismo ácido na Província Magmática Paraná-Etendeka: estudo estrutural, textural e químico de corpos de dacitos e obsidianas na região a sul de Soledade, RS. Exame de Qualificação, Instituto de Geociências, Universidade de São Paulo.

Polo, L.A.; Janasi, V.A. (2014) - Volcanic stratigraphy of intermediate to acidic rocks in southern Paraná Magmatic Province, Brazil. Geologia USP. Série Científica - artigo submetido.

Polo, L.A. (2014) - Estilo eruptivo do vulcanismo ácido na Província Magmática Paraná-Etendeka: estudo estrutural, textural e químico de corpos de dacitos e obsidianas na região a sul de Soledade, RS. Tese de doutorado em andamento, Instituto de Geociências, Universidade de São Paulo.

Putirka, K.D.; Ryerson, F.J.; Mikaelian, H. (2003) - New igneous thermobarometers for mafic and evolved lava compositions, based on clinopyroxene + liquid equilibria. American Mineralogist, 88:1542-1554

Putirka, K.D. (2005b) - Igneous thermometers and barometers based on plagioclase + liquid equilibra: tests of some existing models and new calibrations. American Mineralogist, 90: 336-346.

Putirka, K.D. (2008) - Thermometers and barometers for volcanic systems. Reviews in Mineralogy \& Geochemistry, 69: 61-120.

Ramos, F.C.; Wolff, J.A.; Tollstrup, D.L. (2005) - Sr isotope disequilibrium in Columbia River flood basalts: Evidence for rapid shallow-level opensystem processes. Geology, 33(6): 457-460.

Renne, P.R.; Ernesto, M.; Pacca, I.G.; Coe, R.S.; Glen, J.M.; Prévot, M.; Perrin, M. (1992) - The age of Paraná Flood Volcanism, rifting of Gondwanaland, and the Jurassic-Cretaceous Boundary. Science, 258: 975-979.

Rocha Campos, A.C., Cordani, U.C., Kawashita, K., Sonoki, H.M., Sonoki, I.K. (1988) - Age of the Paraná flood volcanism, in Piccirillo, E.M., Melfi, A.J. (eds.) - The Mesozoic flood volcanism of the Paraná Basin: Petrogenesis and geophysical aspects. IAG-USP press, 25-46.

Seaman, S.J.; Dyar, M.D.; Marinkovic, N. (2009) - The effects of the heterogeneity in magma water concentration on the development of flow banding and spherulites in rhyolitic lava. Journal of Volcanology and Geothermal Research, 183: 157-169. 
Shaw, H.R. (1965) - Comments on viscosity, crystal settling and convection in granitic magmas. American Journal of Science, 263: 120-152.

Shaw, H.R. (1972) - Viscosities of magmatic silicate liquids: An empirical method of prediction. American Journal of Sciences, 272: 870-893.

Sigurdsson, H.; Houghton, B.; McNutt, S. T.; Rymer, H.; Stix, J. (2000) Encyclopedia of Volcanoes. Academic Press, 1417 p.

Silva, L.C. (1999) - Geocronologia U-Ph SHRIMP e Sm-Nd na Província Mantiqueira, no Cinturão Saldania (África do Sul) e a evolução do Ciclo Brasiliano/Pan Africano. Porto Alegre, 243 p. Tese de Doutorado em Geociências, Instituto de Geociências, Universidade Federal do Rio Grande do Sul.

Silver, L.; Thinger, P.D.; Stolper, E. (1990) - The influence of bulk composition on the speciation of water in silicate glasses. Contributions to Mineralogy and Petrology, 104: 142-162.

Spera, F.J. (2000) - Physical properties of magmas. In: Sigurdsson, H.; Houghton, B.; McNutt, S. T.; Rymer, H.; Stix, J. (2000) - Encyclopedia of Volcanoes. Academic Press, 1417 p.

Stewart, K.; Turner, S.; Kelley, K.; Hawkesworth, C.; Kirstein, L.; Mantovani, M. (1996) - 3D - ${ }^{40} \mathrm{Ar} / 39 \mathrm{Ar}$ geochronology in the Paraná continental flood basalt province. Earth and Planetary Science Letters, 143: 95-109.

Stolper, E. (1982) - Water in silicate glasses: an infrared spectroscopic study. Contributions to Mineralogy and Petrology, 81: 1-17.

Stormer, J.C.; Nicholls, J. (1978) - XLFRAC: a program for the interactive testing of magmatic differentiation models. Computers and Geoscience, 4: 143-159.

Streck, M.J. (2008) - Mineral textures and zoning as evidence for open system processes. Reviews in Mineralogy \& Geochemistry, 69: 595-622.

Sun, S.S.; McDonough, W.F. (1989) - Chemical and isotopic systematics of ocean basalts: implications for mantle composition and process. In: Saunders, A.D. \& Norry, M.J. (eds), Magmatism in ocean basin. Geological Society of London, Special Publication, 42: 313-345.

Tarling, D.H.; Hrouda, F. (1993) - The Magnetic Anisotropy of Rocks. Chapman and Hall, London, 217 pp. 
Theide, D.S.; Vasconcelos, P.M. (2008) - Paraná flood basalts: rapid extrusion hypothesis supported by new ${ }^{40} \mathrm{Ar} / 39 \mathrm{Ar}$ results. Anais do $44^{\circ}$ Congresso Brasileiro de Geologia, Curitiba, p.348.

Turner, S.; Regelous, M.; Kelley, S.; Hawkesworth, C.; Mantovani, M. (1994) Magmatism and continental break-up in the South Atlantic: highprecision ${ }^{40} \mathrm{Ar} /{ }^{39} \mathrm{Ar}$ geochronology. Earth and Planetary Science Letters, 121: $333-348$.

Waichel, B.L.; Lima, E.F.; Viana, A.R.; Scherer, C.M.; Bueno, G.V.; Dutra, G. (2011) - Stratigraphy and volcanic facies architecture of the Torres Syncline, Southern Brazil, and its role in understanding the ParanáEtendeka Continental Flood Basalt Province. Journal of Volcanology and Geothermal Research, 215-216: 74-82.

Wallace, P.; Anderson Jr, A.T. (2000) - Volatiles in magmas. In: Sigurdsson, H.; Houghton, B.; McNutt, S. T.; Rymer, H.; Stix, J. (2000) - Encyclopedia of Volcanoes. Academic Press, 1417 p.

Waters, L.E.; Lange, R.A. (2013) - Crystal-poor, multiply saturated rhyolites (obsidians) from the Cascade and Mexican arcs: evidence of degassinginduced crystallization of phenocrysts. Contributions to Mineralogy and Petrology, 166: 731-754.

Zhang, Y.; Stolper, E.M.; Wasseburg, G.J. (1991a) - Diffusion of water in rhyolitic glasses. Geochimica et Cosmochimica Acta, 55: 441-456.

Zhang, Y.; Stolper, E.M.; Wasseburg, G.J. (1991b) - Diffusion of a multi-species component and its role in the diffusion of water and oxygen in silicates. Earth and Planetary Science Letters, 103: 228-240.

Zhang, Y. (1999) - $\mathrm{H}_{2} \mathrm{O}$ in rhyolitic glasses and melts: measurement, speciation, solubility, and diffusion. Reviews of Geophysics, 37: 493-516.

Zhang, Y.; Xu, Z.; Zhu, M.; Wang, H. (2007) - Silicate melt properties and volcanic eruptions. Reviews of Geophysics, 45: 1-27.

Zhang, Y.; Behrens, H. (2000) $-\mathrm{H}_{2} \mathrm{O}$ diffusion in rhyolitic melts and glasses. Chemical Geology, 169: 243-262.

Závada, P.; Kratinová, Z.; Kusbach, V.; Schulmann, K. (2009) - Internal fabric development in complex lava domes. Tectonophysics, 466: 101-113. 
ANEXOS 


\section{Anexo 01}

Anisotropia de Susceptibilidade Magnética: mapas geológicos com dados estruturais e croquis de afloramentos amostrados 


\section{Mapa Geológico e de Foliação e Lineação Magnética}
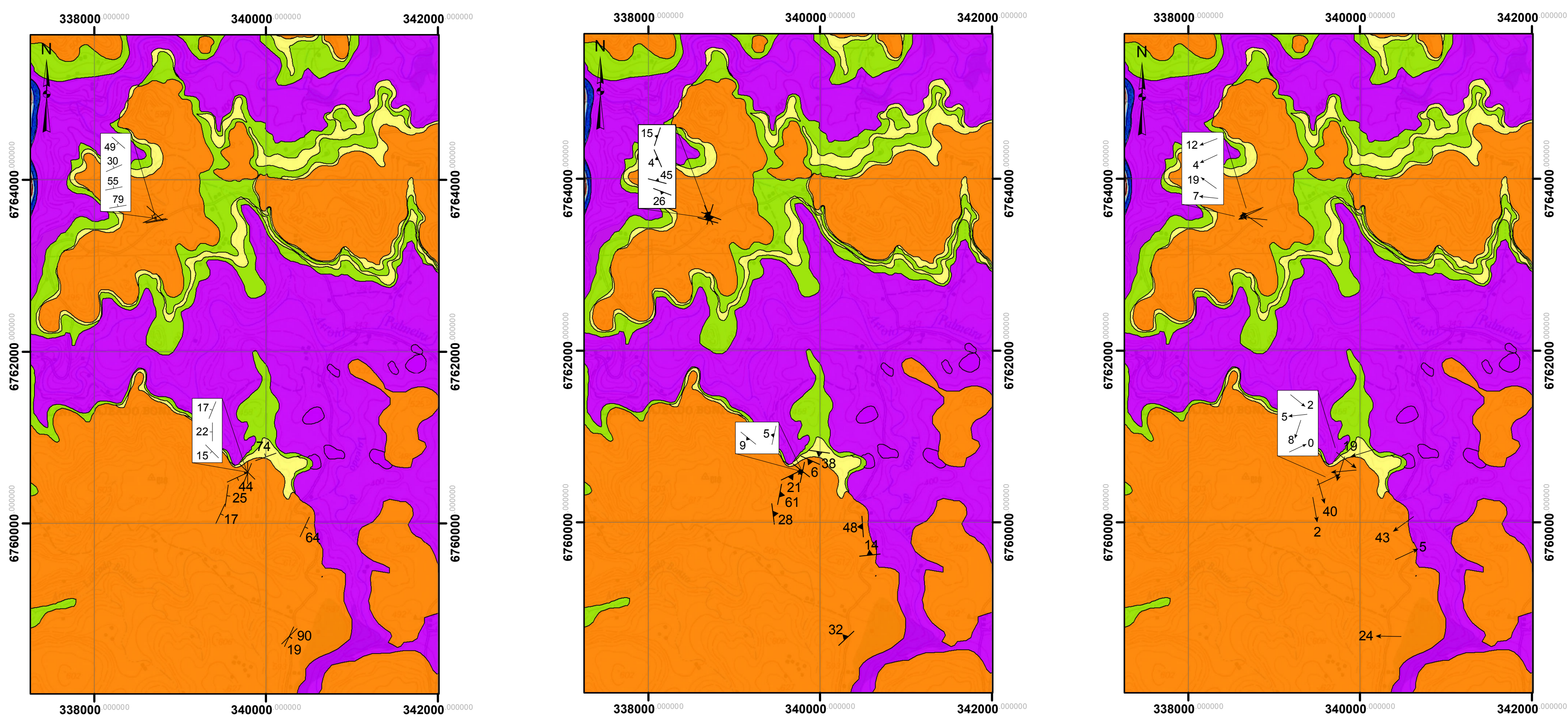

\section{Legenda}

Un. Santa Maria (riolitos) Un. Barros Cassal (andesitos dacitos)

Un. Barros Cassal (basaltos)

Sedimentos Pós-Caxias do Sul

Un. Caxias do Sul (dacitos)

Estruturas medidas em campo (foliação magmática / disjunção de resfriamento)

Foliação magnética

Lineação magnética

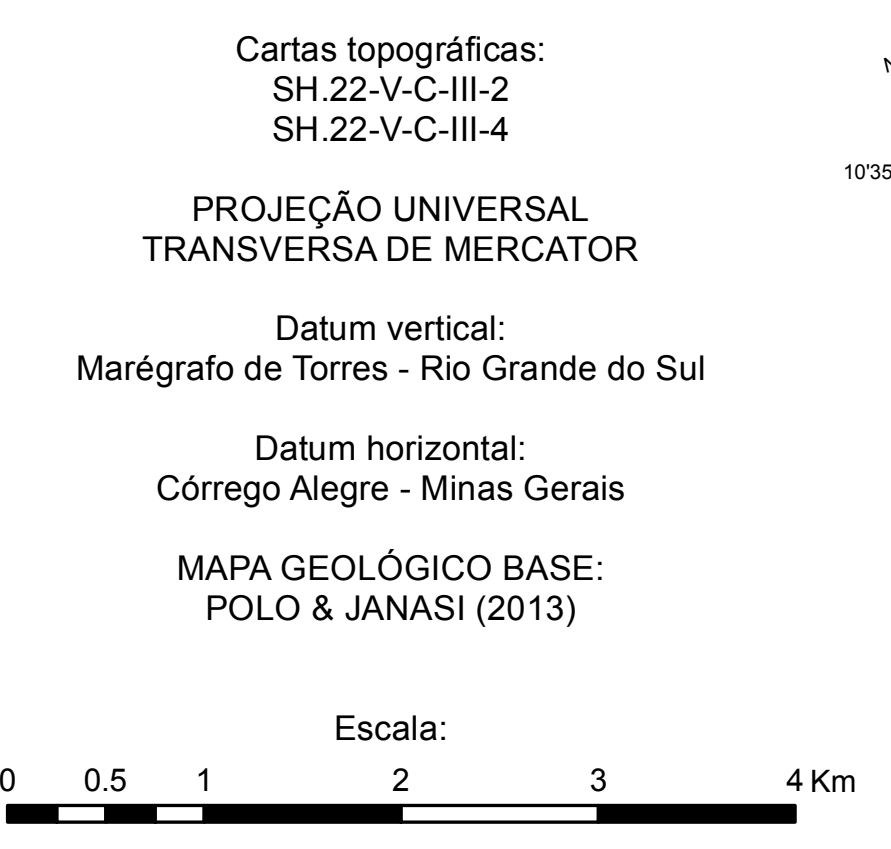

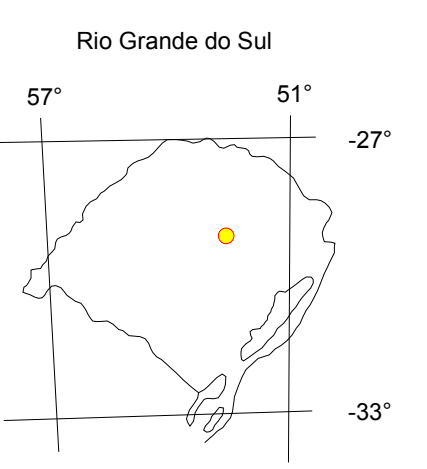

Letícia Freitas Guimarães

Dissertação de Mestrado "Características físicas e químicas e modelo evolutivo para os riolitos tipo Santa Maria (Província Magmática Paraná) na região de 


\section{Croquis dos principais afloramentos e comparação entre os dados estruturais obtidos em campo e os dados obtidos via ASM}
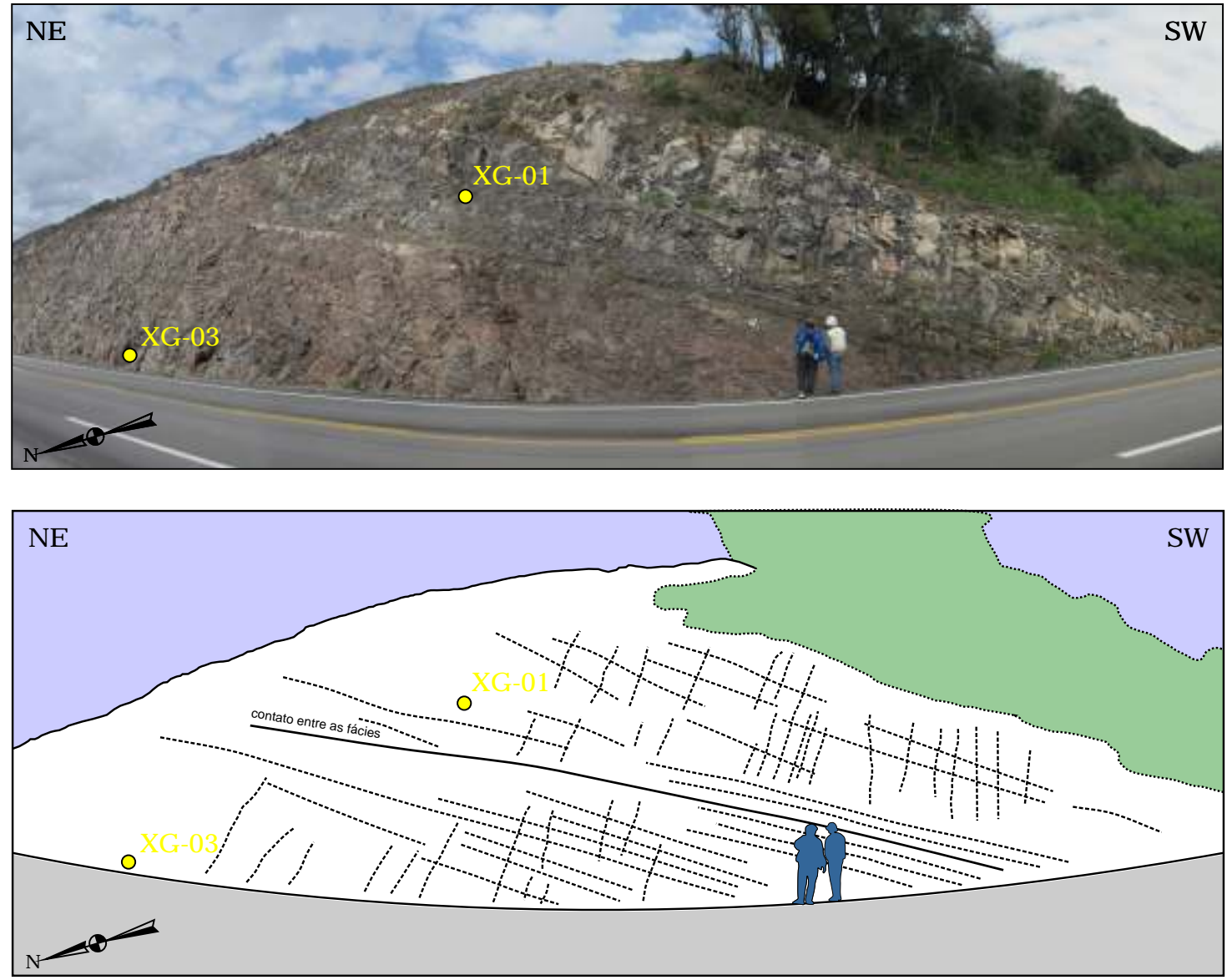

\section{Legenda}

eixo к máximo (к1)

$\triangle$ eixo к intermediário (к2)

eixo к mínimo (к3)

Foliação magnética: definida pelo plano $\kappa 1+\kappa 3$

Lineação magnética: definida pelo eixo $\kappa 1$
Representação estereográfica dos resultados obtidos para as anisotropias de susceptibilidade magnética:
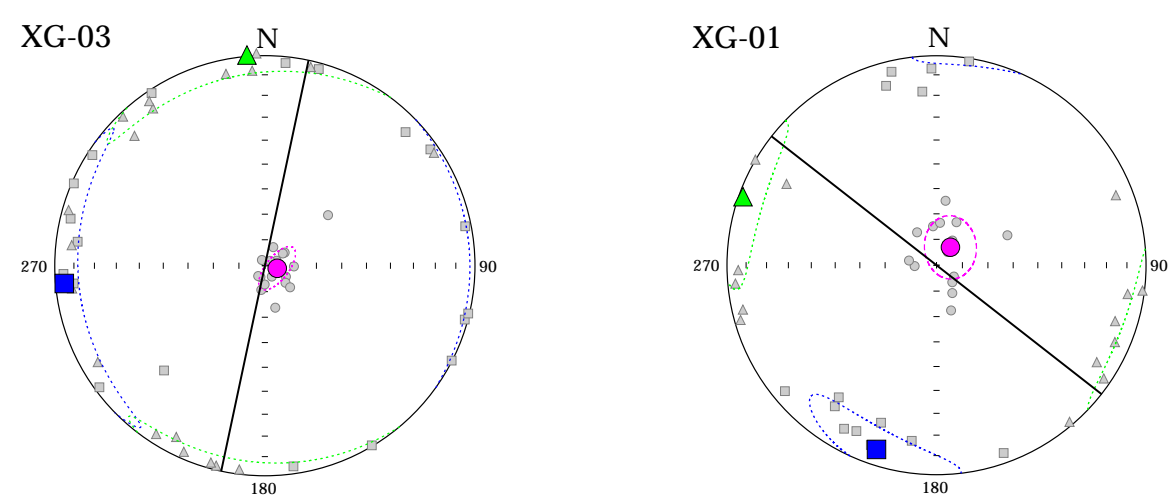

Representação estereográfica das atitudes dos padrões de disjunções:

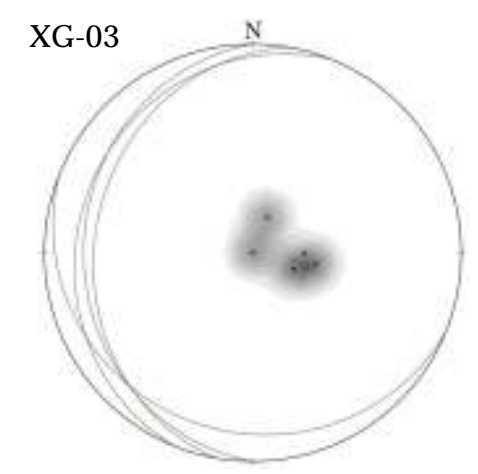

Dissertação de Mestrado

Características físicas e modelo eruptivo para os riolitos tipo Santa Maria (Província Magmática Paraná) na região de Gramado Xavier, RS. 


\section{Croquis dos principais afloramentos e comparação entre os dados estruturais obtidos em campo e os dados obtidos via ASM}
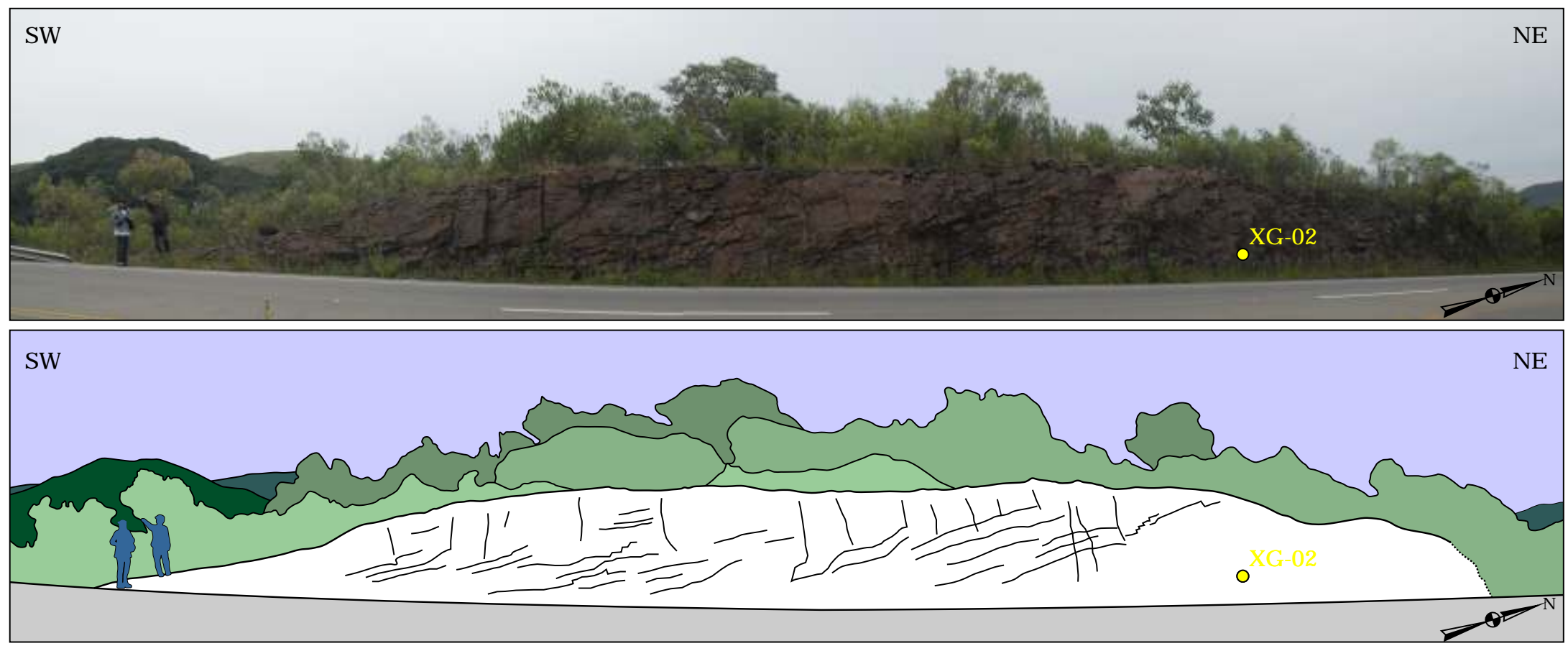

Representação estereográfica dos resultados obtidos para as anisotropias de susceptibilidade magnética:

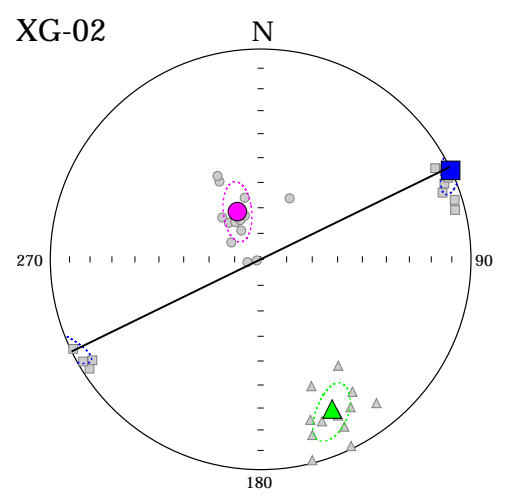

Representação estereográfica das atitudes dos padrões de disjunções:

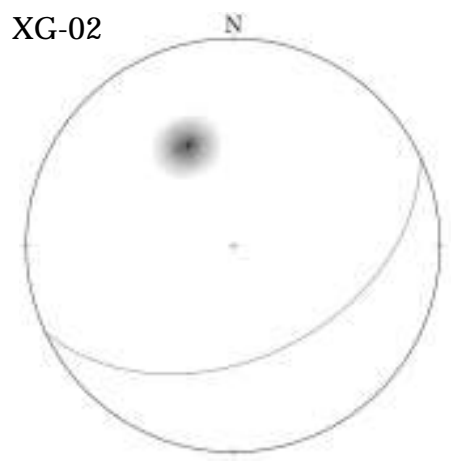

\section{Legenda}

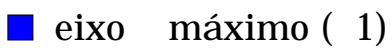

$\triangle$ eixo к intermediário (к2)

- eixo к mínimo (к3)

Foliação magnética: definida pelo plano $\kappa 1+\kappa 3$

Lineação magnética: definida pelo eixo $\kappa 1$ 


\section{Croquis dos principais afloramentos e comparação entre os dados estruturais obtidos em campo e os dados obtidos via ASM}
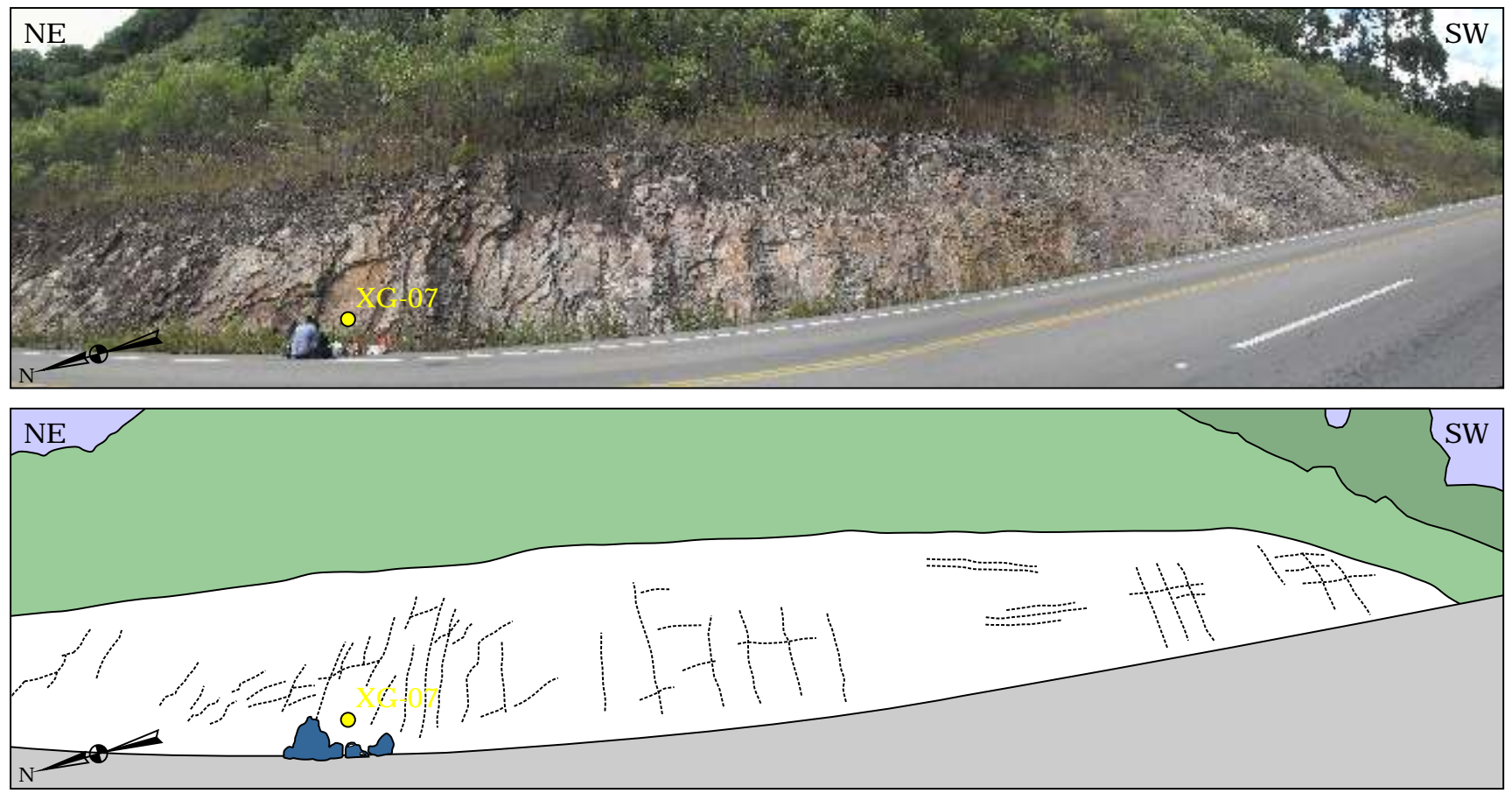

$\begin{array}{|cc|} & \text { Legenda } \\ & \begin{array}{l}\text { Foliação magnética: } \\ \text { eixo } \kappa \text { máximo }(\kappa 1)\end{array} \\ \begin{array}{l}\text { eixo } \kappa \text { intermediário }(\kappa 2) \\ \text { eixo } \kappa \text { mínimo }(\kappa 3)\end{array} & \begin{array}{l}\text { Lineação magnética: } \\ \text { definida pelo eixo } \kappa 1\end{array}\end{array}$

Representação estereográfica dos resultados obtidos para as anisotropias de susceptibilidade magnética:

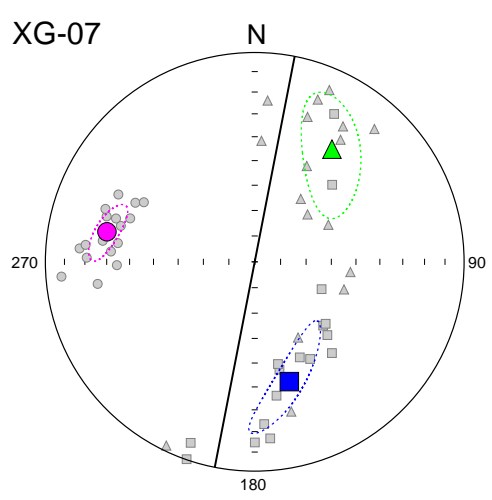

Representação estereográfica das atitudes dos padrões de disjunções:

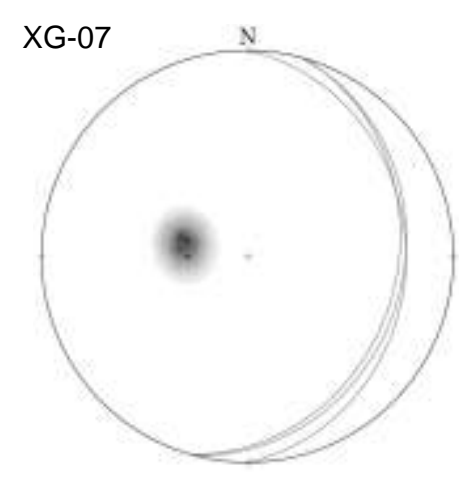

Dissertação de Mestrado

Características físicas e modelo eruptivo para os riolitos tipo Santa Maria (Província Magmática Paraná) na região de Gramado Xavier, RS 


\section{Croquis dos principais afloramentos e comparação entre os dados estruturais obtidos em campo e os dados obtidos via ASM}
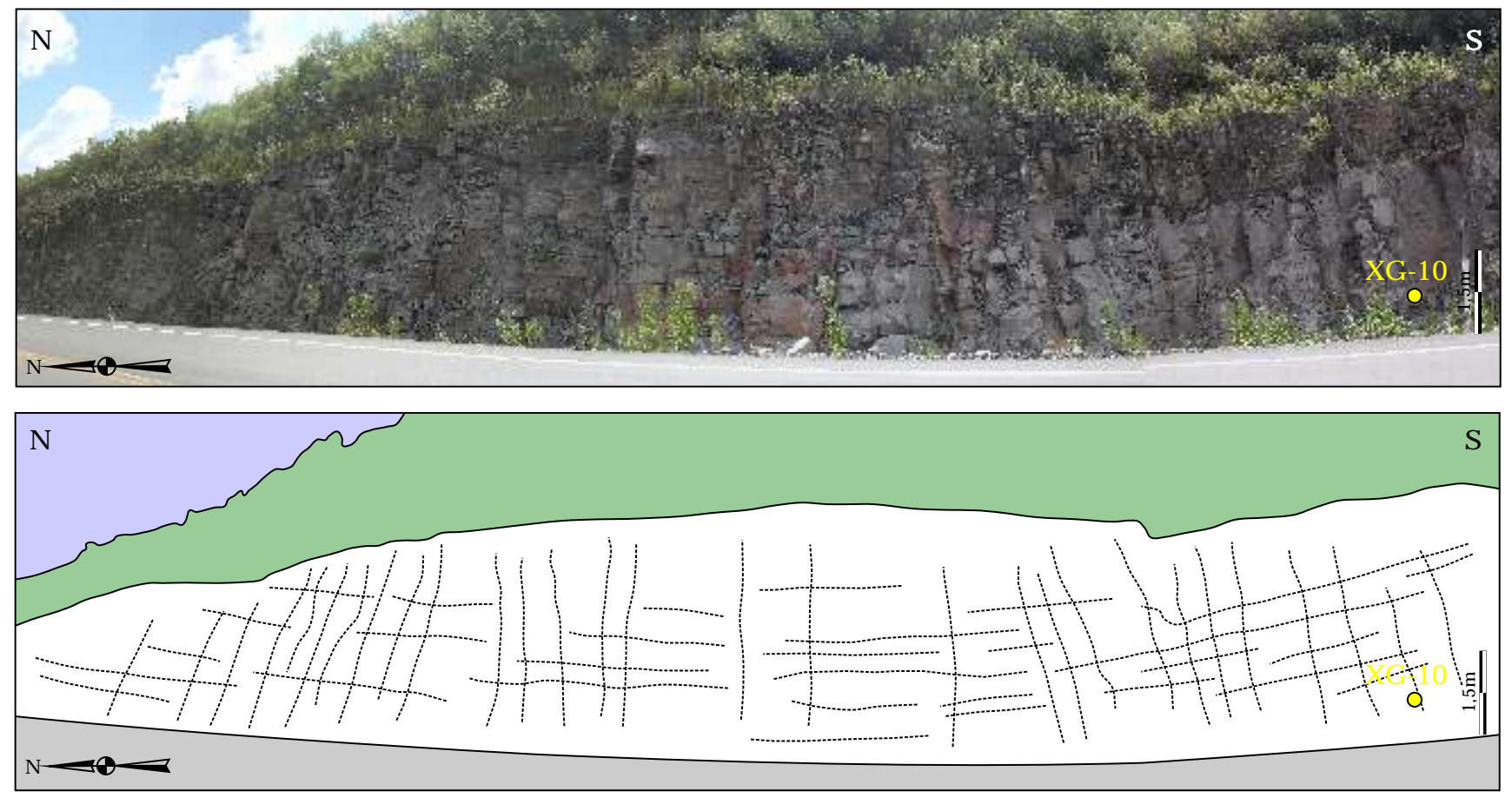

\begin{tabular}{|c|c|}
\hline \multicolumn{2}{|c|}{ Legenda } \\
\hline eixo к máximo $(\kappa 1)$ & $\begin{array}{l}\text { Foliação magnética: } \\
\quad \text { definida pelo plano } \kappa 1+\kappa 3\end{array}$ \\
\hline $\begin{array}{l}\text { eixo к intermediário (к2) } \\
\text { eixo к mínimo (к3) }\end{array}$ & $\begin{array}{l}\text { Lineação magnética: } \\
\quad \text { definida pelo eixo } \mathrm{\kappa} 1\end{array}$ \\
\hline
\end{tabular}

Representação estereográfica dos resultados obtidos para as anisotropias de susceptibilidade magnética:

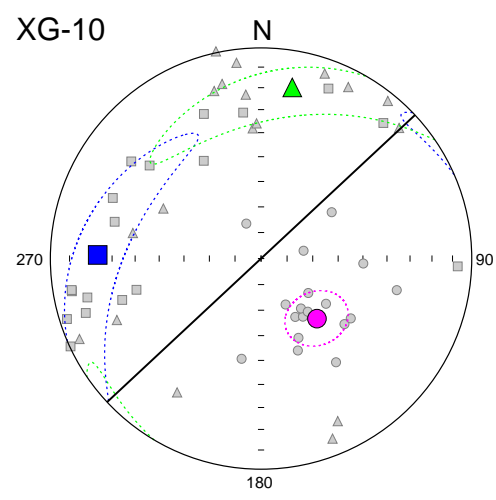

Representação estereográfica das atitudes dos padrões de disjunções:

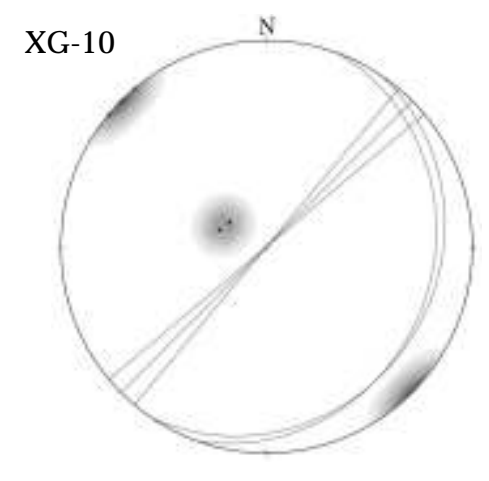

Dissertação de Mestrado

Características físicas e modelo eruptivo para os riolitos tipo Santa Maria (Província Magmática Paraná) na região de Gramado Xavier, RS. 
Croquis dos principais afloramentos e comparação entre os dados estruturais obtidos em campo e os dados obtidos via ASM
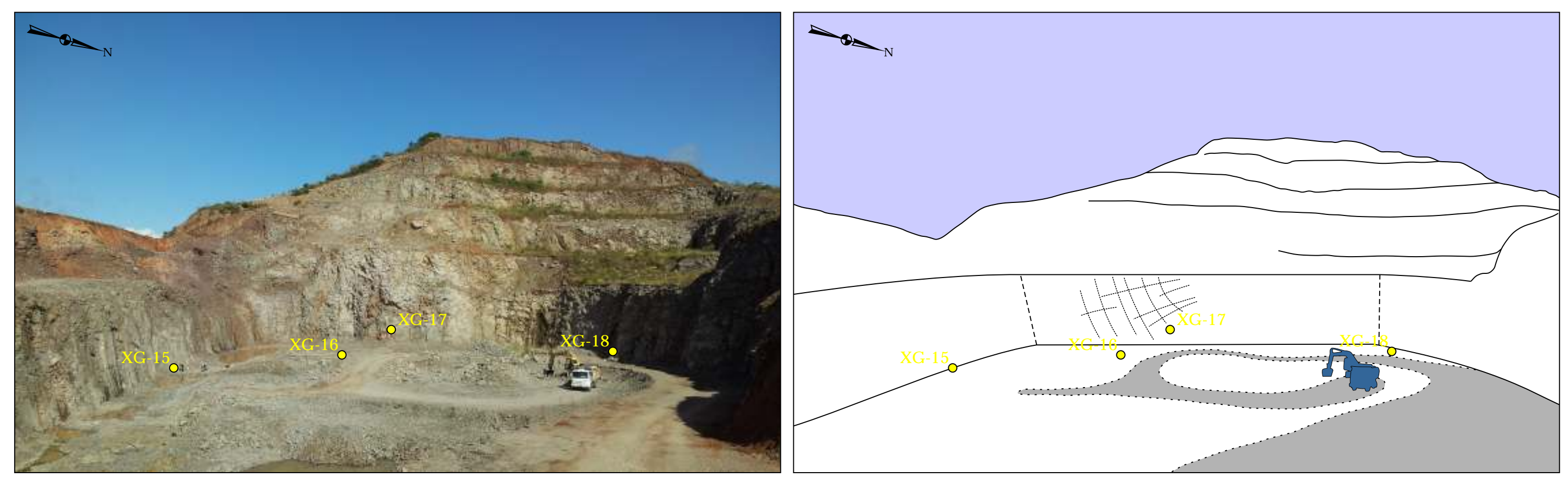

Representação estereográfica dos resultados obtidos para as anisotropias de susceptibilidade magnética:
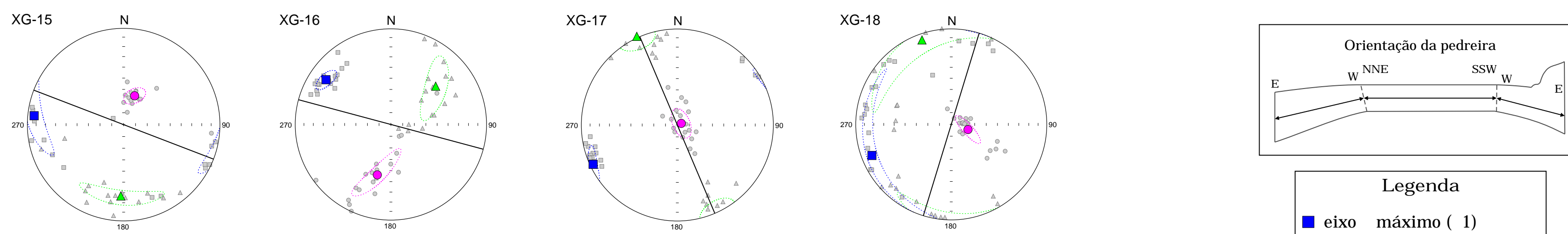

Representação estereográfica das atitudes dos padrões de disjunções:
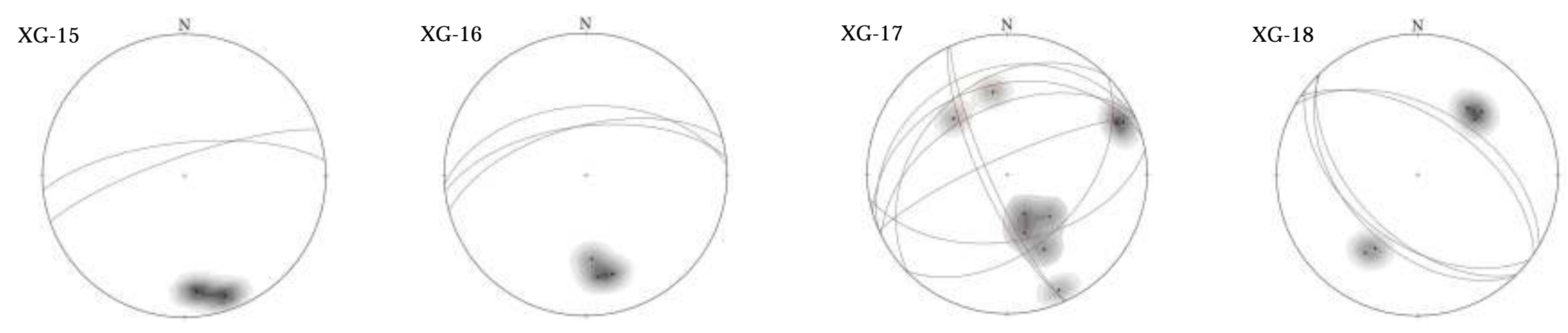

- eixo к máximo (к1)

eixo к intermediário (к2)

- eixo к mínimo (к3)

Foliação magnética:

definida pelo plano $\mathrm{\kappa} 1+\mathrm{\kappa} 3$

Lineação magnética:

definida pelo eixo $\kappa 1$ 


\section{Anexo 02}

Química mineral:

Imagens obtidas via microscopia eletrônica de varredura (MEV) e resultados das análises via microssonda eletrônica 


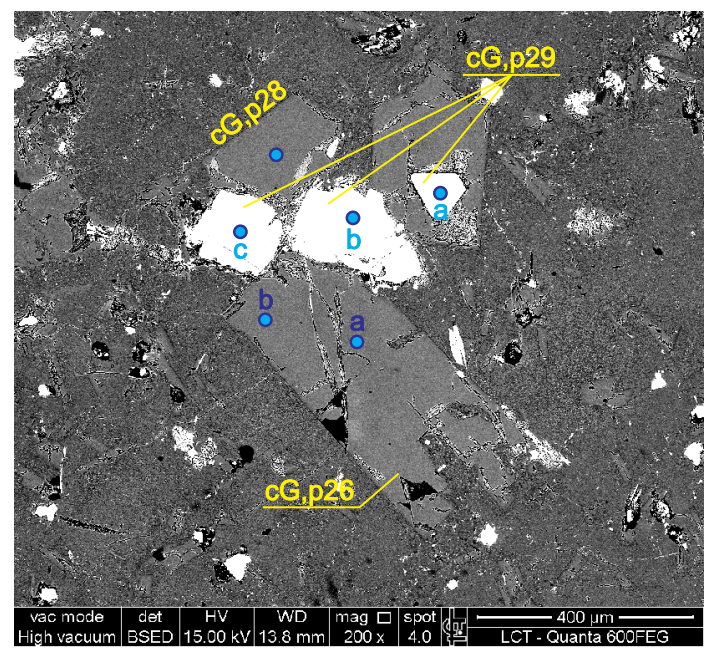

Imagem 01: Cristais de labradorita (cG,p26 e cG,p28), apresentando bordas corroídas (reabsorção) no caso do cristal cG,p26 e cristais subédricos a anédrico de Timagnetita (cG,p29).

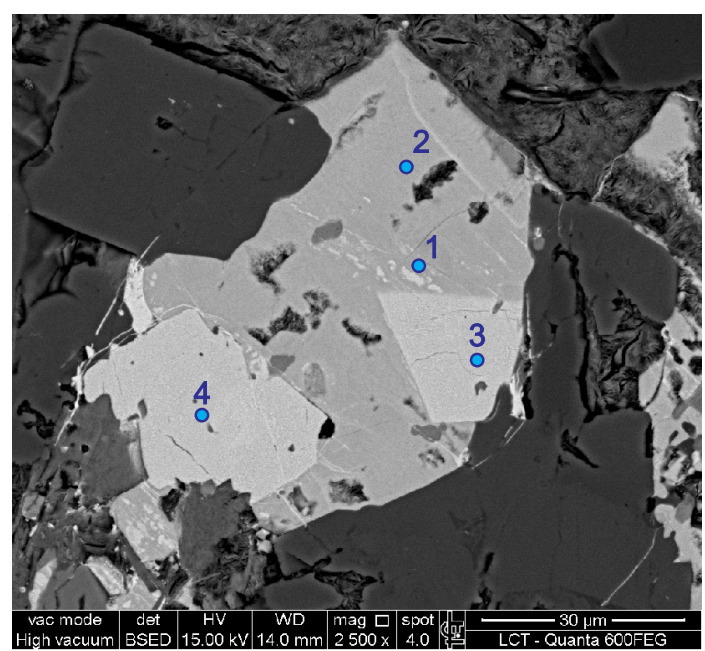

Imagem 03: Cristais subédricos a anédricos de Timagnetita (nomenclatura cA, pA)

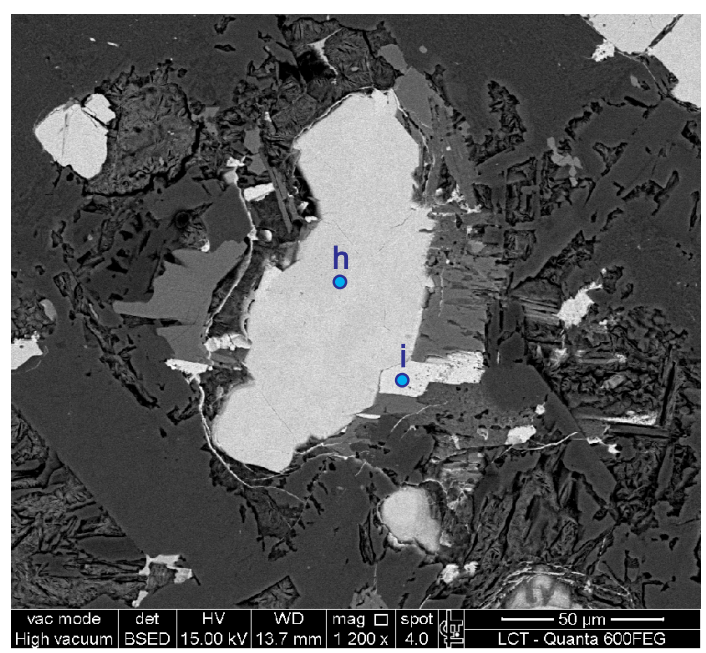

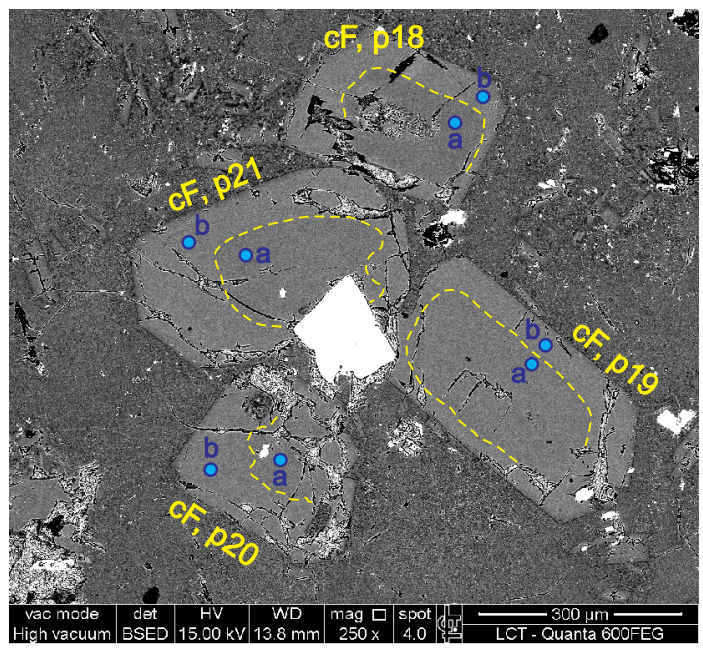

Imagem 02: Cristais de labradorita com zonamento núcleo-borda. Ao centro, cristal subédrico de Ti-magnetita.

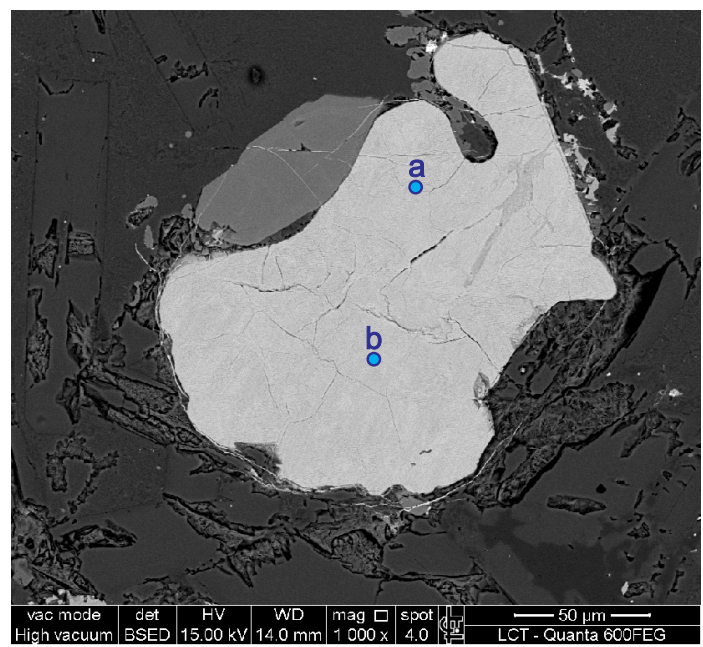

Imagem 04: Cristal anédrico, arredondado e com feições de reabsorção de Ti-magnetita (nomenclatura cA, p3)

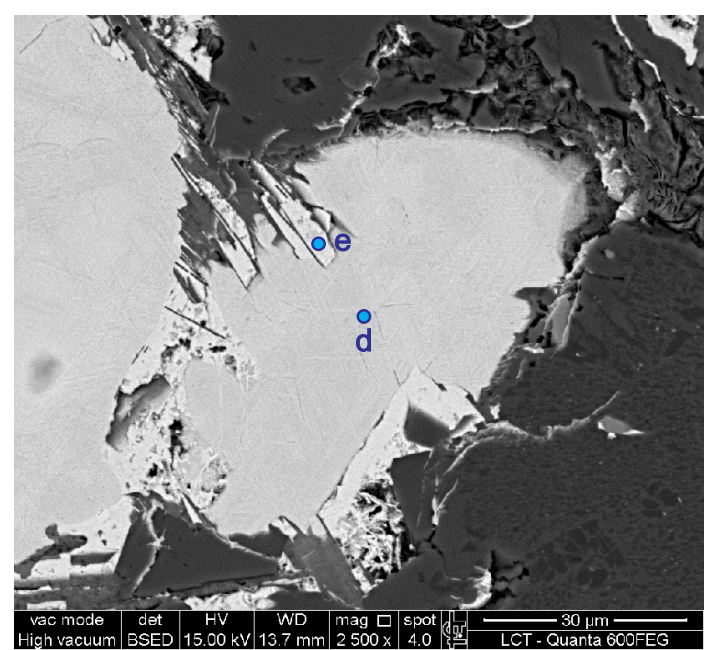

Imagens 05 e 06: Cristais anédricos, com feições de reabsorção, de Ti-magnetita (nomenclatura cE, p16)

A nomenclatura utilizada nas imagens corresponde àquela apresentada nas tabelas onde constam os resultados da análise química mineral (a seguir).

Imagens de MEV

Amostra GX-23 - Localização dos pontos de análise via Microssonda Eletrônica
Dissertação de mestrado Letícia Freitas Guimarães 


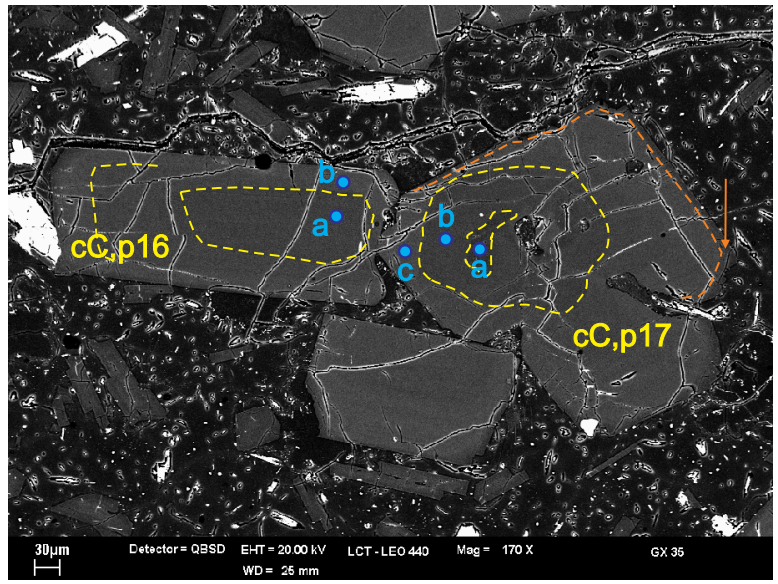

Imagem 07

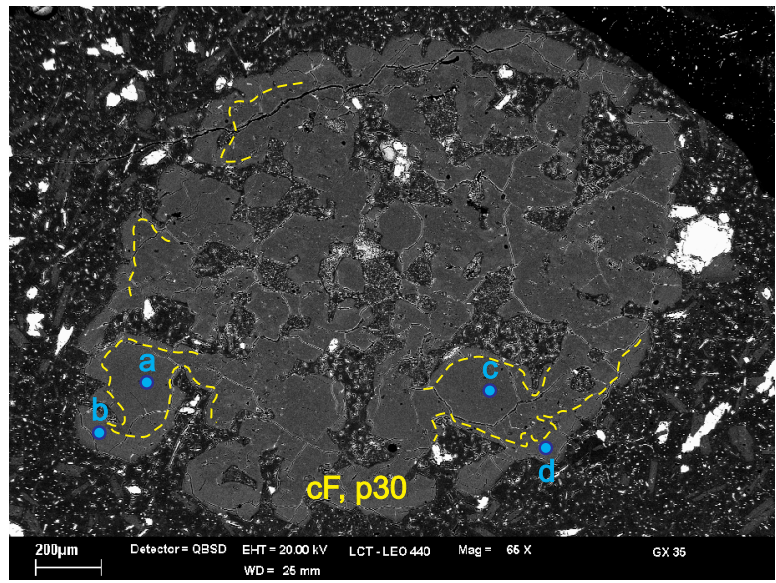

Imagem 09

Images 07 a 09: Cristais de labradorita zonados. Os contornos em amarelo evidenciam o zonamento. A seta alaranjada indica borda formada no estágio final de cristalização (delimitada pela linha alaranjada). Na imagem 09, o plagioclásio apresenta-se com feições de reabsorção.

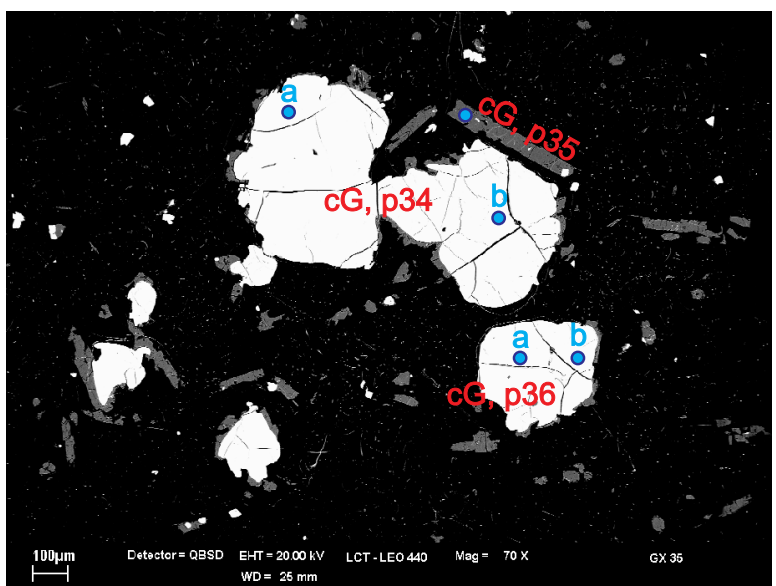

Imagem 11: Cristais anédricos, arredondados, de Ti-magnetita, com bordas de pigeonita. Pigeonita ocorre também como cristais subédricos.

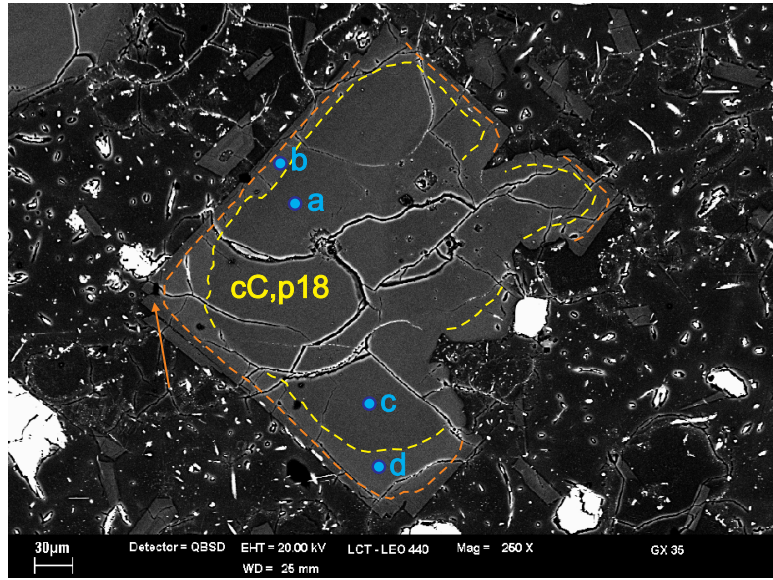

Imagem 08

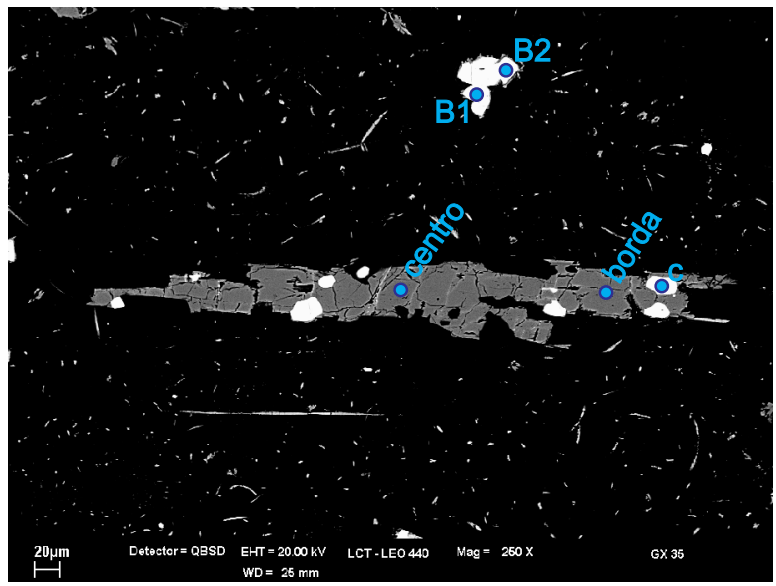

Imagem 10: Cristal de pigeonita (cC, p14), com inclusão de opaco (cC,pC - inc px). Acima, cristais subédricos de Ti-magnetita (cC, pB1; cC, pB2)

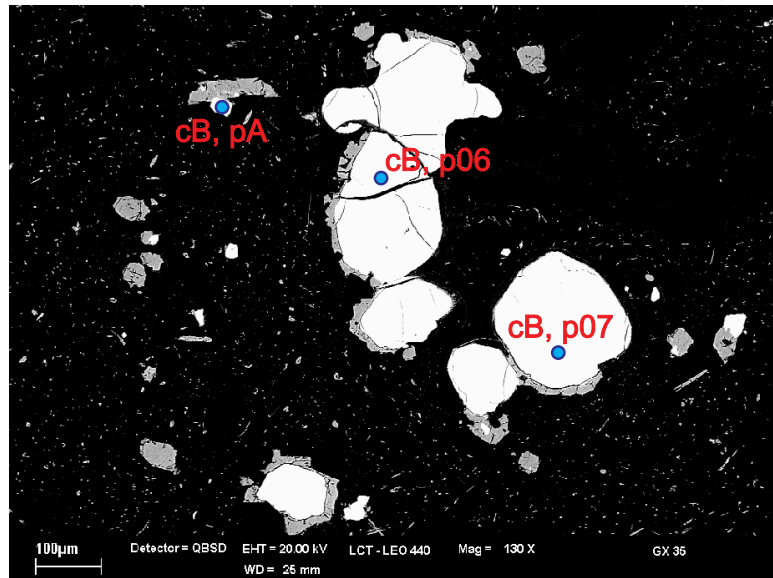

Imagem 12: Minerais anédrios de Ti-magnetita

A nomenclatura utilizada nas imagens corresponde àquela apresentada nas tabelas onde constam os resultados da análise química mineral (a seguir).

Imagens de MEV

Amostra GX-35 - Localização dos pontos de análise via Microssonda Eletrônica
Dissertação de mestrado Letícia Freitas Guimarães 


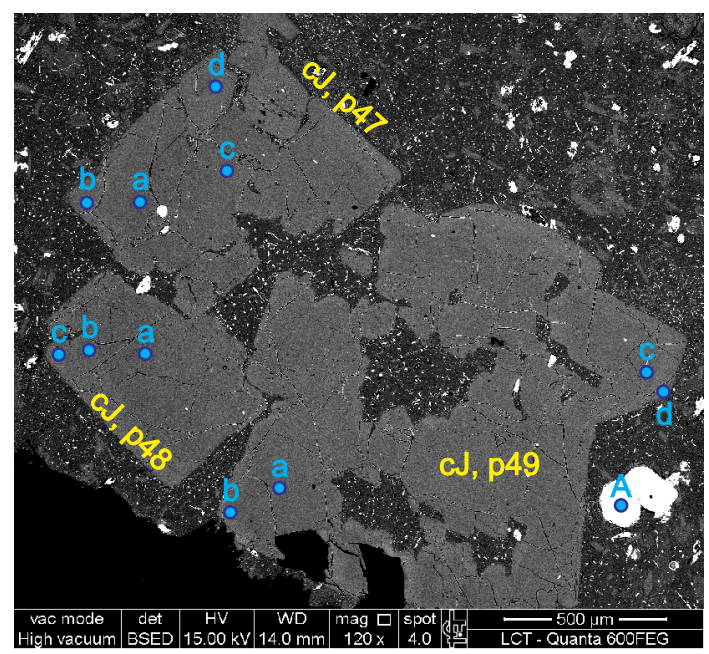

Imagem 13: Microfenocristais de labradorita com zonamento composicional núcleo-borda e feições de reabsorção.

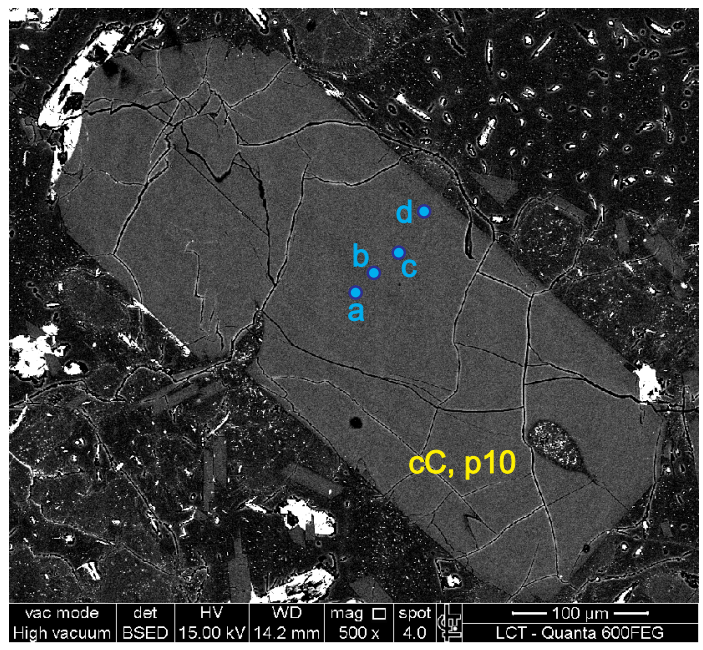

Imagem 14: Microfenocristal de labradorita apresentando zonamento composicional oscilatório e feições de reabsorção.

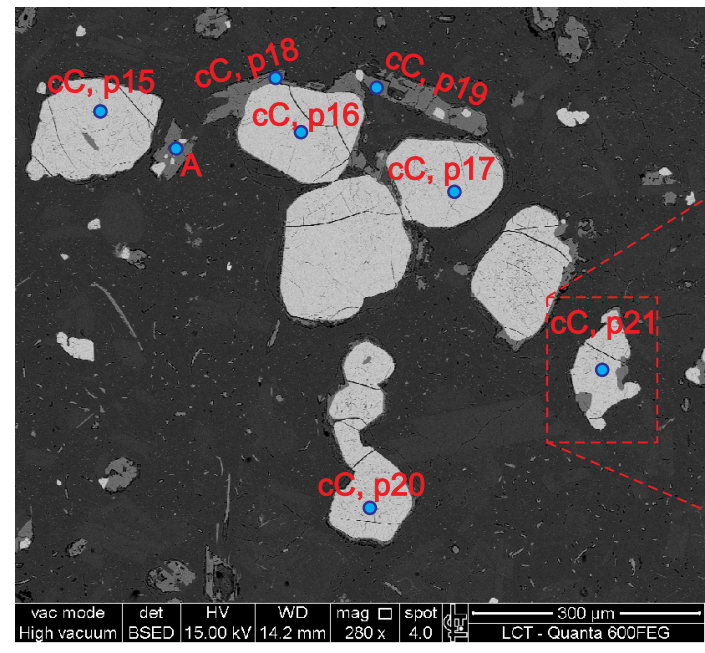

Imagem 15: Cristais anédricos arredondados de Ti-magnetita. Pigeonita ocorre bordeando os minerais opacos, ou como cristais subédricos.

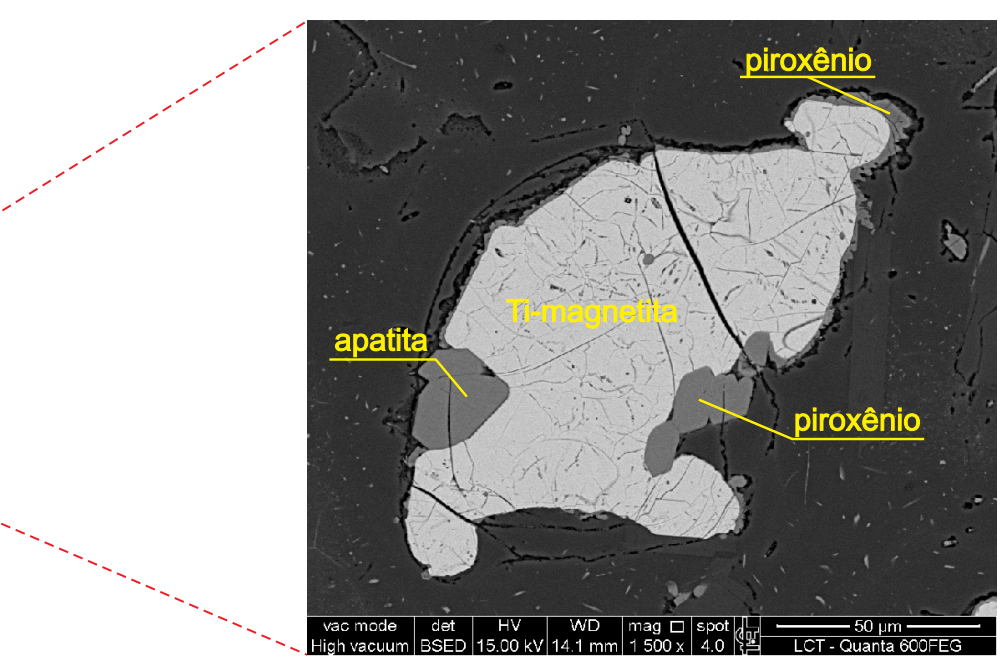

Imagem 16: Cristal anédrico de Timagnetita com borda de piroxênio e apatita.

A nomenclatura utilizada nas imagens corresponde àquela apresentada nas tabelas onde constam os resultados da análise química mineral (a seguir).

Imagens de MEV

Amostra GX-108 - Localização dos pontos de análise via Microssonda Eletrônica
Dissertação de mestrado Letícia Freitas Guimarães 
Análise química (via microssonda eletrônica) dos plagioclásios das rochas vulcânicas ácidas da unidade Santa Maria

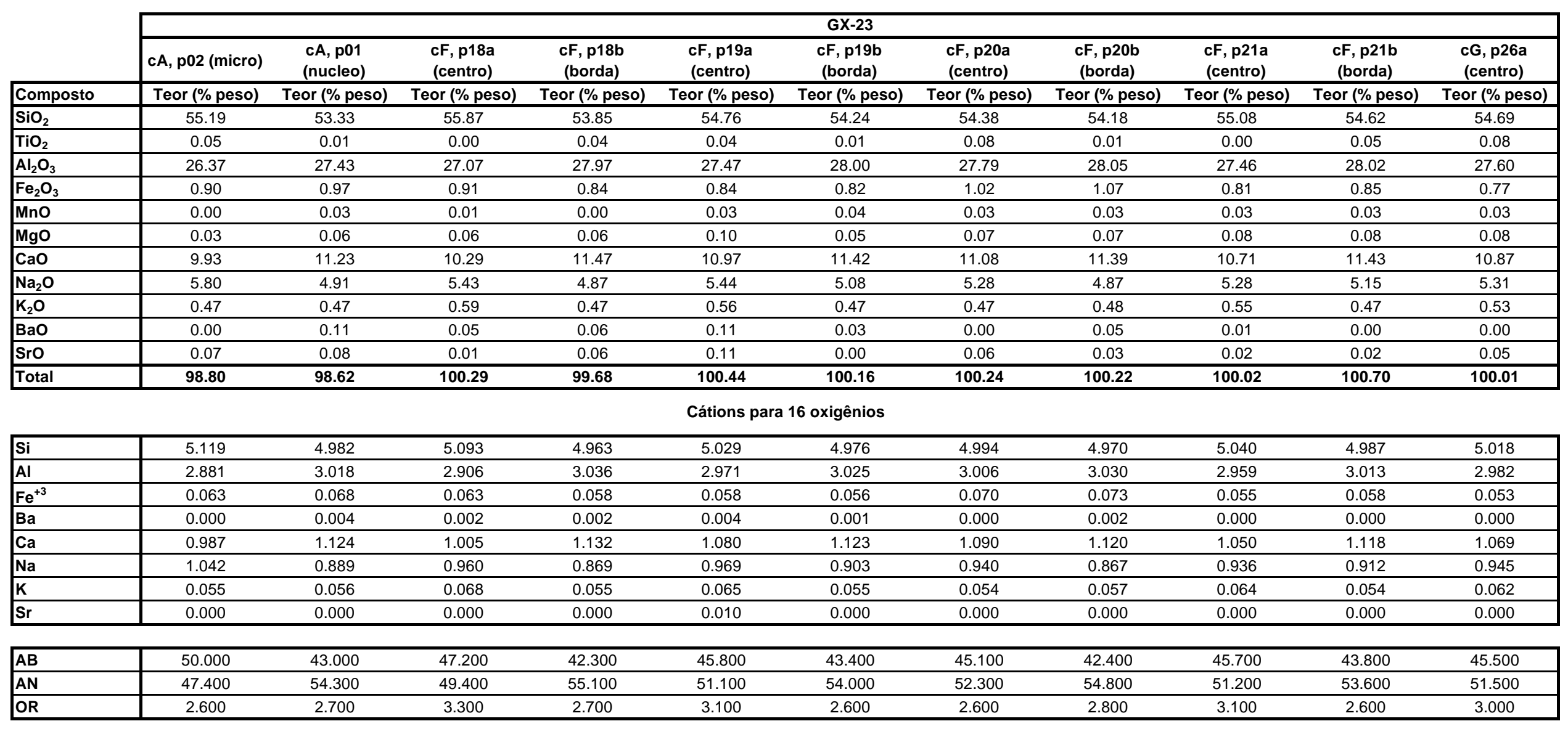


Análise química (via microssonda eletrônica) dos plagioclásios das rochas vulcânicas ácidas da unidade Santa Maria

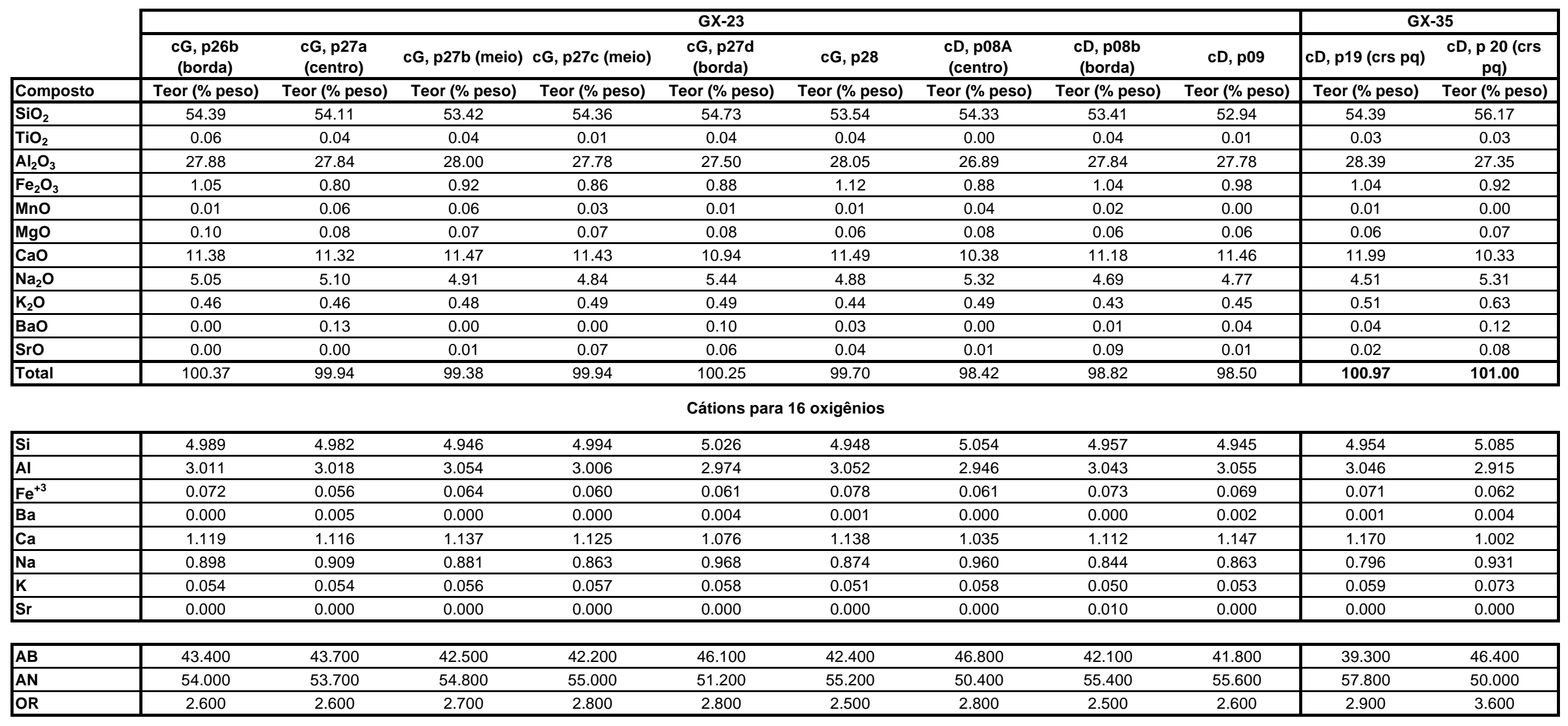


Análise química (via microssonda eletrônica) dos plagioclásios das rochas vulcânicas ácidas da unidade Santa Maria

\begin{tabular}{|c|c|c|c|c|c|c|c|c|c|c|c|}
\hline & \multicolumn{11}{|c|}{ GX-35 } \\
\hline & cD, p19 (crs <) & $\begin{array}{c}\text { cC, p09a } \\
\text { (centro) }\end{array}$ & cC, p09b (meio) & cC, p09c (meio) & $\begin{array}{c}\text { cC, p09d } \\
\text { (borda) }\end{array}$ & $\begin{array}{c}\mathrm{cC}, \mathrm{p} 10 \mathrm{a} \\
\text { (centro) }\end{array}$ & $\begin{array}{c}\text { cC, p10b } \\
\text { (borda) }\end{array}$ & $\begin{array}{c}\text { cD, p16a } \\
\text { (centro) }\end{array}$ & $\begin{array}{c}\text { cD, p16b } \\
\text { (borda) }\end{array}$ & $\begin{array}{c}\text { cD, p17a } \\
\text { (nucleo) }\end{array}$ & cD, p17b (meio) \\
\hline Composto & Teor (\% peso) & Teor (\% peso) & Teor (\% peso) & Teor (\% peso) & Teor (\% peso) & Teor (\% peso) & Teor (\% peso) & Teor (\% peso) & Teor (\% peso) & Teor (\% peso) & Teor (\% peso) \\
\hline $\mathrm{SiO}_{2}$ & 56.06 & 55.67 & 54.27 & 54.26 & 54.48 & 54.46 & 54.41 & 55.30 & 53.63 & 56.98 & 55.12 \\
\hline $\mathrm{TiO}_{2}$ & 0.04 & 0.01 & 0.00 & 0.04 & 0.05 & 0.08 & 0.01 & 0.09 & 0.04 & 0.00 & 0.00 \\
\hline $\mathrm{Al}_{2} \mathrm{O}_{3}$ & 27.23 & 27.80 & 28.32 & 28.54 & 28.14 & 28.35 & 28.25 & 27.51 & 28.65 & 26.45 & 27.59 \\
\hline $\mathrm{Fe}_{2} \mathrm{O}_{3}$ & 1.31 & 0.92 & 0.93 & 1.10 & 0.97 & 1.16 & 0.87 & 0.91 & 0.94 & 0.99 & 1.03 \\
\hline MnO & 0.04 & 0.04 & 0.05 & 0.02 & 0.05 & 0.04 & 0.02 & 0.01 & 0.04 & 0.06 & 0.00 \\
\hline $\mathrm{CaO}$ & 10.34 & 11.04 & 11.78 & 11.91 & 11.38 & 11.69 & 11.59 & 10.68 & 11.67 & 9.58 & 10.79 \\
\hline $\mathrm{Na}_{2} \mathrm{O}$ & 5.76 & 4.93 & 4.77 & 4.57 & 4.96 & 4.65 & 4.75 & 5.10 & 4.61 & 5.63 & 5.22 \\
\hline $\mathrm{K}_{2} \mathrm{O}$ & 0.51 & 0.57 & 0.48 & 0.44 & 0.48 & 0.49 & 0.47 & 0.55 & 0.46 & 0.79 & 0.59 \\
\hline $\mathrm{BaO}$ & 0.04 & 0.05 & 0.07 & 0.00 & 0.05 & 0.12 & 0.05 & 0.00 & 0.08 & 0.00 & 0.14 \\
\hline Sro & 0.02 & 0.04 & 0.05 & 0.00 & 0.06 & 0.07 & 0.02 & 0.07 & 0.02 & 0.05 & 0.06 \\
\hline Total & 101.41 & 101.12 & 100.79 & 100.94 & 100.67 & 101.18 & 100.50 & 100.30 & 100.17 & 100.63 & 100.59 \\
\hline \multicolumn{12}{|c|}{ Cátions para 16 oxigênios } \\
\hline Si & 5.089 & 5.038 & 4.955 & 4.940 & 4.975 & 4.960 & 4.964 & 5.045 & 4.911 & 5.173 & 5.033 \\
\hline $\mathrm{Fe}^{+3}$ & 0.089 & 0.063 & 0.064 & 0.075 & 0.067 & 0.080 & 0.060 & 0.063 & 0.065 & 0.068 & 0.070 \\
\hline $\mathrm{Ba}$ & 0.001 & 0.002 & 0.003 & 0.000 & 0.002 & 0.004 & 0.002 & 0.000 & 0.003 & 0.000 & 0.005 \\
\hline $\mathbf{C a}$ & 1.005 & 1.071 & 1.152 & 1.162 & 1.113 & 1.140 & 1.133 & 1.044 & 1.144 & 0.932 & 1.055 \\
\hline $\mathrm{Na}$ & 1.014 & 0.865 & 0.844 & 0.807 & 0.879 & 0.821 & 0.839 & 0.902 & 0.818 & 0.992 & 0.924 \\
\hline $\mathrm{K}$ & 0.059 & 0.065 & 0.055 & 0.051 & 0.056 & 0.056 & 0.055 & 0.063 & 0.054 & 0.092 & 0.068 \\
\hline $\mathrm{Sr}$ & 0.000 & 0.000 & 0.000 & 0.000 & 0.000 & 0.000 & 0.000 & 0.000 & 0.000 & 0.000 & 0.000 \\
\hline$\overline{A B}$ & 48.800 & 43.200 & 41.200 & 40.000 & 42.900 & 40.700 & 41.400 & 44.900 & 40.600 & 49.200 & 45.100 \\
\hline AN & 48.400 & 53.500 & 56.200 & 57.500 & 54.300 & 56.500 & 55.900 & 52.000 & 56.700 & 46.200 & 51.500 \\
\hline OR & 2.800 & 3.200 & 2.700 & 2.500 & 2.700 & 2.800 & 2.700 & 3.100 & 2.700 & 4.600 & 3.300 \\
\hline
\end{tabular}


Análise química (via microssonda eletrônica) dos plagioclásios das rochas vulcânicas ácidas da unidade Santa Maria

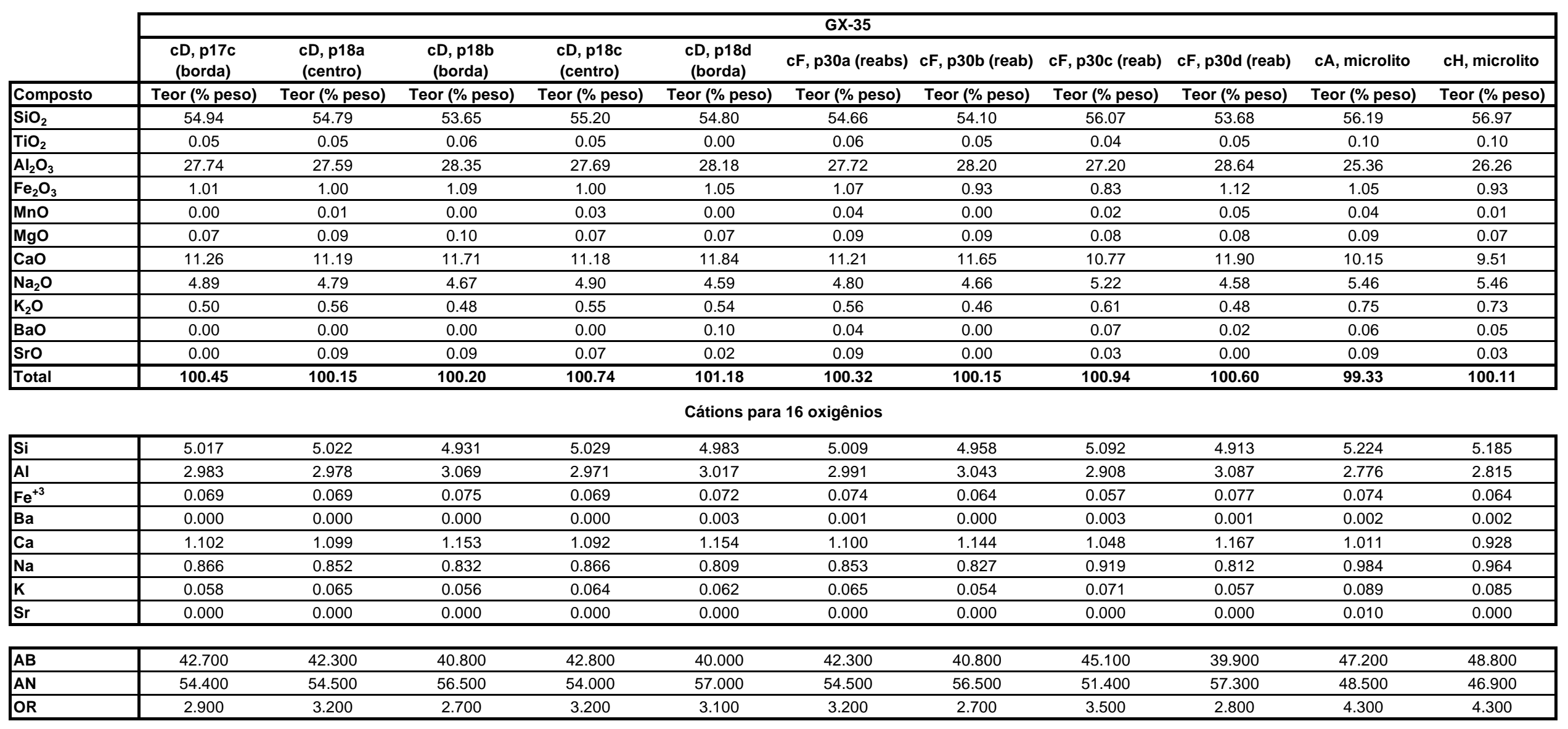


Análise química (via microssonda eletrônica) dos plagioclásios das rochas vulcânicas ácidas da unidade Santa Maria

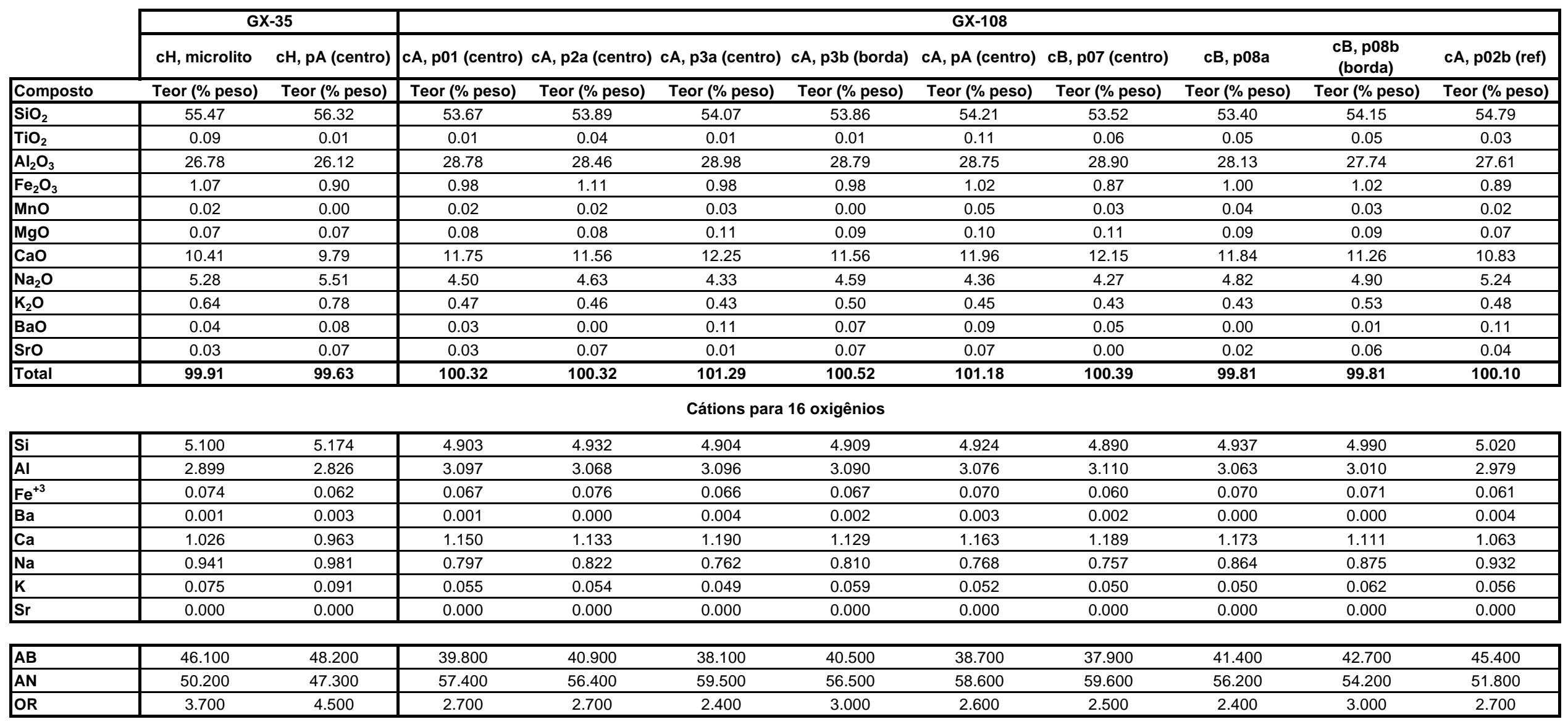


Análise química (via microssonda eletrônica) dos plagioclásios das rochas vulcânicas ácidas da unidade Santa Maria

\begin{tabular}{|c|c|c|c|c|c|c|c|c|c|c|c|}
\hline & \multicolumn{11}{|c|}{ GX-108 } \\
\hline & $\begin{array}{c}\text { cA, p02b } \\
\text { (centro) }\end{array}$ & $\begin{array}{c}\text { cC, p10a } \\
\text { (centro) }\end{array}$ & cC, p10b (meio) & cC, p10c (meio) & $\begin{array}{c}\text { cC, p10d } \\
(\text { borda) }\end{array}$ & cC, p12 (micro) & cC (ext), p23 & $c D, p 33$ & $\begin{array}{c}\text { cE, p34a } \\
\text { (borda) }\end{array}$ & $\begin{array}{c}\text { cE, p34b } \\
\text { (centro) }\end{array}$ & $\begin{array}{c}\text { cE, p34c } \\
\text { (borda) }\end{array}$ \\
\hline Composto & Teor (\% peso) & Teor (\% peso) & Teor (\% peso) & Teor (\% peso) & Teor (\% peso) & Teor (\% peso) & Teor (\% peso) & Teor (\% peso) & Teor (\% peso) & Teor (\% peso) & Teor (\% peso) \\
\hline $\mathrm{SiO}_{2}$ & 54.04 & 53.27 & 53.08 & 53.72 & 54.35 & 56.03 & 54.23 & 55.93 & 53.01 & 56.92 & 53.88 \\
\hline $\mathrm{TiO}_{2}$ & 0.07 & 0.02 & 0.03 & 0.04 & 0.04 & 0.07 & 0.01 & 0.05 & 0.07 & 0.03 & 0.07 \\
\hline $\mathrm{Al}_{2} \mathrm{O}_{3}$ & 27.51 & 28.08 & 28.10 & 28.09 & 27.57 & 26.68 & 27.70 & 26.49 & 28.45 & 26.29 & 27.83 \\
\hline $\mathrm{Fe}_{2} \mathrm{O}_{3}$ & 1.04 & 1.05 & 0.95 & 1.14 & 1.05 & 0.91 & 1.05 & 1.14 & 0.89 & 1.01 & 0.97 \\
\hline MnO & 0.00 & 0.00 & 0.02 & 0.01 & 0.01 & 0.02 & 0.00 & 0.00 & 0.03 & 0.00 & 0.02 \\
\hline $\mathrm{CaO}$ & 11.21 & 11.92 & 11.94 & 11.76 & 11.14 & 10.10 & 11.30 & 10.11 & 12.07 & 9.65 & 11.31 \\
\hline $\mathrm{Na}_{2} \mathrm{O}$ & 5.13 & 4.53 & 4.57 & 4.54 & 5.01 & 5.64 & 4.99 & 5.63 & 4.57 & 5.75 & 5.15 \\
\hline $\mathrm{K}_{2} \mathrm{O}$ & 0.60 & 0.46 & 0.46 & 0.44 & 0.56 & 0.65 & 0.52 & 0.71 & 0.48 & 0.78 & 0.49 \\
\hline $\mathrm{BaO}$ & 0.10 & 0.00 & 0.00 & 0.00 & 0.09 & 0.00 & 0.04 & 0.00 & 0.00 & 0.00 & 0.01 \\
\hline SrO & 0.03 & 0.09 & 0.03 & 0.16 & 0.05 & 0.09 & 0.04 & 0.08 & 0.07 & 0.03 & 0.04 \\
\hline Total & 99.78 & 99.51 & 99.26 & 99.97 & 99.93 & 100.25 & 99.95 & 100.29 & 99.72 & 100.54 & 99.86 \\
\hline \multicolumn{12}{|c|}{ Cátions para 16 oxigênios } \\
\hline Si & 5.001 & 4.936 & 4.928 & 4.951 & 5.008 & 5.126 & 4.995 & 5.136 & 4.902 & 5.181 & 4.974 \\
\hline $\mathrm{Fe}^{+3}$ & 0.073 & 0.073 & 0.066 & 0.079 & 0.073 & 0.063 & 0.072 & 0.079 & 0.062 & 0.069 & 0.068 \\
\hline $\mathrm{Ba}$ & 0.003 & 0.000 & 0.000 & 0.000 & 0.003 & 0.000 & 0.001 & 0.000 & 0.000 & 0.000 & 0.000 \\
\hline $\mathrm{Ca}$ & 1.112 & 1.184 & 1.188 & 1.161 & 1.100 & 0.990 & 1.115 & 0.995 & 1.196 & 0.942 & 1.119 \\
\hline $\mathrm{Na}$ & 0.920 & 0.814 & 0.822 & 0.811 & 0.895 & 1.000 & 0.891 & 1.002 & 0.819 & 1.014 & 0.921 \\
\hline $\mathrm{K}$ & 0.071 & 0.055 & 0.055 & 0.052 & 0.066 & 0.076 & 0.061 & 0.084 & 0.057 & 0.091 & 0.058 \\
\hline $\mathrm{Sr}$ & 0.000 & 0.000 & 0.000 & 0.010 & 0.000 & 0.000 & 0.000 & 0.000 & 0.000 & 0.000 & 0.000 \\
\hline$A B$ & 43.700 & 39.600 & 39.800 & 40.100 & 43.400 & 48.400 & 43.100 & 48.100 & 39.500 & 49.500 & 43.900 \\
\hline AN & 52.900 & 57.700 & 57.500 & 57.400 & 53.400 & 47.900 & 53.900 & 47.800 & 57.700 & 46.000 & 53.300 \\
\hline OR & 3.400 & 2.700 & 2.700 & 2.600 & 3.200 & 3.700 & 3.000 & 4.000 & 2.800 & 4.400 & 2.800 \\
\hline
\end{tabular}


Análise química (via microssonda eletrônica) dos plagioclásios das rochas vulcânicas ácidas da unidade Santa Maria

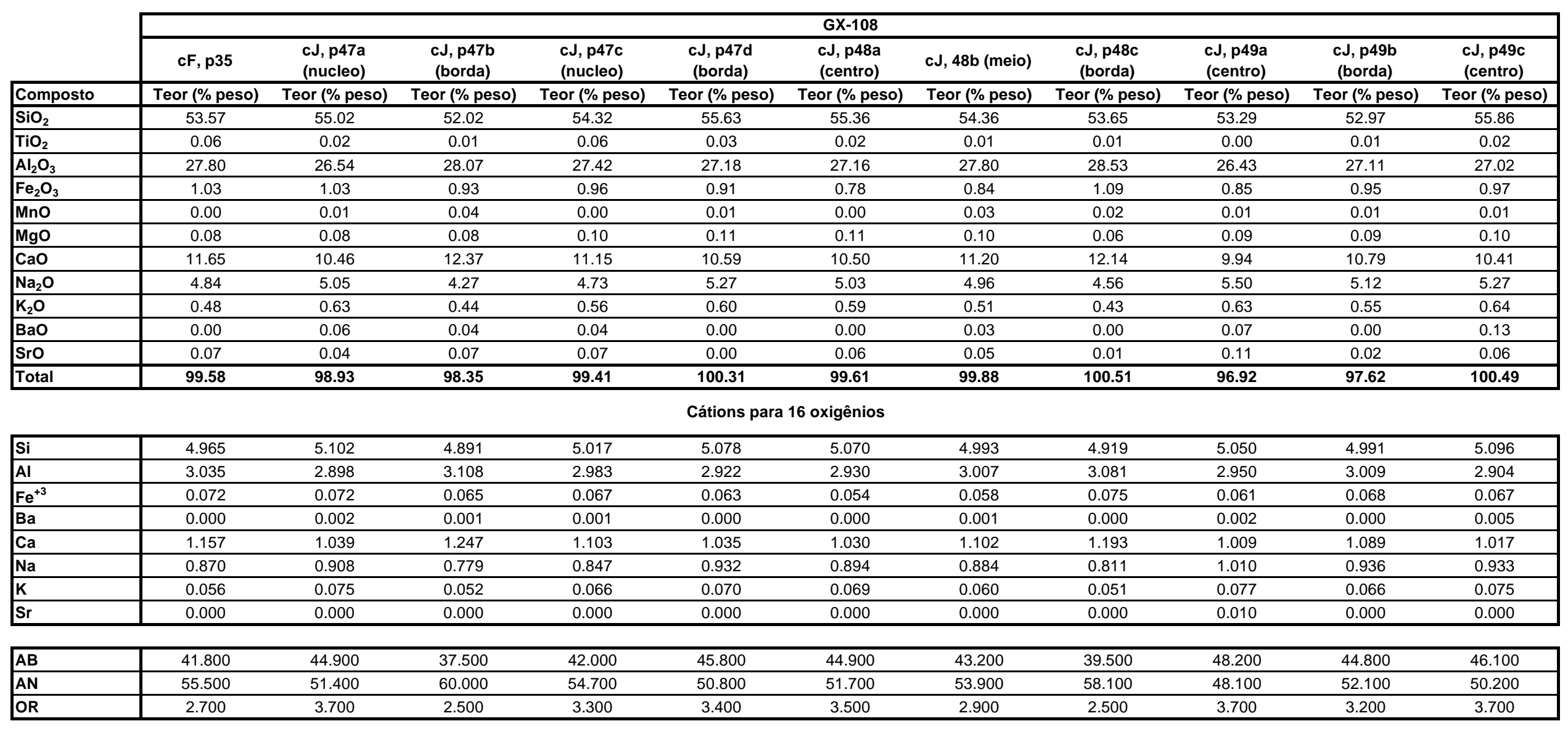


Análise química (via microssonda eletrônica) dos plagioclásios das rochas vulcânicas ácidas da unidade Santa Maria

\begin{tabular}{|c|c|c|c|c|}
\hline & \multicolumn{4}{|c|}{ GX-108 } \\
\hline & $\begin{array}{l}\text { cJ, p49d } \\
\text { (borda) }\end{array}$ & $\begin{array}{l}\text { cJ, p49e } \\
\text { (centro) }\end{array}$ & cH, p42 (micro) & cJ, p50 (micro) \\
\hline Composto & Teor (\% peso) & Teor (\% peso) & Teor (\% peso) & Teor (\% peso) \\
\hline $\mathrm{SiO}_{2}$ & 55.08 & 55.51 & 55.12 & 55.74 \\
\hline $\mathrm{TiO}_{2}$ & 0.02 & 0.02 & 0.09 & 0.03 \\
\hline $\mathrm{Al}_{2} \mathrm{O}_{3}$ & 27.67 & 27.14 & 26.97 & 27.00 \\
\hline $\mathrm{Fe}_{2} \mathrm{O}_{3}$ & 0.97 & 1.05 & 0.69 & 0.93 \\
\hline MnO & 0.00 & 0.03 & 0.01 & 0.00 \\
\hline MgO & 0.10 & 0.10 & 0.09 & 0.05 \\
\hline $\mathrm{CaO}$ & 11.08 & 10.90 & 10.38 & 10.23 \\
\hline $\mathrm{Na}_{2} \mathrm{O}$ & 4.95 & 5.01 & 5.20 & 5.33 \\
\hline $\mathrm{K}_{2} \mathrm{O}$ & 0.54 & 0.62 & 0.60 & 0.54 \\
\hline $\mathrm{BaO}$ & 0.08 & 0.01 & 0.03 & 0.00 \\
\hline SrO & 0.08 & 0.06 & 0.04 & 0.01 \\
\hline Total & 100.57 & 100.45 & 99.23 & 99.86 \\
\hline
\end{tabular}

Cátions para 16 oxigênios

\begin{tabular}{|l|llll|}
\hline $\mathbf{S i}$ & 5.026 & 5.077 & 5.075 & 5.094 \\
\hline $\mathbf{A l}$ & 2.974 & 2.923 & 2.925 & 2.906 \\
\hline $\mathrm{Fe}^{+3}$ & 0.067 & 0.072 & 0.048 & 0.064 \\
\hline $\mathrm{Ba}$ & 0.003 & 0.000 & 0.001 & 0.000 \\
\hline $\mathrm{Ca}$ & 1.083 & 1.069 & 1.024 & 1.002 \\
\hline $\mathrm{Na}$ & 0.876 & 0.889 & 0.928 & 0.945 \\
\hline $\mathrm{K}$ & 0.063 & 0.072 & 0.071 & 0.063 \\
\hline $\mathrm{Sr}$ & 0.000 & 0.000 & 0.000 & 0.000 \\
\hline
\end{tabular}

\begin{tabular}{|l|cccc|}
\hline AB & 43.300 & 43.800 & 45.900 & 47.000 \\
\hline AN & 53.600 & 52.700 & 50.600 & 49.900 \\
\hline OR & 3.100 & 3.500 & 3.500 & 3.100 \\
\hline
\end{tabular}


Análise química (via microssonda eletrônica) dos piroxênios das rochas vulcânicas ácidas da unidade Santa Maria

\begin{tabular}{|c|c|c|c|c|c|c|c|c|c|c|c|}
\hline & \multirow{2}{*}{$\begin{array}{c}\mathrm{GX}-23 \\
\mathrm{cB}, \mathrm{p} 05\end{array}$} & \multicolumn{10}{|c|}{ GX-35 } \\
\hline & & cF, p31 & cC, p14 (centro) & cC, p14 (borda) & $\mathrm{cC}, \mathrm{pA}$ & $\mathrm{cC}, \mathrm{pB}$ & cB, p08 (prox) & cA, p03 (prox) & cA, p22 (prox) & $\mathrm{cH}, \mathrm{p} 46$ (prox) & cX, prox borda \\
\hline Composto & Teor (\% peso) & Teor (\% peso) & Teor (\% peso) & Teor (\% peso) & Teor (\% peso) & Teor (\% peso) & Teor (\% peso) & Teor (\% peso) & Teor (\% peso) & Teor (\% peso) & Teor (\% peso) \\
\hline $\mathrm{SiO}_{2}$ & 50.250 & 51.086 & 50.346 & 50.999 & 50.633 & 49.832 & 51.113 & 50.457 & 50.437 & 50.385 & 50.431 \\
\hline $\mathrm{TiO}_{2}$ & 0.242 & 0.341 & 0.357 & 0.391 & 0.263 & 0.332 & 0.294 & 0.353 & 0.301 & 0.259 & 0.327 \\
\hline $\mathrm{Al}_{2} \mathrm{O}_{3}$ & 0.705 & 0.673 & 0.991 & 0.787 & 0.772 & 0.768 & 0.608 & 0.678 & 0.663 & 0.650 & 0.705 \\
\hline $\mathrm{FeO}$ & 29.998 & 29.121 & 29.162 & 28.986 & 29.166 & 28.888 & 29.313 & 29.135 & 30.704 & 29.737 & 29.990 \\
\hline $\mathrm{MnO}$ & 1.362 & 1.312 & 1.304 & 1.302 & 1.345 & 1.261 & 1.354 & 1.232 & 1.359 & 1.356 & 1.359 \\
\hline MgO & 14.364 & 13.666 & 13.817 & 13.686 & 14.432 & 13.006 & 13.891 & 13.513 & 13.982 & 14.053 & 13.695 \\
\hline $\mathrm{CaO}$ & 4.190 & 4.300 & 3.943 & 3.884 & 3.114 & 4.821 & 3.692 & 3.878 & 3.332 & 3.815 & 3.489 \\
\hline $\mathrm{Na}_{2} \mathrm{O}$ & 0.032 & 0.049 & 0.049 & 0.048 & 0.057 & 0.067 & 0.036 & 0.036 & 0.066 & 0.097 & 0.013 \\
\hline $\mathrm{K}_{2} \mathrm{O}$ & 0.016 & 0.019 & 0.019 & 0.017 & 0.021 & 0.045 & 0.029 & 0.020 & 0.012 & 0.012 & 0.010 \\
\hline $\mathrm{Cr}_{2} \mathrm{O}_{3}$ & 0.002 & 0.000 & 0.000 & 0.000 & 0.007 & 0.019 & 0.000 & 0.005 & 0.008 & 0.000 & 0.000 \\
\hline Total & 101.161 & 100.567 & 99.986 & 100.100 & 99.810 & 99.038 & 100.329 & 99.307 & 100.865 & 100.364 & 100.019 \\
\hline
\end{tabular}

\begin{tabular}{|c|c|c|c|c|c|c|c|c|c|c|c|}
\hline Si & 1.942 & 1.990 & 1.970 & 1.995 & 1.980 & 1.974 & 1.995 & 1.992 & 1.962 & 1.964 & 1.979 \\
\hline $\mathrm{Al}^{\mathrm{IV}}$ & 0.032 & 0.010 & 0.030 & 0.005 & 0.020 & 0.026 & 0.005 & 0.008 & 0.030 & 0.030 & 0.021 \\
\hline $\mathrm{Fe}^{+3}$ & 0.026 & 0.000 & 0.000 & 0.000 & 0.000 & 0.000 & 0.000 & 0.000 & 0.008 & 0.006 & 0.000 \\
\hline$A I^{N}$ & 0.000 & 0.021 & 0.016 & 0.031 & 0.016 & 0.010 & 0.023 & 0.023 & 0.000 & 0.000 & 0.012 \\
\hline $\mathrm{Ti}$ & 0.007 & 0.010 & 0.011 & 0.012 & 0.008 & 0.010 & 0.009 & 0.010 & 0.009 & 0.008 & 0.010 \\
\hline $\mathrm{Fe}^{+3}$ & 0.047 & 0.000 & 0.000 & 0.000 & 0.000 & 0.003 & 0.000 & 0.000 & 0.026 & 0.028 & 0.000 \\
\hline $\mathrm{Fe}^{+2}$ & 0.119 & 0.176 & 0.168 & 0.159 & 0.134 & 0.209 & 0.160 & 0.171 & 0.154 & 0.147 & 0.178 \\
\hline $\mathrm{Cr}$ & 0.000 & 0.000 & 0.000 & 0.000 & 0.000 & 0.001 & 0.000 & 0.000 & 0.000 & 0.000 & 0.000 \\
\hline $\mathrm{Mg}$ & 0.828 & 0.793 & 0.806 & 0.798 & 0.842 & 0.768 & 0.808 & 0.795 & 0.811 & 0.817 & 0.801 \\
\hline $\mathrm{Mg}$ & 0.000 & 0.000 & 0.000 & 0.000 & 0.000 & 0.000 & 0.000 & 0.000 & 0.000 & 0.000 & 0.000 \\
\hline $\mathrm{Fe}^{+2}$ & 0.779 & 0.773 & 0.787 & 0.790 & 0.820 & 0.746 & 0.797 & 0.791 & 0.811 & 0.788 & 0.807 \\
\hline Mn & 0.045 & 0.043 & 0.043 & 0.043 & 0.045 & 0.042 & 0.045 & 0.041 & 0.045 & 0.045 & 0.045 \\
\hline $\mathrm{Ca}$ & 0.174 & 0.179 & 0.165 & 0.163 & 0.131 & 0.205 & 0.154 & 0.164 & 0.139 & 0.159 & 0.147 \\
\hline $\mathrm{Na}$ & 0.002 & 0.004 & 0.004 & 0.004 & 0.004 & 0.005 & 0.003 & 0.003 & 0.005 & 0.007 & 0.001 \\
\hline $\mathrm{K}$ & 0.001 & 0.001 & 0.001 & 0.001 & 0.001 & 0.002 & 0.001 & 0.001 & 0.001 & 0.001 & 0.001 \\
\hline Wo & 8.609 & 9.133 & 8.396 & 8.338 & 6.622 & 10.376 & 7.860 & 8.359 & 6.967 & 8.006 & 7.419 \\
\hline EN & 41.066 & 40.386 & 40.938 & 40.881 & 42.703 & 38.948 & 41.149 & 40.526 & 40.677 & 41.034 & 40.519 \\
\hline FS & 50.324 & 50.481 & 50.666 & 50.781 & 50.674 & 50.676 & 50.991 & 51.116 & 52.356 & 50.960 & 52.061 \\
\hline WEF & 99.754 & 99.625 & 99.624 & 99.628 & 99.563 & 99.480 & 99.723 & 99.720 & 99.495 & 99.256 & 99.900 \\
\hline JD & 0.000 & 0.375 & 0.376 & 0.372 & 0.437 & 0.405 & 0.277 & 0.280 & 0.000 & 0.000 & 0.100 \\
\hline $\mathrm{AE}$ & 0.246 & 0.000 & 0.000 & 0.000 & 0.000 & 0.115 & 0.000 & 0.000 & 0.505 & 0.744 & 0.000 \\
\hline
\end{tabular}


Análise química (via microssonda eletrônica) dos piroxênios das rochas vulcânicas ácidas da unidade Santa Maria

\begin{tabular}{|c|c|c|c|c|c|c|c|c|c|c|c|}
\hline & \multicolumn{3}{|c|}{ GX-35 } & \multicolumn{8}{|c|}{$\begin{array}{l}\text { GX-108 } \\
\end{array}$} \\
\hline & cE, p26 (prox) & cG, p37 (prox) & cG, p38 & cB, p09 (prox) & cC, p11 (prox) & cC, p18 & $c C, p 19$ & $c G, p A$ & $\mathrm{cl}, \mathrm{p} 45$ & cD, p26 (prox) & cJ, prox borda \\
\hline Composto & Teor (\% peso) & Teor (\% peso) & Teor (\% peso) & Teor (\% peso) & Teor (\% peso) & Teor (\% peso) & Teor (\% peso) & Teor (\% peso) & Teor (\% peso) & Teor (\% peso) & Teor (\% peso) \\
\hline $\mathrm{SiO}_{2}$ & 49.572 & 50.677 & 51.001 & 51.629 & 50.541 & 51.213 & 51.030 & 52.385 & 50.380 & 50.896 & 50.196 \\
\hline $\mathrm{TiO}_{2}$ & 0.234 & 0.242 & 0.208 & 0.132 & 0.302 & 0.405 & 0.303 & 0.222 & 0.383 & 0.252 & 0.213 \\
\hline $\mathrm{Al}_{2} \mathrm{O}_{3}$ & 0.758 & 0.676 & 0.657 & 0.722 & $1,078.000$ & 0.677 & 0.717 & 0.880 & 0.878 & 0.713 & 0.709 \\
\hline $\mathrm{FeO}$ & 29.968 & 31.179 & 30.015 & 27.418 & 27.759 & 28.361 & 27.598 & 26.821 & 28.548 & 27.299 & 27.062 \\
\hline MnO & 1.260 & 1.345 & 1.351 & 1.207 & 1.294 & 1.245 & 1.253 & 1.111 & 1.276 & 1.096 & 1.155 \\
\hline $\mathrm{MgO}$ & 13.251 & 13.510 & 14.295 & 16.502 & 14.550 & 14.581 & 16.423 & 14.241 & 15.498 & 17.909 & 17.029 \\
\hline $\mathrm{CaO}$ & 5.091 & 4.056 & 3.401 & 3.187 & 3.235 & 4.523 & 3.164 & 3.167 & 3.923 & 3.054 & 3.330 \\
\hline $\mathrm{Na}_{2} \mathrm{O}$ & 0.022 & 0.113 & 0.078 & 0.042 & 0.039 & 0.082 & 0.034 & 0.094 & 0.066 & 0.078 & 0.056 \\
\hline $\mathrm{K}_{2} \mathrm{O}$ & 0.022 & 0.018 & 0.022 & 0.019 & 0.219 & 0.012 & 0.016 & 0.066 & 0.009 & 0.040 & 0.014 \\
\hline $\mathrm{Cr}_{2} \mathrm{O}_{3}$ & 0.000 & 0.005 & 0.028 & 0.012 & 0.000 & 0.000 & 0.000 & 0.044 & 0.000 & 0.000 & 0.013 \\
\hline Total & 100.179 & 101.821 & 101.055 & 100.870 & 99.017 & 101.099 & 100.538 & 99.031 & 100.961 & 101.338 & 99.778 \\
\hline \multicolumn{12}{|c|}{ Cátions para 6 oxigênios } \\
\hline$\widehat{S i}$ & 1.943 & 1.957 & 1.974 & 1.973 & 1.985 & 1.973 & 1.959 & 2.057 & 1.936 & 1.923 & 1.933 \\
\hline$A I^{I^{N}}$ & 0.035 & 0.031 & 0.026 & 0.027 & 0.015 & 0.027 & 0.032 & 0.000 & 0.040 & 0.032 & 0.032 \\
\hline $\mathrm{Fe}^{+3}$ & 0.022 & 0.013 & 0.000 & 0.000 & 0.000 & 0.000 & 0.009 & 0.000 & 0.025 & 0.045 & 0.035 \\
\hline$A I^{N^{N}}$ & 0.000 & 0.000 & 0.004 & 0.006 & 0.035 & 0.003 & 0.000 & 0.041 & 0.000 & 0.000 & 0.000 \\
\hline $\mathrm{Ti}$ & 0.007 & 0.007 & 0.006 & 0.004 & 0.009 & 0.012 & 0.009 & 0.007 & 0.011 & 0.007 & 0.006 \\
\hline $\mathrm{Fe}^{+3}$ & 0.046 & 0.038 & 0.015 & 0.017 & 0.000 & 0.007 & 0.027 & 0.000 & 0.047 & 0.070 & 0.059 \\
\hline $\mathrm{Fe}^{+2}$ & 0.173 & 0.177 & 0.149 & 0.033 & 0.105 & 0.141 & 0.025 & 0.118 & 0.054 & 0.000 & 0.000 \\
\hline $\mathrm{Cr}$ & 0.000 & 0.000 & 0.001 & 0.000 & 0.000 & 0.000 & 0.000 & 0.001 & 0.000 & 0.000 & 0.000 \\
\hline $\mathrm{Mg}$ & 0.774 & 0.778 & 0.825 & 0.940 & 0.852 & 0.837 & 0.940 & 0.833 & 0.888 & 0.923 & 0.934 \\
\hline $\mathrm{Mg}$ & 0.000 & 0.000 & 0.000 & 0.000 & 0.000 & 0.000 & 0.000 & 0.000 & 0.000 & 0.086 & 0.043 \\
\hline $\mathrm{Fe}^{+2}$ & 0.742 & 0.779 & 0.808 & 0.826 & 0.807 & 0.766 & 0.826 & 0.763 & 0.792 & 0.748 & 0.777 \\
\hline Mn & 0.042 & 0.044 & 0.044 & 0.039 & 0.043 & 0.041 & 0.041 & 0.037 & 0.042 & 0.035 & 0.038 \\
\hline $\mathrm{Ca}$ & 0.214 & 0.168 & 0.141 & 0.131 & 0.136 & 0.187 & 0.130 & 0.133 & 0.161 & 0.124 & 0.137 \\
\hline $\mathrm{Na}$ & 0.002 & 0.008 & 0.006 & 0.003 & 0.003 & 0.006 & 0.003 & 0.007 & 0.005 & 0.006 & 0.004 \\
\hline $\mathrm{K}$ & 0.001 & 0.001 & 0.001 & 0.001 & 0.011 & 0.001 & 0.001 & 0.003 & 0.000 & 0.002 & 0.001 \\
\hline Wo & 10.625 & 8.406 & 7.117 & 6.571 & 7.007 & 9.436 & 6.517 & 7.070 & 8.042 & 6.090 & 6.788 \\
\hline EN & 38.479 & 38.956 & 41.622 & 47.339 & 43.848 & 42.326 & 47.070 & 44.234 & 44.207 & 49.691 & 48.296 \\
\hline $\begin{array}{l}\text { FS } \\
\end{array}$ & 50.897 & 52.638 & 51.261 & 46.090 & 49.145 & 48.238 & 46.413 & 48.696 & 47.750 & 44.219 & 44.917 \\
\hline WEF & 99.828 & 99.138 & 99.408 & 99.685 & 99.695 & 99.382 & 99.743 & 99.246 & 99.495 & 99.407 & 99.568 \\
\hline JD & 0.000 & 0.000 & 0.126 & 0.079 & 0.305 & 0.199 & 0.000 & 0.754 & 0.000 & 0.000 & 0.000 \\
\hline $\mathrm{AE}$ & 0.172 & 0.862 & 0.466 & 0.237 & 0.000 & 0.418 & 0.257 & 0.000 & 0.505 & 0.593 & 0.432 \\
\hline
\end{tabular}


Análise química (via microssonda eletrônica) dos óxidos de Fe e Ti das rochas vulcânicas ácidas da unidade Santa Maria

\begin{tabular}{|c|c|c|c|c|c|c|c|c|c|c|c|}
\hline & \multicolumn{11}{|c|}{ GX-23 } \\
\hline & cA, pA1 & $\mathrm{cA}, \mathrm{pA} 3$ & cA, p3a & cA, p3b & cD, p12 & cE, p16a & cE, p16b & cE, p16c & cE, p16d & cE, p16e & cE, p16f \\
\hline Composto & Teor (\% peso) & Teor (\% peso) & Teor (\% peso) & Teor (\% peso) & Teor (\% peso) & Teor (\% peso) & Teor (\% peso) & Teor (\% peso) & Teor (\% peso) & Teor (\% peso) & Teor (\% peso) \\
\hline $\mathrm{SiO}_{2}$ & 0.09 & 0.11 & 0.16 & 0.14 & 0.18 & 0.13 & 0.13 & 0.13 & 0.10 & 9.87 & 0.14 \\
\hline $\mathrm{TiO}_{2}$ & 17.59 & 15.64 & 16.09 & 14.99 & 13.71 & 16.34 & 16.44 & 16.39 & 15.04 & 1.81 & 17.74 \\
\hline $\mathrm{Al}_{2} \mathrm{O}_{3}$ & 0.51 & 0.78 & 1.51 & 1.96 & 1.26 & 1.99 & 1.16 & 0.92 & 1.01 & 2.82 & 1.02 \\
\hline $\mathrm{Cr}_{2} \mathrm{O}_{3}$ & 0.00 & 0.02 & 0.02 & 0.02 & 0.01 & 0.01 & 0.01 & 0.02 & 0.04 & 0.01 & 0.02 \\
\hline $\mathrm{FeO}_{\mathrm{t}}$ & 71.20 & 67.62 & 66.29 & 71.61 & 71.02 & 68.29 & 70.78 & 71.49 & 70.17 & 70.22 & 73.14 \\
\hline MnO & 0.19 & 0.15 & 2.37 & 0.83 & 0.40 & 0.85 & 0.77 & 0.59 & 0.98 & 0.25 & 0.23 \\
\hline $\mathrm{MgO}$ & 0.02 & 0.01 & 0.02 & 0.07 & 0.20 & 0.36 & 0.20 & 0.11 & 0.04 & 4.65 & 0.07 \\
\hline $\mathrm{CaO}$ & 0.02 & 0.08 & 0.02 & 0.01 & 0.04 & 0.01 & 0.01 & 0.02 & 0.00 & 0.05 & 0.01 \\
\hline NiO & 0.00 & 0.00 & 0.02 & 0.04 & 0.00 & 0.02 & 0.03 & 0.01 & 0.01 & 0.02 & 0.00 \\
\hline $\mathrm{ZnO}$ & 0.08 & 0.18 & 0.13 & 0.26 & 0.12 & 0.17 & 0.15 & 0.06 & 0.20 & 0.00 & 0.18 \\
\hline $\mathrm{Nb}_{2} \mathrm{O}_{5}$ & 0.02 & 0.08 & 0.01 & 0.02 & 0.00 & 0.02 & 0.04 & 0.03 & 0.08 & 0.01 & 0.04 \\
\hline $\mathrm{P}_{2} \mathrm{O}_{5}$ & 0.00 & 0.02 & 0.04 & 0.00 & 0.00 & 0.01 & 0.02 & 0.00 & 0.00 & 0.03 & 0.00 \\
\hline Total & 92.51 & 87.19 & 89.32 & 92.85 & 90.16 & 90.84 & 92.56 & 92.73 & 90.53 & 93.34 & 92.58 \\
\hline $\mathrm{Fe}_{2} \mathrm{O}_{3}$ & 29.07 & 28.69 & 28.43 & 32.58 & 33.91 & 28.69 & 30.56 & 31.04 & 32.05 & 36.94 & 30.08 \\
\hline $\mathrm{FeO}$ & 45.04 & 41.80 & 40.71 & 42.29 & 40.50 & 42.47 & 43.28 & 43.55 & 41.32 & 36.98 & 46.06 \\
\hline \multicolumn{12}{|c|}{ Cátions para 32 oxigênios } \\
\hline $\mathrm{Si}$ & 0.030 & 0.038 & 0.053 & 0.044 & 0.060 & 0.043 & 0.041 & 0.041 & 0.032 & 2.941 & 0.044 \\
\hline Al & 0.194 & 0.315 & 0.596 & 0.743 & 0.493 & 0.767 & 0.441 & 0.352 & 0.394 & 0.990 & 0.376 \\
\hline $\mathrm{Ti}$ & 4.307 & 4.048 & 4.050 & 3.625 & 3.432 & 4.024 & 4.001 & 3.994 & 3.751 & 0.405 & 4.196 \\
\hline $\mathrm{Cr}$ & 0.000 & 0.005 & 0.004 & 0.005 & 0.004 & 0.001 & 0.001 & 0.004 & 0.010 & 0.001 & 0.005 \\
\hline Fe2 & 12.261 & 12.030 & 11.396 & 11.373 & 11.273 & 11.630 & 11.709 & 11.797 & 11.458 & 9.219 & 12.115 \\
\hline $\mathrm{Fe} 3$ & 7.113 & 7.422 & 7.154 & 7.876 & 8.484 & 7.062 & 7.432 & 7.558 & 7.989 & 8.278 & 7.112 \\
\hline $\mathrm{Mn}$ & 0.052 & 0.043 & 0.671 & 0.225 & 0.114 & 0.236 & 0.212 & 0.161 & 0.275 & 0.063 & 0.062 \\
\hline $\mathrm{Mg}$ & 0.011 & 0.007 & 0.012 & 0.035 & 0.098 & 0.175 & 0.098 & 0.053 & 0.020 & 2.066 & 0.032 \\
\hline $\mathrm{Ca}$ & 0.006 & 0.031 & 0.008 & 0.004 & 0.015 & 0.003 & 0.002 & 0.007 & 0.000 & 0.016 & 0.003 \\
\hline $\mathrm{Zn}$ & 0.018 & 0.046 & 0.032 & 0.061 & 0.030 & 0.041 & 0.036 & 0.015 & 0.048 & 0.000 & 0.042 \\
\hline $\mathrm{Nb}$ & 0.003 & 0.012 & 0.001 & 0.002 & 0.000 & 0.003 & 0.005 & 0.005 & 0.012 & 0.001 & 0.006 \\
\hline $\mathbf{P}$ & 0.000 & 0.010 & 0.010 & 0.000 & 0.000 & 0.000 & 0.010 & 0.000 & 0.000 & 0.010 & 0.000 \\
\hline Magnetita & 45.23 & 47.83 & 46.90 & 52.07 & 55.28 & 46.74 & 48.15 & 48.62 & 51.57 & 91.09 & 45.87 \\
\hline Ulvoespinélio & 54.77 & 52.17 & 53.10 & 47.93 & 44.72 & 53.26 & 51.85 & 51.38 & 48.43 & 8.91 & 54.13 \\
\hline
\end{tabular}


Análise química (via microssonda eletrônica) dos óxidos de Fe e Ti das rochas vulcânicas ácidas da unidade Santa Maria

\begin{tabular}{|c|c|c|c|c|c|c|c|c|c|c|c|}
\hline & \multicolumn{9}{|c|}{ GX-23 } & \multicolumn{2}{|c|}{ GX-35 } \\
\hline & $c E, p 16 g$ & $\mathrm{cE}, \mathrm{p} 16 \mathrm{~h}$ & cE, p16i & $c G, p 29 a$ & $c G, p 29 b$ & $c G, p 29 c$ & $\mathrm{cX}, \mathrm{p} 33$ & cX, p34 & $\mathrm{cX}, \mathrm{p} 35$ & $\mathrm{cB}, \mathrm{p} 06$ & $\mathrm{cB}, \mathrm{p} 07$ \\
\hline Composto & Teor (\% peso) & Teor (\% peso) & Teor (\% peso) & Teor (\% peso) & Teor (\% peso) & Teor (\% peso) & Teor (\% peso) & Teor (\% peso) & Teor (\% peso) & Teor (\% peso) & Teor (\% peso) \\
\hline $\mathrm{SiO}_{2}$ & 0.17 & 0.13 & 0.54 & 0.17 & 0.19 & 0.47 & 0.14 & 0.13 & 1.01 & 0.32 & 0.22 \\
\hline $\mathrm{TiO}_{2}$ & 14.01 & 16.90 & 0.75 & 12.53 & 10.82 & 11.73 & 16.07 & 15.66 & 10.21 & 16.44 & 16.44 \\
\hline $\mathrm{Al}_{2} \mathrm{O}_{3}$ & 0.91 & 0.92 & 0.01 & 2.41 & 2.15 & 1.66 & 1.80 & 2.19 & 1.36 & 2.24 & 2.16 \\
\hline $\mathrm{Cr}_{2} \mathrm{O}_{3}$ & 0.04 & 0.01 & 0.00 & 0.01 & 0.00 & 0.02 & 0.02 & 0.04 & 0.02 & 0.04 & 0.02 \\
\hline $\mathrm{FeO}_{\mathrm{t}}$ & 72.52 & 71.92 & 85.11 & 77.24 & 76.43 & 73.85 & 73.20 & 71.79 & 73.49 & 68.43 & 71.25 \\
\hline MnO & 0.68 & 1.37 & 0.13 & 0.59 & 0.63 & 0.46 & 0.77 & 0.59 & 0.74 & 0.71 & 0.66 \\
\hline MgO & 0.09 & 0.15 & 0.07 & 0.52 & 0.50 & 0.60 & 0.17 & 0.32 & 0.10 & 1.08 & 1.05 \\
\hline $\mathrm{CaO}$ & 0.00 & 0.02 & 0.08 & 0.10 & 0.01 & 0.05 & 0.00 & 0.02 & 0.08 & 0.02 & 0.00 \\
\hline $\mathrm{NiO}$ & 0.01 & 0.02 & 0.03 & 0.00 & 0.00 & 0.00 & 0.00 & 0.00 & 0.01 & 0.00 & 0.00 \\
\hline $\mathrm{ZnO}$ & 0.12 & 0.16 & 0.00 & 0.12 & 0.20 & 0.06 & 0.17 & 0.22 & 0.18 & 0.08 & 0.20 \\
\hline $\mathrm{Nb}_{2} \mathrm{O}_{5}$ & 0.05 & 0.03 & 0.01 & 0.00 & 0.01 & 0.02 & 0.00 & 0.00 & 0.01 & 0.00 & 0.05 \\
\hline $\mathrm{P}_{2} \mathrm{O}_{5}$ & 0.00 & 0.08 & 0.03 & 0.00 & 0.00 & 0.00 & 0.00 & 0.00 & 0.00 & 0.00 & 0.05 \\
\hline Total & 91.87 & 94.60 & 92.77 & 97.45 & 94.91 & 92.63 & 95.40 & 93.85 & 90.80 & 92.11 & 94.94 \\
\hline $\mathrm{Fe}_{2} \mathrm{O}_{3}$ & 34.92 & 31.25 & 61.32 & 40.03 & 41.95 & 38.54 & 32.47 & 31.83 & 39.02 & 29.01 & 31.19 \\
\hline $\mathrm{FeO}$ & 41.09 & 43.79 & 29.92 & 41.21 & 38.67 & 39.17 & 43.97 & 43.14 & 38.37 & 42.32 & 43.18 \\
\hline \multicolumn{12}{|c|}{ Cátions para 32 oxigênios } \\
\hline Si & 0.054 & 0.042 & & 0.050 & 0.060 & 0.153 & 0.045 & 0.040 & 0.332 & 0.101 & 0.068 \\
\hline Al & 0.352 & 0.345 & 0.003 & 0.868 & 0.797 & 0.630 & 0.665 & 0.817 & 0.527 & 0.844 & 0.791 \\
\hline $\mathrm{Ti}$ & 3.451 & 4.029 & 0.187 & 2.884 & 2.563 & 2.846 & 3.788 & 3.735 & 2.536 & 3.965 & 3.850 \\
\hline $\mathrm{Cr}$ & 0.010 & 0.004 & 0.000 & 0.002 & 0.000 & 0.006 & 0.004 & 0.009 & 0.006 & 0.009 & 0.004 \\
\hline Fe2 & 11.254 & 11.605 & 8.268 & 10.546 & 10.186 & 10.566 & 11.522 & 11.444 & 10.592 & 11.349 & 11.246 \\
\hline Fe3 & 8.597 & 7.445 & 15.232 & 9.209 & 9.933 & 9.345 & 7.648 & 7.590 & 9.683 & 6.993 & 7.302 \\
\hline $\mathrm{Mn}$ & 0.190 & 0.367 & 0.037 & 0.152 & 0.168 & 0.126 & 0.205 & 0.159 & 0.206 & 0.191 & 0.173 \\
\hline $\mathrm{Mg}$ & 0.043 & 0.073 & 0.035 & 0.239 & 0.234 & 0.289 & 0.079 & 0.150 & 0.050 & 0.518 & 0.487 \\
\hline $\mathrm{Ca}$ & 0.000 & 0.007 & 0.029 & 0.034 & 0.003 & 0.016 & 0.000 & 0.008 & 0.027 & 0.008 & 0.000 \\
\hline$Z n$ & 0.030 & 0.037 & 0.000 & 0.028 & 0.047 & 0.014 & 0.040 & 0.051 & 0.044 & 0.019 & 0.045 \\
\hline $\mathrm{Nb}$ & 0.008 & 0.005 & 0.001 & 0.000 & 0.002 & 0.003 & 0.000 & 0.000 & 0.001 & 0.000 & 0.007 \\
\hline $\mathbf{P}$ & 0.000 & 0.020 & 0.010 & 0.000 & 0.000 & 0.000 & 0.000 & 0.000 & 0.000 & 0.000 & 0.010 \\
\hline Magnetita & 55.47 & 48.02 & 97.60 & 61.49 & 65.96 & 62.15 & 50.24 & 50.40 & 65.63 & 46.86 & 48.67 \\
\hline Ulvoespinélio & 44.53 & 51.98 & 2.40 & 38.51 & 34.04 & 37.85 & 49.76 & 49.60 & 34.37 & 53.14 & 51.33 \\
\hline
\end{tabular}


Análise química (via microssonda eletrônica) dos óxidos de Fe e Ti das rochas vulcânicas ácidas da unidade Santa Maria

\begin{tabular}{|c|c|c|c|c|c|c|c|c|c|c|c|}
\hline & \multicolumn{11}{|c|}{ GX-35 } \\
\hline & cB, pA (prox 06) & $\mathrm{cC}, \mathrm{pB} 1$ & $\mathrm{cC}, \mathrm{pB} 2$ & $\mathrm{cC}, \mathrm{pC}$ (inc px) & cC, pB (prox 14) & $\mathrm{cD}, \mathrm{p} 21$ & cG, p34 (a) & cG, p34 (b) & $c G, p 36(a)$ & cG, p36 (b) & cA, p02 \\
\hline Composto & Teor (\% peso) & Teor (\% peso) & Teor (\% peso) & Teor (\% peso) & Teor (\% peso) & Teor (\% peso) & Teor (\% peso) & Teor (\% peso) & Teor (\% peso) & Teor (\% peso) & Teor (\% peso) \\
\hline $\mathrm{SiO}_{2}$ & 0.22 & 1.01 & 0.62 & 0.18 & 0.26 & 0.61 & 0.41 & 0.96 & 0.79 & 3.11 & 0.79 \\
\hline $\mathrm{TiO}_{2}$ & 16.70 & 15.05 & 15.72 & 16.35 & 16.17 & 16.71 & 14.14 & 15.21 & 16.07 & 17.26 & 15.39 \\
\hline $\mathrm{Al}_{2} \mathrm{O}_{3}$ & 2.21 & 2.05 & 2.03 & 2.06 & 4.43 & 2.16 & 2.24 & 2.29 & 2.21 & 2.50 & 1.98 \\
\hline $\mathrm{Cr}_{2} \mathrm{O}_{3}$ & 0.00 & 0.00 & 0.03 & 0.03 & 0.01 & 0.06 & 0.03 & 0.05 & 0.04 & 0.05 & 0.00 \\
\hline $\mathrm{FeO}_{\mathrm{t}}$ & 66.63 & 69.91 & 72.80 & 73.89 & 70.07 & 69.67 & 71.11 & 70.14 & 69.08 & 65.35 & 69.70 \\
\hline MnO & 0.71 & 0.76 & 0.69 & 0.66 & 0.78 & 0.80 & 0.62 & 0.68 & 0.80 & 0.94 & 0.67 \\
\hline $\mathrm{MgO}$ & 0.47 & 0.45 & 0.53 & 0.46 & 0.48 & 1.03 & 1.05 & 0.99 & 0.96 & 0.27 & 0.43 \\
\hline $\mathrm{CaO}$ & 0.41 & 0.04 & 0.44 & 0.08 & 0.10 & 0.02 & 0.01 & 0.02 & 0.03 & 0.12 & 0.13 \\
\hline NiO & 0.00 & 0.03 & 0.00 & 0.00 & 0.00 & 0.01 & 0.00 & 0.02 & 0.01 & 0.00 & 0.03 \\
\hline $\mathrm{ZnO}$ & 0.13 & 0.12 & 0.07 & 0.11 & 0.14 & 0.20 & 0.11 & 0.13 & 0.15 & 0.23 & 0.20 \\
\hline $\mathrm{Nb}_{2} \mathrm{O}_{5}$ & 0.04 & 0.02 & 0.01 & 0.06 & 0.00 & 0.04 & 0.00 & 0.05 & 0.01 & 0.03 & 0.01 \\
\hline $\mathrm{P}_{2} \mathrm{O}_{5}$ & 0.39 & 0.00 & 0.30 & 0.00 & 0.00 & 0.00 & 0.00 & 0.00 & 0.00 & 0.00 & 0.00 \\
\hline Total & 89.99 & 92.23 & 95.91 & 96.84 & 95.08 & 93.90 & 92.96 & 93.33 & 92.82 & 91.40 & 91.93 \\
\hline $\mathrm{Fe}_{2} \mathrm{O}_{3}$ & 26.67 & 30.08 & 32.05 & 32.58 & 28.91 & 29.12 & 33.80 & 30.72 & 29.07 & 19.64 & 29.76 \\
\hline $\mathrm{FeO}$ & 42.63 & 42.84 & 43.96 & 44.56 & 44.05 & 43.47 & 40.69 & 42.49 & 42.92 & 47.68 & 42.91 \\
\hline \multicolumn{12}{|c|}{ Cátions para 32 oxigênios } \\
\hline Si & 0.071 & 0.323 & 0.189 & 0.055 & 0.080 & 0.192 & 0.130 & 0.302 & 0.251 & 0.993 & 0.255 \\
\hline Al & 0.850 & 0.775 & 0.736 & 0.744 & 1.609 & 0.798 & 0.841 & 0.850 & 0.826 & 0.939 & 0.751 \\
\hline $\mathrm{Ti}$ & 4.104 & 3.639 & 3.638 & 3.779 & 3.751 & 3.947 & 3.389 & 3.612 & 3.841 & 4.144 & 3.733 \\
\hline $\mathrm{Cr}$ & 0.000 & 0.000 & 0.007 & 0.008 & 0.002 & 0.014 & 0.008 & 0.013 & 0.011 & 0.012 & 0.000 \\
\hline Fe2 & 11.650 & 11.517 & 11.310 & 11.452 & 11.363 & 11.417 & 10.840 & 11.220 & 11.408 & 12.731 & 11.572 \\
\hline Fe3 & 6.552 & 7.269 & 7.412 & 7.526 & 6.704 & 6.875 & 8.094 & 7.292 & 6.945 & 4.714 & 7.214 \\
\hline Mn & 0.196 & 0.207 & 0.181 & 0.171 & 0.204 & 0.213 & 0.168 & 0.181 & 0.215 & 0.253 & 0.183 \\
\hline $\mathrm{Mg}$ & 0.227 & 0.217 & 0.244 & 0.209 & 0.223 & 0.481 & 0.499 & 0.465 & 0.455 & 0.130 & 0.208 \\
\hline $\mathrm{Ca}$ & 0.144 & 0.014 & 0.146 & 0.025 & 0.032 & 0.006 & 0.002 & 0.007 & 0.012 & 0.040 & 0.044 \\
\hline $\mathrm{Zn}$ & 0.032 & 0.029 & 0.016 & 0.025 & 0.031 & 0.045 & 0.025 & 0.030 & 0.034 & 0.054 & 0.047 \\
\hline $\mathrm{Nb}$ & 0.006 & 0.003 & 0.002 & 0.008 & 0.000 & 0.006 & 0.000 & 0.007 & 0.001 & 0.004 & 0.001 \\
\hline $\mathbf{P}$ & 0.110 & 0.000 & 0.080 & 0.000 & 0.000 & 0.000 & 0.000 & 0.000 & 0.000 & 0.000 & 0.000 \\
\hline Magnetita & 44.39 & 49.97 & 50.46 & 49.89 & 47.19 & 46.55 & 54.42 & 50.23 & 47.48 & 36.26 & 49.14 \\
\hline Ulvoespinélio & 55.61 & 50.03 & 49.54 & 50.11 & 52.81 & 53.45 & 45.58 & 49.77 & 52.52 & 63.74 & 50.86 \\
\hline
\end{tabular}


Análise química (via microssonda eletrônica) dos óxidos de Fe e Ti das rochas vulcânicas ácidas da unidade Santa Maria

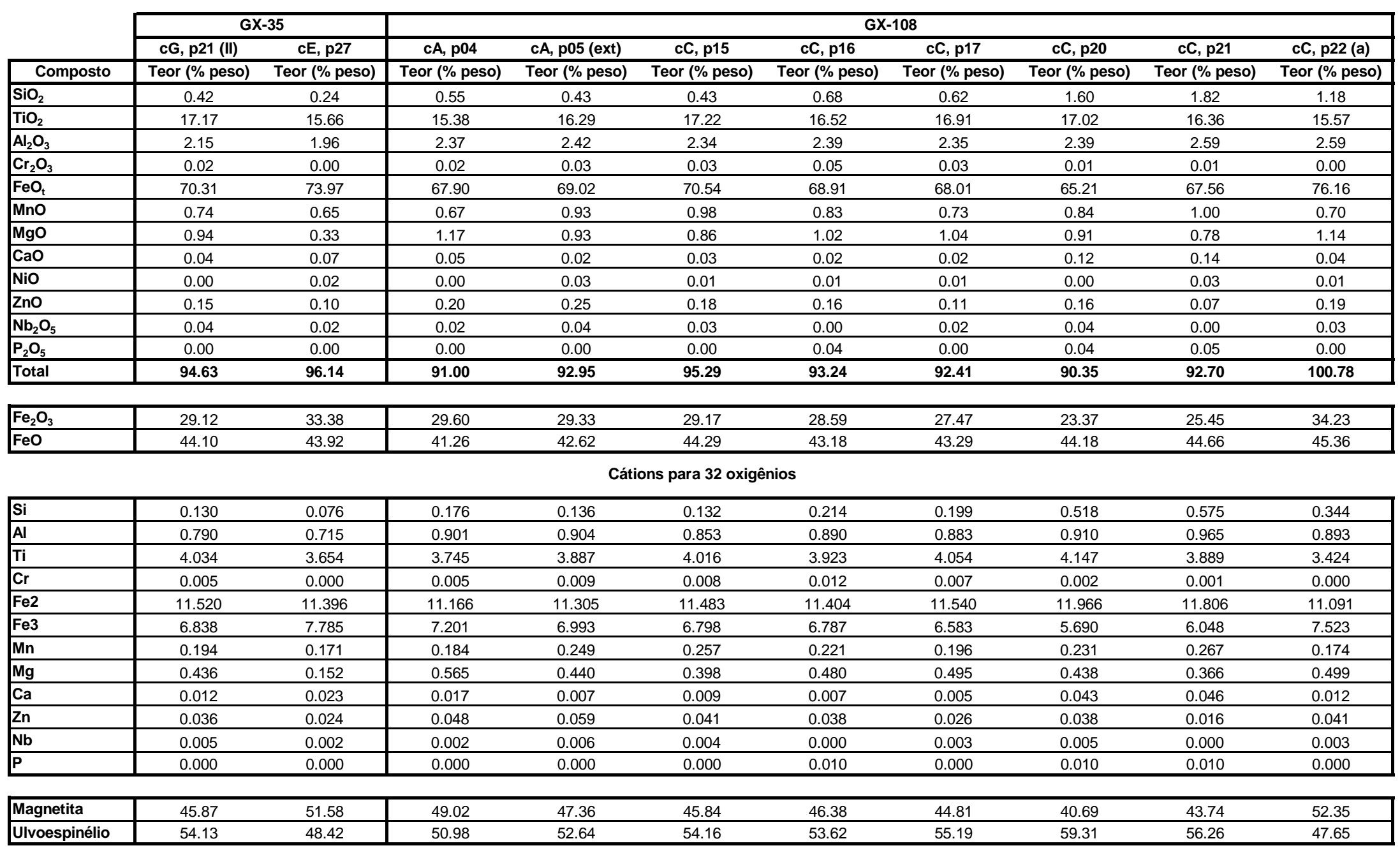


Análise química (via microssonda eletrônica) dos óxidos de Fe e Ti das rochas vulcânicas ácidas da unidade Santa Maria

\begin{tabular}{|l|ccc|}
\cline { 2 - 4 } \multicolumn{1}{c|}{} & \multicolumn{3}{c|}{ GX-108 } \\
\cline { 2 - 4 } \multicolumn{1}{c|}{ Composto } & cC, 22(b) & cJ, pA & cJ, p51 \\
\hline $\mathrm{SiO}_{2}$ & 1.90 & 0.34 & 0.83 \\
\hline $\mathrm{TiO}_{2}$ & 15.95 & 15.60 & 15.38 \\
\hline $\mathrm{Al}_{2} \mathrm{O}_{3}$ & 2.48 & 2.48 & 2.13 \\
\hline $\mathrm{Cr}_{2} \mathrm{O}_{3}$ & 0.04 & 0.03 & 0.01 \\
\hline $\mathrm{FeO}_{\mathbf{t}}$ & 67.58 & 70.38 & 70.27 \\
\hline $\mathrm{MnO}$ & 0.87 & 0.83 & 0.95 \\
\hline $\mathrm{MgO}$ & 1.03 & 0.98 & 0.62 \\
\hline $\mathrm{CaO}$ & 0.19 & 0.01 & 0.16 \\
\hline $\mathrm{NiO}$ & 0.01 & 0.00 & 0.01 \\
\hline $\mathrm{ZnO}^{\mathrm{NnO}}$ & 0.21 & 0.15 & 0.13 \\
\hline $\mathrm{Nb}_{2} \mathrm{O}_{\mathbf{5}}$ & 0.06 & 0.00 & 0.02 \\
\hline $\mathrm{Total}_{\mathbf{5}}$ & 0.05 & 0.03 & 0.05 \\
\hline
\end{tabular}

\begin{tabular}{|l|lll|}
\hline $\mathrm{Fe}_{2} \mathrm{O}_{3}$ & 26.08 & 31.41 & 30.50 \\
\hline $\mathrm{FeO}$ & 44.10 & 42.11 & 42.82 \\
\hline
\end{tabular}

Cátions para 32 oxigênios

\begin{tabular}{|l|ccc|}
\hline $\mathbf{S i}$ & 0.601 & 0.108 & 0.262 \\
\hline $\mathbf{A l}$ & 0.922 & 0.921 & 0.793 \\
\hline $\mathrm{Ti}$ & 3.789 & 3.697 & 3.668 \\
\hline $\mathbf{C r}$ & 0.009 & 0.008 & 0.002 \\
\hline $\mathrm{Fe} 2$ & 11.643 & 11.092 & 11.354 \\
\hline $\mathrm{Fe} 3$ & 6.190 & 7.437 & 7.269 \\
\hline $\mathrm{Mn}$ & 0.232 & 0.220 & 0.256 \\
\hline $\mathrm{Mg}$ & 0.482 & 0.460 & 0.294 \\
\hline $\mathbf{C a}$ & 0.065 & 0.003 & 0.055 \\
\hline $\mathbf{Z n}$ & 0.049 & 0.034 & 0.031 \\
\hline $\mathbf{N b}$ & 0.008 & 0.000 & 0.002 \\
\hline $\mathbf{P}$ & 0.010 & 0.010 & 0.010 \\
\hline
\end{tabular}

\begin{tabular}{|l|lll|}
\hline Magnetita & 44.96 & 50.14 & 49.77 \\
\hline Ulvoespinélio & 55.04 & 49.86 & 50.23 \\
\hline
\end{tabular}


Análise química (via microssonda eletrônica) de vidro das rochas vulcânicas ácidas da unidade Santa Maria

\begin{tabular}{|c|c|c|c|c|c|c|c|c|c|c|c|}
\hline & \multicolumn{5}{|c|}{ GX-23 } & \multicolumn{6}{|c|}{ GX-35 } \\
\hline & cG, p32 & cB, extra & cD, extra & cA, extra & cF, extra & cC, p15 & cD, p23 & cD, p24 & cF, p32 & cG, p40 & cE, p29 \\
\hline Composto & Teor (\%peso) & Teor (\%peso) & Teor (\%peso) & Teor (\%peso) & Teor (\%peso) & Teor (\%peso) & Teor (\%peso) & Teor (\%peso) & Teor (\%peso) & Teor (\%peso) & Teor (\%peso) \\
\hline $\mathrm{SiO}_{2}$ & 77.70 & 76.25 & 76.51 & 76.58 & 75.97 & 75.753 & 75.158 & 74.626 & 75.935 & 74.059 & 74.322 \\
\hline $\mathrm{TiO}_{2}$ & 0.32 & 0.38 & 0.37 & 0.35 & 0.24 & 0.364 & 0.397 & 0.310 & 0.337 & 0.436 & 0.419 \\
\hline $\mathrm{Al}_{2} \mathrm{O}_{3}$ & 11.78 & 11.79 & 11.90 & 11.69 & 11.84 & 11.776 & 11.881 & 11.713 & 11.887 & 11.665 & 11.808 \\
\hline $\mathrm{Fe}_{2} \mathrm{O}_{3}$ & 0.96 & 0.96 & 0.70 & 0.72 & 1.06 & 0.743 & 0.796 & 1.071 & 0.636 & 1.748 & 0.687 \\
\hline MnO & 0.02 & 0.02 & 0.00 & 0.00 & 0.01 & 0.009 & 0.035 & 0.023 & 0.047 & 0.030 & 0.020 \\
\hline MgO & 0.04 & 0.07 & 0.02 & 0.03 & 0.07 & 0.005 & 0.000 & 0.010 & 0.025 & 0.010 & 0.027 \\
\hline $\mathrm{CaO}$ & 0.46 & 0.56 & 0.39 & 0.37 & 0.54 & 0.268 & 0.270 & 0.262 & 0.267 & 0.413 & 0.262 \\
\hline $\mathrm{Na}_{2} \mathrm{O}$ & 2.84 & 2.93 & 2.75 & 2.74 & 3.00 & 2.535 & 1.887 & 1.864 & 2.872 & 2.610 & 2.875 \\
\hline $\mathrm{K}_{2} \mathrm{O}$ & 6.08 & 5.83 & 6.58 & 6.21 & 5.87 & 5.459 & 6.116 & 6.122 & 4.957 & 5.091 & 5.116 \\
\hline $\mathrm{P}_{2} \mathrm{O}_{5}$ & 0.00 & 0.06 & 0.01 & 0.05 & 0.00 & 0.000 & 0.000 & 0.040 & 0.114 & 0.052 & 0.000 \\
\hline \multirow[t]{3}{*}{ Total } & 100.19 & 98.84 & 99.23 & 98.73 & 98.59 & 96.912 & 96.541 & 96.042 & 97.077 & 96.114 & 95.537 \\
\hline & & GX-35 & & \multicolumn{8}{|c|}{ GX-108 } \\
\hline & cX, p45 & cD, p49 & cD, p50 & $c A, p 06$ & cC, p14 & cC, p24 & $\mathrm{cD}, \mathrm{p} 30$ & cD, p31 & cD, p32 & cG, p38 & cl, p46 \\
\hline Composto & Teor (\%peso) & Teor (\%peso) & Teor (\%peso) & Teor (\%peso) & Teor (\%peso) & Teor (\%peso) & Teor (\%peso) & Teor (\%peso) & Teor (\%peso) & Teor (\%peso) & Teor (\%peso) \\
\hline $\mathrm{SiO}_{2}$ & 74.855 & 75.508 & 75.226 & 70.511 & 73.122 & 73.310 & 73.276 & 73.116 & 72.948 & 73.750 & 74.533 \\
\hline $\mathrm{TiO}_{2}$ & 0.360 & 0.431 & 0.423 & 0.291 & 0.468 & 0.526 & 0.467 & 0.447 & 0.435 & 0.527 & 0.313 \\
\hline $\mathrm{Al}_{2} \mathrm{O}_{3}$ & 11.790 & 11.631 & 11.670 & 15.829 & 11.737 & 11.802 & 11.850 & 11.443 & 11.671 & 11.457 & 11.671 \\
\hline $\mathrm{Fe}_{2} \mathrm{O}_{3}$ & 0.715 & 0.875 & 0.828 & 1.406 & 1.747 & 1.023 & 1.176 & 1.493 & 1.733 & 1.597 & 0.867 \\
\hline $\mathrm{MnO}$ & 0.000 & 0.006 & 0.009 & 0.027 & 0.028 & 0.059 & 0.028 & 0.017 & 0.074 & 0.041 & 0.014 \\
\hline MgO & 0.000 & 0.009 & 0.004 & 0.052 & 0.021 & 0.003 & 0.031 & 0.014 & 0.043 & 0.026 & 0.024 \\
\hline $\mathrm{CaO}$ & 0.312 & 0.283 & 0.281 & 2.947 & 0.372 & 0.355 & 0.310 & 0.345 & 0.419 & 0.393 & 0.307 \\
\hline $\mathrm{Na}_{2} \mathrm{O}$ & 2.864 & 1.843 & 2.832 & 3.729 & 2.987 & 3.095 & 3.103 & 2.923 & 2.876 & 2.815 & 2.951 \\
\hline $\mathrm{K}_{2} \mathrm{O}$ & 5.000 & 6.303 & 5.016 & 3.660 & 4.445 & 4.470 & 4.454 & 4.542 & 4.277 & 4.608 & 4.503 \\
\hline $\mathrm{P}_{2} \mathrm{O}_{5}$ & 0.007 & 0.086 & 0.000 & 0.041 & 0.196 & 0.031 & 0.045 & 0.144 & 0.074 & 0.097 & 0.131 \\
\hline Total & 95.905 & 96.974 & 96.289 & 98.493 & 95.124 & 94.673 & 94.741 & 94.484 & 94.550 & 95.311 & 95.313 \\
\hline
\end{tabular}




\section{Anexo 03}

Química de rocha total:

Resultados das Análises de elementos maiores, menores e traços via FRX e análises de elementos traço via ICP-MS 
Análises químicas de rocha total via FRX das rochas vulcânicas ácidas da região de Gramado Xavier (RS)

\begin{tabular}{|c|c|c|c|c|c|c|c|c|c|c|c|c|c|c|c|}
\hline \multirow[b]{2}{*}{ Amostra } & \multicolumn{11}{|c|}{ Unidade Santa Maria } & \multicolumn{2}{|c|}{ Caxias do Sul } & \multicolumn{2}{|c|}{ Barros Cassal } \\
\hline & $\begin{array}{c}\text { RS } 73 \text { B } \\
\text { vitrea }\end{array}$ & $\begin{array}{c}\text { RS } 96 \\
\text { cristalina }\end{array}$ & $\begin{array}{c}\text { GX-23 } \\
\text { cristalina }\end{array}$ & $\begin{array}{l}\text { GX-35 } \\
\text { vítrea }\end{array}$ & $\begin{array}{c}\text { GX-108 } \\
\text { vítrea }\end{array}$ & $\begin{array}{c}\text { GX-115 } \\
\text { vítrea }\end{array}$ & $\begin{array}{l}\text { TF - 02A } \\
\text { cristalina }\end{array}$ & $\begin{array}{l}\text { TF - 02B } \\
\text { cristalina }\end{array}$ & $\begin{array}{l}\mathrm{TF}-02 \mathrm{C} \\
\text { cristalina }\end{array}$ & $\begin{array}{c}\text { TF - 02D } \\
\text { vítrea }\end{array}$ & $\begin{array}{c}\text { TF-02E } \\
\text { vitrea }\end{array}$ & GX-07ob & GX-118 & RS-73A & GX-113 \\
\hline \multicolumn{16}{|c|}{ Elementos Maiores (\% em peso) } \\
\hline $\mathrm{SiO2}$ & 69.3 & 70.5 & 70.3 & 69.4 & 69.7 & 70.6 & 70.2 & 70.1 & 70.0 & 68.3 & 68.6 & 66.0 & 68.0 & 63.0 & 57.0 \\
\hline TiO2 & 0.66 & 0.68 & 0.67 & 0.65 & 0.67 & 0.65 & 0.68 & 0.69 & 0.69 & 0.67 & 0.67 & 0.87 & 0.89 & 1.19 & 1.49 \\
\hline $\mathrm{Al} 2 \mathrm{O} 3$ & 12.2 & 12.5 & 12.3 & 12.2 & 12.1 & 11.9 & 12.1 & 12.2 & 12.1 & 11.9 & 11.9 & 12.5 & 12.6 & 12.5 & 12.6 \\
\hline $\mathrm{Fe} 2 \mathrm{O3}$ & 4.93 & 5.01 & 4.81 & 4.99 & 5.09 & 4.67 & 5.10 & 5.33 & 5.24 & 5.16 & 4.98 & 5.55 & 5.69 & 8.88 & 12.10 \\
\hline MnO & 0.09 & 0.06 & 0.08 & 0.08 & 0.08 & 0.06 & 0.10 & 0.10 & 0.09 & 0.09 & 0.09 & 0.10 & 0.08 & 0.15 & 0.17 \\
\hline MgO & 0.59 & 0.52 & 0.50 & 0.61 & 0.73 & 0.36 & 0.49 & 0.60 & 0.45 & 0.85 & 0.51 & 1.23 & 0.75 & 1.55 & 2.77 \\
\hline $\mathrm{CaO}$ & 2.01 & 1.66 & 2.11 & 1.93 & 2.06 & 0.79 & 1.89 & 2.22 & 1.61 & 2.15 & 2.20 & 3.09 & 2.76 & 4.24 & 6.36 \\
\hline $\mathrm{Na} 2 \mathrm{O}$ & 3.02 & 2.60 & 2.66 & 2.44 & 2.70 & 2.15 & 2.69 & 2.73 & 2.51 & 2.68 & 3.28 & 3.37 & 2.79 & 3.62 & 2.82 \\
\hline K2O & 3.97 & 4.96 & 4.97 & 4.63 & 4.03 & 6.74 & 4.82 & 4.50 & 5.17 & 3.91 & 3.58 & 2.80 & 4.31 & 2.21 & 1.93 \\
\hline P2O5 & 0.19 & 0.19 & 0.19 & 0.19 & 0.19 & 0.18 & 0.20 & 0.20 & 0.20 & 0.20 & 0.20 & 0.26 & 0.27 & 0.34 & 0.29 \\
\hline LOI & 3.35 & 1.56 & 1.50 & 3.00 & 2.37 & 0.98 & 0.82 & 0.94 & 1.20 & 3.29 & 2.72 & 3.74 & 0.77 & 2.02 & 1.22 \\
\hline Total & 100.30 & 100.22 & 100.13 & 100.03 & $\begin{array}{l}99.70 \\
\end{array}$ & 99.03 & 98.99 & 99.57 & 99.22 & 99.21 & 98.71 & 99.55 & $\begin{array}{l}98.91 \\
\end{array}$ & 99.68 & 98.73 \\
\hline \multicolumn{16}{|c|}{ Elementos Menores e Traços (ppm) } \\
\hline Ba & 698 & 651 & 666 & 725 & 667 & 602 & 647 & 651 & 637 & 648 & 804 & 584 & 595 & 848 & 596 \\
\hline $\mathrm{Ce}$ & 75.6 & 91.4 & 70.3 & 79.3 & 95.0 & 69.2 & 86.8 & 85.5 & 103 & 107 & 96.8 & 89.9 & 74.1 & 71.3 & 69.5 \\
\hline Co & & & & 6.00 & & & & & & & 6.80 & 10.2 & 11.7 & 14.9 & 32.3 \\
\hline $\mathrm{Cr}$ & & & & & & & & & & & & & & 29.7 & \\
\hline $\mathrm{Cu}$ & 20.0 & 25.2 & 20.8 & 19.0 & 20.0 & 18.2 & 19.9 & 18.5 & 19.8 & 15.2 & 17.7 & 38.7 & 35.9 & 81.3 & 157 \\
\hline$F$ & & & & & 717 & 725 & 820 & 730 & 937 & & 1092 & & 846 & & 576 \\
\hline Ga & 19.2 & 19.6 & 19.0 & 18.7 & 15.0 & 17.0 & 17.6 & 16.2 & 16.6 & 18.1 & 16.6 & 19.2 & 17.8 & 20.7 & 21.3 \\
\hline \multicolumn{16}{|l|}{ Hf } \\
\hline La & 47.1 & 40.7 & 70.6 & 51.9 & 49.0 & 75.1 & 54.2 & 60.4 & 48.9 & 50.6 & 45.5 & 49.6 & 54.9 & 43.3 & 30.9 \\
\hline $\mathrm{Nb}$ & 26.5 & 26.5 & 26.3 & 25.5 & 23.0 & 24.3 & 26.8 & 26.3 & 26.2 & 25.6 & 26.3 & 19.8 & 19.1 & 18.4 & 15.2 \\
\hline Nd & 49.3 & 33.8 & 44.8 & 40.6 & 36.0 & 51.8 & 31.7 & 31.5 & 25.9 & 27.2 & 23.2 & 34.3 & 32.7 & 50.2 & 52.5 \\
\hline $\mathbf{N i}$ & & & & & & & & & & & & & & 9.70 & 17.2 \\
\hline $\mathbf{P b}$ & 29.4 & 26.9 & 17.2 & 17.8 & 19.5 & 20.9 & 18.5 & 18.8 & 19.0 & 18.2 & 19.3 & 14.8 & 16.4 & 19.5 & 31.2 \\
\hline $\mathbf{R b}$ & 238 & 210 & 207 & 257 & 254 & 272 & 199 & 195 & 201 & 247 & 202 & 177 & 205 & 171 & 98.3 \\
\hline \multicolumn{16}{|l|}{$\mathrm{s}$} \\
\hline Sc & 13.4 & & 14.8 & 12.8 & & & 14.8 & 16.0 & 13.8 & 15.3 & 13.9 & 14.7 & 18.0 & 19.9 & 29.4 \\
\hline $\begin{array}{l}\mathbf{S r} \\
\end{array}$ & 104 & 95.4 & 99.4 & 101 & 120 & 53.4 & 97.5 & 109 & 90.7 & 105 & 109 & 153 & 153 & 167 & 174 \\
\hline \multicolumn{16}{|l|}{$\mathrm{Ta}$} \\
\hline Th & 21.6 & 22.8 & 22.8 & 22.5 & 11.0 & 15.2 & 15.3 & 14.5 & 16.0 & 15.9 & 16.2 & 12.3 & 11.8 & 14.9 & 10.0 \\
\hline $\mathbf{U}$ & 9.30 & 7.70 & 8.40 & 11.2 & & 7.40 & 6.60 & 6.20 & 6.70 & 6.30 & 5.90 & 7.10 & 4.70 & 4.20 & 4.70 \\
\hline $\mathbf{V}$ & 24.1 & 20.8 & 26.6 & 17.7 & 27.0 & 23.0 & 14.3 & & 20.3 & 20.1 & 6.40 & 53.6 & 76.5 & 98.0 & 281 \\
\hline $\mathbf{Y}$ & 55.1 & 49.5 & 57.1 & 67.8 & 53.0 & 58.7 & 54.8 & 55.6 & 53.7 & 54.8 & 54.7 & 42.7 & 44.4 & 58.8 & 45.4 \\
\hline $\mathrm{Zn}$ & 79.8 & 79.9 & 79.0 & 83.4 & 81.0 & 69.9 & 74.8 & 75.5 & 78.2 & 76.8 & 76.3 & 77.2 & 83.9 & 105 & 107 \\
\hline $\mathrm{Zr}$ & 304 & 303 & 310 & 310 & 294 & 298 & 303 & 307 & 302 & 301 & 304 & 237 & 241 & 294 & 207 \\
\hline
\end{tabular}

Por se tratarem de unidades quimicamente homogêneas, as amostras aqui apresentadas são representativas de cada unidade. Os dados referentes às unidades Caxias do Sul e Barros Cassal são de Polo (2014) 
Análises químicas de rocha total via ICP-MS das rochas vulcânicas ácidas da região de Gramado Xavier (RS)

\begin{tabular}{|c|c|c|c|c|c|c|c|c|c|c|c|}
\hline \multirow[b]{2}{*}{ Amostra } & \multicolumn{7}{|c|}{ Unidade Santa Maria } & \multicolumn{2}{|c|}{ Caxias do Sul } & \multicolumn{2}{|c|}{ Barros Cassal } \\
\hline & $\begin{array}{c}\text { RS } 73 \text { B } \\
\text { vítrea }\end{array}$ & $\begin{array}{c}\text { GX-23 } \\
\text { cristalina }\end{array}$ & $\begin{array}{c}\text { GX-35 } \\
\text { vítrea }\end{array}$ & $\begin{array}{c}\text { GX-108 } \\
\text { vítrea }\end{array}$ & $\begin{array}{c}\text { GX-115 } \\
\text { vítrea }\end{array}$ & $\begin{array}{c}\text { TF - 02E } \\
\text { vítrea }\end{array}$ & $\begin{array}{c}\text { TF - 02B } \\
\text { cristalina }\end{array}$ & GX-07ob & GX-118 & RS-73A & GX-113 \\
\hline $\mathbf{R b}$ & 261 & 213 & 276 & 285 & 302 & 211 & 218 & 201 & 231 & 188 & 103 \\
\hline $\mathbf{S r}$ & 105 & 85 & 108 & 127 & 57 & 108 & 115 & 166 & 157 & 169 & 172 \\
\hline $\mathrm{Nb}$ & 25.4 & 30.7 & 26.6 & 26.2 & 26.2 & 25.8 & 25.8 & 22.3 & 22.0 & 20.5 & 16.1 \\
\hline Cs & 13.1 & 9.2 & 16.3 & 12.7 & 13.7 & 11.8 & 12.0 & 10.4 & 10.4 & 7.44 & 6.06 \\
\hline $\mathbf{B a}$ & 782 & 717 & 853 & 717 & 676 & 729 & 932 & 633 & 647 & 845 & 603 \\
\hline La & 54.6 & 52.3 & 67.2 & 54.3 & 76.8 & 52.9 & 53.3 & 46.8 & 47.6 & 45.5 & 32.0 \\
\hline Sm & 10.8 & 10.3 & 13.7 & 10.9 & 14.0 & 10.6 & 10.5 & 9.1 & 9.1 & 10.1 & 7.4 \\
\hline $\mathbf{E u}$ & 1.87 & 1.79 & 2.42 & 1.89 & 2.38 & 1.87 & 1.86 & 1.72 & 1.75 & 2.16 & 1.80 \\
\hline Gd & 10.1 & 9.8 & 13.1 & 10.1 & 12.0 & 9.98 & 9.86 & 8.12 & 8.23 & 10.1 & 7.75 \\
\hline $\mathbf{T b}$ & 1.68 & 1.63 & 2.16 & 1.68 & 1.94 & 1.67 & 1.65 & 1.31 & 1.32 & 1.69 & 1.30 \\
\hline Dy & 9.69 & 9.44 & 12.4 & 9.71 & 10.9 & 9.67 & 9.44 & 7.43 & 7.47 & 9.85 & 7.76 \\
\hline Ho & 2.08 & 2.05 & 2.64 & 2.07 & 2.27 & 2.08 & 2.03 & 1.55 & 1.57 & 2.13 & 1.74 \\
\hline $\mathbf{E r}$ & 5.58 & 5.46 & 7.10 & 5.61 & 6.03 & 5.57 & 5.48 & 4.12 & 4.17 & 5.72 & 4.70 \\
\hline Tm & 0.86 & 0.84 & 1.08 & 0.85 & 0.91 & 0.86 & 0.83 & 0.61 & 0.63 & 0.87 & 0.73 \\
\hline $\mathbf{Y b}$ & 5.41 & 5.07 & 6.79 & 5.39 & 5.71 & 5.36 & 5.25 & 3.85 & 4.00 & 5.45 & 4.51 \\
\hline
\end{tabular}

Por se tratarem de unidades quimicamente homogêneas, as amostras aqui apresentadas são representativas de cada unidade. Os dados referentes às unidades Caxias do Sul e Barros Cassal são de Polo (2014) 


\section{Anexo 04}

Química mineral:

Indicação dos pontos analisados em imagens obtidas via MEV e resultados das análises de elementos traços em plagioclásio via LA-ICPMS 


\section{Amostra GX-23}

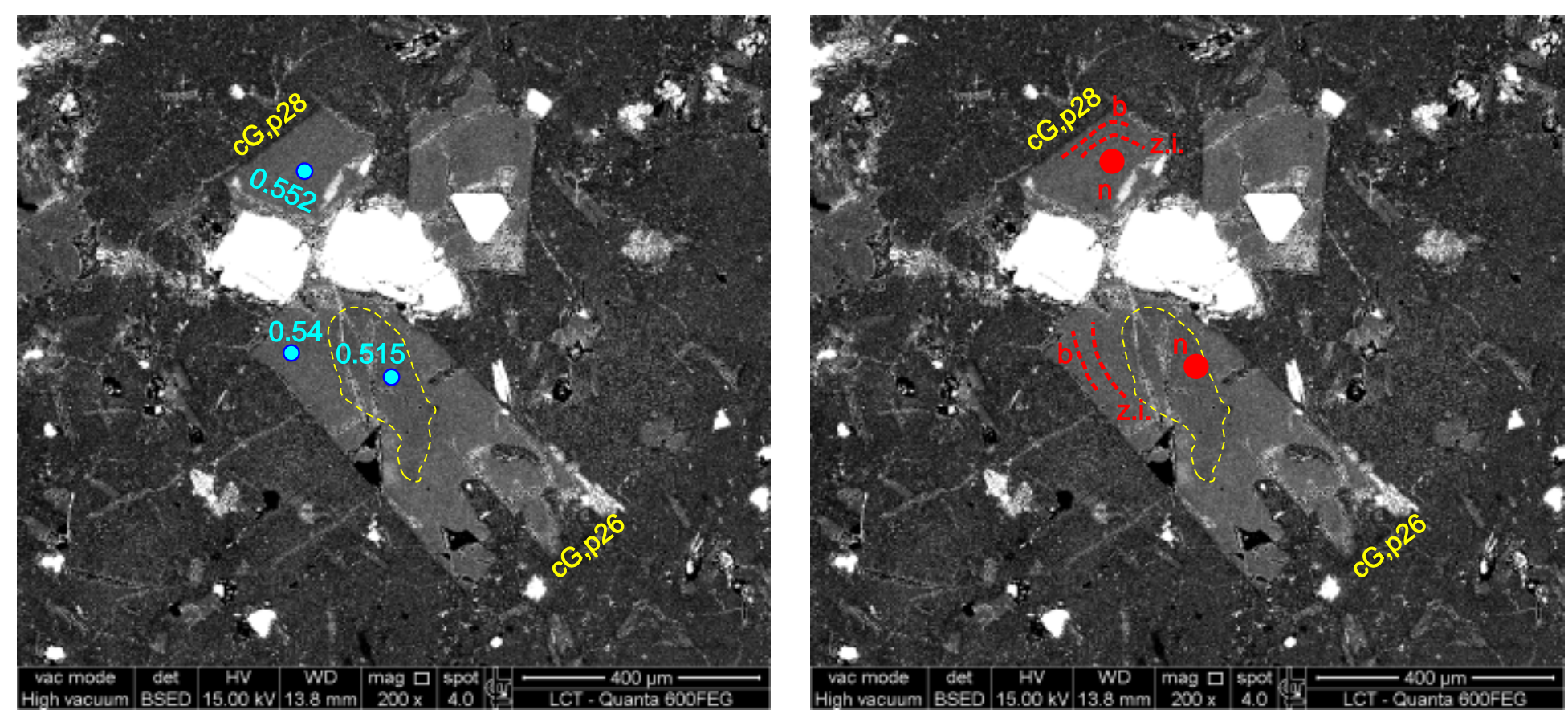

\section{Amostra GX-35}
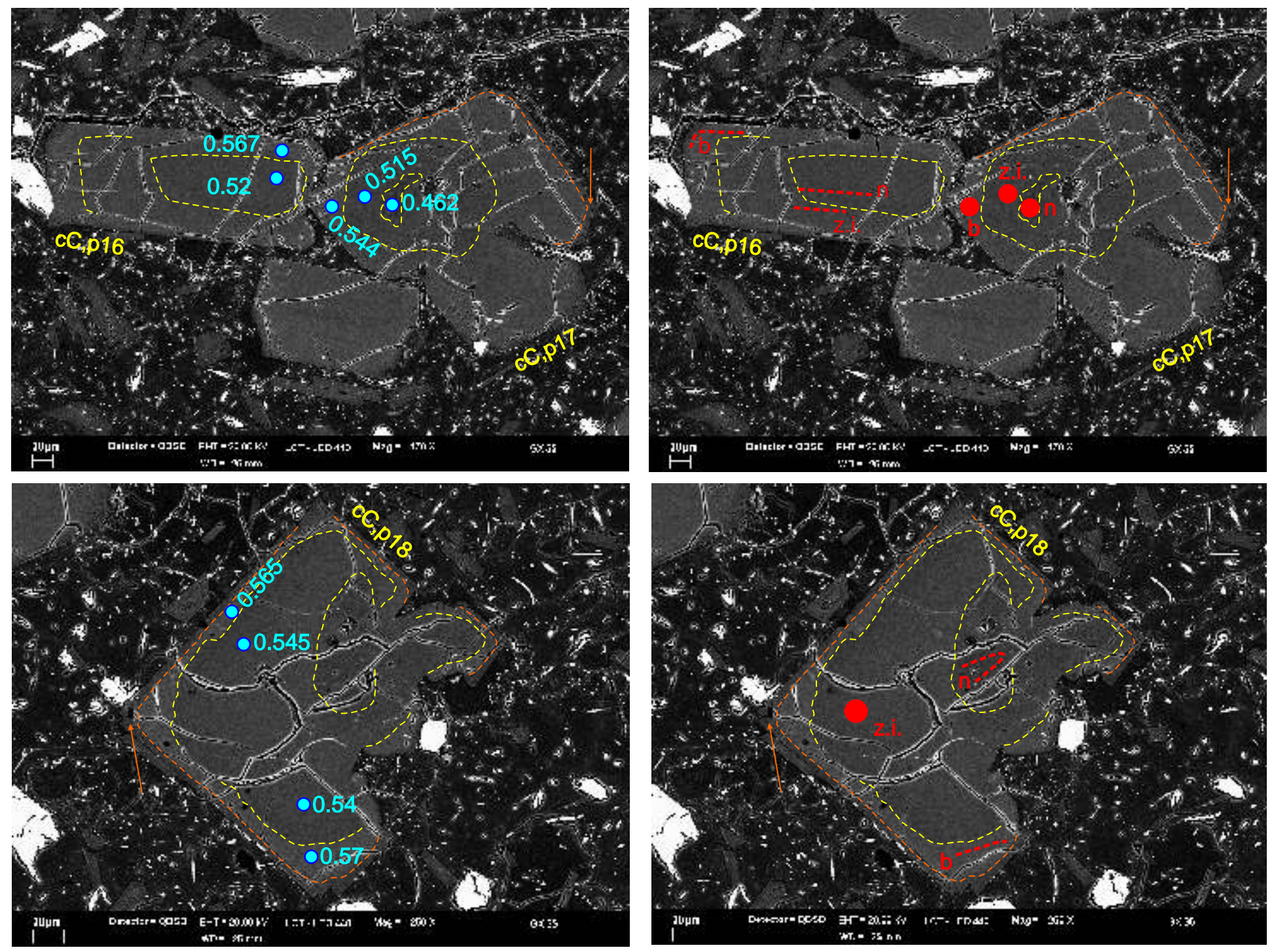

\section{LEGENDA:}

- Análise por microssonda eletrônica

‥ Análise por LA-ICPMS

Zonamento composicional

Imagens de MEV

Localização dos pontos de análise via Microssonda (teor de An indicado) e LA-ICPMS
Dissertação de mestrado Letícia Freitas Guimarães 


\section{Amostra GX-35}
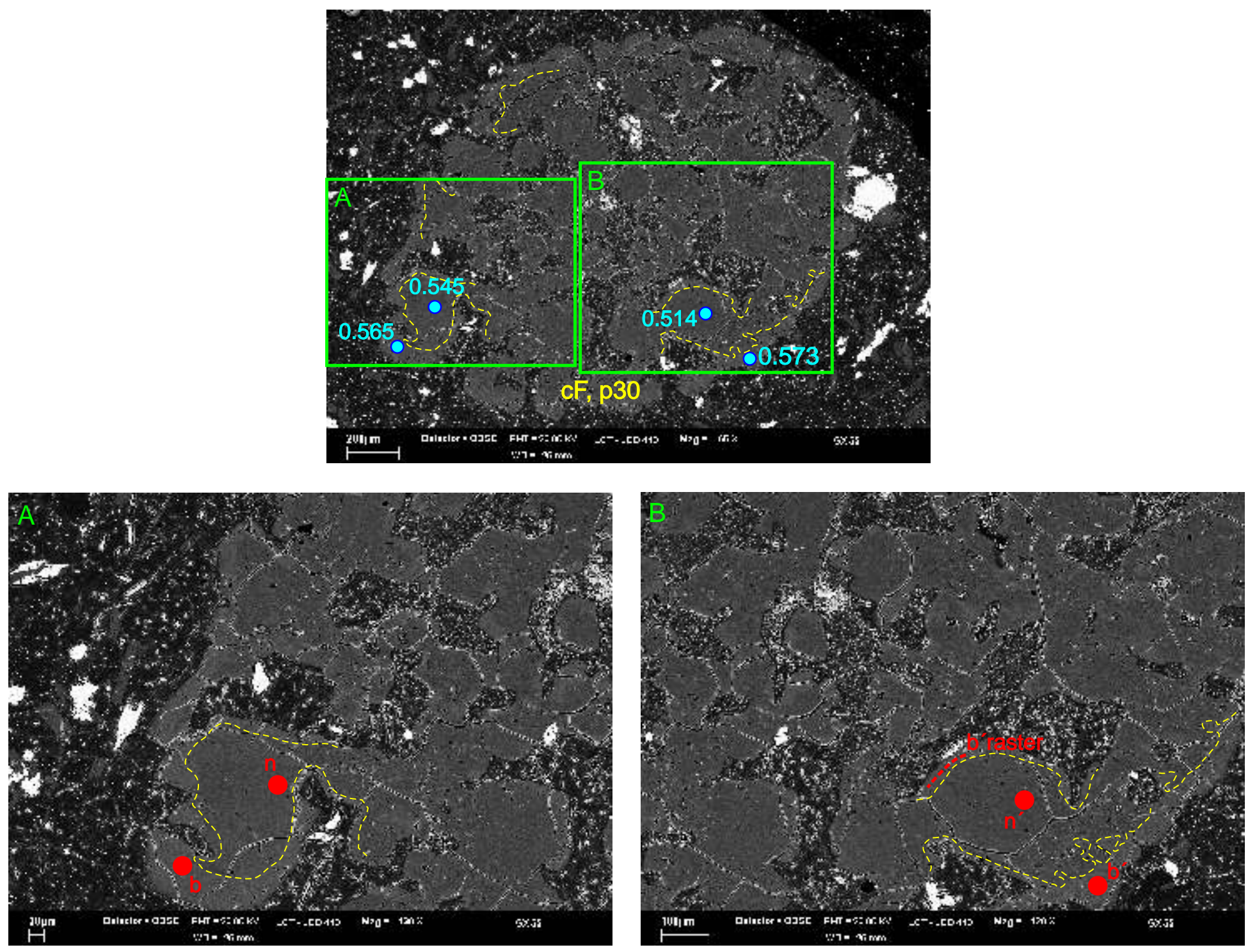

\section{LEGENDA:}

- Análise por microssonda eletrônica

\section{Imagens de MEV}

Localização dos pontos de análise via Microssonda (teor de An indicado) e LA-ICPMS
Dissertação de mestrado Letícia Freitas Guimarães 


\section{Amostra GX-108}
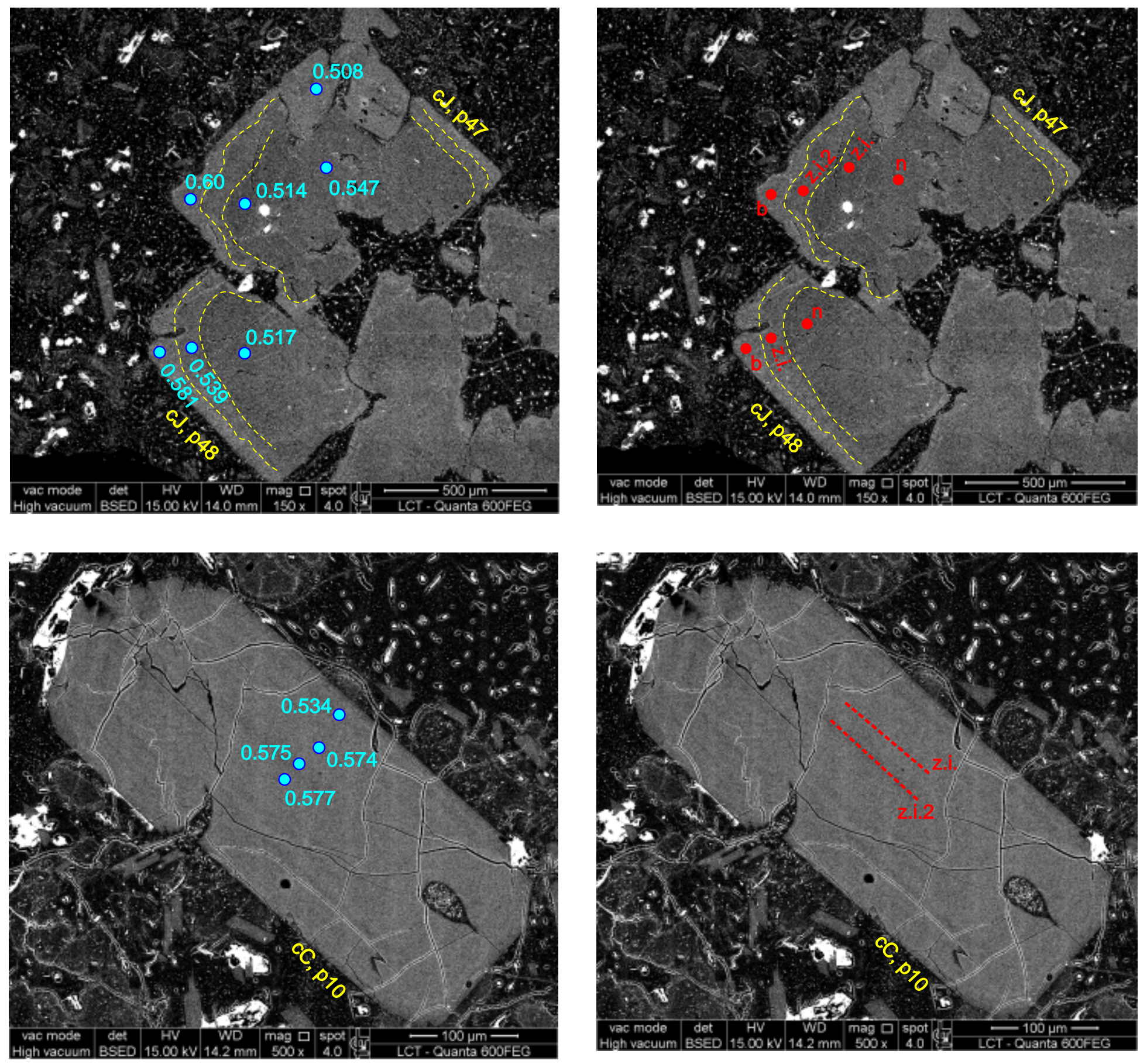

\section{LEGENDA:}

- Análise por microssonda eletrônica

๑. Análise por LA-ICPMS

$\therefore$ Zonamento composicional

Imagens de MEV

Localização dos pontos de análise via Microssonda (teor de An indicado) e LA-ICPMS
Dissertação de mestrado Letícia Freitas Guimarães 
Análises quimicas (via LA-ICPMS) de elementos traço e terras raras em microfenocristais de plagioclásio dos riolitos da unidade Santa Maria

\begin{tabular}{|c|c|c|c|c|c|c|c|}
\hline \multirow[b]{2}{*}{ Elemento } & \multicolumn{7}{|c|}{ GX-23 } \\
\hline & cG, p28 & $\begin{array}{c}\text { cG, p28 raster } \\
\text { borda1 }\end{array}$ & $\begin{array}{c}\text { cG, p28 raster } \\
\text { borda2 }\end{array}$ & $c G$, p26 & $\begin{array}{l}\text { cG, p26 } \\
\text { borda1 }\end{array}$ & $\begin{array}{l}\text { cG, p26 } \\
\text { borda2 }\end{array}$ & $c D, p 08$ \\
\hline $\mathbf{L i}$ & 96.8 & 70.6 & 63.7 & 84.9 & 85.2 & 59.4 & 75.0 \\
\hline $\mathrm{Na}$ & 40728 & 38177 & 39786 & 42515 & 36821 & 36303 & 43889 \\
\hline $\mathrm{Mg}$ & 474 & 632 & 498 & 721 & 524 & 537 & 472 \\
\hline Al & 144671 & 156778 & 152609 & 138753 & 158912 & 155758 & 155300 \\
\hline Si & 268034 & 230029 & 218641 & 266343 & 206554 & 207968 & 261955 \\
\hline $\mathbf{P}$ & 111 & 150 & 154 & 83.8 & $<124$ & $<113$ & $<164$ \\
\hline $\mathrm{Ca}$ & 82119 & 82119 & 82119 & 77688 & 81333 & 81333 & 74186 \\
\hline Sc & 2.04 & $<2.25$ & $<2.43$ & 2.35 & $<2.56$ & $<2.03$ & $<2.95$ \\
\hline $\mathrm{Ti}$ & 250 & 256 & 229 & 244 & 254 & 259 & 224 \\
\hline $\mathrm{V}$ & 0.36 & $<1.85$ & $<1.78$ & 0.30 & $<2.05$ & $<1.75$ & $<2.68$ \\
\hline $\mathrm{Fe}$ & $<0.00$ & $<0.00$ & $<0.00$ & $<0.00$ & $<0.00$ & $<0.00$ & $<0.00$ \\
\hline $\mathrm{Mn}$ & 82.9 & 78.8 & 69.0 & 75.9 & 68.3 & 66.7 & 62.8 \\
\hline $\mathrm{Zn}$ & 16.2 & 25.4 & 21.5 & 20.9 & 19.5 & 21.2 & 27.5 \\
\hline Ga & 40.5 & 39.6 & 32.3 & 39.7 & 35.8 & 38.2 & 36.2 \\
\hline Ge & $<0.00$ & $<0.00$ & $<0.00$ & $<0.00$ & $<0.00$ & $<0.00$ & $<0.00$ \\
\hline $\mathbf{R b}$ & 1.43 & 1.21 & 1.71 & 2.46 & 1.83 & 1.63 & 1.59 \\
\hline $\mathrm{Sr}$ & 537 & 553 & 536 & 530 & 575 & 568 & 548 \\
\hline $\mathbf{Y}$ & 0.96 & 0.93 & 1.02 & 0.98 & 1.28 & 1.04 & 0.94 \\
\hline $\mathrm{Zr}$ & 0.17 & 0.31 & $<0.26$ & 0.46 & $<0.41$ & $<0.27$ & $<0.37$ \\
\hline $\mathrm{Nb}$ & 0.02 & $<0.23$ & 0.05 & 0.05 & $<0.17$ & $<0.00$ & 0.14 \\
\hline Cs & $<0.02$ & $<0.12$ & $<0.19$ & 0.03 & $<0.21$ & $<0.12$ & $<0.24$ \\
\hline $\mathrm{Ba}$ & 379 & 368 & 402 & 336 & 347 & 373 & 375 \\
\hline La & 11.1 & 11.8 & 11.6 & 13.9 & 14.0 & 12.9 & 14.3 \\
\hline $\mathrm{Ce}$ & 20.6 & 20.2 & 21.6 & 25.1 & 24.3 & 23.4 & 24.4 \\
\hline $\mathrm{Pr}$ & 1.76 & 1.89 & 2.15 & 2.16 & 2.09 & 1.72 & 1.74 \\
\hline Nd & 6.17 & 5.88 & 5.83 & 6.54 & 6.51 & 7.74 & 8.19 \\
\hline Sm & 0.84 & 0.64 & 1.16 & 0.81 & 0.94 & 0.62 & $<0.61$ \\
\hline Eu & 3.43 & 4.07 & 4 & 3.7 & 4.33 & 3.7 & 3.91 \\
\hline Gd & 0.49 & 0.52 & 0.28 & 0.58 & 0.85 & 1.03 & $<0.54$ \\
\hline Tb & 0.06 & 0.1 & $<0.07$ & 0.08 & 0.08 & $<0.07$ & 0.05 \\
\hline Dy & $<-\mathrm{NaN}$ & $<-\mathrm{NaN}$ & $<-\mathrm{NaN}$ & $<-\mathrm{NaN}$ & $<-\mathrm{NaN}$ & $<-\mathrm{NaN}$ & $<-\mathrm{NaN}$ \\
\hline Ho & 0.04 & 0.06 & $<0.05$ & 0.05 & $<0.08$ & 0.10 & $<0.15$ \\
\hline Er & 0.07 & $<0.23$ & 0.05 & 0.10 & 0.36 & 0.17 & 0.15 \\
\hline $\mathrm{Tm}$ & 0.01 & $<0.07$ & $<0.05$ & 0.01 & $<0.08$ & $<0.00$ & $<0.00$ \\
\hline $\mathrm{Yb}$ & $<0.04$ & 0.18 & $<0.53$ & 0.05 & $<0.34$ & 0.15 & $<0.45$ \\
\hline Lu & 0.01 & $<0.05$ & $<0.00$ & 0.01 & 0.02 & 0.02 & $<0.07$ \\
\hline $\mathrm{Hf}$ & 0.07 & $<0.00$ & $<0.00$ & 0.04 & 0.25 & $<0.00$ & $<0.00$ \\
\hline $\mathrm{Ta}$ & $<0.01$ & $<0.12$ & $<0.00$ & $<0.02$ & $<0.00$ & $<0.12$ & 0.05 \\
\hline $\mathrm{Pb}$ & 7.08 & 7.81 & 7.37 & 7.99 & 6.89 & 8.53 & 6.32 \\
\hline Th & $<0.01$ & 0.13 & $<0.00$ & $<0.00$ & 0.08 & 0.15 & $<0.16$ \\
\hline U & $<0.00$ & $<0.09$ & $<0.09$ & $<0.01$ & $<0.00$ & $<0.16$ & $<0.00$ \\
\hline
\end{tabular}

Condições analíticas:

Padrão utilizado: BHVO - 2 G (basalto; Jochum et al. 2006)

Taxa de repetição: $10 \mathrm{~Hz}$ para todas as análises

Diâmetro do furo : 30 a $40 \mu \mathrm{m}$ para análises pontuais; $25 \mu \mathrm{m}$ para análises lineares (raster) 
Análises quimicas (via LA-ICPMS) de elementos traço e terras raras em microfenocristais de plagioclásio dos riolitos da unidade Santa Maria

\begin{tabular}{|c|c|c|c|c|c|c|c|}
\hline \multirow[b]{2}{*}{ Elemento } & \multicolumn{3}{|c|}{ GX-23 } & \multicolumn{4}{|c|}{ GX-35 } \\
\hline & $\begin{array}{l}\text { CD, p08 } \\
\text { borda }\end{array}$ & cD, p09 & $\begin{array}{l}\text { CD, p09 } \\
\text { borda }\end{array}$ & $\mathrm{cC}, \mathrm{p} 16$ raster & $\begin{array}{c}\text { cC, p16 raster } \\
\text { borda1 }\end{array}$ & $\begin{array}{c}\text { cC, p16 raster } \\
\text { borda2 }\end{array}$ & cC, p17 \\
\hline Li & 63.6 & 68.7 & 31.9 & 18.3 & 15.8 & 20.9 & 21.6 \\
\hline $\mathrm{Na}$ & 38621 & 35560 & 29530 & 38422 & 39560 & 36053 & 48137 \\
\hline $\mathrm{Mg}$ & 454 & 543 & 658 & 426 & 446 & 492 & 482 \\
\hline Al & 157764 & 137695 & 118793 & 151467 & 164914 & 160968 & 131899 \\
\hline Si & 238864 & 247878 & 178866 & 213629 & 230274 & 231582 & 244397 \\
\hline $\mathbf{P}$ & $<144$ & 91.6 & 139 & $<124$ & 254 & $<112$ & 94.4 \\
\hline $\mathrm{Ca}$ & 79904 & 81905 & 71470 & 76330 & 83406 & 83406 & 68468 \\
\hline Sc & $<2.89$ & 2.18 & 2.72 & $<2.36$ & $<2.31$ & 2.43 & 2.31 \\
\hline $\mathrm{Ti}$ & 240 & 232 & 187 & 225 & 219 & 232 & 237 \\
\hline v & $<2.03$ & 0.28 & $<1.43$ & $<1.85$ & $<1.45$ & $<1.40$ & 0.38 \\
\hline $\mathrm{Fe}$ & $<0.00$ & $<0.00$ & $<0.00$ & $<0.00$ & $<0.00$ & $<0.00$ & $<0.00$ \\
\hline Mn & 68.4 & 71.7 & 272 & 67.5 & 70.9 & 71.0 & 88.9 \\
\hline $\mathrm{Zn}$ & 24.0 & 19.3 & 23.4 & 22.8 & 28.0 & 34.1 & 23.0 \\
\hline Ga & 36.2 & 36.3 & 29.5 & 34.0 & 39.1 & 39.9 & 47.0 \\
\hline Ge & $<0.00$ & $<0.00$ & $<0.00$ & $<0.00$ & $<0.00$ & $<0.00$ & $<0.00$ \\
\hline $\mathbf{R b}$ & 1.66 & 3.05 & 4.90 & 1.26 & 2.18 & 2.91 & 3.98 \\
\hline $\mathrm{Sr}$ & 573 & 479 & 429 & 540 & 584 & 585 & 587 \\
\hline$Y$ & 1.12 & 1.23 & 13.34 & 0.73 & 1.46 & 2.66 & 2.48 \\
\hline $\mathrm{Zr}$ & 0.12 & 0.80 & 1.16 & 0.19 & $<0.33$ & $<0.30$ & 0.57 \\
\hline $\mathrm{Nb}$ & $<0.28$ & 0.09 & $<0.00$ & $<0.19$ & $<0.19$ & 0.07 & 0.07 \\
\hline Cs & $<0.15$ & 0.09 & $<0.16$ & $<0.30$ & $<0.28$ & 0.33 & 0.25 \\
\hline Ba & 360 & 326 & 236 & 341 & 378 & 440 & 361 \\
\hline La & 14.1 & 12.0 & 12.8 & 15.5 & 15.1 & 14.1 & 15.1 \\
\hline $\mathrm{Ce}$ & 22.5 & 19.4 & 24.1 & 23.8 & 23.6 & 19.9 & 24.8 \\
\hline $\mathrm{Pr}$ & 2.38 & 1.87 & 2.64 & 2.30 & 2.53 & 1.94 & 2.40 \\
\hline Nd & 4.65 & 6.61 & 9.37 & 5.74 & 8.68 & 7.49 & 8.23 \\
\hline Sm & 0.69 & 0.76 & 2.25 & 0.75 & 1.52 & 0.89 & 1.88 \\
\hline Eu & 3.97 & 2.77 & 3.13 & 3.13 & 4.05 & 4.23 & 3.79 \\
\hline Gd & 0.90 & 0.54 & 2.12 & 0.53 & $<0.66$ & 0.75 & 0.83 \\
\hline Tb & $<0.07$ & 0.05 & 0.27 & 0.15 & $<0.07$ & 0.18 & 0.10 \\
\hline Dy & $<-\mathrm{NaN}$ & $<-\mathrm{NaN}$ & $<-\mathrm{NaN}$ & $<0.41$ & $<0.43$ & $<0.48$ & 0.43 \\
\hline Ho & $<0.07$ & 0.05 & 0.22 & $<0.06$ & $<0.09$ & $<0.11$ & 0.07 \\
\hline Er & $<0.30$ & 0.12 & 0.74 & $<0.19$ & 0.09 & 0.15 & 0.10 \\
\hline $\mathrm{Tm}$ & $<0.07$ & 0.02 & 0.13 & $<0.08$ & $<0.09$ & 0.05 & $<0.01$ \\
\hline Yb & $<0.00$ & 0.08 & $<0.44$ & $<0.62$ & $<0.38$ & $<0.00$ & 0.14 \\
\hline Lu & $<0.09$ & $<0.01$ & $<0.08$ & $<0.07$ & 0.04 & $<0.10$ & 0.06 \\
\hline $\mathrm{Hf}$ & $<0.87$ & $<0.00$ & $<0.64$ & $<0.00$ & $<0.88$ & $<1.12$ & 0.21 \\
\hline Ta & 0.05 & 0.01 & $<0.11$ & $<0.00$ & $<0.00$ & 0.05 & $<0.03$ \\
\hline $\mathrm{Pb}$ & 8.99 & 6.03 & 6.63 & 6.21 & 7.73 & 8.83 & 6.80 \\
\hline Th & $<0.00$ & 0.02 & $<0.10$ & 0.08 & $<0.13$ & 0.10 & 0.03 \\
\hline $\mathbf{U}$ & $<0.16$ & 0.02 & 0.17 & 0.06 & $<0.10$ & $<0.09$ & $<0.02$ \\
\hline
\end{tabular}

Condições analíticas:

Padrão utilizado: BHVO - 2 G (basalto; Jochum et al. 2006)

Taxa de repetição: $10 \mathrm{~Hz}$ para todas as análises

Diâmetro do furo : 30 a $40 \mu \mathrm{m}$ para análises pontuais; $25 \mu \mathrm{m}$ para análises lineares (raster) 
Análises quimicas (via LA-ICPMS) de elementos traço e terras raras em microfenocristais de plagioclásio dos riolitos da unidade Santa Maria

\begin{tabular}{|c|c|c|c|c|c|c|c|}
\hline \multirow[b]{2}{*}{ Elemento } & \multicolumn{7}{|c|}{ GX-35 } \\
\hline & $\begin{array}{l}\mathrm{cC}, \mathrm{p} 17 \\
\text { borda1 }\end{array}$ & $\begin{array}{l}\mathrm{cC}, \mathrm{p} 17 \\
\text { borda2 }\end{array}$ & cC, p18 raster & $\begin{array}{l}\text { cC, p18 } \\
\text { borda1 }\end{array}$ & $\begin{array}{l}\text { cC, p18 raster } \\
\text { borda2 }\end{array}$ & cF, p30 & $\begin{array}{l}\mathrm{cF}, \mathrm{p} 30 \\
\text { borda1 }\end{array}$ \\
\hline $\mathbf{L i}$ & 18.4 & 13.4 & 66.9 & 30.1 & 24.1 & 33.8 & 15.6 \\
\hline $\mathrm{Na}$ & 44989 & 38744 & 44763 & 44455 & 43138 & 45537 & 38264 \\
\hline $\mathrm{Mg}$ & 487 & 434 & 4371 & 677 & 459 & 1438 & 499 \\
\hline Al & 154893 & 154946 & 176946 & 161894 & 173885 & 159556 & 178592 \\
\hline Si & 281074 & 270946 & 296468 & 285313 & 246947 & 271443 & 268221 \\
\hline $\mathbf{P}$ & 101 & 305 & 131 & 83.9 & $<135$ & 89.8 & 108 \\
\hline $\mathrm{Ca}$ & 77116 & 80475 & 80047 & 79904 & 84621 & 80118 & 83263 \\
\hline Sc & 1.41 & 1.68 & 5.27 & 1.2 & $<2.80$ & 1.92 & 1.77 \\
\hline $\mathrm{Ti}$ & 239 & 201 & 437 & 241 & 241 & 301 & 245 \\
\hline v & $<0.50$ & 0.71 & 3.53 & 0.44 & $<1.71$ & 0.98 & 0.69 \\
\hline $\mathrm{Fe}$ & $<0.00$ & $<0.00$ & $<0.00$ & $<0.00$ & $<0.00$ & $<0.00$ & $<0.00$ \\
\hline Mn & 73.6 & 71.5 & 99.4 & 81.6 & 78.4 & 92.3 & 89.1 \\
\hline $\mathrm{Zn}$ & 19.1 & 24.1 & 58.0 & 21.4 & 22.6 & 24.0 & 28.8 \\
\hline Ga & 47.7 & 44.0 & 45.9 & 46.9 & 49.2 & 50.8 & 51.8 \\
\hline Ge & $<0.00$ & $<0.00$ & $<0.00$ & $<0.00$ & $<0.00$ & $<0.00$ & $<0.00$ \\
\hline $\mathbf{R b}$ & 4.23 & 3.68 & 63.1 & 3.52 & 1.23 & 10.8 & 1.57 \\
\hline $\mathrm{Sr}$ & 640 & 557 & 579 & 646 & 619 & 586 & 605 \\
\hline $\mathbf{Y}$ & 1.99 & 3.69 & 34.0 & 2.46 & 1.35 & 6.82 & 1.78 \\
\hline $\mathrm{Zr}$ & 0.73 & 0.58 & 47.0 & 0.73 & 0.31 & 4.28 & 0.35 \\
\hline Nb & 0.11 & $<0.06$ & 1.76 & 0.19 & $<0.30$ & 0.34 & $<0.04$ \\
\hline Cs & 0.12 & 0.19 & 19.4 & 0.68 & $<0.16$ & 4.17 & $<0.05$ \\
\hline Ba & 443 & 311 & 609 & 423 & 400 & 408 & 330 \\
\hline La & 18.4 & 16.0 & 35.4 & 20.2 & 14.7 & 19.1 & 12.7 \\
\hline $\mathrm{Ce}$ & 26.1 & 24.2 & 32.9 & 27.0 & 21.2 & 26.1 & 20.9 \\
\hline $\operatorname{Pr}$ & 2.36 & 2.73 & 7.24 & 2.75 & 1.86 & 2.70 & 2.36 \\
\hline Nd & 7.84 & 9.54 & 29.1 & 10.2 & 9.05 & 10.3 & 8.65 \\
\hline Sm & 1.06 & 1.25 & 4.40 & 0.90 & 0.41 & 1.64 & 1.17 \\
\hline Eu & 3.10 & 3.45 & 4.46 & 3.66 & 4.12 & 3.30 & 2.99 \\
\hline Gd & 0.77 & 1.46 & 5.22 & 0.83 & 1.09 & 1.84 & 0.61 \\
\hline Tb & 0.06 & 0.18 & 1.13 & 0.09 & $<0.10$ & 0.23 & 0.04 \\
\hline Dy & 0.30 & 0.56 & 5.80 & 0.60 & $<0.34$ & 0.95 & 0.33 \\
\hline Ho & 0.04 & 0.10 & 1.34 & 0.11 & 0.24 & 0.20 & 0.05 \\
\hline Er & 0.14 & 0.27 & 3.68 & 0.28 & $<0.00$ & 0.55 & 0.09 \\
\hline $\mathrm{Tm}$ & 0.03 & 0.04 & 0.43 & 0.05 & $<0.12$ & 0.09 & 0.04 \\
\hline Yb & 0.14 & $<0.21$ & 3.19 & 0.30 & $<0.57$ & 0.91 & 0.20 \\
\hline Lu & 0.02 & 0.06 & 0.48 & 0.03 & $<0.08$ & 0.14 & $<0.02$ \\
\hline Hf & 0.17 & $<0.29$ & 1.90 & $<0.27$ & $<0.91$ & $<0.24$ & $<0.00$ \\
\hline Ta & $<0.05$ & 0.02 & 0.15 & $<0.00$ & $<0.21$ & 0.06 & $<0.00$ \\
\hline $\mathrm{Pb}$ & 6.55 & 6.98 & 9.09 & 8.67 & 8.93 & 7.29 & 7.13 \\
\hline Th & 0.01 & 0.06 & 0.59 & 0.04 & $<0.00$ & $<0.04$ & $<0.03$ \\
\hline U & $<0.03$ & 0.06 & 0.26 & 0.04 & 0.05 & 0.01 & $<0.00$ \\
\hline
\end{tabular}

Análise desconsiderada devido contaminação por inclusões ou de borda

Condições analíticas:

Padrão utilizado: BHVO - 2 G (basalto; Jochum et al. 2006)

Taxa de repetição: $10 \mathrm{~Hz}$ para todas as análises

Diâmetro do furo: 30 a $40 \mu \mathrm{m}$ para análises pontuais; $25 \mu \mathrm{m}$ para análises lineares (raster) 
Análises quimicas (via LA-ICPMS) de elementos traço e terras raras em microfenocristais de plagioclásio dos riolitos da unidade Santa Maria

\begin{tabular}{|c|c|c|c|c|c|c|c|}
\hline \multirow[b]{2}{*}{ Elemento } & \multicolumn{3}{|c|}{ GX-35 } & \multicolumn{4}{|c|}{ GX-108 } \\
\hline & cF, p30 (a) & $\begin{array}{l}\mathrm{cF}, \mathrm{p} 30 \\
\text { borda2 }\end{array}$ & $\begin{array}{c}\text { cF, p30 raster } \\
\text { borda3 }\end{array}$ & cJ, p47 & cJ, p47 (a) & $\begin{array}{l}\mathrm{cJ}, \mathrm{p} 47 \\
\text { borda1 }\end{array}$ & $\begin{array}{l}\mathrm{cJ}, \mathrm{p} 47 \\
\text { borda2 }\end{array}$ \\
\hline $\mathbf{L i}$ & 26.8 & 18.6 & 97.2 & 36.8 & 95.3 & 39.6 & 63.3 \\
\hline $\mathrm{Na}$ & 41818 & 36788 & 39365 & 41565 & 47356 & 39548 & 39085 \\
\hline $\mathrm{Mg}$ & 787 & 440 & 13091 & 590 & 2179 & 618 & 1439 \\
\hline Al & 155290 & 161076 & 170675 & 148429 & 159988 & 151993 & 156390 \\
\hline Si & 264145 & 252222 & 288539 & 285942 & 330138 & 263072 & 269482 \\
\hline $\mathbf{P}$ & $<39.6$ & 82.5 & $<157$ & 105.3 & 94.1 & 86.3 & 89.9 \\
\hline $\mathrm{Ca}$ & 76973 & 85049 & 85049 & 79689 & 79689 & 74758 & 88409 \\
\hline Sc & 1.43 & 1.42 & 25.1 & 1.17 & 2.77 & 1.08 & 1.46 \\
\hline $\mathrm{Ti}$ & 224 & 241 & 605 & 249 & 315 & 225 & 299 \\
\hline $\mathrm{V}$ & $<0.56$ & $<0.45$ & 2.84 & 0.31 & 1.10 & $<0.32$ & 1.23 \\
\hline $\mathrm{Fe}$ & $<0.00$ & $<0.00$ & $<0.00$ & $<0.00$ & $<0.00$ & $<0.00$ & $<0.00$ \\
\hline Mn & 68.5 & 79.5 & 1255 & 76.6 & 96.2 & 73.8 & 92.5 \\
\hline $\mathrm{Zn}$ & 21.0 & 29.2 & 207 & 21.0 & 24.0 & 16.8 & 18.6 \\
\hline Ga & 55.7 & 51.3 & 43.5 & 47.9 & 48.4 & 42.8 & 37.2 \\
\hline Ge & $<0.00$ & $<0.00$ & $<0.00$ & $<0.00$ & $<0.00$ & $<0.00$ & $<0.00$ \\
\hline $\mathbf{R b}$ & 3.77 & 2.55 & 30.1 & 2.32 & 19.1 & 1.75 & 10.1 \\
\hline $\mathrm{Sr}$ & 574 & 616 & 587 & 599 & 679 & 551 & 491 \\
\hline $\mathbf{Y}$ & 2.49 & 1.94 & 48.4 & 1.34 & 1.52 & 1.17 & 1.14 \\
\hline $\mathrm{Zr}$ & 1.04 & 0.69 & 24.5 & 0.20 & 7.15 & 0.08 & 6.36 \\
\hline Nb & 0.05 & 0.10 & 1.45 & 0.08 & 0.70 & $<0.04$ & 0.66 \\
\hline Cs & 0.25 & 0.07 & 10.0 & $<0.05$ & 0.96 & $<0.02$ & 0.41 \\
\hline Ba & 349 & 368 & 612 & 370 & 451 & 338 & 303 \\
\hline La & 14.9 & 15.3 & 29.0 & 15.4 & 16.4 & 14.8 & 12.1 \\
\hline $\mathrm{Ce}$ & 20.9 & 22.9 & 29.2 & 26.6 & 26.9 & 25.4 & 21.9 \\
\hline $\operatorname{Pr}$ & 2.2 & 2.3 & 5.26 & 2.43 & 2.65 & 2.15 & 1.97 \\
\hline Nd & 8.21 & 6.76 & 21.0 & 7.86 & 6.30 & 6.27 & 6.19 \\
\hline Sm & 1.12 & 1.55 & 4.74 & 0.70 & 1.23 & 1.14 & 0.66 \\
\hline Eu & 3.36 & 3.40 & 6.37 & 2.67 & 3.04 & 2.42 & 2.82 \\
\hline Gd & 0.85 & 0.88 & 5.81 & 0.63 & 0.77 & 0.57 & 0.64 \\
\hline Tb & 0.06 & 0.04 & 1.12 & 0.04 & 0.08 & 0.06 & 0.07 \\
\hline Dy & $<0.11$ & 0.62 & 8.24 & 0.7 & 0.24 & 0.16 & 0.26 \\
\hline Ho & 0.05 & 0.09 & 1.79 & 0.05 & 0.08 & 0.02 & 0.08 \\
\hline Er & 0.18 & 0.11 & 4.24 & 0.13 & 0.27 & 0.07 & $<0.05$ \\
\hline $\mathrm{Tm}$ & 0.05 & 0.03 & 1.03 & 0.03 & 0.03 & 0.03 & $<0.02$ \\
\hline Yb & $<0.22$ & 0.12 & 5.09 & $<0.18$ & $<0.09$ & 0.07 & 0.10 \\
\hline Lu & 0.02 & $<0.02$ & 0.73 & $<0.03$ & $<0.02$ & 0.03 & $<0.01$ \\
\hline Hf & $<0.49$ & $<0.23$ & 0.76 & $<0.21$ & 0.14 & $<0.18$ & $<0.00$ \\
\hline Ta & $<0.05$ & $<0.06$ & $<0.19$ & $<0.03$ & 0.06 & $<0.03$ & 0.06 \\
\hline $\mathrm{Pb}$ & 8.89 & 8.81 & 9.85 & 6.82 & 6.54 & 6.30 & 7.14 \\
\hline Th & $<0.00$ & 0.05 & 0.48 & 0.02 & 0.04 & $<0.00$ & 0.17 \\
\hline U & 0.03 & 0.03 & 0.37 & 0.03 & 0.31 & 0.01 & 0.20 \\
\hline
\end{tabular}

Análise desconsiderada devido contaminação por inclusões ou de borda

Condições analíticas:

Padrão utilizado: BHVO - 2 G (basalto; Jochum et al. 2006)

Taxa de repetição: $10 \mathrm{~Hz}$ para todas as análises

Diâmetro do furo: 30 a $40 \mu \mathrm{m}$ para análises pontuais; $25 \mu \mathrm{m}$ para análises lineares (raster) 
Análises quimicas (via LA-ICPMS) de elementos traço e terras raras em microfenocristais de plagioclásio dos riolitos da unidade Santa Maria

\begin{tabular}{|c|c|c|c|c|c|}
\hline & & & GX-108 & & \\
\hline Elemento & cJ, p48 & $\begin{array}{l}\mathrm{cJ}, \mathrm{p} 48 \\
\text { borda1 }\end{array}$ & $\begin{array}{l}\mathrm{cJ}, \mathrm{p} 48 \\
\text { borda2 }\end{array}$ & $\mathrm{cC}, \mathrm{p} 10$ raster & $\begin{array}{c}\text { cC, p10 raster } \\
\text { (b) }\end{array}$ \\
\hline Li & 145 & 30.5 & 35.7 & 43.9 & 27.7 \\
\hline $\mathrm{Na}$ & 47816 & 42510 & 39314 & 39632 & 34971 \\
\hline $\mathrm{Mg}$ & 2844 & 573 & 571 & 688 & 550 \\
\hline Al & 161932 & 155519 & 160282 & 162840 & 148030 \\
\hline$S i$ & 300504 & 273534 & 250290 & 255916 & 206410 \\
\hline $\mathbf{P}$ & 47.7 & 98.8 & 91.1 & $<117$ & 173 \\
\hline $\mathrm{Ca}$ & 75044 & 80047 & 86765 & 83620 & 79618 \\
\hline Sc & 1.59 & 2.04 & 1.56 & 2.95 & $<2.16$ \\
\hline $\mathrm{Ti}$ & 313 & 238 & 237 & 260 & 243 \\
\hline $\mathbf{v}$ & 0.96 & $<0.32$ & 0.27 & $<1.36$ & 2.01 \\
\hline $\mathrm{Fe}$ & $<0.00$ & $<0.00$ & $<0.00$ & $<0.00$ & $<0.00$ \\
\hline Mn & 99.0 & 90.2 & 82.2 & 90.4 & 79.0 \\
\hline $\mathrm{Zn}$ & 25.5 & 16.6 & 20.9 & 23.3 & 19.6 \\
\hline Ga & 46.4 & 48.2 & 42.3 & 40.6 & 34.8 \\
\hline Ge & $<0.00$ & $<0.00$ & $<0.00$ & $<0.00$ & $<0.00$ \\
\hline $\mathbf{R b}$ & 20.6 & 1.60 & 1.38 & 1.89 & 1.24 \\
\hline $\mathrm{Sr}$ & 586 & 566 & 552 & 556 & 520 \\
\hline$Y$ & 0.96 & 0.82 & 1.09 & 1.04 & 1.52 \\
\hline $\mathrm{Zr}$ & 4.11 & $<0.13$ & 0.11 & $<0.45$ & 0.25 \\
\hline $\mathrm{Nb}$ & 0.78 & $<0.00$ & $<0.04$ & $<0.18$ & $<0.33$ \\
\hline Cs & 1.33 & 0.04 & $<0.05$ & $<0.20$ & $<0.18$ \\
\hline $\mathrm{Ba}$ & 423 & 353 & 318 & 318 & 286 \\
\hline La & 16.4 & 14.2 & 11.6 & 11.5 & 11.2 \\
\hline $\mathrm{Ce}$ & 28.1 & 25.3 & 21.0 & 21.1 & 20.1 \\
\hline $\mathrm{Pr}$ & 2.12 & 2.38 & 2.09 & 1.87 & 1.83 \\
\hline Nd & 6.49 & 7.16 & 6.61 & 5.54 & 5.66 \\
\hline Sm & 1.03 & 0.54 & 0.54 & 1.17 & 0.63 \\
\hline Eu & 3.28 & 3.12 & 2.67 & 2.71 & 2.66 \\
\hline Gd & 0.42 & 0.33 & 0.36 & 0.97 & $<0.56$ \\
\hline Tb & 0.09 & 0.06 & 0.08 & $<0.06$ & 0.13 \\
\hline Dy & 0.32 & 0.21 & 0.13 & $<0.32$ & 0.47 \\
\hline Ho & $<0.02$ & 0.07 & $<0.02$ & $<0.06$ & 0.06 \\
\hline Er & 0.06 & $<0.07$ & 0.06 & $<0.25$ & $<0.23$ \\
\hline $\mathrm{Tm}$ & 0.02 & 0.03 & $<0.02$ & $<0.09$ & 0.09 \\
\hline Yb & $<0.08$ & $<0.11$ & 0.18 & $<0.51$ & $<0.46$ \\
\hline Lu & 0.03 & $<0.01$ & 0.01 & 0.04 & $<0.06$ \\
\hline $\mathrm{Hf}$ & $<0.00$ & $<0.00$ & 0.12 & $<0.00$ & 0.35 \\
\hline $\mathrm{Ta}$ & 0.02 & $<0.00$ & $<0.00$ & 0.08 & $<0.00$ \\
\hline $\mathrm{Pb}$ & 7.59 & 6.91 & 5.52 & 9.31 & 6.58 \\
\hline Th & 0.09 & $<0.00$ & $<0.00$ & 0.08 & $<0.16$ \\
\hline $\mathrm{U}$ & 0.28 & 0.02 & $<0.00$ & $<0.00$ & $<0.00$ \\
\hline
\end{tabular}

Condições analíticas:

Padrão utilizado: BHVO - 2 G (basalto; Jochum et al. 2006)

Taxa de repetição: $10 \mathrm{~Hz}$ para todas as análises

Diâmetro do furo: 30 a $40 \mu \mathrm{m}$ para análises pontuais; $25 \mu \mathrm{m}$ para análises lineares (raster) 


\section{Anexo 05}

Modelamentos:

Resultados para os modelamentos de cristalização fracionada para elementos maiores e modelamentos de assimilação e cristalização fracionada para os elementos traço 


\begin{tabular}{|c|c|c|c|c|c|}
\hline \multicolumn{6}{|c|}{ Análises recalculadas para 100 (\% em peso) } \\
\hline Óxido & $\begin{array}{l}\text { Barros } \\
\text { Cassal }^{1}\end{array}$ & Santa Maria ${ }^{2}$ & Plagioclásio $^{3}$ & Piroxênio $^{3}$ & Magnetita $^{4}$ \\
\hline $\mathrm{SiO}_{2}$ & 64.673 & 71.803 & 54.39 & 50.43 & 0.70 \\
\hline $\mathrm{TiO}_{2}$ & 1.236 & 0.685 & 0.07 & 0.67 & 13.27 \\
\hline $\mathrm{Al}_{2} \mathrm{O}_{3}$ & 12.828 & 12.553 & 27.76 & 1.73 & 0.37 \\
\hline $\mathrm{FeO}_{\text {tot }}$ & 9.073 & 5.130 & 1.29 & 15.86 & 85.36 \\
\hline $\mathrm{MnO}$ & 0.148 & 0.074 & 0.01 & 0.44 & 0.20 \\
\hline $\mathrm{MgO}$ & 1.449 & 0.589 & 0.13 & 14.31 & 0.00 \\
\hline $\mathrm{CaO}$ & 4.317 & 1.729 & 10.62 & 16.33 & 0.08 \\
\hline $\mathrm{Na}_{2} \mathrm{O}$ & 3.715 & 2.670 & 5.2 & 0.21 & 0.00 \\
\hline $\mathrm{K}_{2} \mathrm{O}$ & 2.562 & 4.766 & 0.52 & 0.01 & 0.01 \\
\hline Total & 100 & 100 & 100 & 100 & 100 \\
\hline
\end{tabular}

\begin{tabular}{|c|c|c|c|c|}
\hline \multicolumn{5}{|c|}{ Resultados } \\
\hline Óxido & $\begin{array}{l}\text { Quantidade adicionada ou } \\
\text { subtraída (\% em peso) }\end{array}$ & $\begin{array}{c}\text { Diferenças entre os magmas } \\
\text { (\% em peso) }\end{array}$ & $\begin{array}{l}\text { Cálculo da diferença entre } \\
\text { os magmas (\% em peso) }\end{array}$ & Resíduos \\
\hline $\mathrm{SiO}_{2}$ & 44.576 & 7.13 & 7.32 & -0.19 \\
\hline $\mathrm{TiO}_{2}$ & 2.359 & -0.55 & -0.45 & -0.101 \\
\hline $\mathrm{Al}_{2} \mathrm{O}_{3}$ & 14.66 & -0.275 & -0.567 & 0.291 \\
\hline $\mathrm{FeO}_{\text {tot }}$ & 19.481 & -3.943 & -3.858 & -0.084 \\
\hline $\mathrm{MnO}$ & 0.188 & -0.074 & -0.03 & -0.043 \\
\hline $\mathrm{MgO}$ & 4.89 & -0.86 & -1.156 & 0.296 \\
\hline $\mathrm{CaO}$ & 10.88 & -2.588 & -2.46 & -0.128 \\
\hline $\mathrm{Na}_{2} \mathrm{O}$ & 2.698 & -1.044 & -0.007 & -1.037 \\
\hline \multirow[t]{2}{*}{$\mathrm{K}_{2} \mathrm{O}$} & 0.268 & 2.205 & 1.209 & 0.995 \\
\hline & & & TOTAL & 0 \\
\hline & Soma dos $\mathrm{q}$ & uadrados dos resíduos $\left(\sum \operatorname{res}^{2}\right)$ & & 2.3101 \\
\hline
\end{tabular}

\begin{tabular}{|c|c|c|}
\hline Fase & $\begin{array}{l}\text { Quantidade de fases } \\
\text { adicionadas }\end{array}$ & Quantidade de fases subtraídas \\
\hline Plagioclásio & 0 & 50.49 \\
\hline Piroxênio & 0 & 33.72 \\
\hline Magnetita & 0 & 15.8 \\
\hline \multicolumn{2}{|c|}{ Total restante do magma inicial } & $73.11 \%$ \\
\hline \multicolumn{2}{|c|}{ Total cristalizado do magma inicial } & $26.89 \%$ \\
\hline
\end{tabular}

${ }^{1}$ Dacito andesítico - unidade Barros Cassal (amostra GX-22)

${ }^{2}$ Riolito - unidade Santa Maria (média das análises químicas)

${ }^{3}$ Dados de química mineral da amostra GX-22 - unidade Barros Cassal (Polo, tese de doutorado em andamento)

${ }^{4}$ Dados de química mineral para magnetita - unidade Anita Garibaldi (Garland et al. (1995) 


\begin{tabular}{lcc}
\hline \multicolumn{1}{c}{ Óxido } & $\begin{array}{c}\text { Barros } \\
\text { Cassal }\end{array}$ & Análises recalc \\
\hline $\mathrm{SiO}_{2}$ & 58.612 & 71.803 \\
\hline $\mathrm{TiO}_{2}$ & 1.533 & 0.685 \\
\hline $\mathrm{Al}_{2} \mathrm{O}_{3}$ & 12.935 & 12.553 \\
\hline $\mathrm{FeO}_{\text {tot }}$ & 12.564 & 5.130 \\
\hline $\mathrm{MnO}$ & 0.176 & 0.074 \\
\hline $\mathrm{MgO}$ & 2.892 & 0.589 \\
\hline $\mathrm{CaO}$ & 6.606 & 1.729 \\
\hline $\mathrm{Na}{ }_{2} \mathrm{O}$ & 2.850 & 2.670 \\
\hline $\mathrm{K}_{2} \mathrm{O}$ & 1.832 & 4.766 \\
\hline $\mathrm{Total}$ & 100 & 100 \\
\hline
\end{tabular}

\begin{tabular}{ccc}
00 (\% em peso) & & \\
\hline Plagioclásio $^{3}$ & Piroxênio $^{3}$ & Magnetita $^{4}$ \\
\hline 54.76 & 50.49 & 0.70 \\
\hline 0.11 & 0.59 & 13.27 \\
\hline 27.53 & 1.93 & 0.37 \\
\hline 1.03 & 14.62 & 85.36 \\
\hline 0.01 & 0.35 & 0.20 \\
\hline 0.1 & 15.51 & 0.00 \\
\hline 10.42 & 16.28 & 0.08 \\
\hline 5.54 & 0.23 & 0.00 \\
\hline 0.5 & 0 & 0.01 \\
\hline 100 & 100 & 100 \\
\hline
\end{tabular}

\begin{tabular}{|c|c|c|c|c|}
\hline \multicolumn{5}{|c|}{ Resultados } \\
\hline Óxido & $\begin{array}{l}\text { Quantidade adicionada ou } \\
\text { subtraída (\% em peso) }\end{array}$ & $\begin{array}{c}\text { Diferenças entre os magmas } \\
\text { (\% em peso) }\end{array}$ & $\begin{array}{l}\text { Cálculo da diferença entre } \\
\text { os magmas (\% em peso) }\end{array}$ & Resíduos \\
\hline $\mathrm{SiO}_{2}$ & 44.38 & 13.191 & 13.474 & -0.284 \\
\hline $\mathrm{TiO}_{2}$ & 2.424 & -0.848 & -0.854 & 0.006 \\
\hline $\mathrm{Al}_{2} \mathrm{O}_{3}$ & 13.466 & -0.381 & -0.449 & 0.067 \\
\hline $\mathrm{FeO}_{\text {tot }}$ & 19.829 & -7.434 & -7.222 & -0.212 \\
\hline $\mathrm{MnO}$ & 0.17 & -0.102 & -0.047 & -0.055 \\
\hline $\mathrm{MgO}$ & 5.899 & -2.303 & -2.609 & 0.307 \\
\hline $\mathrm{CaO}$ & 10.957 & -4.878 & -4.534 & -0.343 \\
\hline $\mathrm{Na}_{2} \mathrm{O}$ & 2.64 & -0.18 & 0.015 & -0.195 \\
\hline \multirow[t]{2}{*}{$\mathrm{K}_{2} \mathrm{O}$} & 0.235 & 2.935 & 2.226 & 0.708 \\
\hline & & & TOTAL & 0 \\
\hline \multicolumn{4}{|c|}{ Soma dos quadrados dos resíduos $\left(\sum \mathrm{res}^{2}\right)$} & 0.8842 \\
\hline
\end{tabular}

\begin{tabular}{|c|c|c|}
\hline Fase & $\begin{array}{l}\text { Quantidade de fases } \\
\text { adicionadas }\end{array}$ & Quantidade de fases subtraídas \\
\hline Plagioclásio & 0 & 46.06 \\
\hline Piroxênio & 0 & 37.73 \\
\hline Magnetita & 0 & 16.21 \\
\hline \multicolumn{2}{|c|}{ Total restante do magma inicial } & $50.86 \%$ \\
\hline \multicolumn{2}{|c|}{ Total cristalizado do magma inicial } & $49.14 \%$ \\
\hline
\end{tabular}

${ }^{1}$ Dacito andesítico - unidade Barros Cassal (amostra GX-94)

${ }^{2}$ Riolito - unidade Santa Maria (média das análises químicas)

${ }^{3}$ Dados de química mineral da amostra GX-94 - unidade Barros Cassal (Polo, tese de doutorado em andamento)

${ }^{4}$ Dados de química mineral para magnetita - unidade Anita Garibaldi (Garland et al. (1995) 


\begin{tabular}{lcc}
\hline \multicolumn{1}{c}{ Óxido } & $\begin{array}{c}\text { Barros } \\
\text { Cassal }\end{array}$ & Análises recalc \\
\hline $\mathrm{SiO}_{2}$ & 58.590 & 71.803 \\
\hline $\mathrm{TiO}_{2}$ & 1.529 & 0.685 \\
\hline $\mathrm{Al}_{2} \mathrm{O}_{3}$ & 12.981 & 12.553 \\
\hline $\mathrm{FeO}_{\text {tot }}$ & 12.446 & 5.130 \\
\hline $\mathrm{MnO}$ & 0.177 & 0.074 \\
\hline $\mathrm{MgO}$ & 2.849 & 0.589 \\
\hline $\mathrm{CaO}$ & 6.542 & 1.729 \\
\hline $\mathrm{Na}{ }_{2} \mathrm{O}$ & 2.901 & 2.670 \\
\hline $\mathrm{K}_{2} \mathrm{O}$ & 1.985 & 4.766 \\
\hline $\mathrm{Total}$ & 100 & 100 \\
\hline
\end{tabular}

100 (\% em peso)

\begin{tabular}{ccc} 
Plagioclásio $^{3}$ & Piroxênio $^{3}$ & Magnetita $^{4}$ \\
\hline 53.74 & 50.29 & 0.70 \\
\hline 0.05 & 0.67 & 13.27 \\
\hline 27.72 & 1.77 & 0.37 \\
\hline 1.46 & 15.68 & 85.36 \\
\hline 0.01 & 0.38 & 0.20 \\
\hline 0.3 & 14.27 & 0.00 \\
\hline 11.34 & 16.72 & 0.08 \\
\hline 4.93 & 0.21 & 0.00 \\
\hline 0.44 & 0.01 & 0.01 \\
\hline 100 & 100 & 100 \\
\hline
\end{tabular}

\begin{tabular}{|c|c|c|c|c|}
\hline \multicolumn{5}{|c|}{ Resultados } \\
\hline Óxido & $\begin{array}{l}\text { Quantidade adicionada ou } \\
\text { subtraída (\% em peso) }\end{array}$ & $\begin{array}{c}\text { Diferenças entre os magmas } \\
\text { (\% em peso) }\end{array}$ & $\begin{array}{l}\text { Cálculo da diferença entre } \\
\text { os magmas (\% em peso) }\end{array}$ & Resíduos \\
\hline $\mathrm{SiO}_{2}$ & 44.017 & 13.213 & 13.363 & -0.15 \\
\hline $\mathrm{TiO}_{2}$ & 2.383 & -0.843 & -0.816 & -0.027 \\
\hline $\mathrm{Al}_{2} \mathrm{O}_{3}$ & 13.589 & -0.428 & -0.498 & 0.07 \\
\hline $\mathrm{FeO}_{\text {tot }}$ & 20.143 & -7.316 & -7.22 & -0.096 \\
\hline $\mathrm{MnO}$ & 0.181 & -0.103 & -0.051 & -0.051 \\
\hline $\mathrm{MgO}$ & 5.525 & -2.26 & -2.374 & 0.114 \\
\hline $\mathrm{CaO}$ & 11.583 & -4.813 & -4.739 & -0.074 \\
\hline $\mathrm{Na}_{2} \mathrm{O}$ & 2.368 & -0.23 & 0.145 & -0.376 \\
\hline \multirow[t]{2}{*}{$\mathrm{K}_{2} \mathrm{O}$} & 0.211 & 2.781 & 2.191 & 0.59 \\
\hline & & & TOTAL & 0 \\
\hline & Soma dos c & uadrados dos resíduos $\left(\sum\right.$ res $\left.^{2}\right)$ & & 0.5478 \\
\hline
\end{tabular}

\begin{tabular}{|l|c|c|}
\hline \multicolumn{1}{|c|}{ Fase } & $\begin{array}{c}\text { Quantidade de fases } \\
\text { adicionadas }\end{array}$ & Quantidade de fases subtraídas \\
\hline Plagioclásio & 0 & 46.39 \\
\hline Piroxênio & 0 & 37.74 \\
\hline Magnetita & 0 & 15.87 \\
\hline \multicolumn{2}{|c|}{ Total restante do magma inicial } & $51.91 \%$ \\
\hline \multicolumn{2}{|c|}{ Total cristalizado do magma inicial } & $48.09 \%$ \\
\hline
\end{tabular}

\footnotetext{
${ }^{1}$ Dacito andesítico - unidade Barros Cassal (amostra GX-113)

${ }^{2}$ Riolito - unidade Santa Maria (média das análises químicas)

${ }^{3}$ Dados de química mineral da amostra GX-113 - unidade Barros Cassal (Polo, tese de doutorado em andamento)

${ }^{4}$ Dados de química mineral para magnetita - unidade Anita Garibaldi (Garland et al. (1995)
} 


\begin{tabular}{lcc}
\hline \multicolumn{1}{c}{ Óxido } & $\begin{array}{c}\text { Barros } \\
\text { Cassal }\end{array}$ & Análises recalc \\
\hline $\mathrm{SiO}_{2}$ & 55.740 & 71.803 \\
\hline $\mathrm{TiO}_{2}$ & 1.706 & 0.685 \\
\hline $\mathrm{Al}_{2} \mathrm{O}_{3}$ & 12.811 & 12.553 \\
\hline $\mathrm{FeO}_{\text {tot }}$ & 14.340 & 5.130 \\
\hline $\mathrm{MnO}$ & 0.242 & 0.074 \\
\hline $\mathrm{MgO}$ & 3.281 & 0.589 \\
\hline $\mathrm{CaO}$ & 7.342 & 1.729 \\
\hline $\mathrm{Na}{ }_{2} \mathrm{O}$ & 2.785 & 2.670 \\
\hline $\mathrm{K}_{2} \mathrm{O}$ & 1.752 & 4.766 \\
\hline $\mathrm{Total}$ & 100 & 100 \\
\hline
\end{tabular}

(\% em peso)

\begin{tabular}{ccc} 
Plagioclásio $^{3}$ & Piroxênio $^{3}$ & Magnetita $^{4}$ \\
\hline 53.74 & 50.29 & 0.700 \\
\hline 0.05 & 0.67 & 13.270 \\
\hline 27.72 & 1.77 & 0.370 \\
\hline 1.46 & 15.68 & 85.360 \\
\hline 0.01 & 0.38 & 0.200 \\
\hline 0.3 & 14.27 & 0.000 \\
\hline 11.34 & 16.72 & 0.080 \\
\hline 4.93 & 0.21 & 0.000 \\
\hline 0.44 & 0.01 & 0.010 \\
\hline 100 & 100 & 100.000 \\
\hline
\end{tabular}

\begin{tabular}{|c|c|c|c|c|}
\hline \multicolumn{5}{|c|}{ Resultados } \\
\hline Óxido & $\begin{array}{l}\text { Quantidade adicionada ou } \\
\text { subtraída (\% em peso) }\end{array}$ & $\begin{array}{c}\text { Diferenças entre os magmas } \\
\text { (\% em peso) }\end{array}$ & $\begin{array}{l}\text { Cálculo da diferença entre } \\
\text { os magmas (\% em peso) }\end{array}$ & Resíduos \\
\hline $\mathrm{SiO}_{2}$ & 43.359 & 16.063 & 16.164 & -0.101 \\
\hline $\mathrm{TiO}_{2}$ & 2.546 & -1.021 & -1.057 & 0.036 \\
\hline $\mathrm{Al}_{2} \mathrm{O}_{3}$ & 13.16 & -0.258 & -0.345 & 0.087 \\
\hline $\mathrm{FeO}_{\text {tot }}$ & 21.217 & -9.21 & -9.142 & -0.068 \\
\hline $\mathrm{MnO}$ & 0.184 & -0.168 & -0.063 & -0.105 \\
\hline $\mathrm{MgO}$ & 5.573 & -2.692 & -2.832 & 0.14 \\
\hline $\mathrm{CaO}$ & 11.466 & -5.613 & -5.533 & -0.08 \\
\hline $\mathrm{Na}_{2} \mathrm{O}$ & 2.291 & -0.115 & 0.216 & -0.33 \\
\hline \multirow[t]{2}{*}{$\mathrm{K}_{2} \mathrm{O}$} & 0.204 & 3.014 & 2.593 & 0.422 \\
\hline & & & TOTAL & 0 \\
\hline & Soma dos $\mathrm{C}$ & uadrados dos resíduos $\left(\sum \mathrm{res}^{2}\right)$ & & 0.3478 \\
\hline
\end{tabular}

\begin{tabular}{|l|c|c|}
\hline \multicolumn{1}{|c|}{ Fase } & $\begin{array}{c}\text { Quantidade de fases } \\
\text { adicionadas }\end{array}$ & Quantidade de fases subtraídas \\
\hline Plagioclásio & 0 & 44.8 \\
\hline Piroxênio & 0 & 38.11 \\
\hline Magnetita & 0 & 17.09 \\
\hline \multicolumn{2}{|c|}{ Total restante do magma inicial } & $43.17 \%$ \\
\hline \multicolumn{2}{|c|}{ Total cristalizado do magma inicial } & $56.83 \%$ \\
\hline
\end{tabular}

\footnotetext{
${ }^{1}$ Dacito andesítico - unidade Barros Cassal (amostra GX-157)

${ }^{2}$ Riolito - unidade Santa Maria (média das análises químicas)

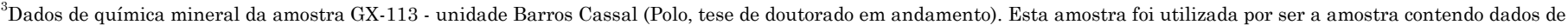
química mineral com a composição mais próxima de uma composição basáltica (caso da amostra GX-157)

${ }^{4}$ Dados de química mineral para magnetita - unidade Anita Garibaldi (Garland et al. (1995)
} 
Modelamento de AFC para elementos traço a partir de composições BASÁLTICAS da unidade Barros Cassal, considerando-se como contaminante a composição média dos Granitóides Garopaba

\begin{tabular}{|c|c|c|c|c|c|c|c|c|}
\hline & Elemento & $\mathbf{B a}$ & $\mathbf{R b}$ & $\mathrm{Sr}$ & $\mathrm{Zr}$ & $\mathbf{L a}$ & Th & Nd \\
\hline & $\mathrm{C}_{0}$ & 384 & 81 & 166 & 175 & 26.9 & 7.2 & 28.3 \\
\hline & $\mathbf{C}_{\mathrm{A}}$ & 962.4 & 184.8 & 106.8 & 190.8 & 58.8 & 18.26 & 49.36 \\
\hline & $\mathbf{C}_{\mathrm{SM}}$ & 690.4 & 227.3 & 95.7 & 307.6 & 60.8 & 19.1 & 58 \\
\hline \multirow{5}{*}{$\begin{array}{l}0 \\
0 \\
11 \\
10\end{array}$} & $\mathrm{C}_{\mathrm{L}}$ & 714.0 & 229.3 & 91.8 & 331.7 & 60.5 & 18.7 & 55.6 \\
\hline & $\mathbf{r}$ & 0.1 & 0.3 & 0.5 & 0.1 & 0.2 & 0.2 & 0.2 \\
\hline & $\mathrm{C}_{\mathrm{L}} / \mathrm{C}_{\mathrm{SM}}$ & 1.03 & 1.01 & 0.96 & 1.08 & 0.99 & 0.98 & 0.96 \\
\hline & Cristalização & \multicolumn{7}{|c|}{$50 \%$} \\
\hline & Assimilação & $5 \%$ & $15 \%$ & $25 \%$ & $5 \%$ & $10 \%$ & $10 \%$ & $10 \%$ \\
\hline \multirow{5}{*}{$\begin{array}{l}0 \\
0 \\
\text { II } \\
\text { ⿷匚丿 }\end{array}$} & $\mathbf{C}_{\mathrm{L}}$ & 681.0 & 246.2 & 94.2 & 312.8 & 63.4 & 19.8 & 56.9 \\
\hline & $\mathbf{r}$ & 0.2 & 0.5 & 0.6 & 0.3 & 0.4 & 0.4 & 0.4 \\
\hline & $\mathrm{C}_{\mathrm{L}} / \mathrm{C}_{\mathrm{SM}}$ & 0.99 & 1.08 & 0.98 & 1.02 & 1.04 & 1.04 & 0.98 \\
\hline & Cristalização & \multicolumn{7}{|c|}{$40 \%$} \\
\hline & Assimilação & $8 \%$ & $20 \%$ & $24 \%$ & $12 \%$ & $16 \%$ & $16 \%$ & $16 \%$ \\
\hline \multirow{5}{*}{$\begin{array}{l}\tilde{0} \\
\text { II } \\
\text { ⿷匚 }\end{array}$} & $\mathbf{C}_{\mathrm{L}}$ & 716.5 & 225.2 & 96.0 & 301.9 & 58.0 & 17.9 & 59.8 \\
\hline & $\mathbf{r}$ & 0.4 & 0.6 & 0.7 & 0.5 & 0.5 & 0.5 & 0.6 \\
\hline & $\mathrm{C}_{\mathrm{L}} / \mathrm{C}_{\mathrm{SM}}$ & 1.04 & 0.99 & 1.00 & 0.98 & 0.95 & 0.94 & 1.03 \\
\hline & Cristalização & \multicolumn{7}{|c|}{$30 \%$} \\
\hline & Assimilação & $12 \%$ & $18 \%$ & $21 \%$ & $15 \%$ & $15 \%$ & $15 \%$ & $18 \%$ \\
\hline
\end{tabular}

$\mathrm{C}_{0}$ - composição do magma parental: média dos basaltos da unidade Barros Cassal

$\mathrm{C}_{\mathrm{A}}$ - composição do material assimilado: média dos Granitóides Garopaba

$\mathrm{C}_{\mathrm{L}}$ - composição do líquido obtido

$\mathrm{C}_{\mathrm{SM}}$ - composição média dos riolitos Santa Maria (composição desejada)

$\mathrm{C}_{\mathrm{L}} / \mathrm{C}_{\mathrm{SM}}$ - razão entre o líquido obtido e a composição "alvo" (riolitos Santa Maria). Ideal: $\mathrm{C}_{\mathrm{L}} / \mathrm{C}_{\mathrm{SM}}=1$

r - razão assimilação/cristalização 
Modelamento de AFC para elementos traço a partir de composições ANDESÍTICAS da unidade Barros Cassal, considerando-se como contaminante a composição média dos Granitóides Garopaba

\begin{tabular}{|c|c|c|c|c|c|c|c|c|}
\hline & Elemento & $\mathbf{B a}$ & $\mathbf{R b}$ & $\mathrm{Sr}$ & $\mathrm{Zr}$ & $\mathbf{L a}$ & Th & Nd \\
\hline & $\mathrm{C}_{0}$ & 579 & 135 & 161 & 252 & 39.3 & 11.6 & 40.2 \\
\hline & $\mathbf{C}_{\mathrm{A}}$ & 962.4 & 184.8 & 106.8 & 190.8 & 58.8 & 18.26 & 49.36 \\
\hline & $\mathbf{C}_{\mathrm{SM}}$ & 690.4 & 227.3 & 95.7 & 307.6 & 60.8 & 19.1 & 58 \\
\hline \multirow{5}{*}{$\begin{array}{l}\tilde{0} \\
\text { II } \\
\text { I }\end{array}$} & $\mathbf{C}_{\mathrm{L}}$ & 783.5 & 220.4 & 94.6 & 348.0 & 62.1 & 19.7 & 58.5 \\
\hline & $\mathbf{r}$ & 0.1 & 0.3 & 0.7 & 0.1 & 0.3 & 0.3 & 0.3 \\
\hline & $\mathrm{C}_{\mathrm{L}} / \mathrm{C}_{\mathrm{SM}}$ & 1.13 & 0.97 & 0.99 & 1.13 & 1.02 & 1.03 & 1.01 \\
\hline & Cristalização & \multicolumn{7}{|c|}{$30 \%$} \\
\hline & Assimilação & $3 \%$ & $9 \%$ & $21 \%$ & $3 \%$ & $9 \%$ & $9 \%$ & $9 \%$ \\
\hline \multirow{5}{*}{$\begin{array}{l}\infty \\
\dot{\infty} \\
\text { II } \\
{[}\end{array}$} & $\mathbf{C}_{\mathrm{L}}$ & 701.0 & 231.3 & 96.2 & 308.7 & 59.9 & 18.9 & 56.1 \\
\hline & $\mathbf{r}$ & 0.1 & 0.6 & 0.8 & 0.1 & 0.5 & 0.5 & 0.5 \\
\hline & $\mathrm{C}_{\mathrm{L}} / \mathrm{C}_{\mathrm{SM}}$ & 1.02 & 1.02 & 1.00 & 1.00 & 0.99 & 0.99 & 0.97 \\
\hline & Cristalização & \multicolumn{7}{|c|}{$20 \%$} \\
\hline & Assimilação & $6 \%$ & $12 \%$ & $16 \%$ & $2 \%$ & $10 \%$ & $10 \%$ & $10 \%$ \\
\hline
\end{tabular}

$\mathrm{C}_{0}$ - composição do magma parental: média dos basaltos da unidade Barros Cassal

$\mathrm{C}_{\mathrm{A}}$ - composição do material assimilado: média dos Granitóides Garopaba

$\mathrm{C}_{\mathrm{L}}$ - composição do líquido obtido

$\mathrm{C}_{\mathrm{SM}}$ - composição média dos riolitos Santa Maria (composição desejada)

$\mathrm{C}_{\mathrm{L}} / \mathrm{C}_{\mathrm{SM}}$ - razão entre o líquido obtido e a composição "alvo" (riolitos Santa Maria). Ideal: $\mathrm{C}_{\mathrm{L}} / \mathrm{C}_{\mathrm{SM}}=1$

r - razão assimilação/cristalização 
Modelamento de AFC para elementos traço a partir de composições DACÍTICAS da unidade Barros Cassal, considerando-se como contaminante a composição média dos Granitóides Garopaba

\begin{tabular}{|c|c|c|c|c|c|c|c|c|}
\hline & Elemento & $\mathbf{B a}$ & $\mathbf{R b}$ & $\mathrm{Sr}$ & $\mathrm{Zr}$ & La & Th & Nd \\
\hline & $\mathbf{C}_{0}$ & 627 & 178 & 157 & 289 & 45.8 & 13.8 & 46.4 \\
\hline & $\mathbf{C}_{\mathrm{A}}$ & 962.4 & 184.8 & 106.8 & 190.8 & 58.8 & 18.26 & 49.36 \\
\hline & $\mathbf{C}_{\mathrm{SM}}$ & 690.4 & 227.3 & 95.7 & 307.6 & 60.8 & 19.1 & 58 \\
\hline \multirow{5}{*}{$\begin{array}{l}\tilde{0} \\
\text { II } \\
\text { I }\end{array}$} & $\mathbf{C}_{\mathrm{L}}$ & 844.9 & 257.0 & 93.5 & 397.8 & 64.1 & 20.4 & 61.8 \\
\hline & $\mathbf{r}$ & 0.1 & 0.1 & 0.7 & 0.1 & 0.1 & 0.1 & 0.1 \\
\hline & $\mathrm{C}_{\mathrm{L}} / \mathrm{C}_{\mathrm{SM}}$ & 1.22 & 1.13 & 0.98 & 1.29 & 1.05 & 1.07 & 1.07 \\
\hline & Cristalização & \multicolumn{7}{|c|}{$30 \%$} \\
\hline & Assimilação & $3 \%$ & $3 \%$ & $21 \%$ & $3 \%$ & $3 \%$ & $3 \%$ & $3 \%$ \\
\hline \multirow{5}{*}{\begin{tabular}{l}
$\infty$ \\
0 \\
II \\
\multicolumn{1}{|c}{}
\end{tabular}} & $\mathbf{C}_{\mathrm{L}}$ & 757.0 & 230.3 & 95.1 & 353.3 & 60.5 & 19.1 & 58.3 \\
\hline & $\mathbf{r}$ & 0.1 & 0.2 & 0.8 & 0.1 & 0.3 & 0.3 & 0.3 \\
\hline & $\mathrm{C}_{\mathrm{L}} / \mathrm{C}_{\mathrm{SM}}$ & 1.10 & 1.01 & 0.99 & 1.15 & 1.00 & 1.00 & 1.00 \\
\hline & Cristalização & \multicolumn{7}{|c|}{$20 \%$} \\
\hline & Assimilação & $2 \%$ & $4 \%$ & $16 \%$ & $2 \%$ & $6 \%$ & $6 \%$ & $6 \%$ \\
\hline
\end{tabular}

$\mathrm{C}_{0}$ - composição do magma parental: média dos basaltos da unidade Barros Cassal

$\mathrm{C}_{\mathrm{A}}$ - composição do material assimilado: média dos Granitóides Garopaba

$\mathrm{C}_{\mathrm{L}}$ - composição do líquido obtido

$\mathrm{C}_{\mathrm{SM}}$ - composição média dos riolitos Santa Maria (composição desejada)

$\mathrm{C}_{\mathrm{L}} / \mathrm{C}_{\mathrm{SM}}$ - razão entre o líquido obtido e a composição "alvo" (riolitos Santa Maria). Ideal: $\mathrm{C}_{\mathrm{L}} / \mathrm{C}_{\mathrm{SM}}=1$

r - razão assimilação/cristalização 